\title{
Wind-Driven Circulation on a Shallow, Stratified Shelf
}

\author{
by \\ Jay Alan Austin \\ B.S., California Polytechnic State University, San Luis Obispo (1990) \\ Submitted in partial fulfillment of the \\ requirements for the degree of \\ Doctor of Philosophy \\ at the \\ MASSACHUSETTS INSTITUTE OF TECHNOLOGY \\ and the \\ WOODS HOLE OCEANOGRAPHIC INSTITUTION \\ August 1998 \\ (C) Jay Alan Austin, 1998 \\ The author hereby grants to MIT and to WHOI permission to reproduce \\ and to distribute copies of this thesis document in whole or in part.
}

Signature of Author...

Joint Program in Physical Oceanography
Massachusetts Institute of Technology
Woods Hole Oceanographic Institution
July 27,1998

Certified by ....

Steven J. Lentz

Professor

Thesis Supervisor

Accepted by ...

W. Brechner Owens

Chair, Joint Committee for Physical Oceanography 


\title{
Wind-Driven Circulation on a Shallow, Stratified Shelf
}

by

\author{
Jay Alan Austin
}

\begin{abstract}
Submitted in partial fulfillment of the requirements for the degree of Doctor of Philosophy at the Massachusetts Institute of Technology and the Woods Hole Oceanographic Institution
\end{abstract}

July 27,1998

\begin{abstract}
Data from the Coastal Ocean Processes Inner Shelf Study are analyzed to determine atmospheric forcing characteristics and the heat balance of the inner shelf, and are used as motivation for a numerical study of inner shelf circulation during upwelling and downwelling. Variation in meteorological forcing on the North Carolina Inner shelf is shown to be dominated by synoptic weather systems. The structure of cold fronts, which are the dominant synoptic feature, and the local meteorological conditions they produce result in a strong correlation between the surface heat flux and the wind orientation. This has implications for the heat balance of the inner shelf, which is considered next. During stratified conditions (observed during August 1994), cross-shelf heat fluxes due to Ekman dynamics dominate variation in heat content of the inner shelf, while during weakly-stratified conditions (observed during October 1994), the surface heat flux dominated variation in heat content. Both processes are correlated with the alongshelf wind, implying that the heat balance of the inner shelf can be modeled largely in terms of the alongshelf wind. The dominance of cross-shelf processes during stratified conditions motivated numerical studies of upwelling and downwelling. It was found that the feedback between mixing and stratification played a role in determining the strength of the circulation on the inner shelf, which differed between upwelling and downwelling. During upwelling, dense water is brought onto the inner shelf from below the pycnocline,
\end{abstract}


producing vertical stratification, lowering eddy viscosities, and enhancing the inner shelf circulation. In contrast, during downwelling, circulation was weakened by the presence of stratification. These circulation patterns are discussed in the context of coastal observations, and the implications for cross-shelf transport and exchange processes are considered. 


\section{Acknowledgments}

First and foremost I would like to thank my advisor, Steve Lentz. Steve's enthusiasm and patience has made my experience as a graduate student a pleasureable one, and he has given me the freedom to independently explore problems that interested me. He has also been a conscientious editor, taking my initially muddled prose and helping me to turn it into clear (or at least less muddled) scientific writing. My committee members, Bob Beardsley, Dave Chapman, Glenn Flierl, and Rocky Geyer have been constant sources of good suggestions and ideas.

The CoOP Inner Shelf Study would not have taken place without the hard work of many principal investigators and their teams. I would especially like to thank Cheryl Ann Butman's lab and Alan Shanks's lab for interesting conversations about shelf biology. I learned much about regional oceanography and instrumentation through conversations with John Brubaker and John Largier. The Army Corps of Engineer's Field Research Facility provided much logistical support for the entire project, and was also a valuable source of historical data which greatly improved this thesis.

The two summer "vacations" I spent at Oregon State University helped me to develop the modeling skills I needed to complete this thesis. Special thanks to John Allen and his students, postdocs, and researchers for their help and friendship while I was out there.

Help and encouragement from friends and family has been essential for making the past six years very enjoyable. Thanks to Jamie Pringle and Kelsey Jordahl for four years of sharing fine housing and lots of insight, scientific and otherwise. Derek Fong provided many hours of good scientific discussion and cost me as many hours by encouraging my running. Special thanks, of course, to Liz Minor, constant companion, source of support, and best friend for these six years and many to come. Finally, I would not have gotten through the program (quite literally) without the 
generous financial support of several agencies. My first two years were supported by a Graduate Fellowship from the National Science Foundation, which gave me the freedom to explore different topics and settle on something I really enjoyed. For the last four years I have been supported by an Office of Naval Research AASERT grant (N00014-93-1-1154), and by a National Science Foundation grant (OCE-9633025). 


\section{Contents}

1 Introduction $\quad 11$

1.1 Introduction . . . . . . . . . . . . . . . 11

1.2 Motivation ...................... 14

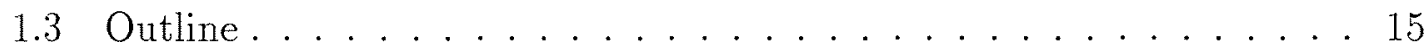

1.3.1 Chapter 2: The Surface Heat Flux during CoOP ISS . . . . 16

1.3.2 Chapter 3: The Heat Budget during CoOP . . . . . . . . 16

1.3.3 Chapter 4: Upwelling . . . . . . . . . . . . 17

1.3.4 Chapter 5: Downwelling . . . . . . . . . . . 17

1.3.5 Chapter 6: Summary ................ 18

2 The Relationship between Synoptic Weather Systems and Meteorological Forcing on the North Carolina Inner Shelf $\quad 19$

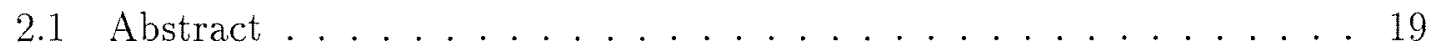

2.2 Introduction . . . . . . . . . . . . . . . . 21

2.3 Field Program, Methods ................. 25

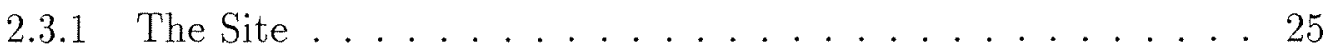


2.3 .2 Oceanographic Setting . . . . . . . . . . . . 26

2.3.3 Instrumentation and Other Data Sources . . . . . . . . . 28

2.3.4 Estimation of the Surface Heat Flux and Wind Stress . . . . 33

2.3.5 Estimation of Instrument-Induced Flux Uncertainty . . . . . 36

2.4 Observations and Results . . . . . . . . . . . . . . 40

2.4.1 Seasonal Variation . . . . . . . . . . . . . . 45

2.4 .2 Synoptic Variation . . . . . . . . . . . 46

2.4.3 Implications for the Heat Balance . . . . . . . . . . . . 59

2.5 Spatial Variation in the Surface Heat Flux . . . . . . . . 60

2.5.1 The Wind Field . . . . . . . . . . . . . . . . 61

2.5.2 The Water Temperature Field . . . . . . . . . . . 62

2.5.3 The Air Temperature Field . . . . . . . . . . 62

2.5.4 Implications for Meteorological Forcing . . . . . . . . . 64

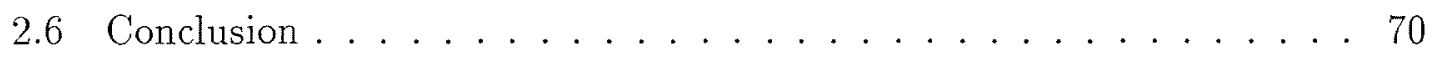

2.7 Acknowledgments . . . . . . . . . . . . 71

\section{The Role of the Alongshore Wind Stress in the Heat Budget} of the North Carolina Inner Shelf 72

3.1 Abstract ....................... 72

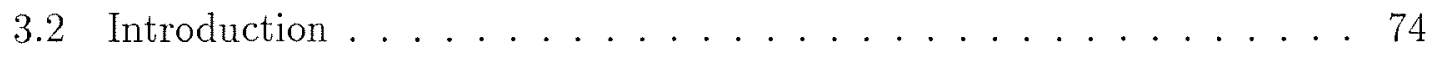

3.3 Field Site, Instrumentation and Methods . . . . . . . . 76

$3.3 .1 \quad$ Field Site $\ldots \ldots \ldots \ldots \ldots \ldots \ldots$ 
3.3 .2 Instrumentation . . . . . . . . . . . . 78

3.3.3 The Heat Budget Equation . . . . . . . . . . 80

3.4 Data . . . . . . . . . . . . . . . . . . 82

3.4 .1 Atmospheric Forcing . . . . . . . . . . . . . . 82

3.4.2 Temperature Data . . . . . . . . . . . . . . . . 85

3.5 The Heat Budget $\ldots \ldots \ldots \ldots \ldots \ldots \ldots$

3.5.1 The Mean Heat Budget . . . . . . . . . . . . 88

3.5.2 The Fluctuating Heat Budget . . . . . . . . . . . . . . 89

3.6 The Role of the Alongshore Wind . . . . . . . . . . . 94

3.6.1 Simple Wind-Driven Models and the CoOP Data . . . . . 96

3.6 .2 Seasonal Cycle . . . . . . . . . . . . . . . . . . 101

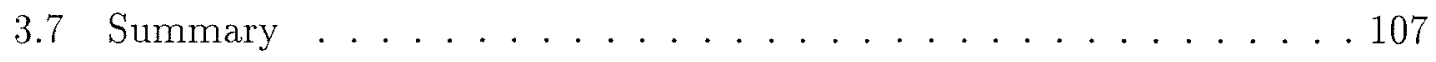

3.8 Acknowledgments . . . . . . . . . . . . . . . 108

3.9 Appendix A: Derivation of the Heat Budget Equation . . . . . . . 109

3.10 Appendix B: Discretization of the Heat Budget Terms . . . . . . 110

3.10 .1 The Storage Term . . . . . . . . . . . . . . 110

3.10.2 The Cross-Shore Heat Flux . . . . . . . . . . . . . 111

3.10 .3 The Surface Heat Flux . . . . . . . . . . . . . . . . . 112

3.10 .4 The Alongshore Heat Flux . . . . . . . . . . . . . . 113

4 The Dynamics of Upwelling on a Shallow, Stratified Shelf 114

4.1 Introduction . . . . . . . . . . . . . . . . . . . . . 114 
4.2 The Numerical Model . . . . . . . . . . . . . . . . . . . . . . . . . 118

4.2.1 Description of the Model . . . . . . . . . . . . . . . . 119

4.2.2 Configuration of the Base-Case Model . . . . . . . . . 122

4.3 The Base Case . . . . . . . . . . . . . . 127

4.3.1 Basic Description . . . . . . . . . . . . . . . . . 129

4.3.2 Regional Dynamics . . . . . . . . . . . . . . . . . . 133

4.3.3 The Inner Shelf . . . . . . . . . . . . . . . . . 134

4.3.4 The Frontal Region . . . . . . . . . . . . . . . . . . . 147

4.3.5 The Mid-Shelf . . . . . . . . . . . . . . . . 153

4.3.6 Offshore Propagation . . . . . . . . . . . . . . . 154

4.4 Uniform Stratification $\ldots \ldots \ldots \ldots \ldots \ldots \ldots \ldots$

4.4.1 The Burger Number Criterion . . . . . . . . . . 166

4.5 Discussion . . . . . . . . . . . . . . 172

4.5.1 Observations . . . . . . . . . . . . . . 172

4.5.2 Passive Tracer Experiments . . . . . . . . . . . 175

$4.5 .3 \quad$ Summary . . . . . . . . . . . . . . . . 178

4.6 Appendix A: Surface Mixed-Layer deepening . . . . . . . . . . 180

5 The Dynamics of Downwelling on a Stratified Shelf 182

5.1 Introduction . . . . . . . . . . . . . . 182

5.1 .1 Previous work . . . . . . . . . . . . . . 183

$5.1 .2 \quad$ Outline . . . . . . . . . . . . . . . 184 
5.2 The Downwelling Response . . . . . . . . . . . . . . . . 185

5.2 .1 Description of the Base-Case Response . . . . . . . . . 187

5.2 .2 Regional Analysis . . . . . . . . . . . . . . . . 188

5.3 Discussion . . . . . . . . . . . . . . . . . . . 214

5.3 .1 Continuous Stratification . . . . . . . . . . . 215

5.3 .2 Observational Evidence. . . . . . . . . . . . . . . . . 217

5.3 .3 Passive Tracers . . . . . . . . . . . . . . 220

5.3 .4 Summary . . . . . . . . . . . . . . . . . . 2223

\section{Discussion and Summary 225}

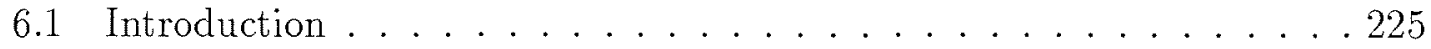

6.2 Upwelling vs. Downwelling . . . . . . . . . . . . . . . . 226

6.3 Other forcing Mechanisms; Future directions. . . . . . . . . . . . 229

6.3 .1 Alongshore Variation . . . . . . . . . . . . . 230

6.3 .2 Surface Heat Flux . . . . . . . . . . . . . . . . . 232

6.4 Conclusion . . . . . . . . . . . . . . . . 233 


\section{Chapter 1}

\section{Introduction}

\subsection{Introduction}

During upwelling and downwelling on a stratified shelf, a surface (or bottom) density front will often form, separating the shelf into dynamically distinct regions. The wind-driven circulation inshore of this front, and the role that stratification may play in that region, are not well understood. Aspects of the circulation in this region differ from more thoroughly studied waters further offshore, due to the proximity of the coastal boundary and shallowness of the water. These differences are interesting, important, and in some sense unintuitive, so a careful investigation of the character of the circulation of this region is warranted. The focus of this thesis is on the wind-driven response of this region, in the presence of density stratification. The goal of the thesis is to examine and interpret observations made in this region, and to develop a framework for the study of simple wind-driven processes on the inner shelf.

The necessity of an adjustment region near the coast was recognized concurrently 
with the development of Ekman dynamics. In his seminal paper, Ekman [1905] showed that (assuming a vertically uniform eddy viscosity profile) in water shallower than approximately three Ekman depths (he used "depth of frictional influence" for "Ekman depth"), the cross-shelf transport decreased closer to shore as the surface and bottom boundary layers interacted. In the limit of extremely shallow water, all of the flow must be in the direction of the wind. Mitchum and Clarke [1986] term this adjustment region the "nearshore region", and discuss the role that this region plays in the adjustment of the cross-shelf Ekman transport to the coastal boundary condition. They conclude that, in models of unstratified shelves with constant eddy viscosity, a coastal wall can be placed in water with depth equal to three Ekman scale depths without affecting the response further offshore. This is an important result for the modeling of coastally trapped waves but depends on the absence of stratification. Lentz [1995] followed up on this work by exploring the dependence of the inner shelf circulation on the eddy viscosity profile. By comparing the results using various eddy viscosity profiles previously discussed in the literature, he found that although changing the eddy viscosity profile may quantitatively change the response, the overall character of the transport divergence on the inner shelf does not change. He also offers a dynamical definition of the inner shelf:

[the] region characterized by a cross-shelf divergence in the [surface] Ekman transport due to the interaction of the surface and bottom boundary layers.

This definition has a dynamical underpinning and in theory is very useful. However, transport divergence due to the interaction of the surface and bottom boundary layers (or the characteristics of the stress field associated with this behavior) are 
notoriously hard to measure, especially in a stratified fluid. This makes the definition difficult to apply in the field.

This thesis attempts the next step, namely considering the effect of stratification on the eddy viscosity profile and the consequences of this dependence. The main focus is on the formation of the inner shelf region on a stratified shelf during upwelling and downwelling, during which a front is formed (in upwelling, at the surface; during downwelling, at the bottom). In this case, the following definition is used for the inner shelf:

The inner shelf is the portion of the shelf inshore of the upwelling (or downwelling) front and offshore of the surf zone.

It is shown that this definition is closely related to the Lentz [1995] definition, and in fact they only differ in extreme cases. By this definition, the inner shelf can become arbitrarily wide as a front is advected offshore, and in the case of a coast like the west coast of North America, may span the entire shelf. In addition, as density fronts are relatively easy to observe, the definition is much simpler to apply to observations. The region characterized as the inner shelf changes in time as the front is advected offshore. One of the major results of this thesis is that the circulation on the inner shelf differs between upwelling and downwelling (beyond just a sign change) and the circulation depends on the initial vertical density stratification. The asymmetry between upwelling and downwelling is due to the influence of the density field on the eddy viscosity profile. 


\subsection{Motivation}

Circulation on the inner shelf plays an important role in physical oceanography as well as other oceanographic disciplines. This is the region in which the surface Ekman transport (and hence the bottom Ekman transport) diverges, so it is in this region that the transport is "closed", in the sense that the two boundary layers merge and exchange properties. Understanding this process is vital to a better understanding of the response further offshore to upwelling and downwelling favorable winds. The formation of inner shelf regions may also have impacts on air-sea exchange processes and on the generation and propagation of coastally trapped waves. From an interdisciplinary point of view, cross-shelf transport and exchange processes which link the coastal boundary to waters further offshore are vital to many biological processes, and Ekman transport is often cited as a potential mechanism. The region also plays a key role in coastal pollution transport and dispersal, as most oil spills and all runoff from terrestrial sources impact this region.

One of the implications of this work with potential interdisciplinary significance is that vertical mixing can significantly impact the ability of cross-shelf upwelling or downwelling circulation to advect passive tracers to and from the coastal boundary. This "barrier" to cross-shelf transport can be overcome to some extent by invoking vertical migration strategies or by assuming that other forcing mechanisms besides the surface wind stress are important in determining the circulation.

Much of the motivation for the work presented in this dissertation was provided by the Coastal Ocean Processes (CoOP) Inner Shelf Study (ISS), a field program conducted off the Outer Banks of North Carolina during the summer and fall of 1994. The field program was conducted to address a lack of data concerning the 
inner shelf. The CoOP ISS was a coordinated effort by physicists, biologists and geologists to collect data on the inner shelf during both stratified and unstratified conditions, and to start to develop hypotheses about important inner-shelf processes in the various disciplines. From the standpoint of physical oceanography, two of the most important processes observed during CoOP ISS were wind-driven cross-shelf circulation and plume-related effects (freshwater plumes from the Chesapeake Estuary, approximately $80 \mathrm{~km}$ north of the main study site, have been considered in another PhD dissertation [Rennie 1997]). Very little literature existed that gave any insight into what the expected contribution of wind forcing to the inner shelf circulation should be, suggesting a real shortcoming in the understanding of this region. The CoOP ISS setting, instrumentation, and data is discussed more extensively in Chapters 2 and 3 .

\subsection{Outline}

This thesis is divided into two parts; first, two chapters devoted to the description and interpretation of observations made during the CoOP ISS, focusing on winddriven phenomena. The next two chapters are process-oriented numerical modeling studies of upwelling and downwelling on a stratified shelf. The modeling is not an attempt at simulation of specific events, although it is motivated by the observations made during the CoOP ISS. The study considers a wide range of conditions not necessarily observed during the COOP ISS, with the intent of developing hypotheses concerning the inner shelf that are not tied to a specific geographical location. 


\subsubsection{Chapter 2: The Surface Heat Flux during CoOP ISS}

Chapter 2 is a study of the meteorological forcing over the inner shelf during the CoOP ISS, based on meteorological observations from a variety of sources. The primary result of this chapter is that variation in meteorological forcing over the inner shelf at this site is due primarily to the passage of atmospheric fronts. The wind forcing on this shelf is episodic, characterized by short (approximately 1-3 day), moderate to intense wind events. In addition, the surface heat flux is highly correlated with the orientation of the wind, due to the structure of the fronts and their orientation to the coastline. The cross-shelf variation of the forcing is also considered, and available data suggests that spatial variation in heat fluxes across the inner shelf may be of the same order as the temporal variation at a fixed point.

\subsubsection{Chapter 3: The Heat Budget during CoOP}

Chapter 3 is an analysis of the heat balance on the inner shelf, considered both during strongly stratified (August 1994) and weakly stratified (October 1994) conditions, using data collected as part of the CoOP ISS. In both cases, the change in heat content can be linked to the wind field. During stratified conditions, the wind driven cross-shelf heat flux due to upwelling and downwelling dominates variation in the heat content of the inner shelf. In the absence of stratification, cross-shelf circulation is ineffectual at transporting heat, and surface heat flux and alongshelf heat flux dominate the variation. The surface, cross-shelf, and alongshelf heat flux are all correlated to the wind and variation in the heat content of the inner shelf can once again be linked to the wind field. These results are extended to a 12-year time series, and provide a consistent explanation for seasonal variability in heat content 
variation.

\subsubsection{Chapter 4: Upwelling}

Chapter 4 is the first of two modeling chapters, and concentrates on the response of a stratified shelf to upwelling favorable winds. The primary result of this chapter is that the circulation on the inner shelf is enhanced by the presence of stratification. During upwelling favorable winds, an upwelling front is formed and is advected offshore. During this process, light water is trapped on the inner shelf. The wedge of light water provides vertical stratification which lowers the eddy viscosity on the inner shelf, enhancing the circulation. The light water is maintained on the inner shelf through an advective-diffusive density balance. The conditions under which this scenario occurs are discussed. There is a qualitative difference in the response when the water column is continuously stratified. When the water is initially continuously stratified, dense water keeps the inner shelf strongly stratified and allows cross-shelf circulation on the inner shelf far in excess of that expected in the neutral case. The density structure of the inner shelf in the continuously stratified case depends on the values of the stratification and bottom slope. Observational evidence for the upwelling scenario is discussed, as well as its implications for cross-shelf transport processes.

\subsubsection{Chapter 5: Downwelling}

Chapter 5 parallels Chapter 4 closely, concentrating instead on the response to downwelling favorable winds. In the numerical model, as the pycnocline is advected offshore, it creates a cross-shelf density gradient with light water onshore. Cross- 
shelf circulation on the inner shelf acts to tilt over the isopycnals in this region, causing convective instability, enhancing eddy viscosity and weakening cross-shelf circulation on the inner shelf. Unlike the upwelling case, the initial density structure does not impact the circulation. Observational evidence is discussed, and possible implications of the cross-shelf circulation on cross-shelf transport processes are discussed.

\subsubsection{Chapter 6: Summary}

In Chapter 6, a short summary of the main results of the thesis is presented. Some of the implications of the work are discussed, as well as two potential directions the research may lead. 


\section{Chapter 2}

\section{The Relationship between}

\section{Synoptic Weather Systems and}

\section{Meteorological Forcing on the}

\section{North Carolina Inner Shelf}

To appear in J. Geophys. Res, by Austin, J. A. and S.J. Lentz, accepted for publication, 28 May 1998. Copyright by the American Geophysical Union.

\section{$2.1 \quad$ Abstract}

A strong relationship is observed between synoptic weather systems and atmospheric forcing of the ocean as estimated from buoy measurements made on the North Carolina inner shelf during August and October-November 1994 as part of the Coastal Ocean Processes (CoOP) Inner Shelf Study. Synoptic variation (time scales of days 
to weeks) in the meteorological time series was primarily associated with the passage of atmospheric frontal systems. The most common synoptic weather pattern observed was the passage of a low pressure center to the north of the study site, which caused the associated cold front to pass over the study region. Before passage of the cold front, warm, moist northeastward winds increased the heat flux into the ocean, whereas after the cold front passed, cold, dry southwestward winds decreased the heat flux into the ocean. In addition, in the presence of oceanic stratification, northeastward winds drove coastal upwelling, bringing colder water to the surface, further increasing the air-sea temperature contrast and hence the heat flux into the ocean inshore of the surface front between cool upwelled water and warmer water offshore. The decrease in surface heat flux during the passage of a cold front was of order $400 \mathrm{~W} \mathrm{~m}^{-2}$, due primarily to a decrease in latent heat flux. Although other synoptic patterns were observed, including one warm front passage and two tropical storm systems, the dominance of cold fronts as a source of variability resulted in a strong positive correlation between the alongshelf component of wind stress and the surface heat flux.

To address the issue of spatial variation in the surface heat fluxes, data from several different sources located along a cross-shelf transect were analyzed. This analysis suggests that the temperature of the atmospheric boundary layer undergoes adjustment when warm air blows over cold water, but not when cold air blows over warm water. This produces cross-shelf gradients in the bulk estimates of turbulent heat fluxes during offshore winds, but not during onshore winds. 


\subsection{Introduction}

The surface heat flux and wind stress play a crucial role in determining the behavior of the upper ocean, especially in the shallow coastal zone, where the entire water column can be directly influenced by atmospheric forcing [Winant and Beardsley, 1979; Lee et al., 1989]. This paper presents surface heat flux and wind stress estimates from observations taken off the coast of North Carolina, north of Cape Hatteras during August and October/November 1994 as part of the Coastal Ocean Processes (CoOP) Inner Shelf Study field program [Butman, 1994]. The primary purpose of this paper is to describe the effect of synoptic weather systems on the temporal and spatial variation in meteorological forcing.

There have been few previous observational studies of the surface heat flux over U.S. continental shelves, and even fewer which use direct in situ measurements of the radiative fluxes. On the U.S. west coast, Beardsley et al. [in press] estimated surface fluxes during CODE (Coastal Ocean Dynamics Experiment) and SMILE (Surface MIxed Layer Experiment). They studied seasonal and synoptic variation during both experiments. They found that variation in shortwave radiation and sea surface temperature (due to upwelling) were the most important factors in the seasonal variation of the net surface heat flux. SMILE was one of the first coastal oceanic field experiments to make direct observations of downward longwave radiation. In the South Atlantic Bight Blanton et al. [1989a] estimated turbulent fluxes of moisture, heat, and momentum as part of GALE (Genesis of Atlantic Lows Experiment). They attributed variation in meteorological observations, and hence in the estimated fluxes, to synoptic weather systems. For instance, the passage of a cold-air outbreak on January 27, 1986, was responsible for an estimated decrease in the surface heat 
flux of nearly $1400 \mathrm{~W} \mathrm{~m}^{-2}$. Mountain et al. [1996] used data from moored buoys and coastal stations to estimate the annual cycle and interannual variability of the net surface heat flux in the Gulf of Maine between 1979 and 1987. In this study, annual variation in the shortwave insolation was primarily responsible for the annual variability of the net heat flux. On a larger scale, Bunker [1976] estimated monthly mean surface fluxes over the entire North Atlantic ocean using data from over eight million shipboard weather observations, and discussed heat flux variability on annual scales for the Mid-Atlantic Bight, among other specific regions. Enriquez and Friehe [1997] investigated the effect of coastal upwelling off northern California on the stability of the air column, which in part determines the transfer of heat, momentum, and moisture between atmosphere and ocean. They found that the change in the transfer coefficients due to upwelling affected estimates of surface wind stress, but had a negligible effect on the turbulent transfer of heat.

The effect of fronts on surface fluxes has also been considered in the open ocean. FASINEX (Frontal Air Sea Interaction Experiment) was an observational program which studied the effects of sea surface temperature fronts and atmospheric fronts on open ocean surface heat flux and wind stress variability. During FASINEX, Davidson et al. [1991] observed sharp decreases in surface heat fluxes and differences in wind direction during the passage of cold fronts over the open ocean southeast of Bermuda, with decreases of surface heat flux of up to $600 \mathrm{~W} \mathrm{~m}^{-2}$ during individual frontal passages observed during January-May 1986. Also during FASINEX, Friehe et al. [1991] studied the effect of sea surface temperature fronts on atmospheric boundary layer structure, showing that warm air blowing over cold water leads to a stable, shallow boundary layer while cold air blowing over warm water leads to an unstable, growing boundary layer. Mooers et al. [1976] studied the effects of cold 
fronts on surface heat flux and wind stress using a composite of 34 low pressure systems observed over the Middle Atlantic Bight between 1972 and 1975, for use as an idealized forcing field for ocean models. This composite low pressure system included a trailing cold front with warm, moist air ahead of the front and cold, dry air behind the front. Based on the air temperature and moisture content on either side of the front, they estimated a sharp decline, on the order of $400 \mathrm{~W} \mathrm{~m}^{-2}$, in bulk estimates of the combined turbulent heat fluxes (latent and sensible) across the composite front. They also observed that the highest concentration of clouds lies along the front, another important factor in determining the surface heat flux, and that the wind direction changes during the passage of the front.

The purpose of the interdisciplinary CoOP Inner Shelf Study was to increase understanding of the processes which affect larval distributions over the inner shelf, as well as to increase knowledge of the physical oceanography of the inner shelf, a region of the ocean where there have been relatively few physical oceanographic studies. The experiment took place between August and December 1994, which bracketed the seasonal transition from strong stratification and surface heating to weak stratification and surface cooling. The study site was located on the shallow shelf between Chesapeake Bay and Cape Hatteras (Figure 2.1), and included two moored buoys instrumented with the meteorological sensors necessary to make bulk estimates of the surface heat flux and wind stress. 


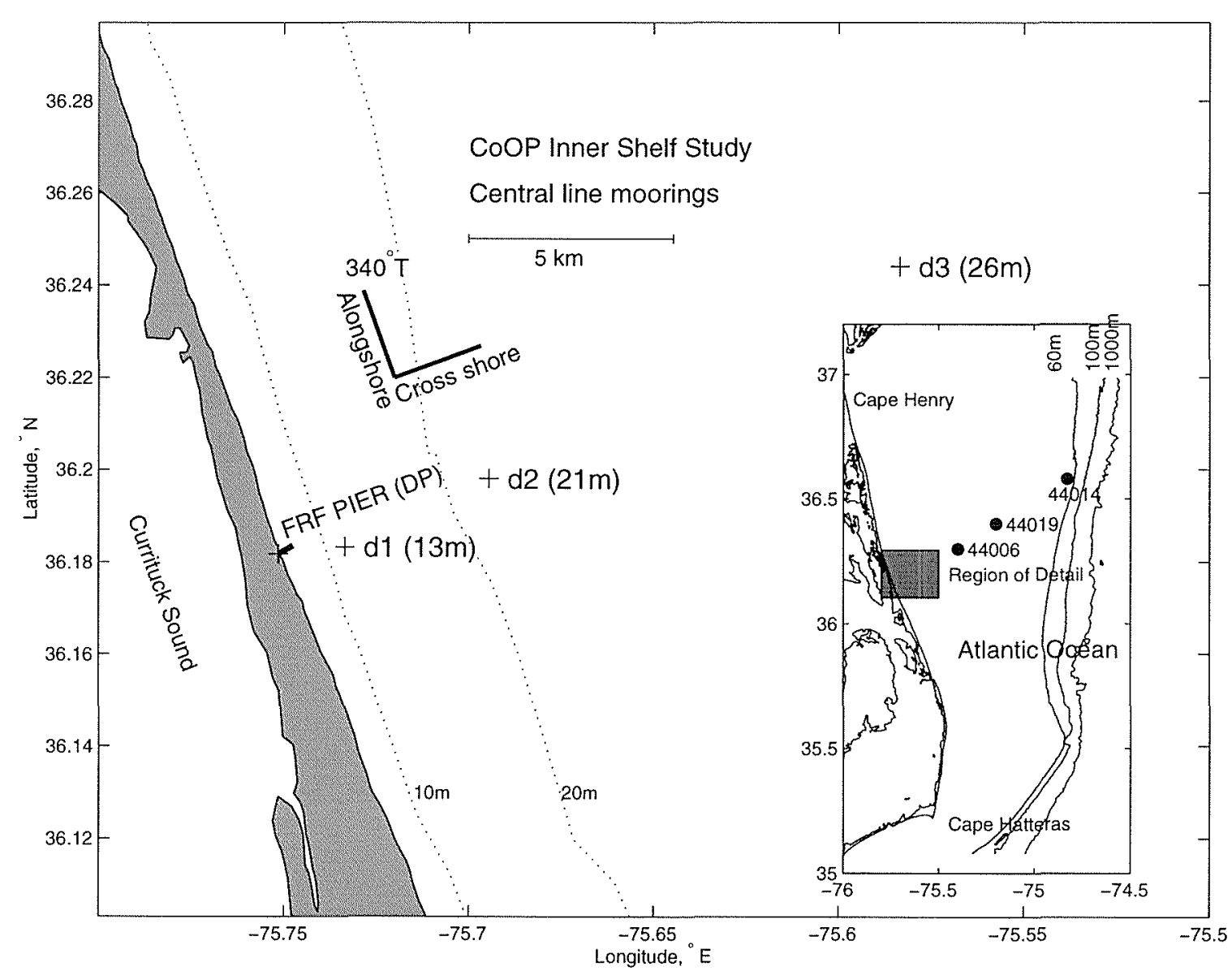

Figure 2.1: A plan view of the CoOP observational site, showing the study area, and the locations of CoOP ISS buoys DP, d1, d2, and d3, and NDBC buoys 44006, 44019, and 44014. The inset is a regional view. 
Variability in the meteorology on time scales of days to weeks during the CoOP Inner Shelf Study can be attributed to three basic scenarios, listed here in order of frequency of occurrence: the passage of cold fronts, the passage of tropical storms, and the passage of warm fronts. The response of the local meteorological variables to these weather systems was distinctive. A key result of this study is that the predominance of cold fronts as sources of variation and the particular response of the surface heat flux and wind stress to their passage leads to a strong relationship between wind direction and surface heat flux.

The rest of the paper is organized as follows. Section 2 describes the instrumentation and methods used to estimate surface heat flux and wind stress. In section 3 , meteorological time series and surface flux estimates are used to examine the relationship between synoptic meteorology and temporal variations in surface fluxes. Section 4 is a discussion of cross-shelf gradients in the air and sea surface temperature fields and the implications this has for the spatial distribution of surface heat flux. Section 5 is a summary.

\subsection{Field Program, Methods}

\subsubsection{The Site}

The CoOP Inner Shelf Study took place offshore of the North Carolina outer banks, between Cape Henry (at the mouth of the Chesapeake Bay) and Cape Hatteras, at

the southern end of the Middle Atlantic Bight (Figure 2.1). The coastline is relatively straight in this region with an orientation of approximately $340^{\circ} \mathrm{T}$. The shelf is approximately $80 \mathrm{~km}$ wide and $60 \mathrm{~m}$ deep at the shelf break, increasing in width 
to the north. On the western side of the Outer Banks lie Currituck Sound, Pamlico Sound, and Albemarle Sound, which are large, shallow inland bodies of water, characterized by high surface temperatures during summer [Roelofs and Bumpus, 1953]. The moored observations focused on a cross-shelf section located offshore of the Army Corps of Engineers' Field Research Facility (FRF) in Duck, NC. This section extended $16 \mathrm{~km}$ offshore and consisted of three main mooring sites, $\mathrm{d} 1, \mathrm{~d} 2$, and $\mathrm{d} 3$, two of which ( $\mathrm{d} 2$ and $\mathrm{d} 3$ ) were instrumented with meteorological equipment.

\subsubsection{Oceanographic Setting}

The CoOP Inner Shelf Study took place during August and October-November 1994, which represented two very distinct oceanic settings. During August, the water

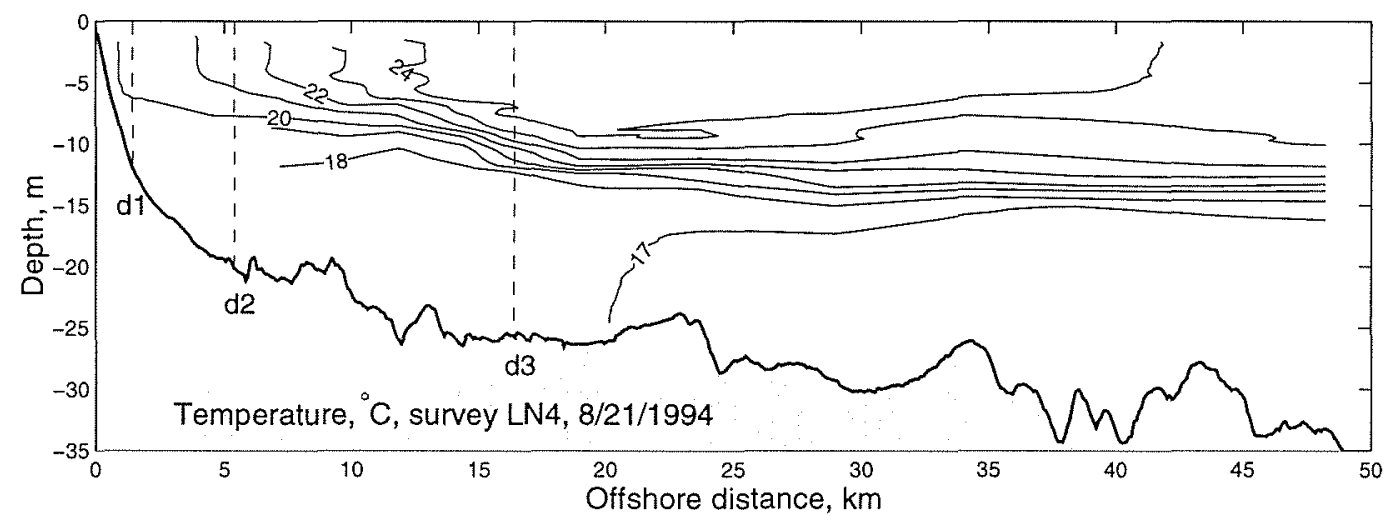

Figure 2.2: Cross-shelf CTD section taken from R/V Cape Hatteras on August 19, 1994, during upwelling-favorable winds (from Waldorf et al., [1995]). The section extends $50 \mathrm{~km}$ offshore from the FRF, perpendicular to the shore. The positions of the three CoOP ISS moorings are indicated by vertical dashed lines.

column was characterized by a strong thermocline with a temperature difference of $5^{\circ} \mathrm{C}$ to $9^{\circ} \mathrm{C}$, usually $3 \mathrm{~m}$ to $6 \mathrm{~m}$ thick, at a depth of approximately $10 \mathrm{~m}$ (Figure 2.2). Upwelling-favorable (northward) winds brought the thermocline to the surface, 

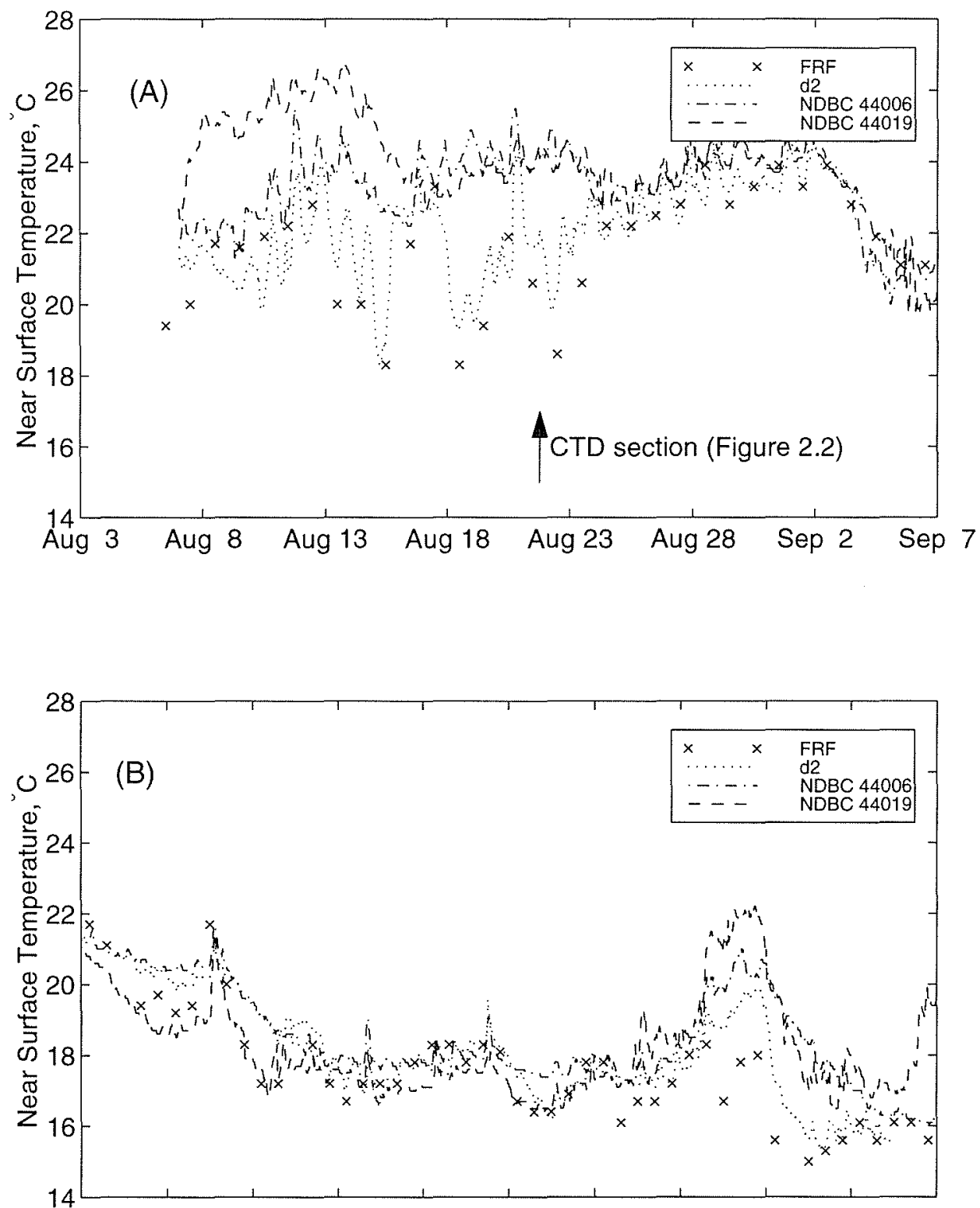

Oct 2 Oct 7 Oct 12 Oct 17 Oct 22 Oct 27 Nov 1 Nov 6 Nov 11 Nov 16 Nov 21

Figure 2.3: Near-surface water temperatures from the FRF pier, d2, NDBC buoys 44006 and 44019, A: August and B: October. FRF values are daily, others are hourly. Arrow indicates timing of CTD section in Figure 2. 
resulting in cross-shelf sea surface temperature differences of up to $8^{\circ} \mathrm{C}$ (Figure $2.3 \mathrm{~A}$ ), which play a significant role in determining the spatial distribution of the surface heat flux. During October-November, the water column was relatively wellmixed in temperature (as inferred from mooring data), and cross-shelf temperature differences were typically less than $1^{\circ} \mathrm{C}$.

\subsubsection{Instrumentation and Other Data Sources}

Many sources of data are utilized in this study to understand the fluxes at the CoOP ISS (Inner Shelf Study) site during August and October-November 1994 and to put these observations into a wider regional and temporal context. The instrumentation is summarized in Table 2.1 .

\section{Moored Instrumentation}

Meteorological instrumentation for the experiment consisted of two Vector Averaging Wind Recorder (VAWR, Table 1) equipped buoys, located at d2 and d3 [Alessi et al., 1996]. These sites were $5 \mathrm{~km}$ and $16.4 \mathrm{~km}$ offshore, on the $21-\mathrm{m}$ and 26$m$ isobaths, respectively. Only data from the $d 2$ VAWR was recovered. The $d 3$ VAWR was lost during Hurricane Gordon on November 18. Each VAWR recorded measurements of air temperature, relative humidity, downward short- and longwave radiation, barometric pressure, sea surface temperature, and wind speed and direction to make bulk estimates of wind stress and surface heat flux. The meteorological

measurements were made at heights of $2.7 \mathrm{~m}$ to $3.3 \mathrm{~m}$ (Table 1 ), and near-surface water temperature measurements were made at a depth of $1.1 \mathrm{~m}$. Data were recorded every 7.5 minutes and were subsequently block-averaged into hourly values. Each 
Table 2.1: Meteorological instruments on the VAWR and associated moorings

\begin{tabular}{|c|c|c|c|}
\hline Parameter & Instrument & Height & Accuracy $^{a}$ \\
\hline $\begin{array}{l}\text { d2 VAWR instruments } \\
\text { Air Temperature }\end{array}$ & $\begin{array}{l}\text { Thermistor } \\
\text { Yellow Springs } \\
5 \mathrm{~K} @ 25^{\circ} \mathrm{C}\end{array}$ & $2.7 \mathrm{~m}$ & $\begin{array}{l} \pm 0.4^{\circ} \\
\left(W S>5 \mathrm{~ms}^{-1}\right)\end{array}$ \\
\hline $\begin{array}{l}\text { Barometric } \\
\text { Pressure }\end{array}$ & $\begin{array}{l}\text { Paroscientific } \\
\text { Model 216-B-101 }\end{array}$ & $\begin{array}{l}2.7 \mathrm{~m} \\
\left(W S<20 \mathrm{~ms}^{-1}\right)\end{array}$ & $\pm 0.6 \mathrm{mb}$ \\
\hline $\begin{array}{l}\text { Longwave } \\
\text { Radiation }\end{array}$ & $\begin{array}{l}\text { Pyrgeometer } \\
\text { Eppley PIR }\end{array}$ & $3.3 \mathrm{~m}$ & $\pm 5 \%$ \\
\hline $\begin{array}{l}\text { Relative } \\
\text { Humidity }\end{array}$ & $\begin{array}{l}\text { Vaisala } \\
\text { Humicap 0062HMP }\end{array}$ & $2.7 \mathrm{~m}$ & $\pm 5 \%$ \\
\hline Insolation & $\begin{array}{l}\text { Pyranometer } \\
\text { Eppley } 8-48\end{array}$ & $3.3 \mathrm{~m}$ & $\pm 5 \%$ \\
\hline Wind Direction & $\begin{array}{l}\text { Integral Vane } \\
\text { w/ vane follower } \\
\text { WHOI/EG\&G }\end{array}$ & $2.7 \mathrm{~m}$ & $\begin{array}{l} \pm 1 \mathrm{bit} \\
\left(5.6^{\circ}\right)\end{array}$ \\
\hline Wind Speed & $\begin{array}{l}\text { R.M. Young } \\
\text { 3-cup anemometer }\end{array}$ & $2.7 \mathrm{~m}$ & $\pm 6 \%^{b}$ \\
\hline $\begin{array}{l}\text { Water } \\
\text { Temperature }(\mathrm{d} 2)\end{array}$ & Thermistor & $-1.1 \mathrm{~m}$ & $\pm 0.5^{\circ} \mathrm{C}^{b}$ \\
\hline $\begin{array}{l}\text { Other CoOP buoy instruments } \\
\text { Water } \\
\text { Temperature }(\mathrm{d} 1, \mathrm{~d} 3)\end{array}$ & SeaCat & $-2.0 \mathrm{~m}$ & $\pm 0.5^{\circ} \mathrm{C}^{c}$ \\
\hline $\begin{array}{l}\text { Water } \\
\text { Temperature (DP) }\end{array}$ & SeaCat & $-4.0 \mathrm{~m}$ & $\pm 1^{\circ} \mathrm{C}^{c}$ \\
\hline $\begin{array}{l}\text { NDBC instruments } d \\
44006\end{array}$ & GSBP payload & & \\
\hline $\begin{array}{l}\text { Air temp. } \\
\text { Water temp. } \\
\text { Wind Speed } \\
\text { Wind Direction }\end{array}$ & & $\begin{array}{l}10 \mathrm{~m} \\
-1.5 \mathrm{~m} \\
10 \mathrm{~m} \\
10 \mathrm{~m}\end{array}$ & $\begin{array}{l} \pm 1^{\circ} \mathrm{C} \\
\pm 1^{\circ} \mathrm{C} \\
\pm 1 \mathrm{~ms}^{-1} \text { or } 10 \% \\
\pm 10^{\circ}\end{array}$ \\
\hline 44019 & VEEP payload & & \\
\hline $\begin{array}{l}\text { Air temperature } \\
\text { Water temperature }\end{array}$ & & $\begin{array}{l}5 \mathrm{~m} \\
-1 \mathrm{~m}\end{array}$ & $\begin{array}{l} \pm 1^{\circ} \mathrm{C} \\
\pm 1^{\circ} \mathrm{C}\end{array}$ \\
\hline Wind Speed & & $5 \mathrm{~m}$ & $\pm 1 \mathrm{~ms}^{-1}$ or $10 \%$ \\
\hline $\begin{array}{l}\text { Wind Direction } \\
44014\end{array}$ & DACT payload & $5 \mathrm{~m}$ & $\pm 10^{\circ}$ \\
\hline Air temperature & & $5 \mathrm{~m}$ & $\pm 1^{\circ} \mathrm{C}$ \\
\hline $\begin{array}{l}\text { Water temperature } \\
\text { Wind Speed }\end{array}$ & & $\begin{array}{l}-1 \mathrm{~m} \\
5 \mathrm{~m}\end{array}$ & $\begin{array}{l} \pm 1^{\circ} \mathrm{C} \\
\pm 1 \mathrm{~ms}^{-1} \text { or } 10 \%\end{array}$ \\
\hline Wind Direction & & $5 \mathrm{~m}$ & $\pm 10^{\circ}$ \\
\hline
\end{tabular}


Table 2.1: (continued)

\begin{tabular}{llll}
\hline Parameter & Instrument & Height & Accuracy $^{a}$ \\
\hline \hline & & & \\
FRF Instruments & & & \\
Water temp. & Bucket thermometer & & $\mathrm{n} / \mathrm{a}$ \\
Air temp. & YSI Thermistor & $20 \mathrm{~m}$ & $\mathrm{n} / \mathrm{a}$ \\
Wind Speed & F420 Anemometer, NWS & $19.5 \mathrm{~m}$ & $\mathrm{n} / \mathrm{a}$ \\
Wind dir. & & $19.5 \mathrm{~m}$ & $\mathrm{n} / \mathrm{a}$ \\
& & & \\
R/V Cape Hatteras instruments & & & \\
Air Temperature & RM Young $41372 \mathrm{C}$ & $15.25 \mathrm{~m}$ & $\mathrm{n} / \mathrm{a}$ \\
Water Temperature & YSI 701 & $0 \mathrm{~m}$ & $2^{\circ} \mathrm{C}^{e}$ \\
\hline
\end{tabular}

${ }^{a}$ Estimated instrument accuracy; Based on manufacturer's specifications unless otherwise noted.

${ }^{\circ}$ From Weller et al., [1990]

${ }^{c}$ Although the sensors themselves have greater accuracy than shown here, the value represents their estimated accuracy as a measure of surface water temperature.

${ }^{d}$ Data taken from the NDBC web site, http://seaboard.ndbc.noaa.gov.

eResolution, not accuracy.

buoy was equipped with an ARGOS transmitter to transmit the meteorological data and buoy position to shore.

The $\mathrm{d} 2$ and $\mathrm{d} 3$ meteorological buoys were deployed on August 6, and recovery was planned for early December. However, failure of the surface moorings during severe storms and failure of the d3 ARGOS transmitter system resulted in only 2.5 months of data from the $\mathrm{d} 2$ site and almost no data from the $\mathrm{d} 3$ site. The $\mathrm{d} 2$ surface mooring failed September 4 during a tropical storm and came ashore with all of its instrumentation intact. The mooring was refurbished and redeployed on October 4. It failed again on November 18 during Hurricane Gordon and came ashore. Although the tower with the VAWR was torn off the buoy as it came ashore, it was eventually recovered with all data intact. This sequence of events determined the two time periods considered here, which are designated the "August" time period, 1:00 UTC 7 August 1994 to 0:00 UTC 4 September 1994, and the "October" time period, from 15:00 UTC 4 October 1994 to 8:00 UTC 18 November 1994. The d3 surface buoy stayed in place until Hurricane Gordon on November 18 when it also came ashore. 
Unfortunately, the VAWR on the $\mathrm{d} 3$ buoy (and hence all of the meteorological data from the $\mathrm{d} 3$ site) was lost as the buoy came ashore. The d3 ARGOS transmitter failed on August 12, was repaired on September 1, and failed again on September 8. The amount of data recovered via the $\mathrm{d} 3 \mathrm{ARGOS}$ transmitter was too small to be useful for this study.

Other measurements from the moored array consisted of near-surface (2-m depth) water temperature at the $\mathrm{d} 1$ site, $1.4 \mathrm{~km}$ offshore in $13 \mathrm{~m}$ of water, and at the $\mathrm{d} 3$ site, $16.4 \mathrm{~km}$ offshore in $25 \mathrm{~m}$ of water. All three moorings were instrumented with thermistors to determine the vertical structure of the water column. Hourly water temperature measurements were made near the end of the FRF pier at a depth of $4.0 \mathrm{~m}$ using a SeaCat (referred to as DP, for "Duck Pier"). This is rather deep for estimating surface temperatures, as the mean temperature difference at $\mathrm{d} 1$ between 4.6- $\mathrm{m}$ and $1.5-\mathrm{m}$ depth is approximately $0.6^{\circ} \mathrm{C}$ during August (maximum difference of $3.2^{\circ} \mathrm{C}$ ), so this measurement is most likely an underestimate of the sea surface temperature of order $1{ }^{\circ} \mathrm{C}$ during August. During October, no data was available at the surface at $\mathrm{d} 1$, but the difference between the temperature at $4.6 \mathrm{~m}$ and $1.1 \mathrm{~m}$ at $\mathrm{d} 2$ was, on average, on the order or $0.02^{\circ} \mathrm{C}$ (with a maximum instantaneous difference of $1.1^{\circ} \mathrm{C}$ ), suggesting that the temperature at 4 -m depth is a reasonable proxy for the surface temperature.

\section{The Field Research Facility (FRF) Measurements}

Wind speed and direction, air temperature, barometric pressure, and water temperature measurements have been taken almost continuously since 1982 at the FRF [Birkemeier, 1985]. Wind speed and direction were measured using an anemometer located $19.4 \mathrm{~m}$ above sea level at the end of the FRF pier ( $560 \mathrm{~m}$ offshore). Air 
temperature was measured in an instrument housing $40 \mathrm{~m}$ onshore, and appeared to suffer from a diurnal instrument heating problem. Therefore, only nighttime values were used. During onshore winds, nighttime values typically differed from measurements at $\mathrm{d} 2$ by less than $1^{\circ} \mathrm{C}$, suggesting measurement errors on the order of $1^{\circ} \mathrm{C}$, though no actual uncertainty values are available. Sea surface temperature was measured using a bucket thermometer at the end of the pier, once per day, typically around $7 \mathrm{AM}$ local time. These data were highly correlated with buoy measurements during the August and October 1994 periods, and were used to gain some perspective on the regional seasonal and interannual variability, as well as qualitative information on the cross-shelf variation during the experiment.

\section{The NDBC Buoy Array}

The National Data Buoy Center (NDBC) maintained three meteorological buoys, designations 44006, 44019, and 44014 (Figure 2.1), across the shelf near the FRF which proved useful to this study. These buoys recorded hourly wind speed and direction, air temperature and water temperature, with quoted accuracies listed in Table 1. While insufficient for complete heat flux calculations, these data were used to examine cross-shelf variations in the meteorology, estimate sensible heat flux, and infer latent heat flux.

\section{Shipboard Data}

The R/V Cape Hatteras performed CTD transects on the North Carolina inner shelf during August and October 1994 as part of the CoOP Inner Shelf Study [Waldorf et al., 1995; Waldorf et al., 1996]. It made 16 transects of the shelf along the FRF - 
d3 central mooring line in August and 20 in October. In addition, cross-shelf transects north and south of the central mooring line were made to quantify alongshelf variation in the hydrography. During each cruise, air temperature, surface water temperature, and wind velocity were measured every 15 seconds. The air temperature measurements suffered from very low $\left(2^{\circ} \mathrm{C}\right)$ resolution, so the air temperature measurements are used only for qualitative comparisons.

\subsubsection{Estimation of the Surface Heat Flux and Wind Stress}

The surface wind stress and the turbulent surface heat flux were estimated using bulk formulas developed by Fairall et al. [1996]. Like most other bulk flux algorithms, these were generated using measurements made in the open ocean, away from boundaries and fronts. A comparison of the heat flux and surface stress estimated with this formulation with those estimated using the Large and Pond [1981, 1982] formulation revealed no qualitative differences.

The appropriateness of these bulk formulas to the coastal ocean is not clear, especially to sites within a few kilometers of the shoreline. Their suitability is especially questionable during offshore winds, when the marine atmospheric boundary layer must quickly adjust to new surface conditions. In addition, surface waves, steepened in shallow water, may affect the transfer coefficients and hence estimates of turbulent fluxes [Large et al. 1995; Geernaert et al. 1986]. It should be noted that neither of these effects have been taken into account in the estimates presented here. In the absence of direct (i.e., eddy correlation) measurements of momentum, heat, and moisture fluxes, the appropriateness of the bulk formulas of Fairall et al. [1996] cannot be judged. The uncertainty of the mean flux estimates due to measurement 
uncertainty will be discussed in section 2.3.5.

\section{Surface Stress}

The surface wind stress is estimated using a stability-dependent transfer coefficient that relates the measured wind speed to the wind stress,

$$
\vec{\tau}=\rho_{A} C_{d}\left(\vec{u}_{a}-\vec{u}_{s}\right)\left|\vec{u}_{a}-\vec{u}_{s}\right|
$$

where $\rho_{A}$ is air density, $C_{d}$ is a stability-dependent transfer coefficient, $\vec{u}_{a}$ is wind velocity measured at a specified height (in this case $2.7 \mathrm{~m}$ ), and $\vec{u}_{s}$ is the surface velocity of the water. The direction of the wind stress is assumed to be the same as the velocity difference vector $\vec{u}_{a}-\vec{u}_{s}$.

\section{Surface Heat Flux}

The net surface heat flux may be considered the sum of four terms $[$ Gill, 1982]:

$$
Q_{T O T}=Q_{S W_{N E T}}+Q_{L W_{N E T}}+Q_{L A T}+Q_{S E N}
$$

where $Q_{S W_{N E T}}$ is the net shortwave radiation, $Q_{L W_{N E T}}$ is the net longwave radiation (the difference between upward and downward longwave radiation), $Q_{L A T}$ is the latent heat flux, and $Q_{S E N}$ is the sensible heat flux. In this paper, positive flux values always denote heat flux into the ocean.

The net shortwave radiation flux $Q_{S W_{N E T}}$ due to solar insolation between $0.28 \mu \mathrm{m}$ 
and $2.8 \mu \mathrm{m}$, is estimated using

$$
Q_{S W_{N E T}}=Q_{S W_{D O W N}}(1-A b)
$$

where $Q_{S W_{D O W N}}$ is measured using an Eppley $8-48$ pyranometer, and $A b$ is the albedo of the sea surface, which is determined empirically as a function of the solar angle and atmospheric transmissivity [Payne, 1972].

The net longwave radiation flux $Q_{L W_{N E T}}$ is the difference between the upward longwave radiation $Q_{L W_{U P}}$ due to blackbody radiation from the ocean surface, calculated using the Stefan-Boltzman law, and the downward longwave radiation $Q_{L W_{D O W N}}$ due to radiation from moisture in the atmosphere, and is measured directly. The formula for the net longwave radiation flux is

$$
Q_{L W}=\epsilon\left(Q_{L W_{D O W N}}-\sigma T_{S}^{4}\right)
$$

where $\epsilon=0.98$ [Dickey et al., 1994], is the radiative efficiency of the water (estimates of $\epsilon$ vary from 0.93 to 1.0 [Fung et al., 1984]), $\sigma=5.67 \times 10^{-8} \mathrm{~W} \mathrm{~m}^{-2} \mathrm{~K}^{-4}$ is the Stefan-Boltzman constant, and $T_{s}$ is the sea surface temperature in degrees Kelvin. $Q_{L W_{D O W N}}$ is due to infrared radiation in the range $3.5 \mu \mathrm{m}$ to $50 \mu \mathrm{m}$ emitted by atmospheric moisture, and is measured directly using an Eppley PIR pyrgeometer. The downward longwave radiation was corrected for instrument heating by subtracting $0.035 Q_{S W_{D O W N}}[$ Alados-Arboledas et al., 1988].

The latent heat flux $Q_{L A T}$ represents the heat released or gained when water evaporates from or condenses on the ocean surface. Although often interpreted as representing only evaporation, there is a significant portion of the August time series during offshore winds when it appears that heat was being gained due to 
condensation at the sea surface [Beardsley et al., in press]. The latent heat flux is related to the moisture gradient at the ocean surface and the air - water velocity difference using the bulk formula

$$
Q_{L A T}=\rho_{A} L C_{e}\left(q_{z}-q_{0}\right)\left|\vec{u}_{a}-\vec{u}_{s}\right|
$$

where $L$ is the latent heat of evaporation, $q_{z}$ is the specific humidity measured at height $z$ above sea level (in this case, $z=2.7 \mathrm{~m}$ ), $q_{0}$ is the estimated humidity at the sea surface, calculated by assuming the air at the water surface is the same temperature as the water and that the air is saturated (assuming that the saturation humidity for air over salt water is 0.98 of the saturation humidity of air over fresh water of the same temperature), and $C_{e}$ is a stability-dependent transfer coefficient, estimated using the Fairall et al. [1996] formulation.

The sensible flux $Q_{S E N}$ is related to the temperature difference between the air and sea surface and the air - water velocity difference using the bulk formula

$$
Q_{S E N}=\rho_{A} C_{p} C_{h}\left(T_{A}-T_{S}\right)\left|\vec{u}_{a}-\vec{u}_{s}\right|
$$

where $C_{p}$ is the heat capacity of water, $T_{S}$ is the sea surface temperature, $T_{A}$ is the air temperature, and $C_{h}$ is a stability-dependent transfer coefficient, also estimated using the Fairall et al. [1996] formulation.

\subsubsection{Estimation of Instrument=Induced Flux Uncertainty}

Although it is impossible to take into account all potential sources of error inherent in making surface flux estimates, it is essential to make as good an estimate as 
possible using manufacturer's specifications (Table 1) and literature values of uncertainty to provide a context for interpreting the surface flux estimates. This error analysis reveals what terms of the surface flux (and what instruments) contribute most significantly to uncertainty in the estimate of the total surface heat flux and wind stress, given what is known about the uncertainties of the measurements. For a more thorough treatment of uncertainty in the VAWR measurements and how they apply to flux estimates, see Weller et al. [1990] and Beardsley et al. [submitted]. Results of the error analysis are summarized in Table 2.2 .

Table 2.2: Statistics of August and October time series of heat flux components measured at $\mathrm{d} 2$. Uncertainties reflect instrument-based uncertainties only.

\begin{tabular}{lllllll}
\hline & \multicolumn{2}{c}{ mean } & \multicolumn{2}{c}{ std. dev. } & \multicolumn{2}{c}{ subtidal std. dev. } \\
\cline { 2 - 7 } & AUG & OCT & AUG & OCT & AUG & OCT \\
\hline \hline$Q_{S W_{N E T}}$ & $220 \pm 11$ & $144 \pm 7$ & 301 & 222 & 83 & 59 \\
$Q_{L W_{D O W N}}$ & $377 \pm 19$ & $325 \pm 16$ & 27 & 37 & 38 & 39 \\
$Q_{L W_{U P}}$ & $-422 \pm 7$ & $-399 \pm 5$ & 8 & 8 & 31 & 23 \\
$Q_{L W_{N E T}}$ & $-45 \pm 20$ & $-74 \pm 17$ & 28 & 37 & 29 & 35 \\
$Q_{S E N}$ & $5 \pm 4$ & $-15 \pm 4$ & 19 & 31 & 22 & 30 \\
$Q_{L A T}$ & $-33 \pm 13$ & $-94 \pm 12$ & 72 & 98 & 68 & 93 \\
$Q_{T O T}$ & $147 \pm 26$ & $-39 \pm 22$ & 317 & 258 & 135 & 138 \\
\hline
\end{tabular}

All values are in $\mathrm{W} \mathrm{m}^{-2}$.

${ }^{a}$ The subtidal standard deviation represents the standard deviation of the lowpassed time series.

\section{Surface Stress}

The quoted accuracy of the wind speed measurement is $2 \%$, but there have been indications that cup anemometers are prone to overspeeding by as much as $6 \%$ [ Weller et al, 1990]. Using a nominal value of $6 \%$ for the uncertainty of the wind speed estimate, and assuming that error in the estimate of wind stress is due primarily to this measurement (as opposed to the measurement of surface ocean currents, which 
are relatively small), overspeeding could be responsible for uncertainties in the stress estimates of up to $12 \%$.

\section{Latent Heat Flux}

An analysis of error propagation in the latent heat flux bulk equation suggests that the main source of instrument error is the measurement of relative humidity, assumed to be $\pm 5 \%$ [Weller et al., 1990]. This error causes an uncertainty in the estimate of the mean latent heat flux of order $12 \mathrm{~W} \mathrm{~m}^{-2}$.

\section{Sensible Heat Flux}

The largest source of uncertainty in the sensible heat flux is the determination of the difference between air and surface water temperatures. The uncertainty in the difference is greatest during strong insolation and weak winds, when the air temperature sensor suffers from overheating and the water temperature sensor underestimates the surface temperature due to formation of stratification in the upper meter of the water column. During strong winds, both of these effects are small. Since the sensible flux is proportional to the wind speed, uncertainty in the temperature difference during weak winds leads to small uncertainties in the sensible flux. With an estimated temperature difference uncertainty of order $1.0^{\circ} \mathrm{C}$, much larger than the air temperature and water temperature instrument errors alone, the corresponding uncertainty in the sensible flux is of order $12 \mathrm{~W} \mathrm{~m}^{-2}$. 


\section{Longwave Radiation}

Upward longwave radiation is a function of the estimated sea surface temperature and the emissivity of the sea surface. Assuming the uncertainty in sea surface temperature in August is $1^{\circ} \mathrm{C}$ (due primarily to near-surface vertical temperature gradients; the value for October is most likely smaller) and the uncertainty in the emissivity to be \pm 0.01 [Dickey et al., 1994], the total uncertainty in the mean upward longwave radiation is about $7 \mathrm{~W} \mathrm{~m}^{-2}$ in August. In October, the uncertainty in the estimation of $\epsilon$ is dominant, and the uncertainty is around $5 \mathrm{Wm}^{-2}$.

The downward longwave radiation was measured directly, and the instrument uncertainty is $5 \%$. Beardsley et al., [in press] compared records from two PIR. records and found a difference of $4.2 \%$, but recent studies suggest that even this may overestimate the uncertainty [Fairall et al., submitted to JAOT]. Using $5 \%$ as an estimate in the uncertainty of the measurement, the uncertainty in the downward longwave flux estimate is of order $19 \mathrm{~W} \mathrm{~m}^{-2}$ in August and $16 \mathrm{~W} \mathrm{~m}^{-2}$ in October.

\section{Shortwave Radiation}

It will be assumed that most of the error in the estimation of shortwave radiation is in the measurement itself, as opposed to the altitude-dependent albedo. The uncertainty in the measurement for an ungimballed sensor is $5 \%$ [Weller et al., 1990], corresponding to mean uncertainties of $11 \mathrm{~W} \mathrm{~m}^{-2}$ in August and $7 \mathrm{~W} \mathrm{~m}^{-2}$ in October. 


\section{Net Heat Flux}

As the instruments that are primarily responsible for the uncertainty are different for each term on the net surface heat flux, the uncertainties can be considered independent. Making this assumption, the estimated uncertainty in the mean net surface heat flux due to measurement uncertainty is approximately $26 \mathrm{~W} \mathrm{~m}^{-2}$ in August and $22 \mathrm{~W} \mathrm{~m}^{-2}$ in October. The largest sources of error, given what is known about the error characteristics of the measurements, are the downward longwave and latent heat flux estimates.

\subsection{Observations and Results}

During the August and October time periods, the surface heat flux (Table 2, Figure 2.4 (August) and Figure 2.5 (October)) varied on two distinct time scales: diurnal (daily) and synoptic (time scales of $2-7$ days). This study focuses on the synoptic variability, which is evident in all of the meteorological time series (Table 2.3, Figure 2.6 (August), Figure 2.7 (October)), and hence the surface heat flux components. Diurnal variability was due almost entirely to the daily shortwave radiation cycle. This variability was removed from the data using the pl64 low pass filter [Beardsley et al., 1985]. However, there is also a large difference between the mean surface heat fluxes during August and October, presumably associated with seasonal variation in the meteorology, which is discussed first. 

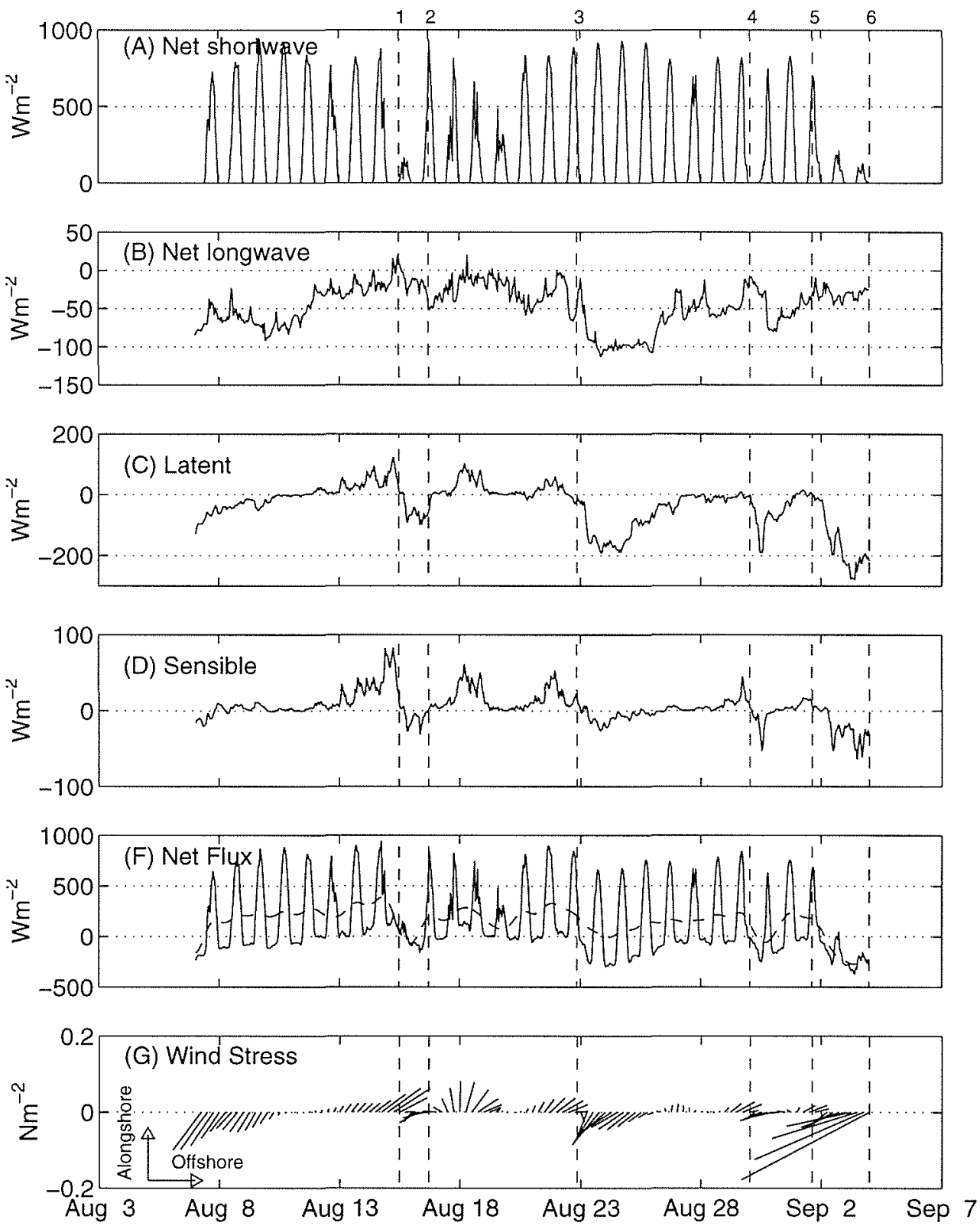

Figure 2.4: Terms of the heat flux and the wind stress for the August time period, measured at d2: (A) net shortwave; (B) net longwave; (C) latent; (D) sensible; (E) net surface heat flux (hourly (solid) and low pass filtered (dashed)), and wind stress (low passed and subsampled every 6 hours). The wind stress is defined with alongshelf up and offshore to the right. The numbers at the top of the figure and the vertical dashed lines mark the meteorological events listed in Table 2.4. 

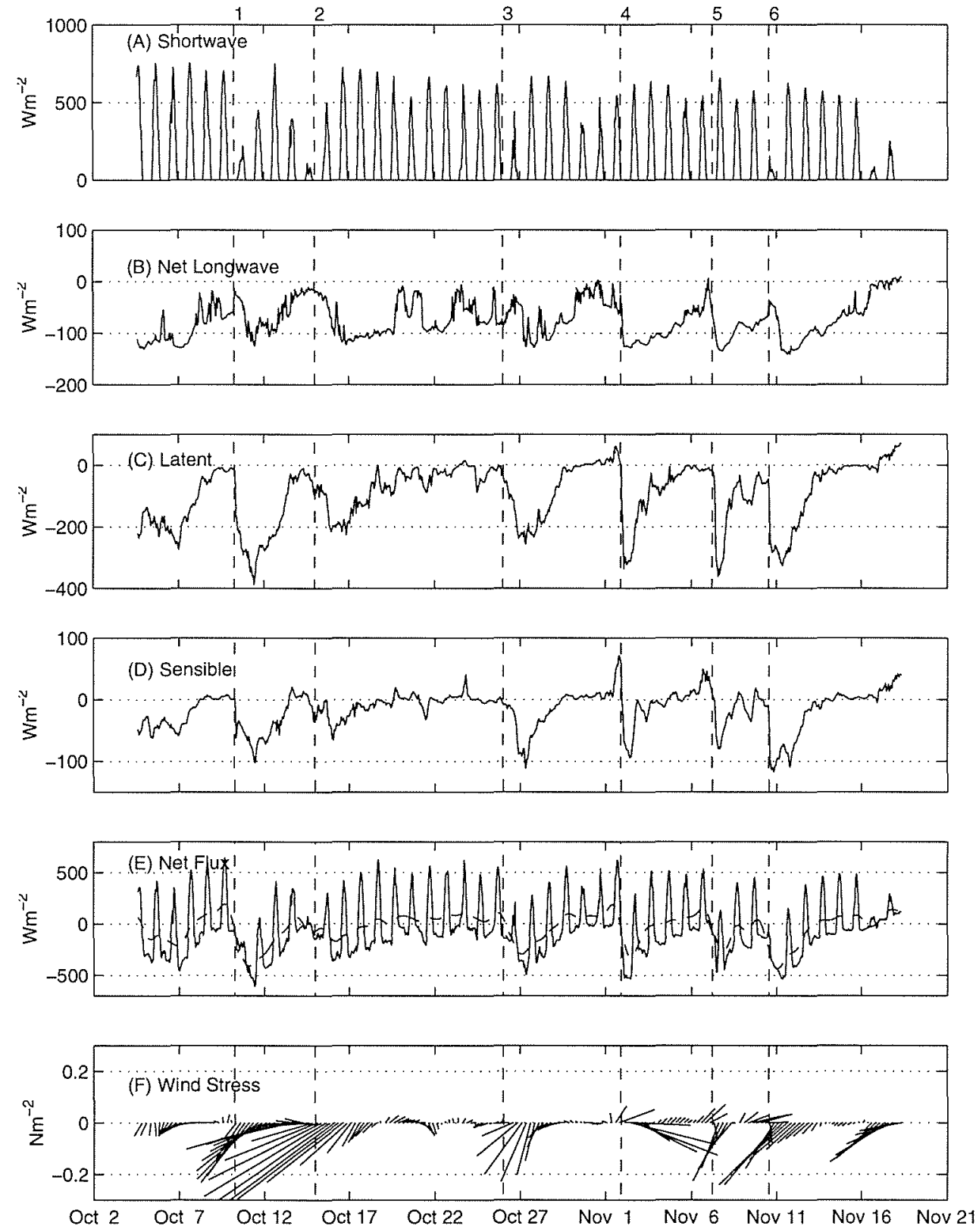

Figure 2.5: Terms of the heat flux and wind stress for the October time period, as in Figure 2.4 . 

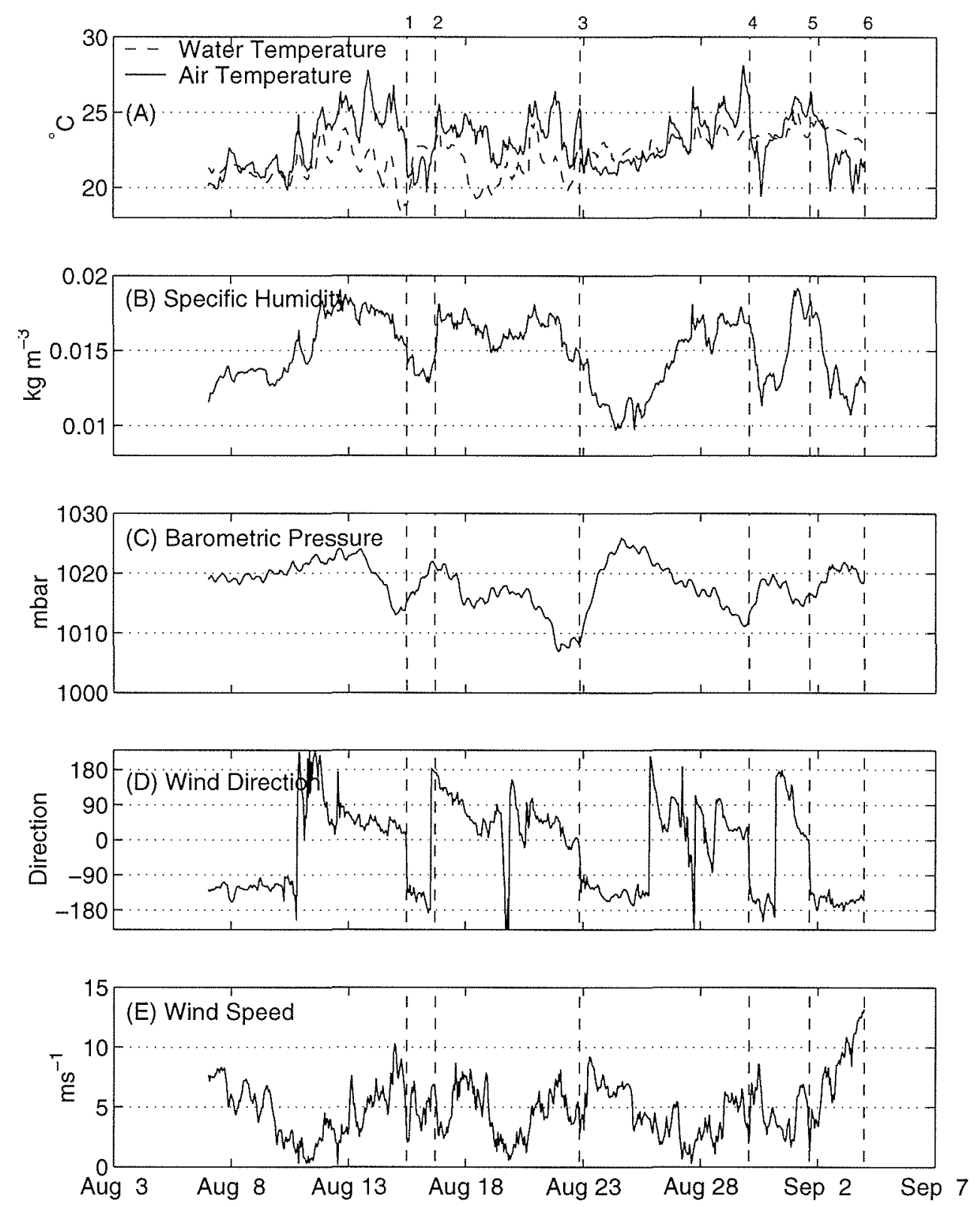

Figure 2.6: Meteorological time series for August: (A) air and water temperature; (B) specific humidity; (C) barometric pressure; (D) wind direction; (E) wind speed. Wind direction is defined such that $0^{\circ}$ represents winds blowing directly offshore, and $90^{\circ}$ represents winds blowing alongshelf poleward. 

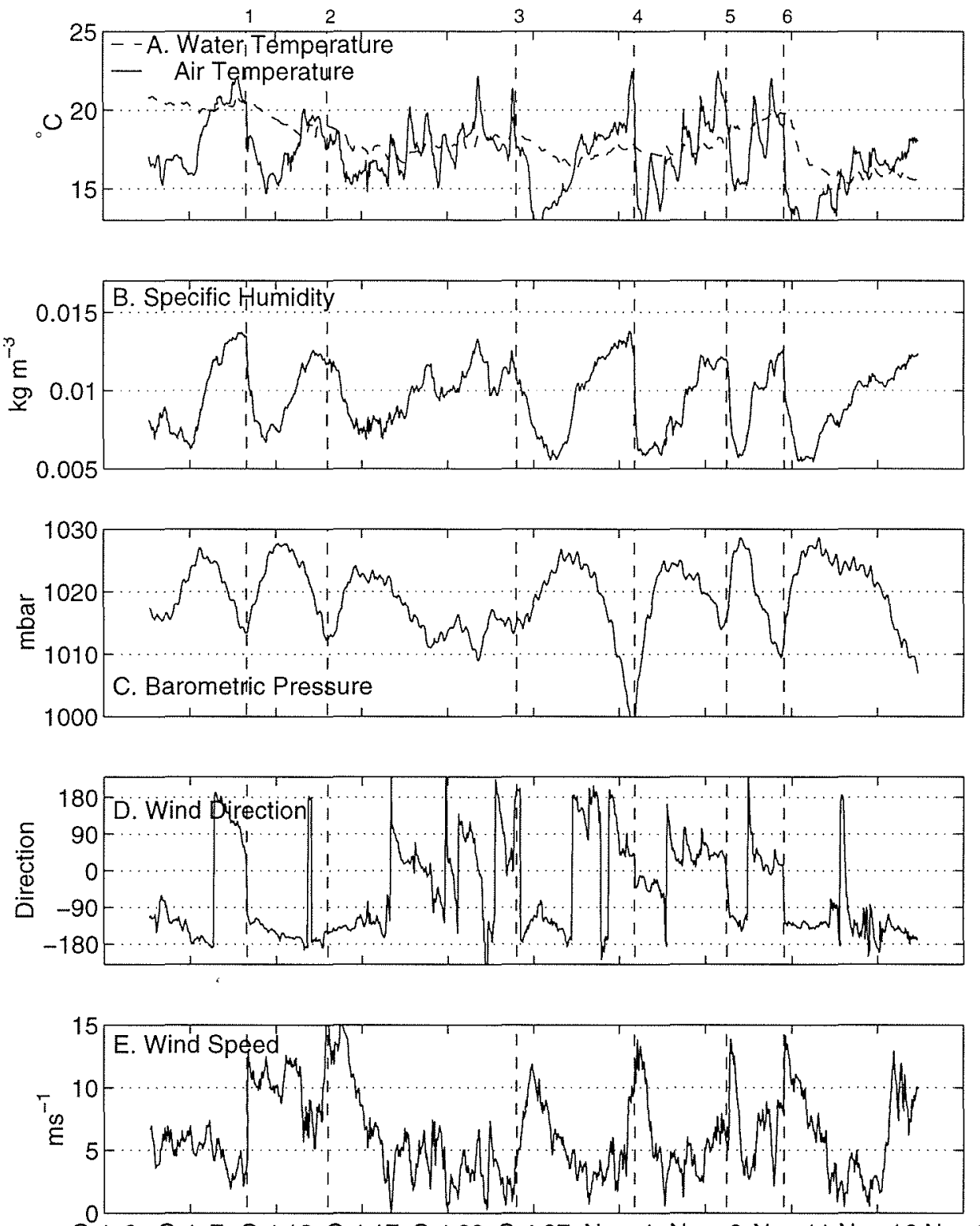

Oct 2 Oct 7 Oct 12 Oct 17 Oct 22 Oct 27 Nov 1 Nov 6 Nov 11 Nov 16 Nov 21

Figure 2.7: Meteorological time series for the October time period, as in Figure 2.6. 
Table 2.3: Statistics of August and October-November meteorological time series

\begin{tabular}{lllllll}
\hline & \multicolumn{2}{c}{ mean } & \multicolumn{3}{c}{ std. dev } & \multicolumn{2}{c}{ subtidal std. } \\
\cline { 2 - 7 } & AUG & OCT & AUG & OCT & AUG & OCT \\
\hline \hline Air temperature, ${ }^{\circ} \mathrm{C}$ & 23.1 & 17.1 & 1.7 & 2.16 & 1.5 & 2.0 \\
Barometric pressure, $\mathrm{mb}$ & 1018 & 1019 & 3.8 & 5.7 & 3.7 & 5.6 \\
Downward longwave, $\mathrm{W} \mathrm{m}^{-2}$ & 393 & 338 & 28 & 36 & 25 & 33 \\
Relative humidity, \% & 86.2 & 78.6 & 8.0 & 11.0 & 6.9 & 10.6 \\
Shortwave radiation, $\mathrm{W} \mathrm{m}^{-2}$ & 236 & 161 & 310 & 234 & 89 & 64 \\
Wind speed, $\mathrm{ms}^{-1}$ & 4.9 & 6.2 & 2.4 & 3.3 & 2.1 & 3.1 \\
WT $(\mathrm{DP}, 4 \mathrm{~m}),{ }^{\circ} \mathrm{C}$ & 21.2 & - & 1.8 & - & 1.7 & - \\
WT $(\mathrm{d} 1,2 \mathrm{~m}),{ }^{\circ} \mathrm{C}$ & 21.7 & - & 1.7 & - & 1.6 & - \\
WT $(\mathrm{d} 2,1.1 \mathrm{~m}),{ }^{\circ} \mathrm{C}$ & 22.2 & 18.0 & 1.3 & 1.4 & 1.2 & 1.4 \\
WT $(\mathrm{d} 3,2 \mathrm{~m}),{ }^{\circ} \mathrm{C}$ & 23.3 & 18.6 & 0.9 & 1.1 & 0.9 & 1.1 \\
\hline
\end{tabular}

\subsubsection{Seasonal Variation}

The mean net surface heat flux was $147 \mathrm{~W} \mathrm{~m}^{-2}$ in August and $-39 \mathrm{~W} \mathrm{~m}^{-2}$ in October (Table 2). About $40 \%$ of this decrease was due to reduction in shortwave radiation. Comparison of measured shortwave radiation with calculated average clear-sky radiation (321 $\mathrm{W} \mathrm{m}^{-2}$ in August and $184 \mathrm{~W} \mathrm{~m}^{-2}$ in October [U.S. Naval Observatory, 1978]) indicates that the reduction in shortwave radiation was due to the seasonal reduction in the angle of incidence of sunlight, as opposed to increased cloud cover. About $33 \%$ of the decrease in the net surface heat flux was due to an increase in latent heat flux loss, associated primarily with a decrease in air temperature relative to the decrease in the surface water temperature (Table 3), which increases the specific humidity difference. A decrease in relative humidity also contributed to the increased latent heat loss from the ocean.

To put the August and October 1994 observations in the context of the seasonal cycle, 13 year records of air temperature and wind data collected between 1982 and 1994 and an 11 year record of near-surface water temperature collected between 1984 
and 1994 at the FRF were averaged into monthly values (Figure 2.8). In general, August is a period of weak winds, and is one of the warmest months in terms of both air and water, with the air temperature $1.1^{\circ} \mathrm{C}$ warmer on average than the water temperature $\left(3.1^{\circ} \mathrm{C}\right.$ warmer in 1994$)$. October, on the other hand, occurs during the period of most rapid cooling of both the water temperature and the air temperature, and the air temperature is $1.8^{\circ} \mathrm{C}$ colder than the water temperature on average $\left(3.5^{\circ} \mathrm{C}\right.$ colder in 1994$)$. At the $\mathrm{d} 2$ site, the air temperature - water temperature difference was of the same sign but smaller in magnitude during both months (Table 3). Winds in October are typically stronger than in August, as was observed in 1994. The seasonal cycles in Figure 2.8 and the mean heat fluxes for August and October are consistent with the analysis of Mid-Atlantic Bight climatology by Bunker [1976]. These results suggest that the differences in the meteorological variables between the August and October time periods, and hence in the heat flux terms, are due to seasonal variations, and that 1994 was a typical year in this sense.

\subsubsection{Synoptic Variation}

The standard deviation of the low-passed net surface heat flux was approximately $135 \mathrm{~W} \mathrm{~m}^{-2}$ (Table 2) in both the August and October time series. The largest contributions to this variability came from the latent heat flux and shortwave radiation. Shortwave radiation variability was largest in August, and the latent heat flux variability was largest in October. The most common source of variability on synoptic time scales was the passage of atmospheric fronts associated with low pressure systems. The net surface heat flux and the pattern of variability depend on the track of the low pressure center relative to the study site. During the CoOP Inner Shelf Study, variability associated with three basic storm tracks was observed. The most 

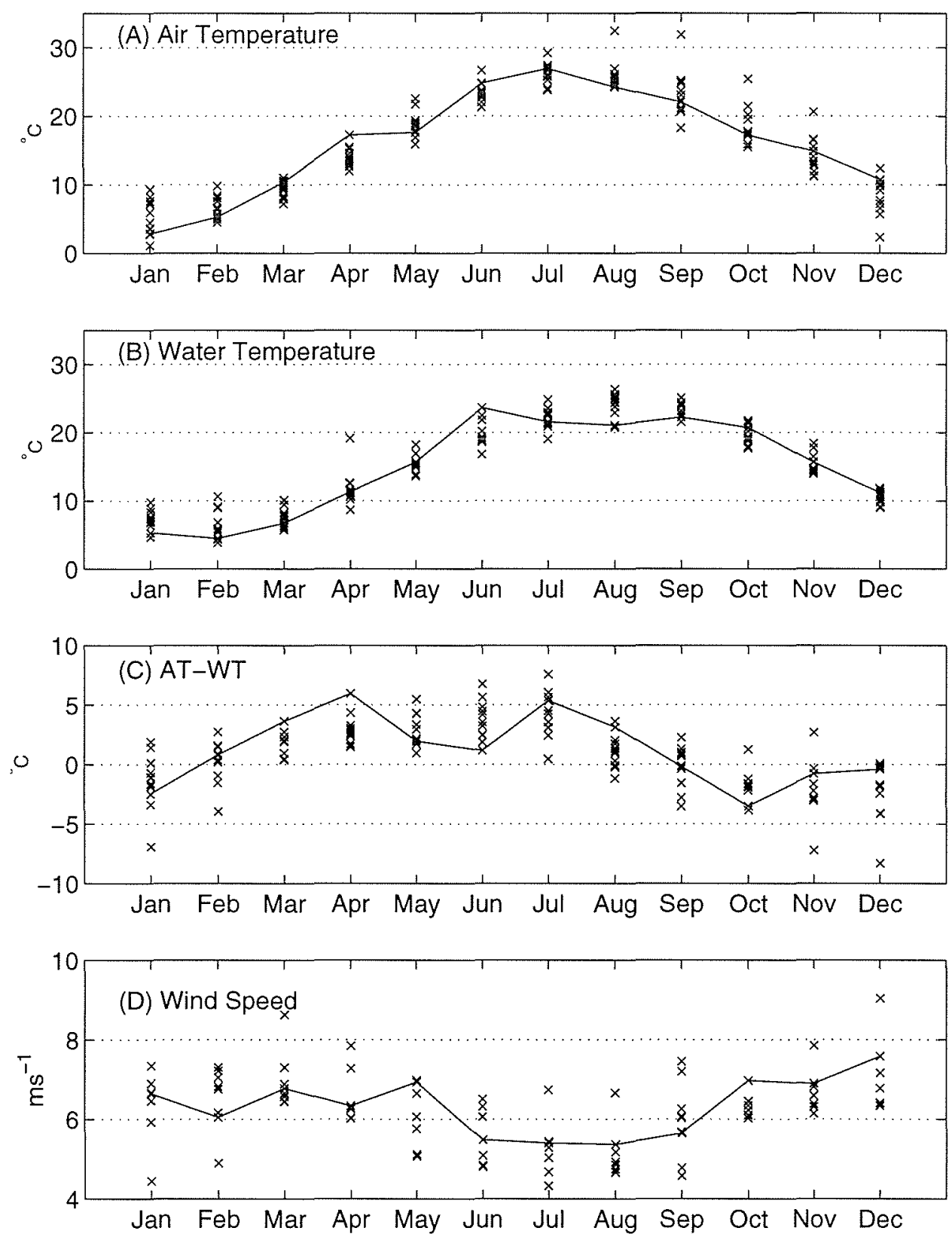

Figure 2.8: Monthly averages of FRF archived data, (1982-1994). Connecting line represents 1994 data. (A) air temperature (outliers between August and November are from first year of operation and may represent instrument error); (B) water temperature; (C) air temperature minus water temperature; (D) wind speed. 
Table 2.4: Characteristics of meteorological events

\begin{tabular}{lllllllll}
\hline Event \# & Date & event type & $\begin{array}{c}\Delta T \\
{ }^{\circ} \mathrm{C}\end{array}$ & $\begin{array}{l}\Delta S H \times 10^{3} \\
\mathrm{~kg} \mathrm{~m}^{-3}\end{array}$ & clouds & $\begin{array}{c}\text { Wind Direc. } \\
{ }^{\circ} \mathrm{T}\end{array}$ & $\begin{array}{c}\text { Max. Wind } \\
\mathrm{m} \mathrm{s}^{-1}\end{array}$ & $\begin{array}{c}\Delta S H F \\
\mathrm{~W} \mathrm{~m}^{-2}\end{array}$ \\
\hline \hline AUG \#1 & $8 / 15$ & Cold Front & -4.5 & -4.5 & No & $45 \rightarrow-135$ & 10 & -160 \\
AUG \#2 & $8 / 16$ & Warm front & 4 & 4 & Yes & $180 \rightarrow 0$ & 8 & $(+100)$ \\
AUG \#3 & $8 / 22$ & Cold Front & -3.5 & -7 & Yes & $0 \rightarrow-135$ & 9 & -300 \\
AUG \#4 & $8 / 29$ & Cold Front & -4 & -5 & Yes & $30 \rightarrow-150$ & 7 & -250 \\
AUG \#5 & $9 / 1$ & Cold Front & -4.5 & -7 & Yes & $0 \rightarrow-135$ & 8 & -370 \\
AUG \#6 & $9 / 4$ & Tropical Storm & $?$ & - & Yes & $-170 \rightarrow-135$ & 16 & -320 \\
OCT \#1 & $10 / 10$ & Cold Front & -6 & -6.5 & Yes & $45 \rightarrow-135$ & 13 & -610 \\
OCT \#2 & $10 / 15$ & Tropical Storm & -4 & -5 & Yes & $-170 \rightarrow-135$ & 15 & -360 \\
OCT \#3 & $10 / 26$ & Cold Front & -6 & -6 & Yes & $0 \rightarrow-170$ & 11 & -490 \\
OCT \#4 & $11 / 1$ & Cold Front & -4.5 & -8 & No & $45 \rightarrow-45$ & 14 & -530 \\
OCT \#5 & $11 / 7$ & Cold Front & -6.5 & -6.5 & No & $45 \rightarrow-135$ & 14 & -470 \\
OCT \#6 & $11 / 10$ & Cold Front & -6.5 & -6.5 & Yes & $30 \rightarrow-135$ & 14 & -530 \\
\hline
\end{tabular}

The changes in air temperature $(\Delta T)$, specific humidity $(\triangle S H)$ and net surface heat flux $(\triangle S H F)$ were determined by judging the maximum change in these parameters in a 24 hour window around the frontal passage. Low-pass filtered net surface heat flux was used for this purpose. Wind direction is defined such that $0^{\circ}$ is directly offshore, $90^{\circ}$ is alongshelf poleward.

common pattern of variation was due to low pressure systems passing from west to east-northeast, to the north of the study site. In this case, a trailing cold front associated with the low pressure system passed over the study site. This occurred four times during the August time period (August 15, 22, 29, and September 1), and five times during the October time period (October 10, 26, November 1, 7 and 10). The second pattern was associated with tropical storms, low pressure systems moving north to the east of the site, which occurred on September 4 and October 15. The third pattern consisted of the passage of a warm front associated with a low pressure center developing over the southeastern US and moving north, to the west of the site, which occurred once (August 18). Each of these cases had a distinct pattern of variation in the meteorology, surface heat flux and wind stress. Table 4 contains basic characteristics of each synoptic weather event. Historical data from the FRF suggests that the number of low pressure systems observed during 1994 was not unusual for these time periods, with typically 3 to 6 low pressure events occurring in the August time periods between 1982 and 1994, and 5 to 9 occurring in the October time periods. A description of each of the three cases follows. 


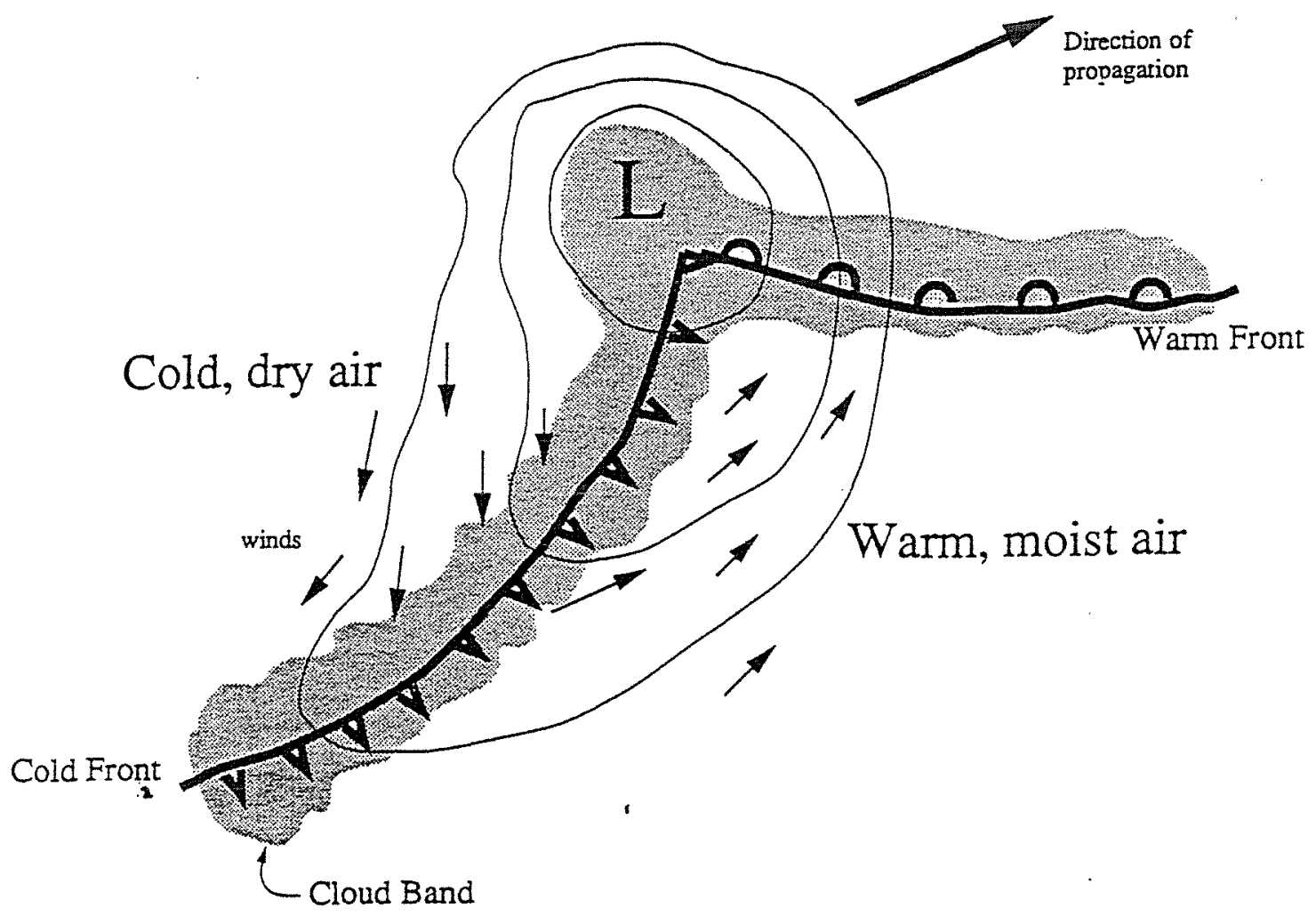

Figure 2.9: Schematic of a low pressure system and associated fronts, plan view.

Cold fronts are regions of strong temperature gradient, usually characterized by large spatial variations in air temperature, specific humidity, and wind speed and direction (Figure 2.9) [Willett and Sanders, 1959]. As cold, dry air moves from west to east, it displaces warm, moist air upwards, often creating a cloud line due to adiabatic cooling. During the passage of a front, the local change in temperature and humidity usually occurs in 6 hours or less. A minimum in barometric pressure accompanies the rapid change in wind direction during the passage of the front. The structure of the pressure field results in an increase in magnitude and change in direction of the wind during the passage of a cold front. During the CoOP Inner 
Shelf Study, the wind direction tended to change from predominantly northeastward before the passage of the front to southwestward after the passage of the front, since surface winds blow primarily $20^{\circ}$ to $50^{\circ}$ to the left of isobars. The change in wind orientation corresponds to upwelling-favorable winds leading the front and downwelling-favorable winds following the front.

This pattern results in a dramatic change in the surface heat flux during the passage of a cold front. Warm, moist air preceding the cold front (and, in August, cool near-shore surface water temperatures due to upwelling) leads to positive latent and sensible heat fluxes into the ocean, as well as less upward longwave radiation loss. After a frontal passage, colder, drier air results in large sensible and latent heat losses from the ocean. Strong winds in the vicinity of the front intensify the variation in the sensible and latent heat fluxes. In addition, the presence of clouds behind the front often result in a dramatic reduction in the amount of shortwave radiation on the day following the frontal passage, further intensifying the decrease in heat flux following the front. However, if the clouds associated with the front pass at night, they have no impact on the shortwave signal.

To illustrate the influence of a cold front passage on the surface fluxes, the passage of a cold front on November 7 is examined in detail (Figures 2.10,2.11). As the low pressure center moved to the northeast, the cold front passed over the study region, resulting in a significant change in the local meteorology. First, a drop in pressure on November 6 preceded the oncoming cold front. As the front passed the study site, the wind changed direction from northeastward to southwestward, the air temperature dropped about $6^{\circ} \mathrm{C}$ and the specific humidity dropped about $0.006 \mathrm{~kg} \mathrm{~m}^{-3}$. Most of the change in the turbulent fluxes took place in approximately 5 hours. Over a one-day long period bracketing the frontal passage, the latent heat flux decreased 

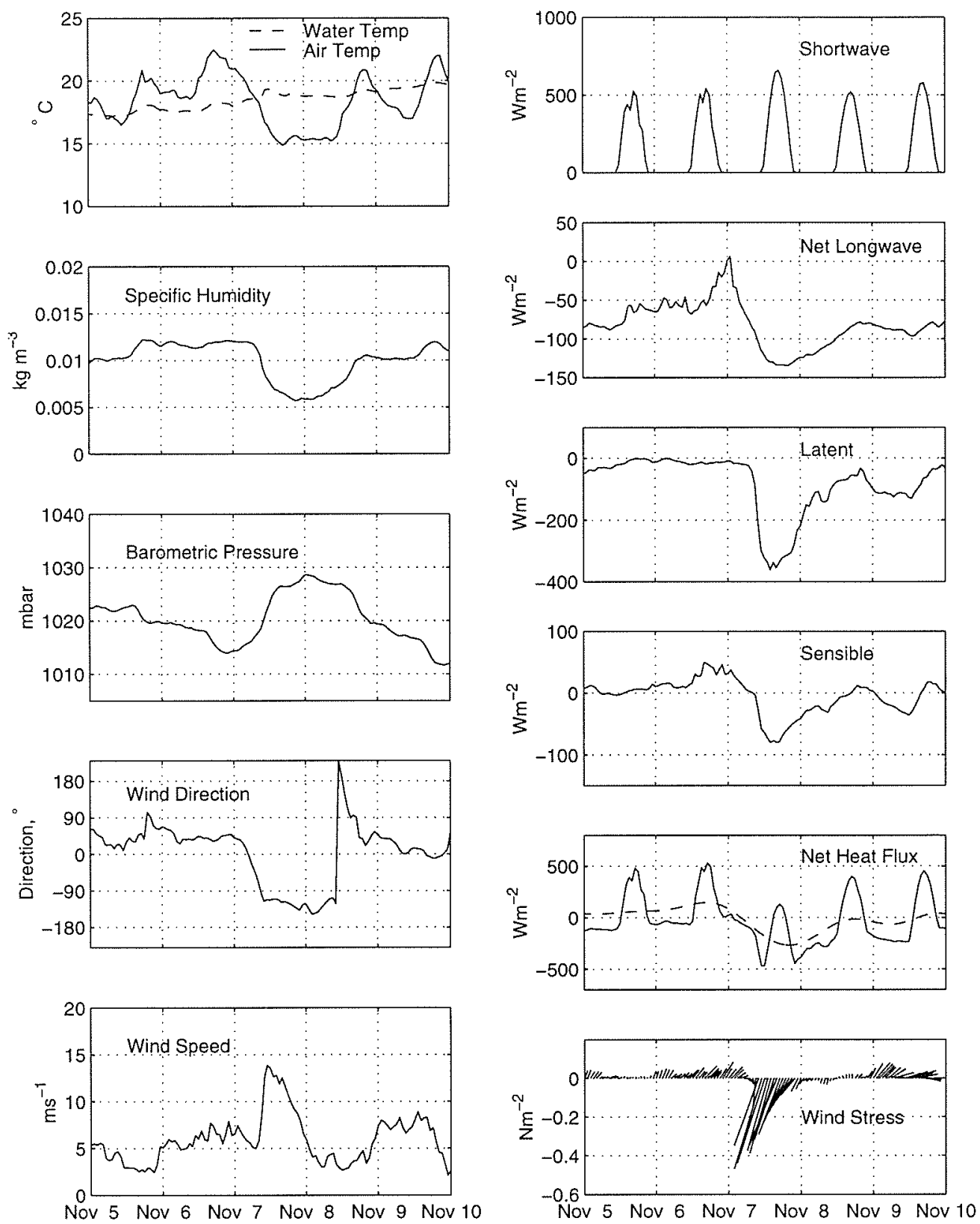

Figure 2.10: Time series of meteorology and surface heat flux terms for the passage of a cold front on November 7 . 


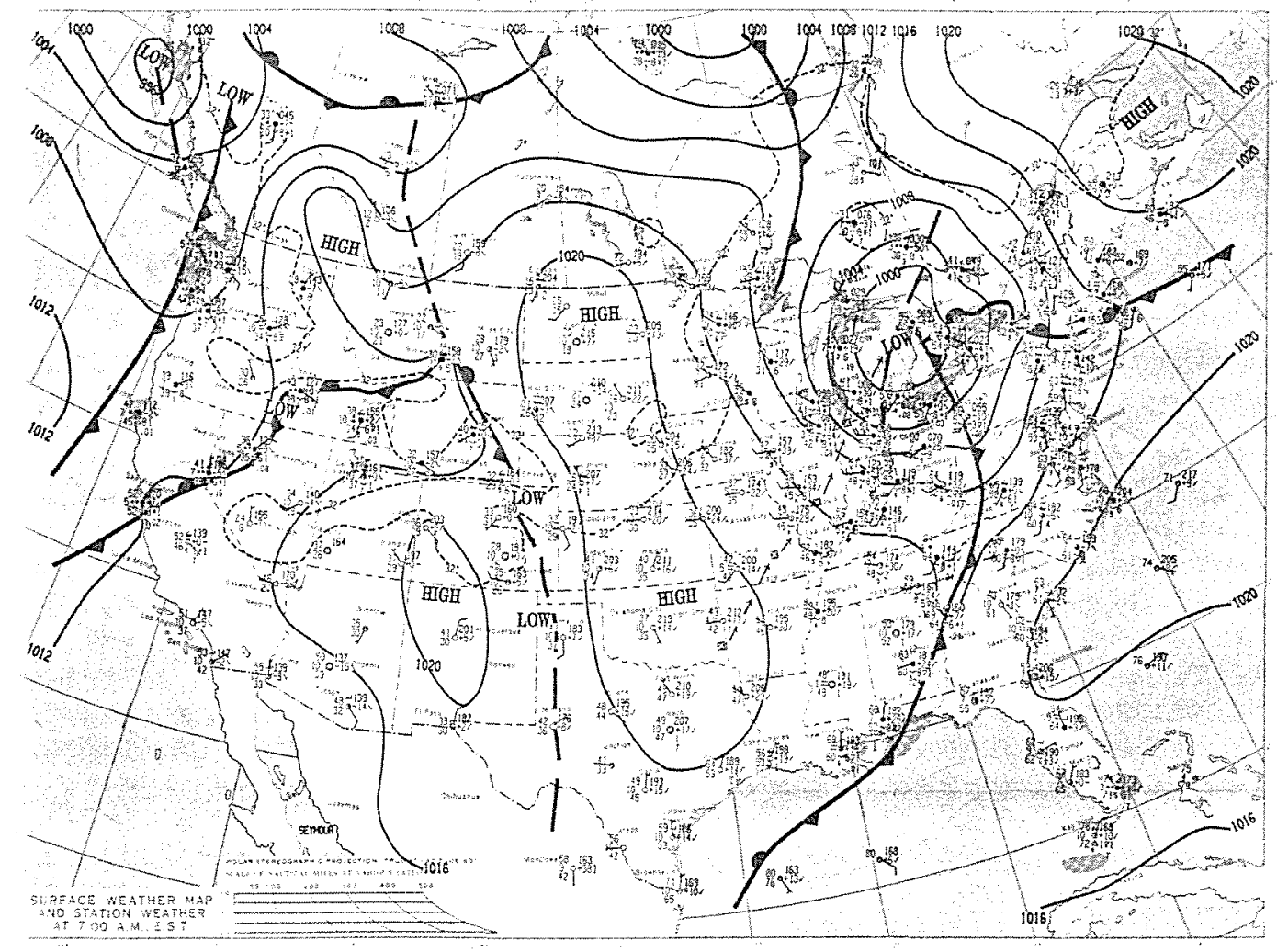

Figure 2.11: Synoptic meteorology map for 1200 UT, November 6 . The cold front extending south from the low pressure center over the Great Lakes passed over the study site on November 7. From NOAA [1994]. 
approximately $350 \mathrm{Wm}^{-2}$, and the sensible heat flux dropped $80 \mathrm{Wm}^{-2}$. There was not much of an impact due to clouds during this particular passage, although the few days preceding the frontal passage show some cloudiness in the shortwave radiation time series. The net longwave radiation initially increased slightly during the passage of the front, possibly due to increased cloud cover, but then decreased on November 7 due to clear skies and drier air. As each heat flux term decreased during the passage of the front, there was a net change in the total surface heat flux of nearly $500 \mathrm{~W} \mathrm{~m}^{-2}$ over a period of a few hours. This change was representative of the other cold front passage events observed during the field program, which caused the net surface heat flux to drop between $160 \mathrm{~W} \mathrm{~m}^{-2}$ and $600 \mathrm{~W} \mathrm{~m}^{-2}$ (Table 4). In each case, the largest contribution to this change was a decrease in latent heat flux, which dropped, on average, about $150 \mathrm{~W} \mathrm{~m}^{-2}$ in August and $300 \mathrm{~W} \mathrm{~m}^{-2}$ in October. The magnitude of the observed changes in surface heat flux are consistent with the changes estimated by Mooers et al. [1976] (on the order of $400 \mathrm{~W} \mathrm{~m}^{-2}$ ) and with the open-ocean values observed by Davidson et al. [1991] of up to $600 \mathrm{~W} \mathrm{~m}^{-2}$ during frontal passages.

An event occurring October 15 is presented next as an example of the influence of the passage of a tropical storm (Figures 2.12,2.13). A low pressure center developed in the South Atlantic Bight and eventually moved north, to the east of the study site. In this case, the site was never in the "warm sector" of the low pressure system, and no fronts passed over the region during the event. Consequently, the observed winds shifted slowly from southwestward to southeastward, consistent with the passage of a low pressure center from south to north, east of the site. In addition, clouds preceded the pressure minimum for two days, and winds gradually built to $15 \mathrm{~m} \mathrm{~s}^{-1}$ as the low passed, with the most intense winds being concurrent with the 

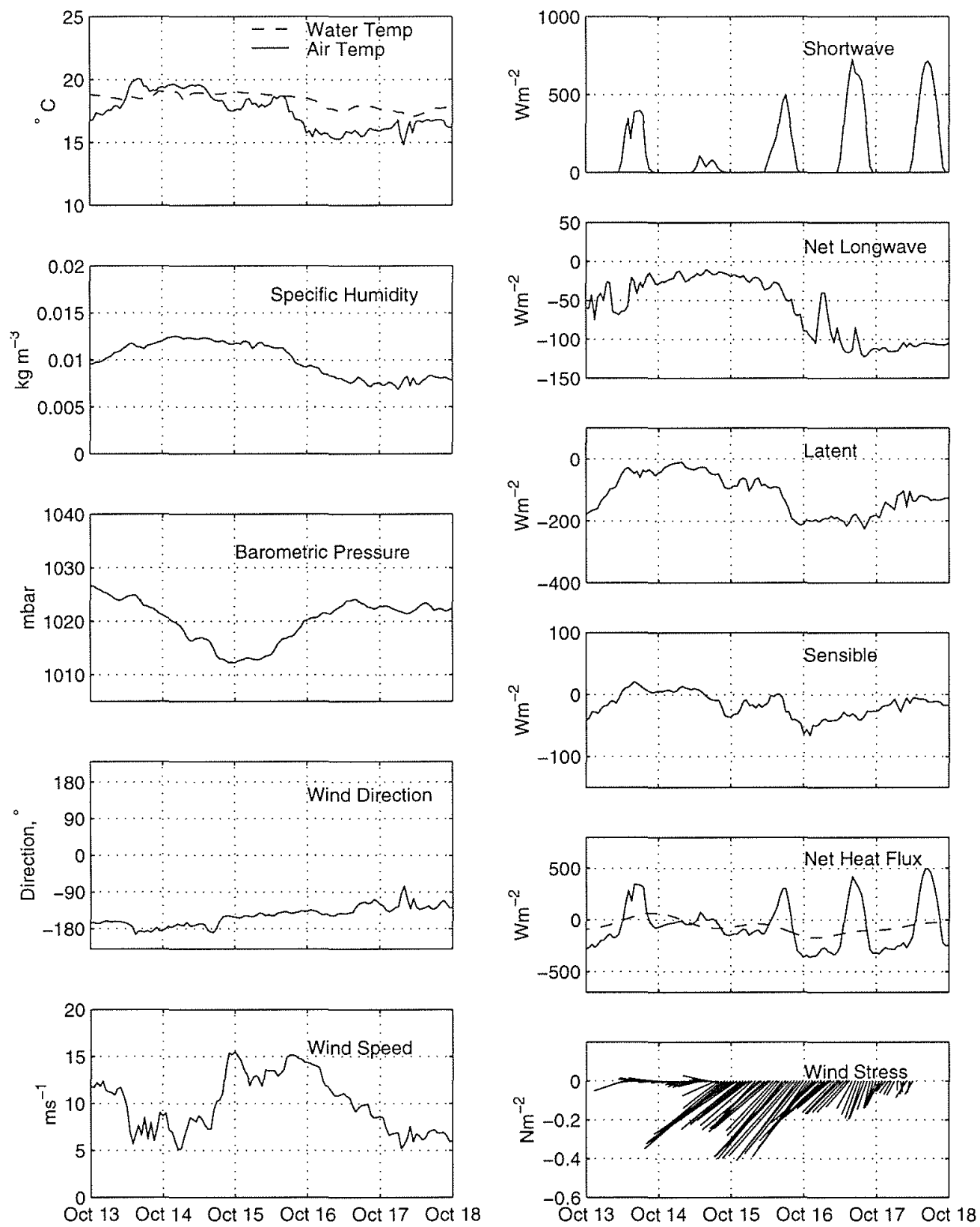

Figure 2.12: Time series of meteorology and surface heat flux terms for the October 15 event. 


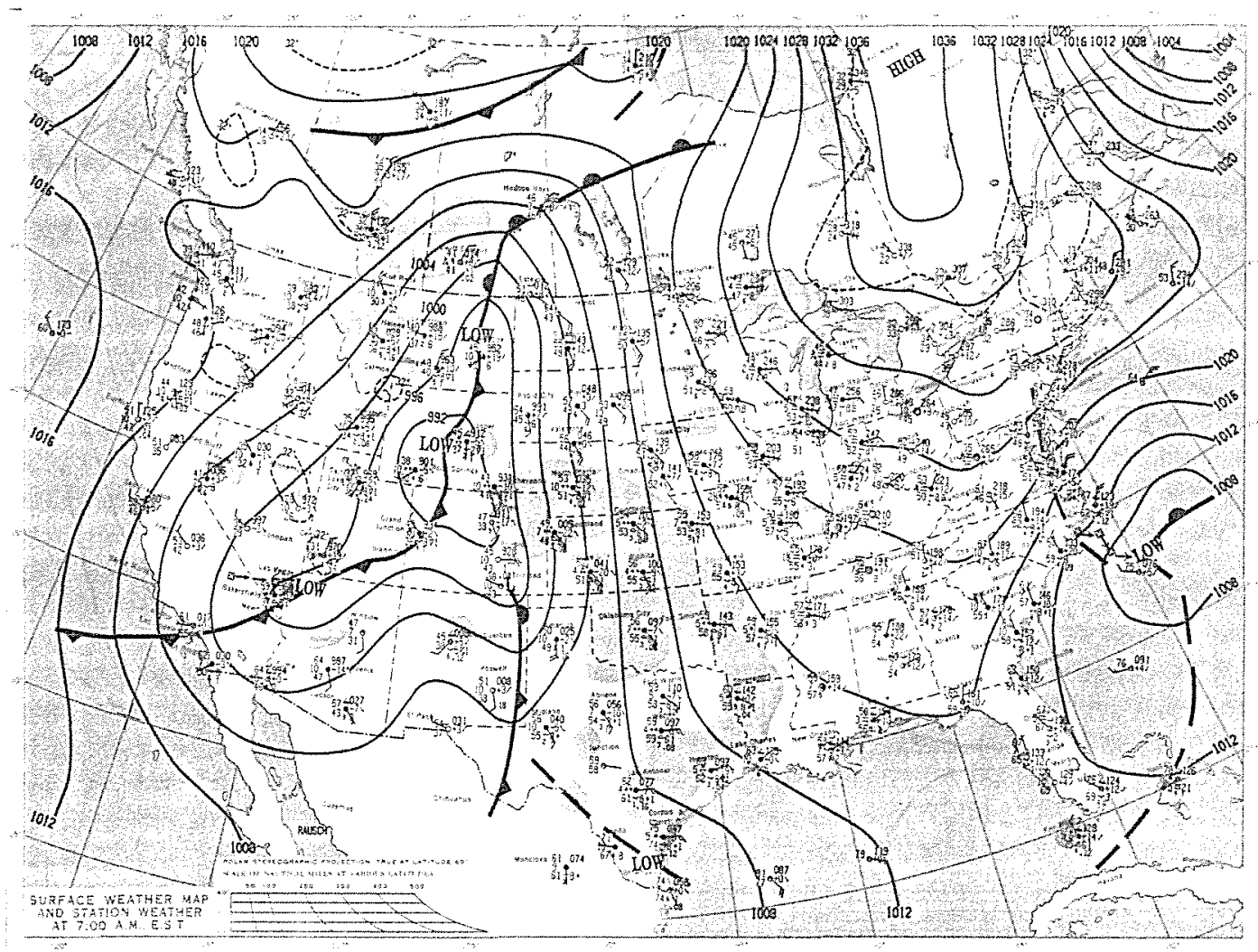

Figure 2.13: Synoptic meteorology map for 1200 UT, October 15. The tropical storm offshore of Cape Hatteras passed to the east of the study site on October 15. From NOA.A [1994]. 
lowest pressure. The specific humidity slowly dropped on the order of $0.005 \mathrm{~kg} \mathrm{~m}^{-3}$, and the air temperature dropped $4^{\circ} \mathrm{C}$. Due to the decreases in air temperature and humidity, the latent flux dropped approximately $100 \mathrm{~W} \mathrm{~m}^{-2}$, and the sensible flux dropped $50 \mathrm{~W} \mathrm{~m}^{-2}$. The shortwave flux decreased on October 14 as cloud cover increased, and the net longwave flux dropped $75 \mathrm{~W} \mathrm{~m}^{-2}$ as the cloud cover cleared on October 15 . Overall, the net surface heat flux decreased approximately $200 \mathrm{~W} \mathrm{~m}^{-2}$ during the passage of the tropical storm.

In the third scenario, which began on August 16 (Figure 2.14, 2.15), a low pressure center developed over the southern United States and moved north, to the west of the study site. The associated warm front passed over the study site. This passage was marked by a $4^{\circ} \mathrm{C}$ increase in air temperature and a $0.004 \mathrm{~kg} \mathrm{~m}^{-3}$ increase in specific humidity. In addition, clouds associated with the low pressure system decreased the shortwave flux by approximately $50 \%$ for the two days following the frontal passage. Winds associated with this system slowly changed from southwestward to northeastward, and included the strongest upwelling-favorable winds observed during the field program. Starting on August 17, the upwelling-favorable winds decreased the near-surface water temperature $2.5^{\circ} \mathrm{C}$ by bringing cold, underlying water to the surface, further increasing the temperature contrast between the air and the sea. The latent flux increased $100 \mathrm{~W} \mathrm{~m}^{-2}$ and the sensible flux increased $50 \mathrm{~W} \mathrm{~m}^{-2}$. Clouds associated with the warm front offset these gains to a certain extent, resulting in an increase in the low-passed net flux on the order of $100 \mathrm{~W} \mathrm{~m}^{-2}$. 

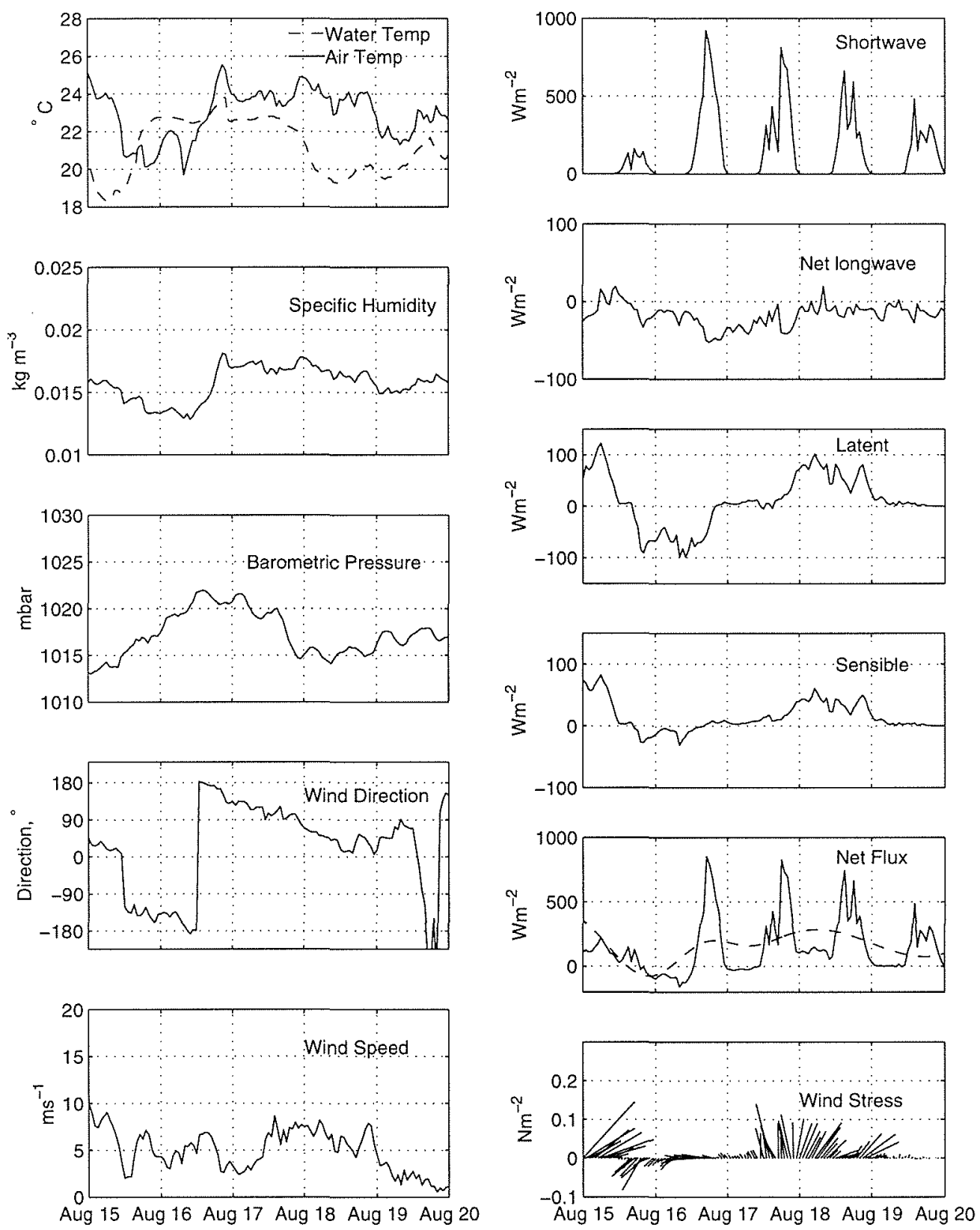

Figure 2.14: Time series of meteorology and surface heat flux terms for the August 18 event. 


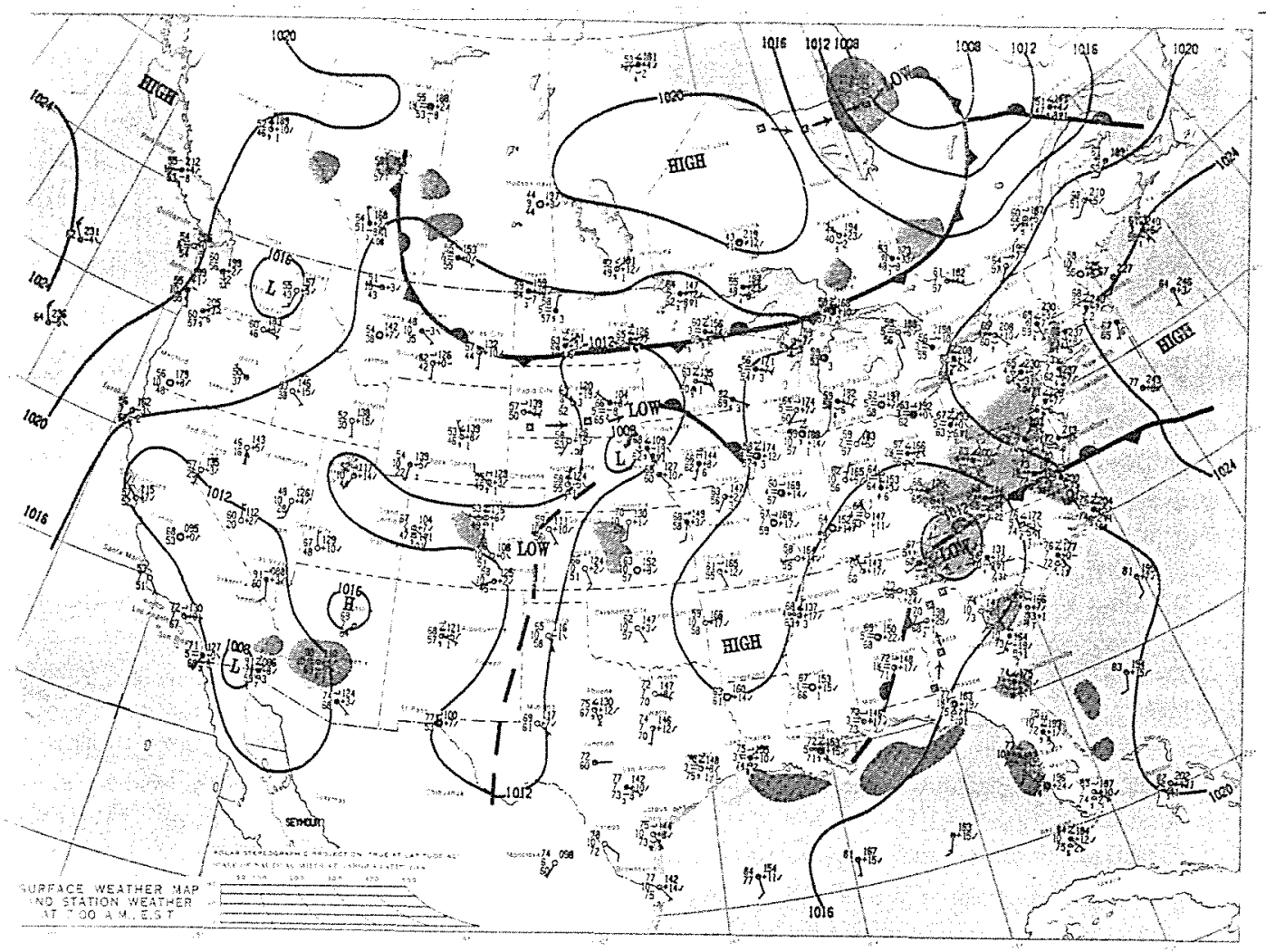

Figure 2.15: Synoptic meteorology map for 1200 UT, August 17. The warm front extending east of the low pressure center over the southeast United States passed over the study region on August 17. From NOAA [1994]. 


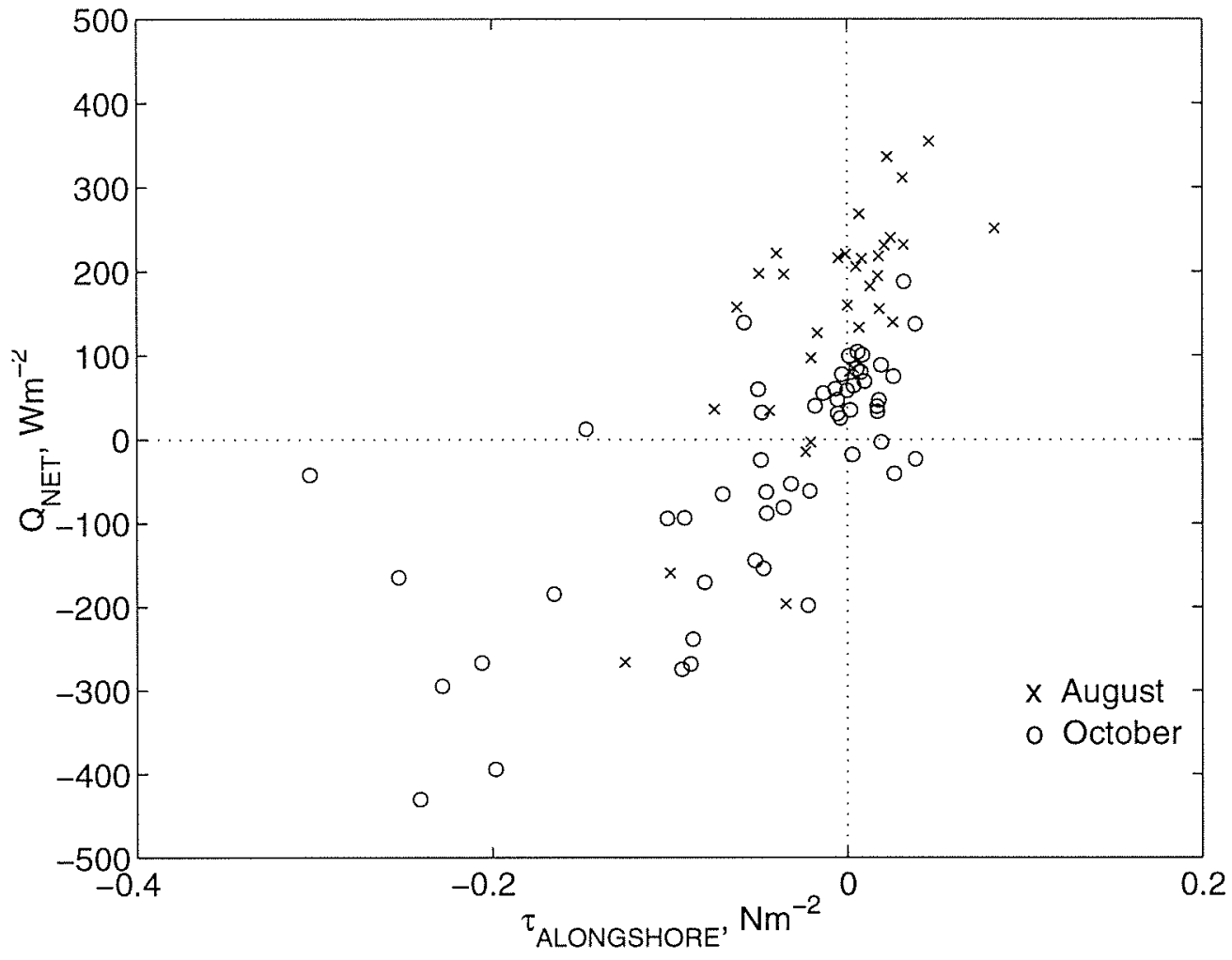

Figure 2.16: Daily values of net surface heat flux as a function of the alongshelf wind stress component, from low-pass filtered time series.

\subsubsection{Implications for the Heat Balance}

An interesting consequence of the subtidal surface heat flux variability being dominated by the passage of cold fronts is a strong correlation between the surface heat flux and the alongshelf wind stress (Figure 2.16). The correlation between the subtidal alongshelf wind stress and the subtidal heat flux is 0.78 in August and 0.72 in October, both significant at the $95 \%$ level. This correlation is not causal, but simply a consequence of the structure and orientation of the cold fronts which dominate the variation in both the wind stress field and the surface heat flux. Specif- 
ically, the leading edge of cold fronts in this region are characterized by poleward (upwelling-favorable) winds and strong positive heat fluxes, whereas the trailing edge is characterized by equatorward (downwelling-favorable) winds and negative heat fluxes. The correlation between the surface heat flux and the alongshelf wind stress has the opposite sign of the correlation between the wind stress and winddriven advective heating and cooling of the shelf, where wind-driven upwelling tends to cool the shelf and downwelling warms the shelf. This suggests that, depending on the relative strength of the surface heat flux and the wind-driven advective heat flux, the heat balance could have two very distinct dependences on the wind stress. This is considered in detail in chapter 3.

\subsection{Spatial Variation in the Surface Heat Flux}

One of the initial goals of the moored experiment was to estimate cross-shelf variation in the surface heat flux, as both meteorological and oceanic properties can vary considerably over the inner shelf. Very little data from the $\mathrm{d} 3$ site was recovered and only d2 provided us with complete meteorological coverage during August and October. However, other sources of data can be used to estimate the variation in some of the meteorological fields, namely wind velocity, air temperature, and near-surface water temperature. Relative humidity was measured only at the $\mathrm{d} 2$ site, making reliable estimates of latent heat flux at any of the other sites impossible. However, the latent and sensible fluxes were highly correlated at the $\mathrm{d} 2$ site (correlation coefficient 0.82 in August, 0.92 in October), suggesting that the sensible heat flux can be used to infer the total turbulent heat flux $\left(Q_{S E N}+Q_{L A T}\right)$ at this location. No estimates of the cross-shelf gradients of downward radiative flux can be made, as 
these were measured exclusively at $\mathrm{d} 2$.

\subsubsection{The Wind Field}

Wind velocity was measured at all of the NDBC buoys, the d2 buoy, and the FRF, for a total of 5 sites. To facilitate comparison, all of the wind velocities were adjusted to a nominal height of $5 \mathrm{~m}$ using a neutral stability wind profile. The principal axes of the wind at all of the sites were approximately $40^{\circ}$ counter-clockwise of directly offshore $\left(20^{\circ} \mathrm{T}\right)$. Due to the polarization of the wind field, offshore and poleward (upwelling-favorable) winds occurred concurrently, as did onshore and equatorward (downwelling-favorable) winds. The magnitude of the major axis at each of the sites was approximately $5.5 \mathrm{~m} \mathrm{~s}^{-1}$ in August and $6.0 \mathrm{~m} \mathrm{~s}^{-1}$ in October (Table 5).

Table 2.5: Summary of wind measurement statistics

\begin{tabular}{|c|c|c|c|c|c|c|c|c|c|}
\hline \multirow[t]{2}{*}{ Location } & \multirow{2}{*}{$\begin{array}{l}\text { offshore dist } \\
\mathrm{km}\end{array}$} & \multicolumn{2}{|c|}{ Mean speed, $\mathrm{ms}^{-1}$} & \multicolumn{2}{|c|}{ primary axis } & \multicolumn{2}{|c|}{ major axis, $\mathrm{ms}^{-1}$} & \multicolumn{2}{|c|}{ minor axis, $\mathrm{ms}^{-1}$} \\
\hline & & AUG & OCT & AUG & OCT & AUG & OCT & AUG & OCT \\
\hline FRF & 0.5 & 5.0 & 5.8 & $44^{\circ} \mathrm{T}$ & $49^{\circ} \mathrm{T}$ & 5.0 & 5.4 & 2.2 & 2.8 \\
\hline $\mathrm{d} 2$ & 5.3 & 4.9 & 6.2 & $39^{\circ} \mathrm{T}$ & $33^{\circ} \mathrm{T}$ & 4.9 & 5.6 & 2.2 & 3.0 \\
\hline 44006 & 34 & 5.2 & 6.3 & $42^{\circ} \mathrm{T}$ & $43^{\circ} \mathrm{T}$ & 5.0 & 5.9 & 2.8 & 3.2 \\
\hline 44019 & 54 & 5.8 & 6.7 & $39^{\circ} \mathrm{T}$ & $42^{\circ} \mathrm{T}$ & 5.7 & 6.3 & 2.9 & 3.6 \\
\hline 44014 & 92 & 5.8 & 6.7 & $42^{\circ} \mathrm{T}$ & $42^{\circ} \mathrm{T}$ & 5.8 & 6.4 & 3.1 & 3.9 \\
\hline
\end{tabular}

Although the observed wind was slightly stronger offshore, the difference was relatively small $(10 \%-20 \%)$ compared to the means. An investigation of a larger array of NDBC buoys (including NDBC 41001, 44004, CHLV2, and DSLN7, not presented here) suggests a decorrelation length scale for the wind field on the order of $600 \mathrm{~km}$, which is consistent with Weller et al. [1991], who estimated the scale of synoptic weather systems to be $500-1000 \mathrm{~km}$. Therefore, the wind field did not vary appreciably over the spatial scales of order $100 \mathrm{~km}$ considered in this analysis. 


\subsubsection{The Water Temperature Field}

There were seven near-surface water temperature measurements on the central line, specifically, DP (near the end of the FRF pier), d1, d2, d3, NDBC 44006, and NDBC 44019, four of which are displayed in Figure 2.3. Most of the observed cross-shelf variation in the near-surface water temperature occurred during upwelling-favorable winds in August, when the thermocline shoaled and created cross-shelf temperature differences of up to $8^{\circ}$. During non-upwelling conditions, the cross-shelf variation in temperature was rarely more than $1^{\circ} \mathrm{C}$, with the water further offshore slightly warmer. During the August time period, the thermocline was never observed in moored water column measurements [Alessi et al. 1996] to move offshore of d3, $15.5 \mathrm{~km}$ offshore.

During October and November, the only large cross-shelf gradients in surface water temperature occurred during an intrusion of warm, salty water and subsequent mixing event, which commenced on November 2. During this event, the surface water temperature at NDBC 44019, $54 \mathrm{~km}$ offshore, attained a maximum along the central line, but was still at most $2.5^{\circ} \mathrm{C}$ warmer than surface water at buoys closer to shore.

\subsubsection{The Air Temperature Field}

The air temperature was measured at the FRF, d2, NDBC 44006, NDBC 44019, and NDBC 44014. Cross-shelf gradients in air temperature appeared to be due primarily to adjustment in the marine atmospheric boundary layer, and were different during onshore and offshore winds (Figure 2.17). Cross-shelf differences in air temperature were generally large during offshore winds and small during onshore winds. During 


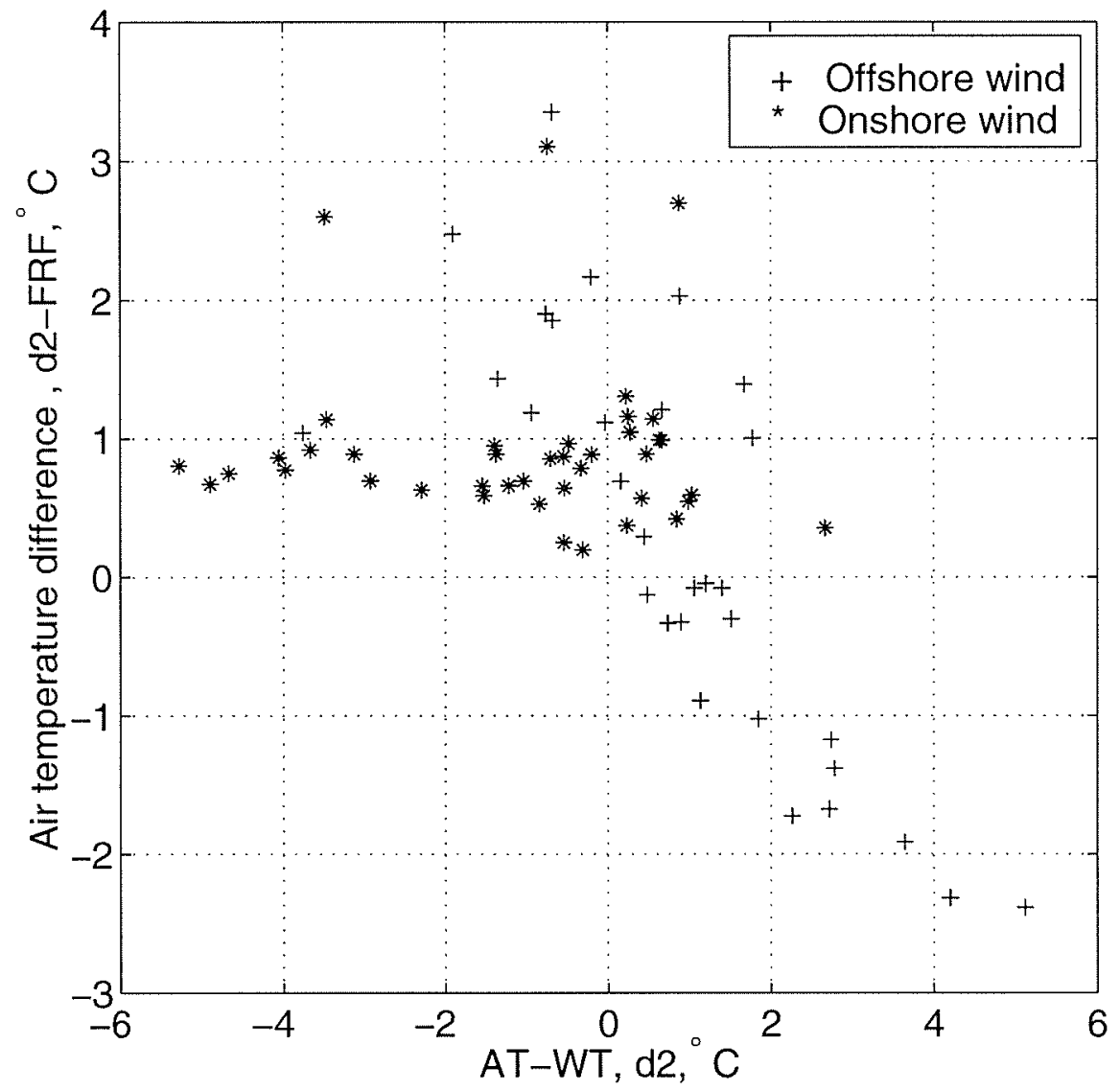

Figure 2.17: Cross-shelf air temperature difference as a function of the air-water temperature difference, from both time periods. Data points represent midnight values, in order to avoid potentially inaccurate daytime FRF values. 
offshore winds, large cross-shelf differences occurred within the closest $34 \mathrm{~km}$ of shore. Offshore winds tended to be concurrent with upwelling-favorable winds in August, during which the air-water temperature contrast at the FRF was as large as $10^{\circ} \mathrm{C}$. The air temperature difference between the FRF and $\mathrm{d} 2$ was a strong function of the air-water temperature contrast (Figure 2.17). When warm air blew over cold water, the air temperature decreased with distance offshore, consistent with the cooling of air in contact with the cool sea surface. During onshore winds, the air temperature rarely changed more than $1^{\circ} \mathrm{C}$ between $\mathrm{d} 2$ and the FRF.

\subsubsection{Implications for Meteorological Forcing}

As the turbulent heat fluxes depend on the difference between the air and water temperature, the cross-shelf structure of this quantity is of interest. Both the air and water temperature cross-shelf gradients were functions of the wind direction, and the air-water temperature contrast will be viewed from that perspective.

During August, the greatest difference between air and water temperature (Figure 2.18) occurred at the pier, with differences of up to $10^{\circ} \mathrm{C}$ during strong offshore, poleward (upwelling-favorable) winds. This difference dropped to $-1^{\circ} \mathrm{C}$ during strong onshore, equatorward (downwelling-favorable) winds, showing a clear asymmetry between onshore and offshore winds. The water temperature differences are due primarily to upwelling fronts (during upwelling-favorable winds). The magnitude of the air-water temperature difference drops steadily as a function of offshore distance as the air temperature adjusts to the surface water temperature until NDBC $44019,55 \mathrm{~km}$ offshore, beyond which the difference is smaller than $2^{\circ} \mathrm{C}$. Data from the R/V Cape Hatteras suggest that the air-water temperature difference, averaged 

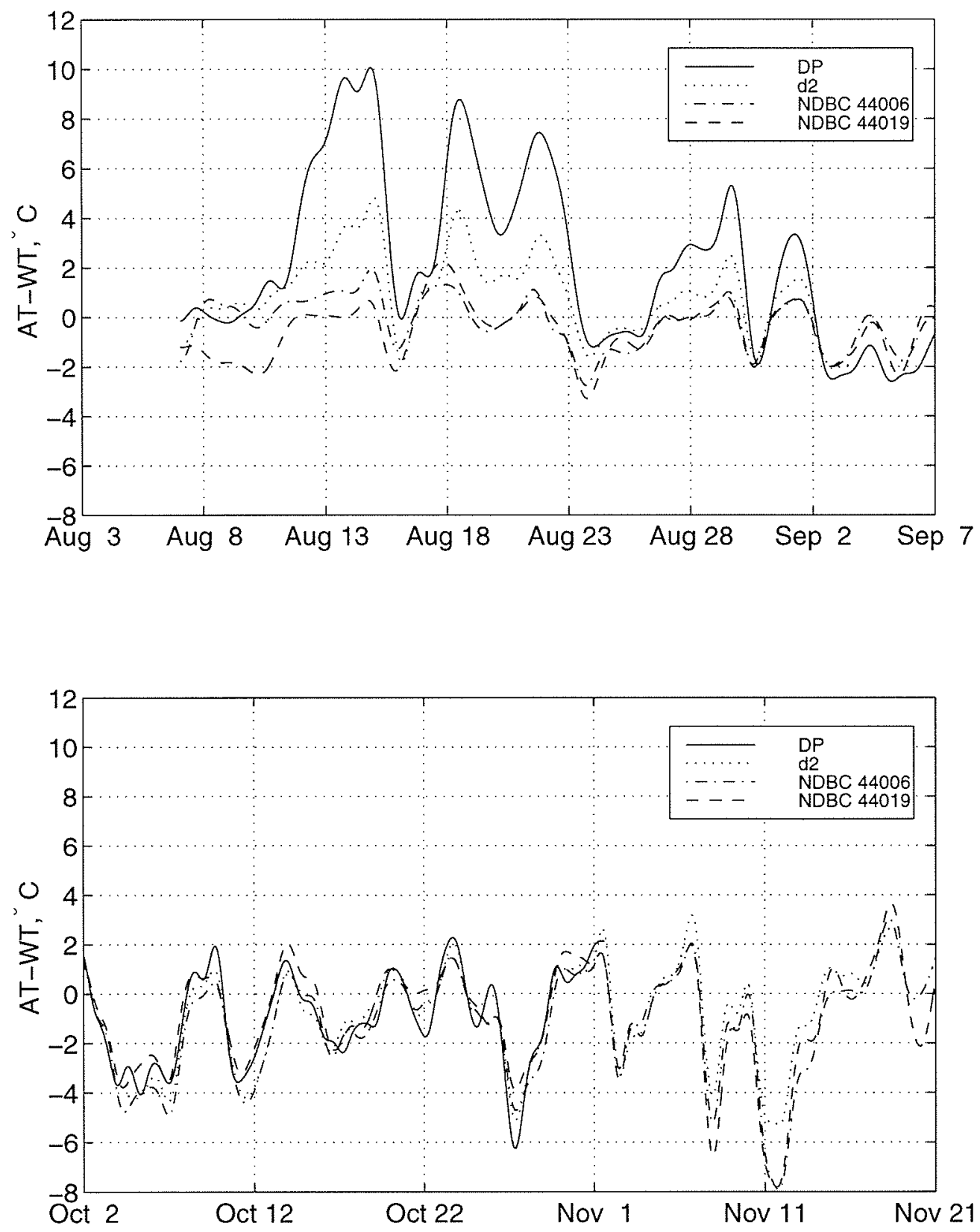

Figure 2.18: Low passed AT-WT time series from DP, d2, NDBC 44006, and NDBC 44019 for August (upper panel) and October (lower panel). 


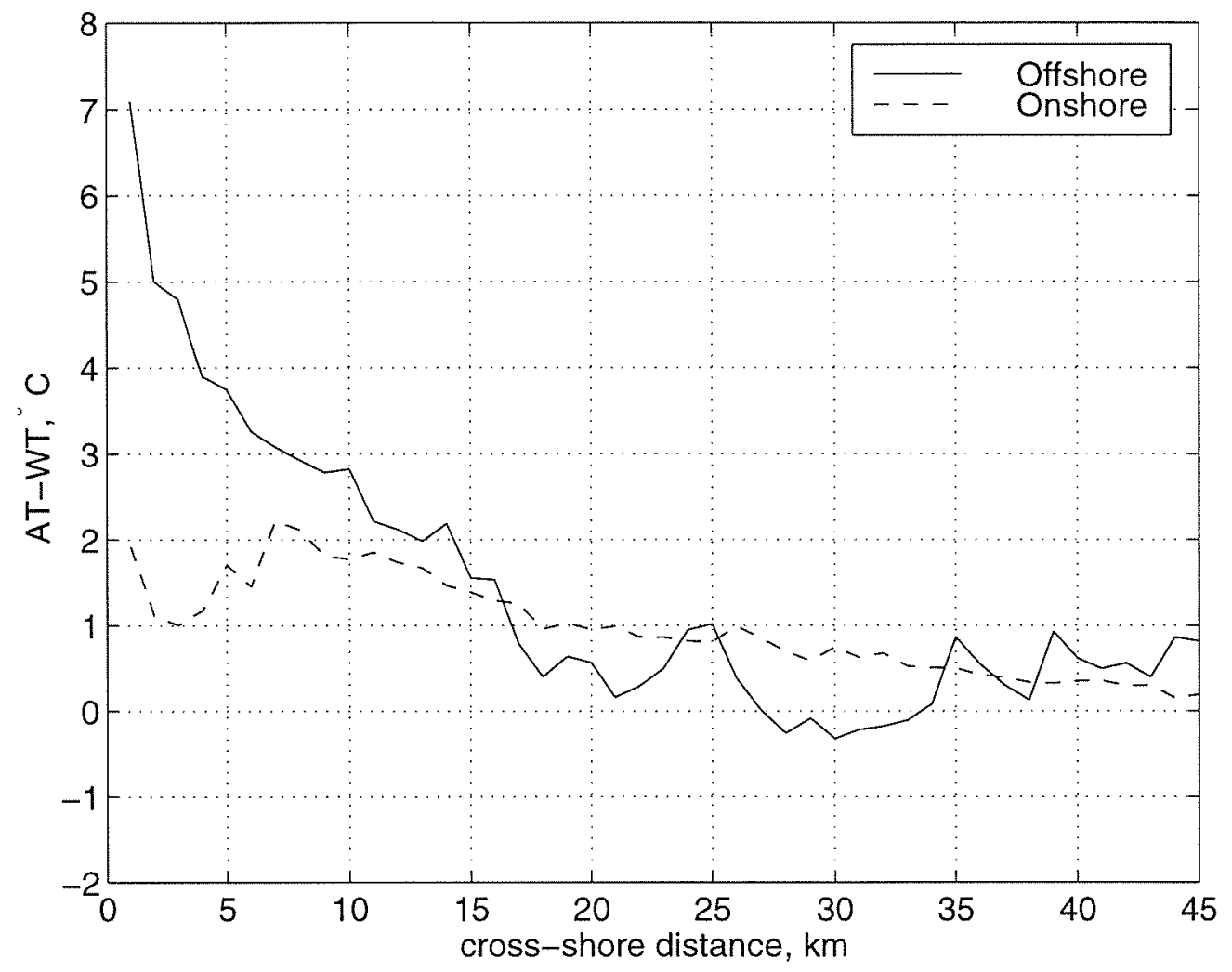

Figure 2.19: Air-water temperature difference as a function of cross-shelf distance for onshore and offshore winds, from the R/V Cape Hatteras underway data. Data are averaged over time and the alongshelf dimension.

over time and the alongshelf dimension, decreases with distance offshore during offshore winds and remains relatively constant (and small) during onshore winds (Figure 2.19), consistent with the buoy analysis. The cross-shore adjustment scale during offshore winds appears to be on the order of $10 \mathrm{~km}$. As the resolution of the $\mathrm{R} / \mathrm{V}$ Cape Hatteras air temperature measurements was $2^{\circ} \mathrm{C}$, this result is qualitative.

During October, the air-water temperature difference stays constant across the shelf, regardless of the direction of the wind. The largest differences occur during 
onshore winds, with air-water temperature differences of up to $8^{\circ} \mathrm{C}$ (Figure 2.18). Buoy data from further north (NDBC 44008) suggest that both air and water are much colder north of the site. The air temperature does not appear to be approaching the water temperature, regardless of the direction of the wind. During onshore winds, this may be due to the fact that as cool air blows over warm water, the vertical density structure of the air is unstable, and the boundary layer quickly becomes so thick that sensible heat flux into the bottom of the atmospheric boundary layer makes little difference to the surface temperature. In contrast, in August, the water was colder than the air, which produced a stable air column and a much thinner boundary layer, so that the difference in temperature changed with offshore distance. Without vertical profiles of air temperature, however, this hypothesis cannot be verified.

The spatial structure of the air-water temperature difference allows us to speculate as to the structure and size of the cross-shelf gradient in the turbulent heat flux. Enough information is present to estimate the sensible flux at the FRF, d2, NDBC 44006, and NDBC 44019. The Bowen ratio [Lewis, 1995], defined as the ratio of the sensible to latent flux, can be used to estimate the gradient in the latent heat flux across the shelf. The Bowen ratio at the $\mathrm{d} 2$ site was observed to be approximately 0.16 in August and 0.23 in October. Literature values range from 0.1 (low latitudes) to 0.45 (high latitudes) [Perry and Walker, 1977]. Although there is no reason to believe that the Bowen ratio is constant across the shelf, it allows an order of magnitude estimate of the spatial variation of the latent flux to be made in the absence of humidity measurements. The validity of this assumption cannot be tested without offshore humidity measurements. The upward longwave radiation term is a function of the surface water temperature alone (see equation 4), and can be estimated at 
these sites. Downward longwave and shortwave radiation were measured only at d2, and will be assumed to be constant over the shelf.

The cross-shore variation in the net heat flux, given the above assumptions (Figure 2.20), shows a marked difference between the August and October time periods. During August, the total instantaneous cross-shelf difference is often large compared to the temporal variations observed at $\mathrm{d} 2$, up to $400 \mathrm{~W} \mathrm{~m}^{-2}$ during offshore (upwelling) winds, but much smaller during onshore (downwelling) winds. In the October time period, the meteorological fields exhibit less cross-shelf variation, and this is reflected in the relatively small differences in the estimated fluxes across the shelf. Table 2.6 is a summary of the mean flux values in the two months.

Table 2.6: Estimated mean turbulent fluxes at sites along central array (FRF, d2, $44006,44019)$.

\begin{tabular}{lllllllll}
\hline \multirow{2}{*}{ Location } & \multicolumn{2}{c}{$Q_{S E N}$} & \multicolumn{2}{c}{$Q_{L A T} \approx Q_{S E N} / B^{a}$} & \multicolumn{2}{c}{$Q_{L W_{U P}}$} & \multicolumn{2}{c}{$Q_{T O T}^{b}$} \\
\cline { 2 - 9 } & AUG & OCT & AUG & OCT & AUG & OCT & AUG & OCT \\
\hline \hline FRF & 12 & -16 & 75 & -70 & -423 & -408 & 261 & -25 \\
d2 & 5 & -15 & $-33^{c}$ & $-94^{c}$ & -431 & -408 & 147 & -19 \\
NDBC 44006 & -2 & -15 & -12 & -65 & -439 & -411 & 144 & -22 \\
NDBC 44019 & -5 & -11 & -31 & -48 & -444 & -408 & 117 & 2 \\
\hline
\end{tabular}

All values in $\mathrm{W} \mathrm{m}^{-2}$.

${ }^{a} B=0.16$ in August, 0.23 in October.

${ }^{b}$ Total computed using downward longwave and shortwave from $\mathrm{d} 2$.

${ }^{c}$ Latent values for $\mathrm{d} 2$ from bulk formula, not Bowen ratio.

To summarize, in August, there were weak cross-shelf gradients in the turbulent fluxes during onshore (equatorward, downwelling-favorable) winds, whereas during offshore (poleward, upwelling-favorable) winds, the temperature contrast between the air and the water was greatest onshore and decreased offshore, since the air was warmer onshore and the water colder onshore. This difference was due to water temperature gradients caused by upwelling, and to the adjustment of the air 

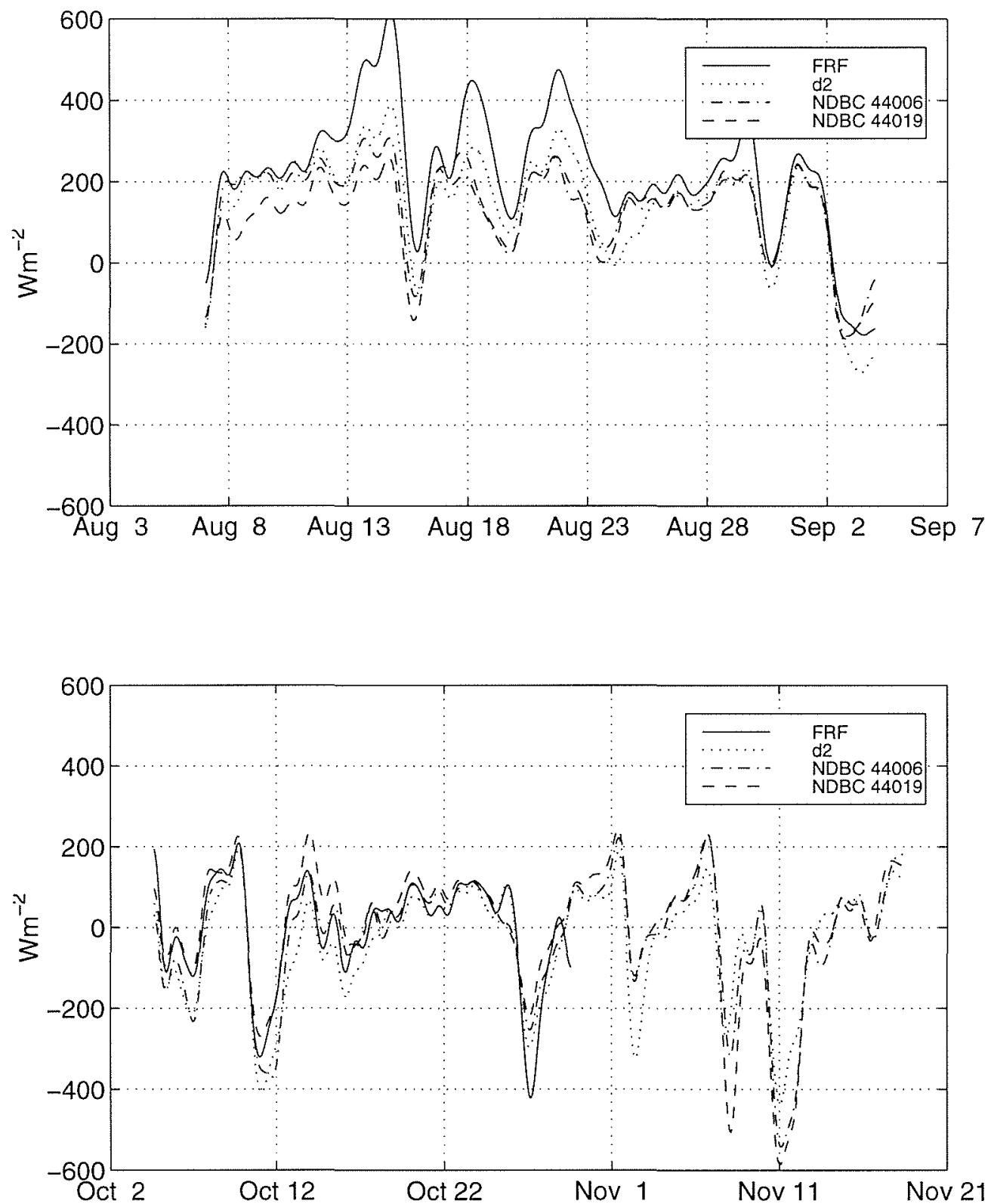

Figure 2.20: Time series of net surface heat flux computed at the FRF, d2, NDBC 44006 and NDBC 44019. Assumes a Bowen ratio of 0.16 in August and 0.23 in October (from d2 data) and no gradient in the downward shortwave or longwave radiation. 
temperature to the surface water temperature. In this case, spatial variation across the shelf in the surface heat flux can be at least as large as the subdiurnal temporal variation. During the October time period, the cross-shelf gradient in the fluxes was small. This spatial variation in the surface heat flux may have implications for the heat balance of the region, necessitating more intensive measurements of meteorological conditions to better understand the heat budget of the inner shelf.

\subsection{Conclusion}

Data collected in August and October-November 1994 were used to estimate atmospheric forcing on the North Carolina inner shelf north of Cape Hatteras. Most of the variation at the synoptic scale can be attributed to one of three types of events: cold fronts, which occurred a total of nine times during the two time periods, tropical storms, which occurred twice, and one warm front. All of these systems were associated with low pressure synoptic weather systems. The structure and orientation of the cold fronts, the most common event, led to a strong correlation between wind direction and the estimated surface heat flux. When the water was vertically thermally stratified, the correlation between the wind direction and the air-water temperature difference was enhanced by upwelling-favorable winds bringing cold water to the surface, further increasing the heat flux into the ocean. A strong cross-shelf gradient in the surface heat flux is postulated during offshore, poleward winds in August, due to observed cross-shelf gradients in air and water temperature. Cross-shelf gradients at other times, including all of the October time period, appear to be much smaller. 


\subsection{Acknowledgments}

The moored meteorological and oceanographic measurements utilized in this paper were funded by National Science Foundation grant OCE-92-21615. Other data were kindly provided by the Army Corps of Engineer's Field Research Facility at Duck, North Carolina and the National Data Buoy Center. Support for the analysis of the data was provided by National Science Foundation grant OCE-96-33025. JAA was supported by an Office of Naval Research AASERT grant N00014-93-1-1154. Conversations held with R. Beardsley, L. Illari, R. Weller, and comments from two anonymous reviewers provided useful input. This is WHOI contribution 9417. 


\section{Chapter 3}

\section{The Role of the Alongshore Wind Stress in the Heat Budget of the North Carolina Inner Shelf}

To appear in J. Geophys. Res, by Austin, J. A., accepted for publication, 11 August 1998. Copyright by the American Geophysical Union.

\subsection{Abstract}

The heat budget of a cross-shelf section extending $16 \mathrm{~km}$ offshore of the outer banks of North Carolina is studied during two time periods: August 1994 and October 1994, using data collected as part of the Coastal Ocean Processes (CoOP) Inner Shelf Study. Heat budgets are computed on two different time scales: monthly averages over August and October, which reflect seasonal variations, and a fluctuation budget, which reflects variation on day to week time scales. During August, 
a period of strong stratification, the increase in the area-averaged water temperature (approximately $3.2^{\circ} \mathrm{C}$ ) was due primarily to the surface heat flux. Fluctuations in temperature during August were caused primarily by the cross-shore heat flux, due to wind-driven upwelling and downwelling circulation. In October, the areaaveraged shelf temperature dropped by approximately $3.5^{\circ} \mathrm{C}$ due to both surface heat loss and the alongshore transport of heat. Weak vertical stratification in October led to small cross-shore heat fluxes, and temperature fluctuations in October were due primarily to fluctuations in the surface and alongshore heat fluxes.

In both August and October, variation on day to week time scales of the areaaveraged temperature of the shelf was strongly correlated with the alongshore component of the wind stress. In August, alongshore poleward winds caused upwelling, and the area-averaged temperature decreased; conversely, equatorward winds caused downwelling and warming. In October, although the variations in temperature were smaller, alongshore winds were positively correlated with alongshore currents and the surface heat flux (for reasons discussed in Chapter 2), so that poleward winds resulted in warming; conversely, equatorward winds resulted in cooling. Therefore, the dependence of the change in heat content on the alongshore wind stress changed sign between August and October. A simple dynamical model was constructed to relate changes in heat content to the alongshore wind stress. The model results were compared to 12 years of meteorological records from the Coastal Engineering Research Center's (CERC's) Field Research Facility (FRF), directly onshore of the experimental site. The results suggest a seasonal cycle in the dominant fluctuating heat balance, consistent with the field results found for August and October 1994. In May through August, cross-shore flux dominates variation in the heat content. In October through March, the surface heat flux and alongshore heat flux dominate 
the variation.

\subsection{Introduction}

Shelf regions are susceptible to surface forcing such as wind stress and surface heat flux due to the shallowness of the water, and they display circulation patterns (such as coastal upwelling and downwelling) unique to the coastal ocean. Aspects of the shelf circulation off North Carolina create a situation in which there are several different potentially significant sources of temperature variability. Understanding these sources and quantifying their relative importance is vital to a more general understanding of observed mean hydrographic conditions and variability. This paper addresses the relationship between various sources of heat and the variability in the heat content of a two-dimensional cross-shelf section of the North Carolina inner shelf and presents a simple model linking the alongshore wind stress to potential sources of variability.

The influence of the alongshore wind stress on the heat budgets of other regions have been considered in previous studies. Atkinson et al. [1989] looked at the heat budget of a region of the South Atlantic Bight on an episodic basis, considering both a one-dimensional balance between the surface heat flux and local heating and a three-dimensional balance, taking cross-shore advection and advection of Gulf Stream water into account. They concluded that heat content variability was due primarily to cross-shelf heat transport, which was balanced by alongshore heat transport generated by alongshore transport divergence. Both Lentz [1987] and Lentz and Chapman [1989] studied the relationship between variability in the heat content of the northern California shelf and the alongshore wind stress during the 
Coastal Ocean Dynamics Experiment (CODE), in which the balance was primarily two-dimensional (cross-shore heat flux and surface flux dominated). In contrast to the results presented here, they noted very little seasonal variability in the relationship between the change in heat content and wind stress, as the wind-driven cross-shore heat flux dominated variability in all seasons. Dever and Lentz [1995] considered seasonal fluctuations in the primary sources of heat and fluctuations in heat content on the northern California shelf during the Surface Mixed Layer Experiment (SMILE). During winter, they observed a mean balance between cross-shelf heat flux and alongshore heat flux divergence, and during spring, a balance between cross-shelf flux and the surface heat flux. In both seasons, fluctuations in the heat content were balanced primarily by the cross-shore heat transport (as in Lentz and Chapman [1989]), which was consistent in magnitude with the alongshore wind stress.

As part of the Coastal Ocean Processes (CoOP) Inner Shelf Study [Butman et al., 1994], an array of instruments was deployed on the North Carolina Shelf north of Cape Hatteras from August 1994 through November 1994. During this time period, the region was characterized by highly variable meteorological forcing (Chapter 2) and the observed circulation reflects this [Lentz et al., submitted to J. Geophys. Res.]. During the field program, the character of the shelf changed from strongly vertically thermally stratified to weakly stratified. By comparing mean and fluctuation budgets between these two distinct time periods, the role of thermal stratification in determining the primary sources of heat content and its variation can be assessed. In addition, by developing relationships between each of the sources of heat and the alongshore wind component, a simple model of thermal variability can be constructed and applied to historical data from the region. Additionally, the robustness 
of the seasonal variation in the strength of the source terms can be studied.

The rest of the paper is organized as follows. In section 2, the field site and instrumentation are described, and the heat budget method is presented. Section 3 is an outline of the data collected, section 4 presents the heat budgets themselves, and section 5 consists of a discussion of the link between the alongshore wind stress and the heat budget, along with the application of a simple model to historical data. Section 6 is a short summary.

\subsection{Field Site, Instrumentation and Methods}

\subsubsection{Field Site}

The CoOP Inner Shelf Study field site (Figure 3.1) is located off the coast of the Outer Banks of North Carolina between Cape Henry (at the mouth of the Chesapeake Bay) and Cape Hatteras. The coastline in the region is relatively straight, extending $80 \mathrm{~km}$ north and south of the central observational region. The shelf is shallow, deepening to approximately $26 \mathrm{~m}$ at the site of the deepest mooring $(16.4 \mathrm{~km}$ offshore). The shelf break is located approximately $80 \mathrm{~km}$ offshore, at which the depth is approximately $60 \mathrm{~m}$. The coastline is unbroken except at Oregon Inlet, $50 \mathrm{~km}$ south of the central observational region. The Chesapeake Bay represents a significant source of fresh water to the region, but as the estuarine water is similar in temperature to the ambient shelf water, it does not appear to be a significant source or sink of heat. Cape Hatteras is located approximately $80 \mathrm{~km}$ south of the observational region. The Gulf Stream separates from the coast at Cape Hatteras, and is responsible for occasional intrusions of warm, salty water onto the shelf in 


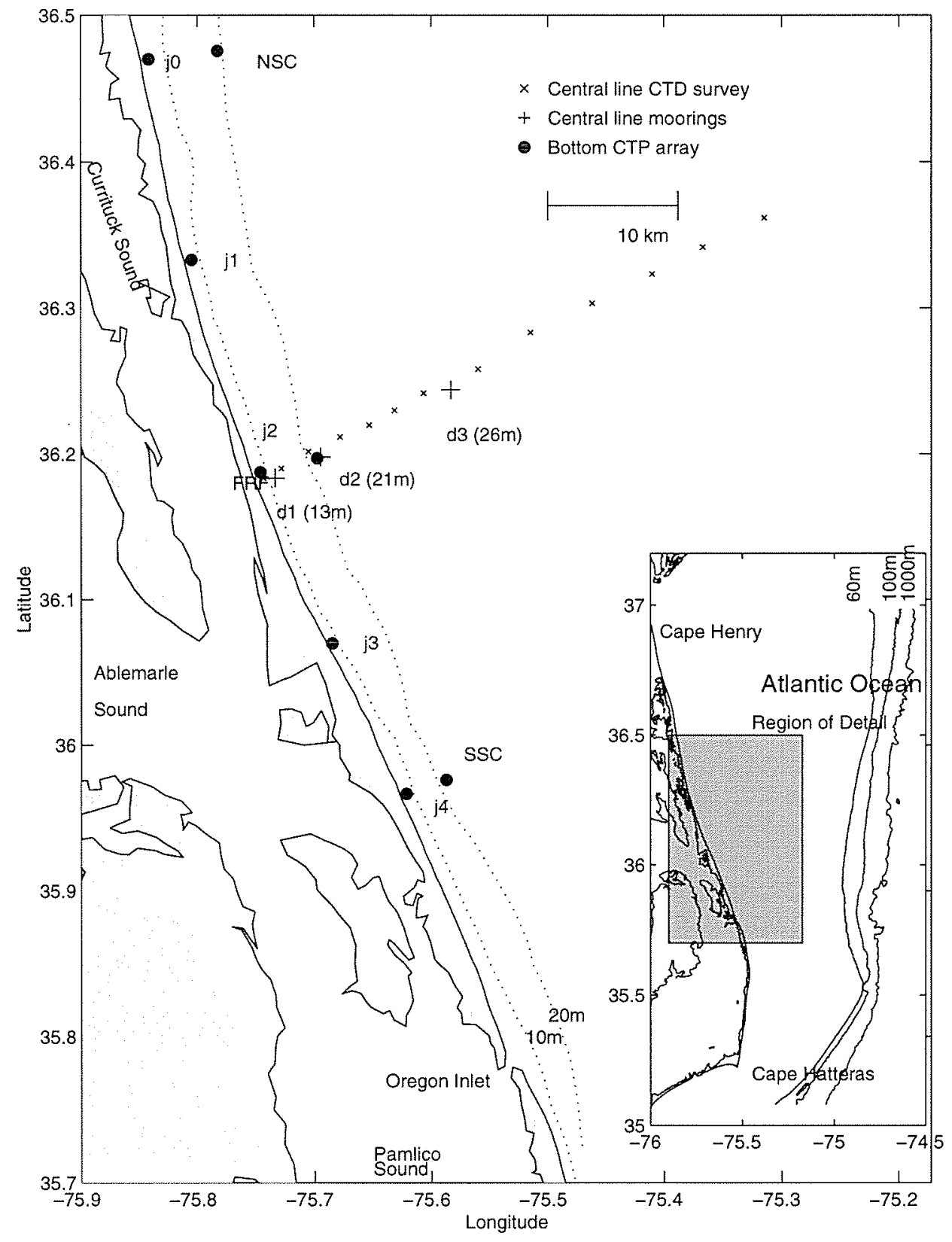

Figure 3.1: The CoOP Inner Shelf Study experimental region, with mooring locations and central line CTD stations specified. Inset is a regional view, showing Cape Henry, at the mouth of the Chesapeake Bay, and Cape Hatteras. 
this region [Gawarkewicz et al., 1992, Churchill and Cornillon, 1991].

\subsubsection{Instrumentation}

This study focuses on moored instrument data [Alessi et al. 1996], which were collected from August 1994 to December 1994 as part of the CoOP Inner Shelf Study. The moored instrumentation was centered around a cross-shore array which consisted of three surface/subsurface mooring pairs located $1.4 \mathrm{~km}, 5.4 \mathrm{~km}$, and $16.4 \mathrm{~km}$ offshore in $13 \mathrm{~m}, 21 \mathrm{~m}$, and $26 \mathrm{~m}$ of water, and are referred to as $\mathrm{d} 1$, $\mathrm{d} 2$, and $\mathrm{d} 3$, respectively (Figure 3.1). These three mooring sites were instrumented with a total of 16 vector measuring current meters (VMCMs), 30 thermistors, and 11 conductivity cells (Figure 3.2 ). The surface mooring at $\mathrm{d} 2$ carried a vector averaging wind recorder (VAWR) meteorological package which measured air and near-surface water temperature, downward short- and longwave radiation, wind speed and direction, barometric pressure, and relative humidity to make estimates of the heat and momentum fluxes from the atmosphere to the ocean. In addition to the central cross-shore array, instruments placed off the central array axis provided information

about alongshore gradients of temperature and salinity. Surface/subsurface mooring pairs with temperature and conductivity sensors near the surface and bottom were placed on the $20 \mathrm{~m}$ isobath approximately $30 \mathrm{~km}$ north (North SeaCat, or NSC) and $30 \mathrm{~km}$ south (South SeaCat, or SSC) of the central array. Temperature and conductivity measurements were made at 5 sites along the $6 \mathrm{~m}$ isobath $(j 0-j 4)$, spaced approximately $15 \mathrm{~km}$ apart in the alongshore direction. Data were recorded every 4 minutes (except for the meteorological data, which were recorded every 7.5 minutes) and binned into hourly averages. 


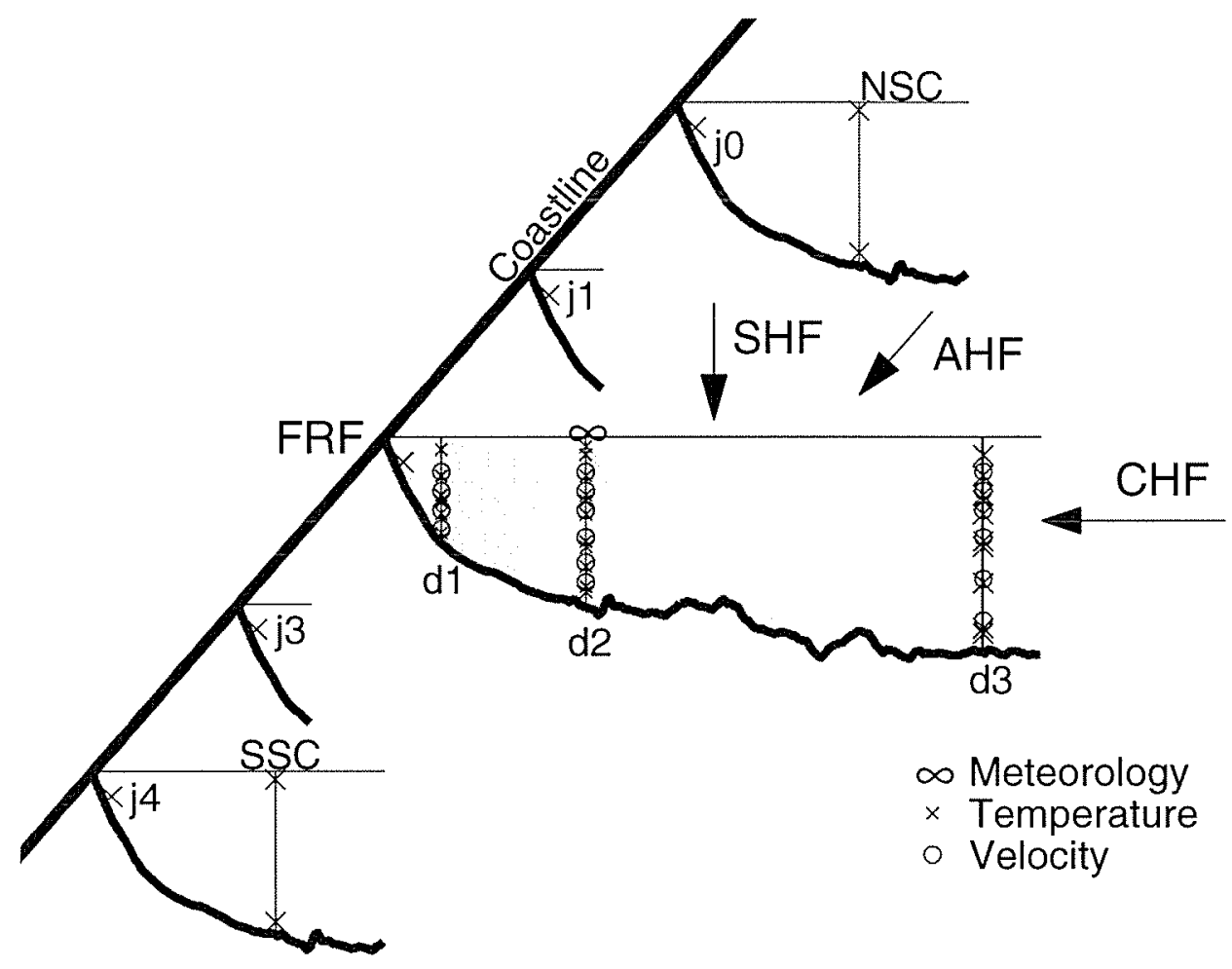

Figure 3.2: A schematic side view of the central and alongshore moored array to show distribution and coverage of measurements, and cartoon definitions of the heat balance terms. 
Other data were used to situate the moored data in a regional and seasonal context. Shipboard CTD sections were made along the central line (Figure 3.1) 16 times in August and 20 times in October by the R/V Cape Hatteras, as well as multiple sections to the north and south of the central line [Waldorf et al. 1995, Waldorf et al. 1996]. The Army Corps of Engineers' Field Research Facility (FRF, Figure 3.1) has archived various meteorological data since 1982 [Birkemeier, 1985], including wind velocity measured at the end of the pier at a height of $19.4 \mathrm{~m}$ (the bulk formulation of Fairall et al. [1996] was used to estimate surface stress), and sea surface temperature from the end of the pier, measured daily (at approximately 7 AM) using a bucket thermometer. CTD sections from the National Marine Fisheries service Marine Resources Monitoring, Assessment, and Prediction (MARMAP, [Manning and Holzwarth, 1990]) project were used to assess seasonal variability in thermal stratification.

\subsubsection{The Heat Budget Equation}

The basic method for defining and estimating the values of the heat budget terms is taken from Dever and Lentz [1995]. The heat budget is applied to a two dimensional wedge, perpendicular to the coastline, extending $16.4 \mathrm{~km}$ offshore from the shore to the $\mathrm{d} 3$ mooring (Figure 3.2 ). The coordinate system is oriented such that $x$ is positive offshore, $y$ is positive poleward alongshore $\left(340^{\circ} \mathrm{T}\right)$, and $z$ is positive upward, with corresponding velocities $\vec{u}=(u, v, w)$. In this coordinate system, the heat budget equation for a two-dimensional coastal wedge, bounded by the surface, the bottom, and $\mathrm{d} 3$, is: 
$\underbrace{\frac{\partial}{\partial t} \int_{0}^{L} \int_{-H(x)}^{0} \rho c_{p} T d z d x}_{\partial_{t}(S T O)}=\underbrace{-\int_{-H(L)}^{0} \rho c_{p} \tilde{u} \widetilde{T} d z}_{C H F} \underbrace{-\int_{0}^{L} \int_{-H(x)}^{0} \rho c_{p} v \frac{\partial T}{\partial y} d z d x}_{A H F} \underbrace{+\int_{0}^{L} Q d x}_{S H F}$

where $H(x)$ is the depth, $L=16.4 \mathrm{~km}$ is the cross-shore width of the region, $T$ the temperature, $Q$ the surface heat flux, $\rho$ the density of water, and $c_{p}=4.16 \times$ $10^{3} \mathrm{~W} \mathrm{skg}^{-1} \mathrm{~K}^{-1}$ is the heat capacity of water. In addition, $u$ and $T$ have been decomposed into their vertical averages $(\langle u\rangle$ and $\langle T\rangle$ ) and the deviations from the vertical averages $(\widetilde{u}$ and $\widetilde{T})$, such that $u(x, z, t)=\widetilde{u}(x, z, t)+<u>(x, t)$. The terms represent, in order, the change in heat content $\left(\partial_{t}(S T O)\right)$, the crossshore heat flux $(C H F)$, the alongshore heat flux $(A H F)$, and the surface heat flux $(S H F)$. The major underlying assumption in the above formulation is that there is no heat transport associated with alongshore mass flux divergence. The validity of this assumption and others made in the derivation of this equation are discussed in appendix A. The estimation of the terms from the mooring data and the uncertainty inherent in that process are considered in Appendix B.

The interpretation of the individual terms of (3.1) are as follows. $C H F$ represents the net exchange of heat across the offshore boundary in the presence of vertical temperature gradients due to depth-dependent cross-shelf flow. An important implication of the form of this term is that if the water column is well-mixed, $\widetilde{T}=0$, the cross-shore heat flux is zero. $A H F$ represents the advection of alongshore temperature gradients into the region. $S H F$ is the surface heat flux over the domain. The estimation of each of these terms and the sources of uncertainties in these estimates 
are discussed in appendix $\mathrm{B}$. The net heat flux $H F$ into the region is defined as:

$$
H F=C H F+A H F+S H F
$$

which can be compared directly to the observed change in heat content. The heat budget closes if $H F=\partial_{t}(S T O)$.

\subsection{Data}

This study focuses on two time periods: from 22:00 UTC 10 August 1994 to 00:00 UTC 4 September, referred to as the "August time period", and from 15:00 UTC 4 October to 00:00 UTC 2 November, referred to as the "October time period". The August time period was chosen to coincide with the greatest availability of meteorological and oceanic data, as described in Chapter 2. The October time period was chosen to avoid the effects of a slope water intrusion which commenced on November 2 (Figure 3.4E), as the focus of this paper is on more local influences to the heat content of the shelf.

\subsubsection{Atmospheric Forcing}

The surface heat flux (Figure 3.3A, 3.4A) and wind stress (Figure 3.3B, 3.4B) are discussed in Chapter 2. The principal axis of the wind forcing was oriented approximately $45^{\circ}$ to the coast, with poleward and offshore winds being correlated $(0.78$ in August and 0.66 in October) and of approximately the same magnitude. The mag-

nitude of the mean wind stress increased between August and October, $0.052 \mathrm{Nm}^{-2}$ to $0.10 \mathrm{Nm}^{-2}$. The surface heat flux changed from a mean value of $147 \mathrm{~W} \mathrm{~m}^{-2}$ (pos- 

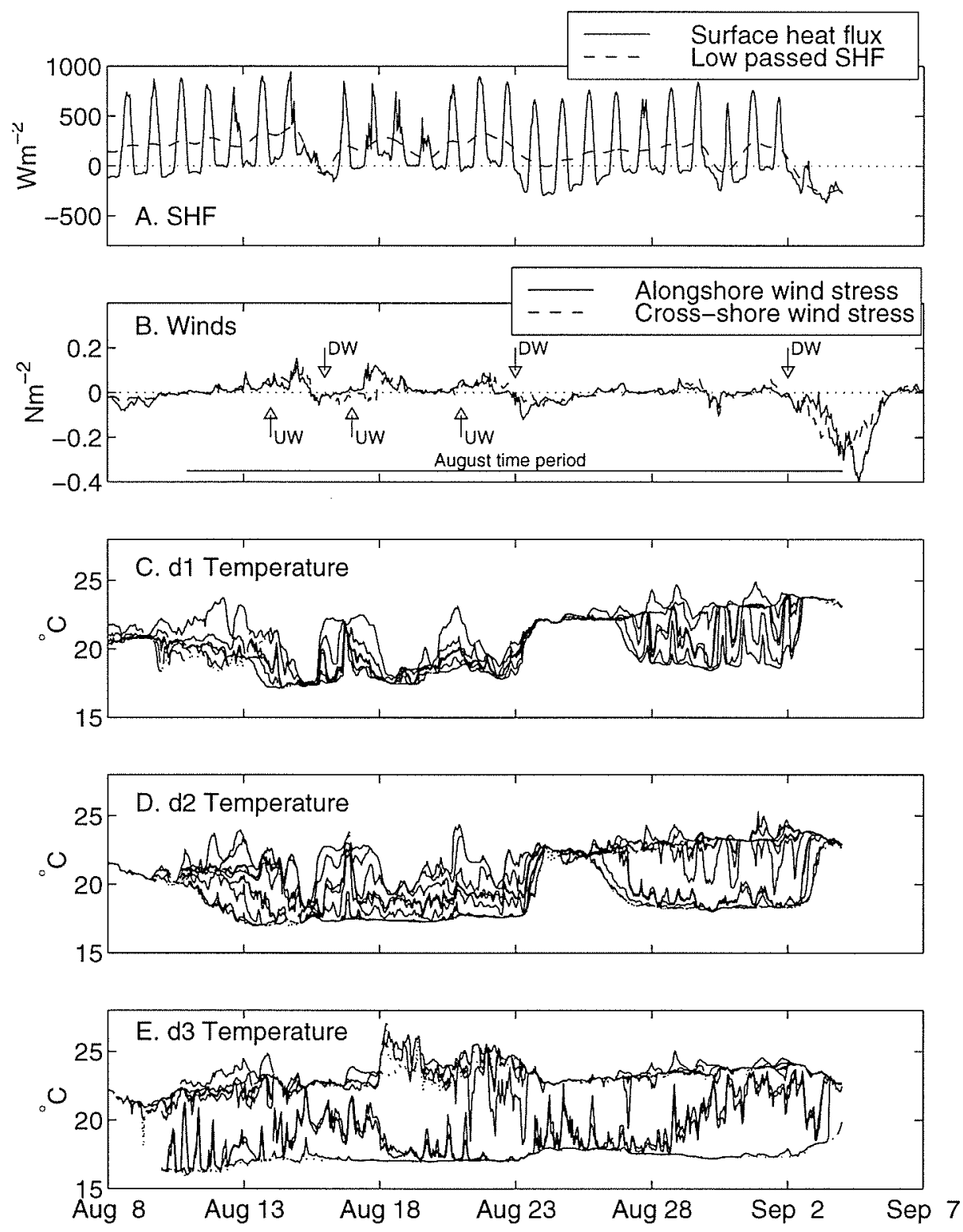

Figure 3.3: Time series of atmospheric forcing and temperature during the August time period. Arrows on panel B indicate timing of CTD sections in figure 3.5. (A) Surface heat flux (solid), low-pass filtered surface heat flux (dashed); (B) Wind stress; (C) Temperature, d1, 7 thermistors; (E) Temperature, d2, 12 thermistors; (E) Temperature, d3, 10 thermistors. 

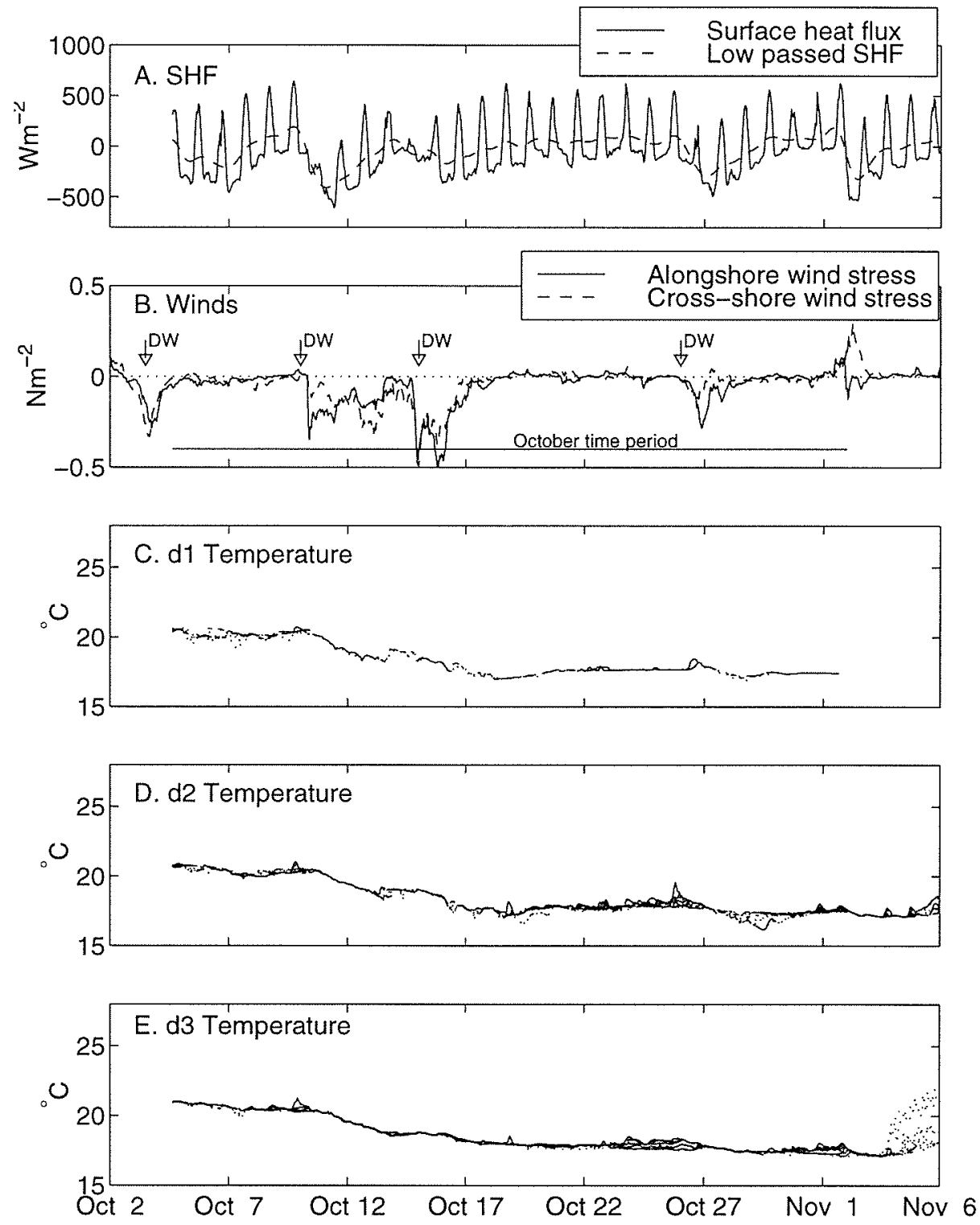

Figure 3.4: Time series of atmospheric forcing and temperature during the October time period. A. Surface heat flux (solid), low-pass filtered surface heat flux (dashed). B. Wind stress, C. Temperature, d1, 3 thermistors. This data is not used in the heat balance, for reasons discussed in Appendix B. D. Temperature, d2, 12 thermistors. E. Temperature, $\mathrm{d} 3,10$ thermistors. 
itive into the ocean) in August to $-39 \mathrm{~W} \mathrm{~m}^{-2}$ in October. The subtidal variance of the surface heat flux in each of the two months was around $135 \mathrm{~W} \mathrm{~m}^{-2}$ (when diurnal variation is included, the variance is much higher). Subtidal variation in the heat and momentum fluxes in both months was due primarily to the passage of atmospheric cold fronts, which cause the surface heat flux to decrease significantly and the wind direction to change from poleward and offshore to equatorward and onshore as they pass. The prevalence of cold fronts causes the heat flux to be highly correlated with the alongshore component of wind stress (correlation 0.73 in August, 0.68 in October), so that positive heat flux into the ocean is associated with poleward offshore winds and negative heat flux is associated with equatorward onshore winds (Figure 2.16). This correlation is not causal, but simply a consequence of the structure and orientation of cold fronts and their dominance as a source of subinertial meteorological variability.

\subsubsection{Temperature Data}

The primary difference in the character of the water column between August and October was the change in vertical thermal stratification, from a highly stratified, layered water column in August (Figure 3.3 C-E) to a weakly stratified water column in October (Figure 3.4 C-E). The change in the stratification from August to October was due primarily to a storm event starting September 4 with sustained wind stress of over $0.4 \mathrm{~N} \mathrm{~m}^{-2}$. Thermal stratification in August was strong, with temperature differences across the thermocline of up to $8^{\circ} \mathrm{C}$, with the strongest vertical thermal gradients at $\mathrm{d} 3$. The $\mathrm{d} 3$ site was characterized by a very sharp thermocline for the duration of August, with a temperature difference of $7^{\circ} \mathrm{C}$ over $3 \mathrm{~m}$ depth, and well-

mixed surface and bottom layers. Before August 24, the d2 site was characterized 

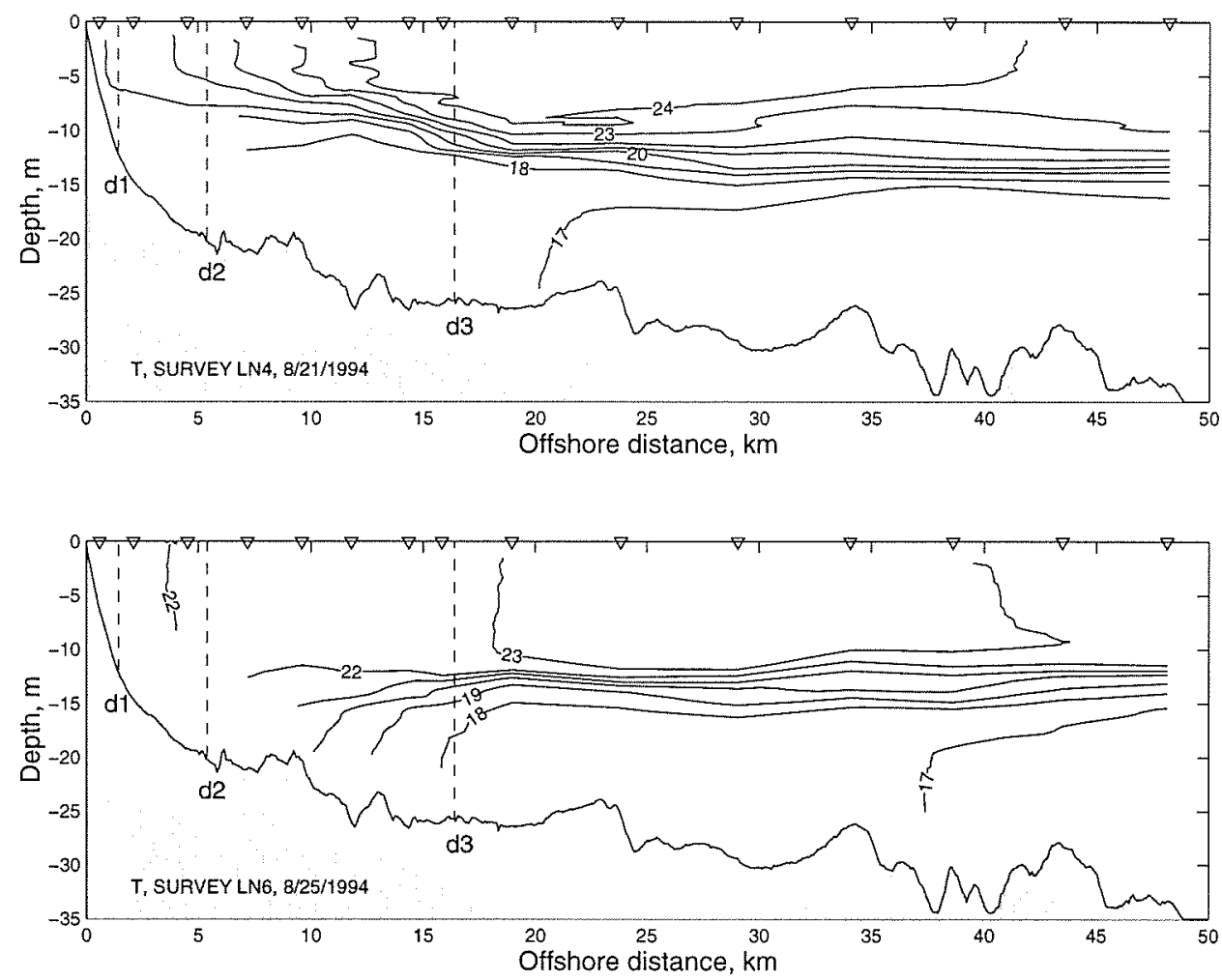

Figure 3.5: CTD sections from (A) August 21 and (B) August 25, taken from the $\mathrm{R} / \mathrm{V}$ Cape Hatteras. Location of CTD stations indicated by small triangles, and the locations of the three mooring sites are indicated by dashed lines.

by a well-mixed bottom layer and a stratified surface layer. After the relaxation of a downwelling event on August 25, the surface layer was also well mixed. Periodic upwelling and downwelling events resulted in local homogeneity of the water column during August at d1 and d2. When the thermocline was advected offshore, the water inshore of the thermocline became uniformly warm (during downwelling) or cold (during upwelling). CTD sections from representative events on August 21 and August 25 (Figure 3.5, timing indicated on Figure 3.3) show the upwelling and downwelling of the thermocline relative to the positions of the moorings. Because the distance the thermocline is advected offshore is a function of the strength and 
duration of the forcing event, they were most often observed closest to shore at $\mathrm{d} 1$, where weak wind events advected the thermocline past the mooring, occasionally at $\mathrm{d} 2$, where a stronger (or longer) wind event was required to advect the thermocline past the mooring. Homogenization was not observed at d3 until a large downwellingfavorable wind event at the beginning of September, which homogenized the water at the $\mathrm{d} 3$ site through both advection and mixing. These upwelling and downwelling events will be shown to have caused the largest fluctuations in the total heat content of the shelf during August. The offshore displacement of the thermocline during upwelling and downwelling is considered in chapters 4 and 5 .

In October, the average temperature dropped from about $21^{\circ} \mathrm{C}$ to $17^{\circ} \mathrm{C}$ (Figure 3.4C-E). The water column was well mixed in temperature except during small surface thermal restratification events, which generated differences of up to $1^{\circ} \mathrm{C}$ between the surface and the bottom water, and lasted up to seven days. Fluctuations in the vertically averaged temperature are correlated at the three sites, and is be linked to fluctuations in the surface heat flux and alongshore heat flux in section 4 .

The mean alongshore temperature gradient in the region, determined using data from NSC and SSC (Figure 3.1), was of order $-10^{-5}{ }^{\circ} \mathrm{Cm}^{-1}$ (colder to the north) in both months. This corresponds to a temperature difference over the alongshore extent of the array $(60 \mathrm{~km})$ of around $0.6^{\circ} \mathrm{C}$. This is consistent with estimates of the alongshore gradients from historical data [Walford and Wicklund, 1968].

\subsection{The Heat Budget}

The heat budget is considered on two time scales: first, the mean heat budget averaged over the August and October time periods, and second, the fluctuation 
heat budget for variation on day to week time scales.

\subsubsection{The Mean Heat Budget}

The mean heat budgets for August and October (Table 3.1) reflect variation in the heat budget on seasonal time scales. The most dramatic difference is the change in the mean value of the surface heat flux. In August, the surface heat flux dominates the mean balance, and in October, the surface heat flux and alongshore heat flux are approximately equally important. The cross-shelf heat flux is relatively unimportant in both months.

\section{August Mean Budget}

The predominant mean balance in August is between the surface heat flux and the increase in heat content of the region (Table 3.1). The estimated mean surface heat flux averaged over the month is approximately $2.2 \times 10^{6} \mathrm{~W} \mathrm{~m}^{-1}$ (equivalent to a temperature increase of $4^{\circ} \mathrm{C}$ averaged over the area). The increase in heat content is $1.7 \times 10^{6} \mathrm{~W} \mathrm{~m}^{-1}$, equivalent to an average temperature increase of approximately $3.2^{\circ} \mathrm{C}$. Neglecting the downwelling event that commences on September 1, the upper and lower layer at the $25 \mathrm{~m}$ site both increase in temperature by approximately $2^{\circ} \mathrm{C}$, while the thermocline deepens from approximately $10 \mathrm{~m}$ to $15 \mathrm{~m}$. Solar radiation cannot be directly responsible for the increase in the heat content of the lower layer, as shortwave extinction lengths were on the order of $2 \mathrm{~m}$, based on transmissometer data from the R/V Cape Hatteras cruises. Presumably, the bottom layer is heated during wind-driven mixing events. Although the alongshore and cross-shore fluxes contributed to the mean, their contributions were much smaller than the standard 
error and hence suggest that the actual mean is not resolved with the time series.

\section{October Mean Budget}

During the October time period, the observed change of the heat content was $-1.9 \times$ $10^{6} \mathrm{~W} \mathrm{~m}^{-1}$ (equivalent to an area averaged decrease in temperature of $-3.6^{\circ} \mathrm{C}$ ). The primary mean sources of loss were the surface heat flux $\left(-0.55 \times 10^{6} \mathrm{~W} \mathrm{~m}^{-1}\right.$, equivalent to an area-averaged decrease of $1.0^{\circ} \mathrm{C}$ ), and the alongshore heat flux $\left(-0.75 \times 10^{6} \mathrm{~W} \mathrm{~m}^{-1}\right.$, equivalent to an area-averaged decrease of $\left.1.4^{\circ} \mathrm{C}\right)$. The mean alongshore heat flux is due primarily $(80 \%)$ to the advection of a mean alongshore temperature gradient. The mean changes are larger than the standard error, suggesting that the mean changes observed in October are properly resolved with the time series.

\subsubsection{The Fluctuating Heat Budget}

The fluctuating budget indicates the primary source of variation in the heat content of the region on synoptic time scales. High frequency variation such as the diurnal shortwave radiation cycle and tides have been removed by low-pass filtering, so most of the remaining variation is due to fluctuations in atmospheric forcing associated with synoptic weather systems. 

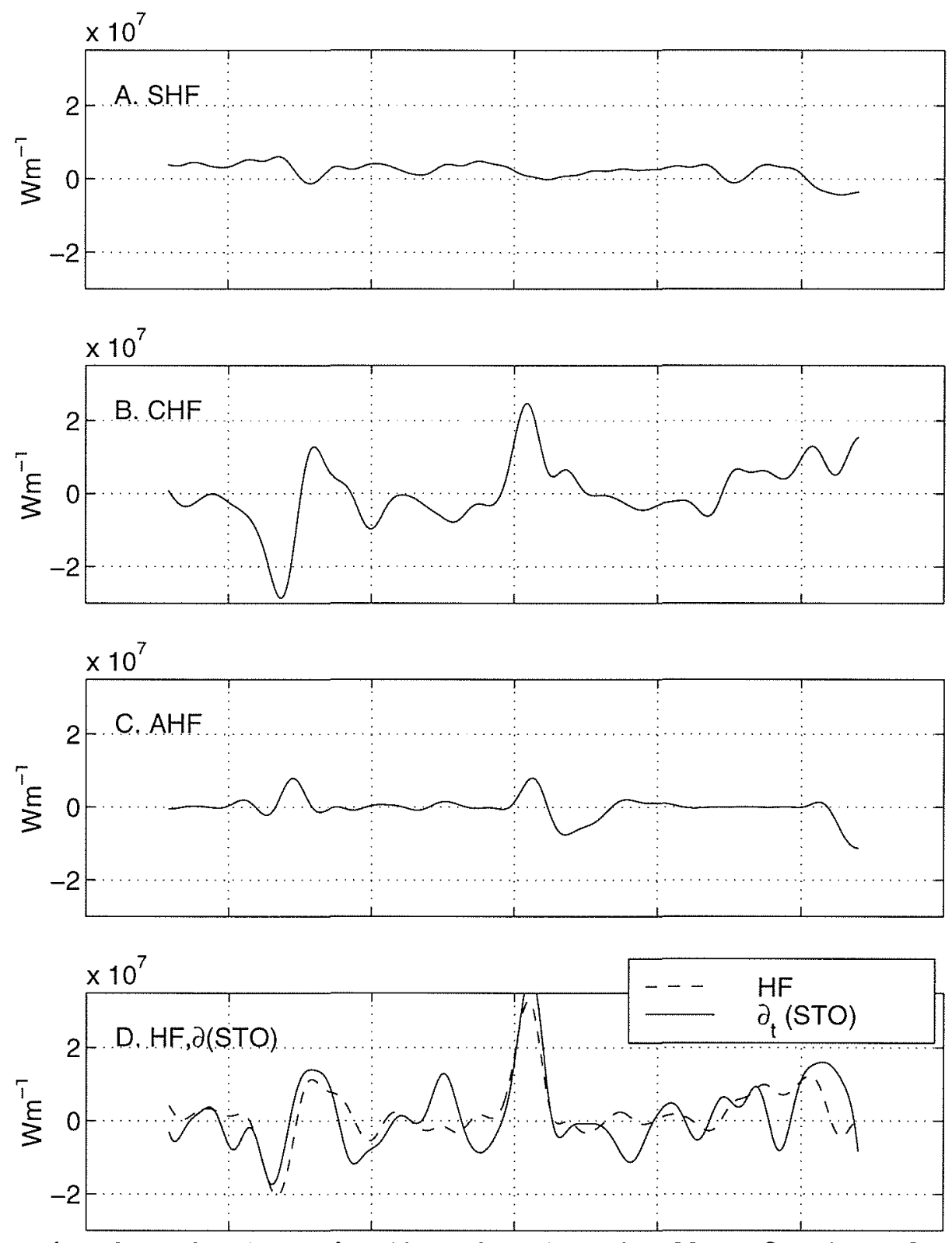

$\begin{array}{lllllll}\text { Aug } 8 & \text { Aug } 13 & \text { Aug } 18 & \text { Aug } 23 & \text { Aug } 28 & \text { Sep } 2 & \text { Sep } 7\end{array}$

Figure 3.6: The low-pass filtered heat budget terms for the August balance. (A) $S H F$; (B) CHF ; (D) AHF ; (E) $\partial_{t}(S T O)$, solid line, $H F$, dashed line. 
Table 3.1: Mean values standard deviations, and standard errors of the heat flux terms.

\begin{tabular}{|c|c|c|c|c|c|c|c|c|c|c|c|c|c|c|c|}
\hline \multirow[t]{2}{*}{ Period } & \multicolumn{3}{|c|}{ SHF } & \multicolumn{3}{|c|}{$\mathrm{CHF}$} & \multicolumn{3}{|c|}{$\mathrm{AHF}$} & \multicolumn{3}{|c|}{$\mathrm{HF}$} & \multicolumn{3}{|c|}{$\partial_{t}(S T O)$} \\
\hline & $\bar{x}^{a}$ & $\sigma_{x}^{b}$ & $\sigma_{\bar{x}}^{c}$ & $\bar{x}$ & $\sigma_{x}$ & $\sigma_{\bar{x}}$ & $\bar{x}$ & $\sigma_{x}$ & $\sigma_{\bar{x}}$ & $\vec{x}$ & $\sigma_{x}$ & $\sigma_{\bar{x}}$ & $\bar{x}$ & $\sigma_{x}$ & $\sigma_{\bar{x}}$ \\
\hline August & 2.22 & $\overline{2.2}$ & 0.55 & 0.15 & 8.6 & 2.1 & -0.14 & 3.0 & 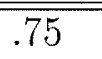 & 2.22 & $\overline{1.9}$ & 7.7 & 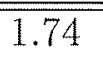 & 9.8 & 2.45 \\
\hline October & -0.55 & 2.2 & 0.5 & -0.14 & 0.5 & 0.09 & -0.75 & 1.5 & 0.35 & -1.44 & 0.77 & 3.3 & -1.87 & 4.3 & 1.0 \\
\hline
\end{tabular}

Units are $10^{6} \mathrm{~W} \mathrm{~m}^{-1}$.

Both time series had 17 degrees of freedom (d.f), assuming a decorrelation time scale of $40 \mathrm{~h}$.

a The mean of the data, $\bar{x}=\frac{\sum x}{N}$.

bStandard deviation, $\sigma_{x}=\left(\frac{\sum(x-\bar{x})^{2}}{N-1}\right)^{1 / 2}$.

'standard error, $\sigma_{\bar{x}}=\sigma_{x} / \sqrt{d . f .}$. 
Table 3.2: Regression statistics between the alongshore wind stress and the heat budget terms.

\begin{tabular}{|c|c|c|c|c|c|c|}
\hline \multirow[t]{2}{*}{ Term } & \multirow[t]{2}{*}{ Mechanism } & \multirow[t]{2}{*}{ model } & \multicolumn{2}{|c|}{$\Gamma$ (observations) $^{\mathrm{a}, \mathrm{b}}$} & \multicolumn{2}{|c|}{$\widehat{\Gamma}(\text { model })^{a}$} \\
\hline & & & $\mathrm{AUG}$ & $\mathrm{OCT}$ & $\mathrm{AUG}$ & $\mathrm{OCT}$ \\
\hline SHF & $\overline{\text { Cold }} \overline{\overline{\text { Fronts }}}$ & $\overline{\kappa \kappa L}$ & $5.4 \pm 1.4,(0.73)$ & $2.1 \pm 0.6,(0.68)$ & $\overline{5.4^{c}}$ & $2.1^{c}$ \\
\hline $\mathrm{CHF}$ & Ekman dynamics & $-\frac{\rho c_{p} \Delta T}{\rho f}$ & $-23 \pm 4.7,(-0.81)$ & $-0.07 \pm 0.1,(-0.18)$ & -25 & 0.6 \\
\hline $\mathrm{AHF}$ & Alongshore flow & $-\frac{\rho c_{p} \Delta A}{\rho r} \frac{d T}{d y}$ & $3.0 \pm 1.2,(0.56)$ & $1.5 \pm 0.4,(0.68)$ & 2.1 & 3.0 \\
\hline $\mathrm{HF}$ & net flux & $\widehat{\Gamma}_{S H F}+\widehat{\Gamma}_{C H F}+\widehat{\Gamma}_{A H F}$ & $-14 \pm 4.3,(-0.69)$ & $3.5 \pm 0.8,(0.73)$ & -18.3 & 5.1 \\
\hline$\partial_{t}(S T O)$ & Balance Closure & $\widehat{\Gamma}_{H F}$ & $-17 \pm 4.4,(-0.73)$ & $4.5 \pm 1.2,(0.69)$ & -18.3 & 5.1 \\
\hline
\end{tabular}

${ }^{a}$ Units are $10^{7} \mathrm{~W} \mathrm{~m} \mathrm{~N}^{-1}$.

$\underset{N}{ }{ }^{b}$ Correlation coefficient in parentheses. Boldface indicates significance at the $95 \%$ level. ${ }^{c} \kappa$ is determined empirically from the observations. 


\section{August Variation}

Variation in the heat content in August is due largely to the cross-shore heat flux (Table 3.1, Figure 3.6). The cross-shore heat flux reflects changes in temperature due to cross-shore advection in the upper layer and a compensating flow in the lower layer. The difference in temperature between the two layers causes these flows drive a large net cross-shelf heat transport, which is highly negatively correlated (0.81 ) with the alongshore wind stress (Table 3.2). The consistency of the transport with Ekman theory is considered in section 5.1.1. Upwelling events occurred on August 15, 17, and 20, resulting in significant losses of heat, and downwelling events occurred on August 24 and September 2, resulting in significant gains of heat. The change in heat on the shelf in these cases was due not to local heating or cooling but to a change in position of the thermocline during wind stress events (Figure 3.5). The dominance of the cross-shore heat flux in determining temperature fluctuation on the shelf during August led to a correlation between the alongshore wind stress and the change in the measured storage term of -0.73 (Table 3.2 ). The measured net heat flux $(H F)$ and the change in storage $\left(\partial_{t}(S T O)\right)$ were highly correlated (correlation 0.74).

\section{October Variation}

For the October time period, variation in the heat content was due primarily to fluctuations in the surface heat fiux, and to a lesser extent, the alongshore heat flux(Figure 3.7, Table 3.1). Although the variance of the surface heat flux was approximately the same in August and October, it played a dominant role in October, since the weak vertical temperature gradient effectively shut down the cross-shore 
heat flux. This led to smaller net changes in heat content in October. Variations in surface heat flux are positively correlated with the alongshore wind stress (correlation 0.68), due to the passage of cold fronts in the atmosphere. The alongshore flux was due to the weak $\left(O\left(-10^{-5}{ }^{\circ} \mathrm{Cm}^{-1}\right)\right)$ negative alongshore temperature gradient (colder to the north) advected by the alongshore current, and was correlated with the alongshore wind (correlation 0.68). These positive correlations resulted in a positive correlation of 0.69 between the alongshore wind and the storage term, and a correlation between the net heat flux and the storage term of 0.88 .

\subsection{The Role of the Alongshore Wind}

The alongshore wind plays a central role in determining coastal circulation, and has been studied in many contexts (Allen, [1973], Winant and Beardsley, [1979], Csanady, [1971]). In this section, it will be shown that on the North Carolina Inner Shelf, the relationships between the wind stress and the heat flux terms are dependent on season, resulting in seasonal changes in the primary fluctuating budget. Variation in the different sources and sinks of heat can be explained in terms of

simple dynamically-based models. In the following section, this simple relationship between the alongshore wind stress and heat fluxes based on the CoOP data set is developed, and this model is used to interpret historical data collected at the FRF between 1984 and 1995 . 

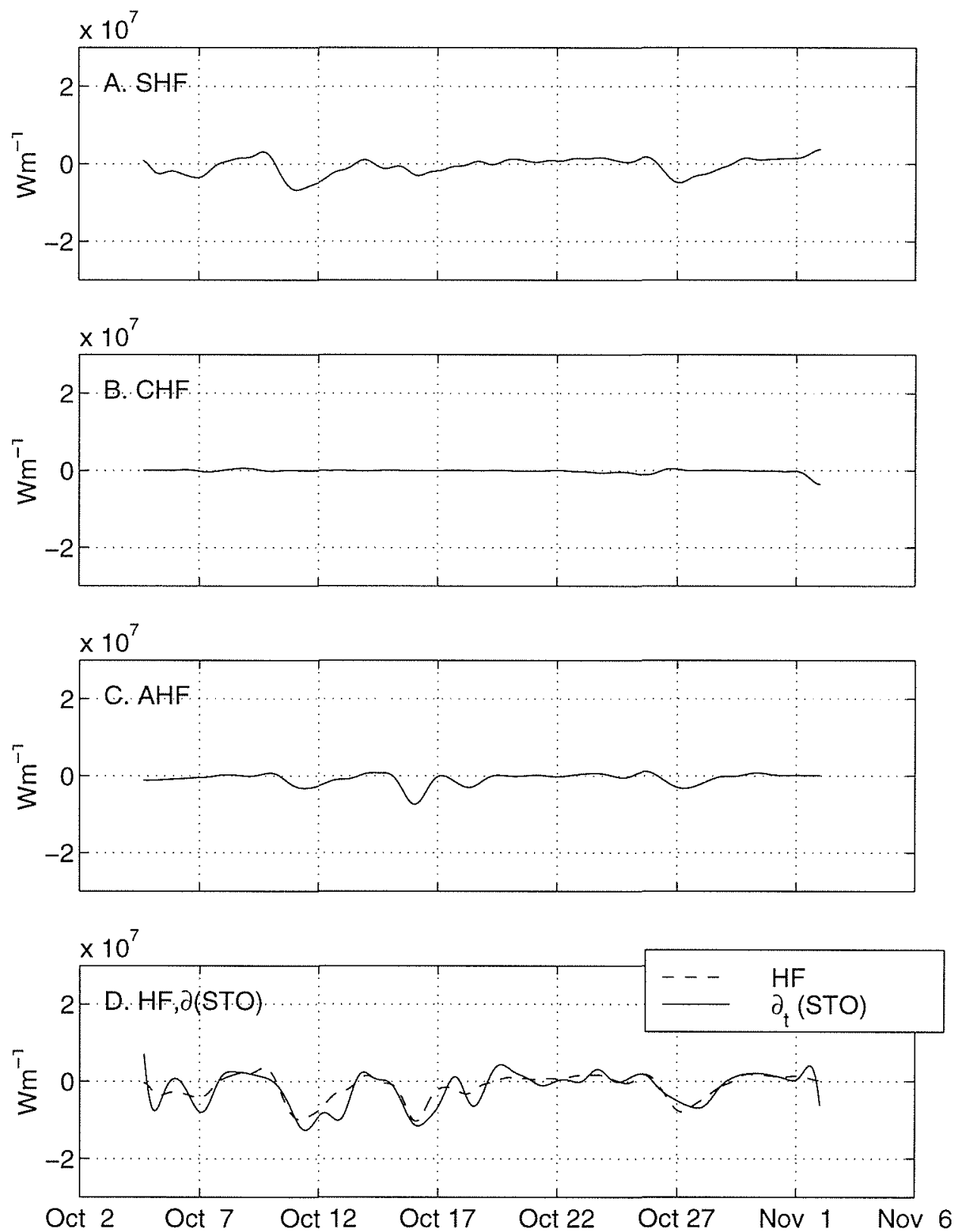

Figure 3.7: The low-pass filtered heat budget terms for the October balance. A: $S H F$. B: CHF. C. AHF. D. $\partial_{t}(S T O)$, solid line, $H F$, dashed line. 


\subsubsection{Simple Wind-Driven Models and the CoOP Data}

In this section, the regression between the heat flux terms and the alongshore wind stress is estimated using a simple model, and compared to the best fit, in the leastsquares sense, between the measured heat flux terms and the alongshore wind stress. The regression coefficients from the observations are denoted by $\Gamma$, which represents the strength of the influence of the alongshore wind stress on a given term in the heat budget. The dependence on the alongshore wind stress in the simple dynamical models are denoted by a corresponding $\widehat{\Gamma}$.

\section{The Cross-Shore Heat Flux}

The cross-shore heat flux is presumably due to Ekman transport in the upper, warm layer balanced by a reciprocating flow in the lower, cold layer. The balance in the upper (lower) layer of the water column is between the surface (bottom) stress and the Coriolis force. For a two-dimensional flow (i.e. the alongshore flux divergence is zero), the transport in the upper layer offshore of the pycnocline front is $(u h)_{1}=\frac{\tau^{S}}{\rho_{0} f}$, where $\tau^{S}$ is the alongshore surface stress. If the flow is two-dimensional, the transports in the upper and lower layer must be opposite in sign but equal in magnitude. Assuming the difference between the temperature in the upper and lower layers is $\Delta T$, the cross-shore heat flux due to the Ekman circulation can be approximated [Lentz 1987] by:

$$
C H F_{M O D E L}=\widehat{\Gamma}_{C H F} \tau^{S}
$$


where

$$
\widehat{\Gamma}_{C H F}=-\frac{\rho_{0} c_{p} \Delta T}{\rho_{0} f}
$$

where $f=0.95 \mathrm{~s}^{-1}$ is the local Coriolis parameter. An estimate of the cross-shore heat flux can be computed for the month of August using the average difference in temperature between the top and the bottom thermistors at $\mathrm{d} 3$ for $\Delta T\left(6^{\circ}\right.$ in August and $0.15^{\circ}$ in October), and the wind stress time series from d2. A comparison of the Ekman model cross-shore heat flux and the actual estimated cross-shore heat flux in August (Table 3.2) shows reasonable agreement between the magnitude of the signals, as $\Gamma_{C H F}=(-23 \pm 4.7) \times 10^{7} \mathrm{Wm} \mathrm{N} \mathrm{m}^{-1}$ and $\widehat{\Gamma}_{C H F}=-25 \times 10^{7} \mathrm{Wm} \mathrm{N}^{-1}$. Therefore, to first order, the size of the regression coefficient $\Gamma_{C H F}$ is consistent with this simple model. In October, both $\Gamma_{C H F}$ and $\widehat{\Gamma}_{C H F}$ are small, as the stratification is weak. In addition, the correlation of the CHF with the alongshore wind stress is not significant in October.

\section{The Alongshore Heat Flux}

Alongshore currents in the same direction as the wind stress occur during both upwelling and downwelling events. These currents can advect the mean alongshore temperature gradient, causing local fluctuations in temperature. During the CoOP Inner Shelf Study, a weak alongshore temperature gradient existed with cooler water to the north. Data from the Serial Atlas of the Marine Environment [Walford and Wicklund, 1968], suggest that this alongshore temperature gradient is a year-round feature of this region. Positive (poleward) wind stress drove alongshore poleward currents, resulting in a net increase in heat content, and equatorward alongshore 
wind stress resulted in a net decrease in heat content. By assuming an approximate balance between the surface and bottom stress [Lentz et al. submitted], a simple model for the alongshore velocity can be derived. Variations in the alongshore heat flux in the CoOP Inner Shelf Study data were primarily due to variations in the alongshore velocity, so the alongshore heat flux can be approximated by:

$$
A H F_{M O D E L}=\widehat{\Gamma}_{A H F} \tau^{S},
$$

where

$$
\widehat{\Gamma}_{A H F}=-\frac{\rho_{0} c_{p}}{\rho_{0} r} \frac{d T}{d y} \Delta A,
$$

and $r=5 \times 10^{-4} \mathrm{~m} \mathrm{~s}^{-1}$ is a reasonable value for linear bottom drag and $\Delta A=3.1 \times$ $10^{5} \mathrm{~m}^{2}$ is the cross-sectional area of the budget region. Values of $T_{y}$, based on mean temperatures measured at NSC and SSC, of $0.8 \times 10^{-5}{ }^{\circ} \mathrm{C} \mathrm{m}^{-1}$ and $1.2 \times 10^{-5}{ }^{\circ} \mathrm{C} \mathrm{m}^{-1}$ are used for August and October, respectively. In the data, the alongshore heat flux is not significantly correlated with the alongshore wind stress in August, but well correlated in October. The lack of correlation in August may be due to the fact that the largest apparent alongshore differences in temperature are due to alongshore variation in the cross-shore shoaling of the thermocline, and do not accurately represent the local alongshore gradient, suggesting that the local alongshore temperature gradient is not well resolved. In October, the observed variation in the alongshore heat flux is less heavily dependent on the wind stress than expected. 


\section{The Surface Heat Flux}

The surface heat flux is correlated with the alongshore wind stress such that positive wind stress is associated with heating (of the ocean) and negative wind stress with cooling (Figure 2.16). This relationship is discussed in chapter 2, and is attributed to the spatial structure of the meteorological fields associated with cold fronts.

The surface heat flux can be modeled as a function of the alongshore wind stress as:

$$
S H F_{M O D E L}=\widehat{\Gamma}_{S H F} \tau^{\mathcal{S}}
$$

where

$$
\widehat{\Gamma}_{S H F}=\kappa L,
$$

and $\kappa$ is a transfer coefficient between the alongshore wind stress and the surface heat flux. Since no dynamical model exists to determine the value of $\kappa$, it must be determined empirically from field observations, so that

$$
\kappa=\Gamma_{S H F} L^{-1} .
$$

It follows that $\widehat{\Gamma}_{S H F}=\Gamma_{S H F} . \kappa$ is determined separately for each month, with $\kappa=$ $3500 \mathrm{Wm} \mathrm{N}^{-1}$ in August and $\kappa=1300 \mathrm{~W} \mathrm{~m} \mathrm{~N}^{-1}$ in October. 


\section{The Net Heat Flux}

All of the heat source terms can be related to the alongshore wind stress, so the the net heat content should also be a function of the alongshore wind stress. The directly measured change in heat content, $\partial_{t}(S T O)$, is related to the alongshore wind stress by

$$
\partial_{t}(S T O)=\widehat{\Gamma}_{\partial_{t}(S T O)} \tau^{S}
$$

The total heat flux into the region is given by (3.2). Similarly, the total heat flux into the region is modeled as:

$$
H F_{M O D E L}=S H F_{M O D E L}+A H F_{M O D E L}+C H F_{M O D E L}
$$

so that

$$
\widehat{\Gamma}_{H F}=\widehat{\Gamma}_{C H F}+\widehat{\Gamma}_{S H F}+\widehat{\Gamma}_{A H F} .
$$

The model for the change in temperature is

$$
\widehat{\Gamma}_{\partial t}(S T O)=\widehat{\Gamma}_{H F}
$$

since the modeled heat balance assumes closure.

Three different comparisons can be made here. Comparing $\Gamma_{H F}$ and $\Gamma_{\partial_{t}}(S T O)$ reflects an imbalance in the observations, due either to measurement error or a breakdown of the assumptions about heat balance closure. Comparing $\Gamma_{H F}$ and and $\widehat{\Gamma}_{H F}$ reflects the adequacy or inadequacy of the simple models to explain variation 
in net heat content, and is simply the sum of the errors in the individual source terms. Finally, comparing $\Gamma_{\partial_{t}(S T O)}$ and $\widehat{\Gamma}_{\partial_{t}(S T O)}$ reflects the combined error of the measurements and the appropriateness of the simple models. All of these values are summarized in Table 3.2

In August, the measured dependence of the net flux was $\Gamma_{H F}=(-14 \pm 4.3) \times$ $10^{7} \mathrm{Wm} \mathrm{N}^{-1}$, which is consistent with the model, where $\widehat{\Gamma}_{H F}=-18 \times 10^{7} \mathrm{~W} \mathrm{~m} \mathrm{~N}^{-1}$. In addition, the observed change in temperature was consistent with both of these estimates, with $\Gamma_{\partial_{t}(S T O)}=(-17 \pm 4.4) \times 10^{7} \mathrm{~W} \mathrm{~m} \mathrm{~N}^{-1}$. In October, the dependence of the net heat flux on the alongshore wind stress, $\Gamma_{H F}=(3.5 \pm 0.8) \times 10^{7} \mathrm{~W} \mathrm{~m} \mathrm{~N}^{-1}$, fell slightly short of the modeled dependence, $\widehat{\Gamma}_{H F}=5.1 \times 10^{7} \mathrm{Wm} \mathrm{N}^{-1}$. This discrepancy is due primarily to a poor estimation of the alongshore heat flux dependence. The dependence of the measured change in temperature, $\Gamma_{\partial_{t}(S T O)}=$ $(-4.5 \pm 1.2) \times 10^{7} \mathrm{~W} \mathrm{~m} \mathrm{~N}^{-1}$, was consistent with the model prediction. The October $\Gamma_{H F}$ and $\Gamma_{\partial_{t}(S T O)}$ are smaller in magnitude and opposite in sign from August, due primarily to the predominance of the cross-shore heat flux in August and its relative lack of importance in October. This suggests that when the shelf is stratified, variations in the heat content of the shelf are strongly dependent on and negatively correlated with the alongshore wind stress. In the absence of stratification, the heat content is positively correlated with the alongshore wind stress but the dependence is not as strong.

\subsubsection{Seasonal Cycle}

Historical archives of several meteorological variables, including wind velocity and water temperature from January 1984 to December 1995 were acquired from the 
Coastal Engineering Research Center's Field Research Facility (FRF), located inshore of the main array of moorings (Figure 3.1). These two time series can be used to estimate a time series of the monthly $\Gamma_{\partial_{t}(S T O)}^{F R F}$. The seasonal cycle in the dominance of the individual terms of the heat budget should be reflected by this analysis. In addition, monthly values of the expected size of $\widehat{\Gamma}_{H F}$ can be estimated from independent sources of data to serve as a means of comparison and verification.

The daily water temperature measurements, taken with a bucket thermometer at the end of the pier (560 $\mathrm{m}$ offshore) were differenced to approximate the time derivative of the temperature. This time series of temperature change was assumed to be representative of the temperature change of the inner shelf out to a distance of $6 \mathrm{~km}$, the region commonly affected by the displacement of the thermocline during upwelling and downwelling episodes during the stratified season. The wind velocities were binned into one-day averages that coincided with the temperature differences. A time series of the regression between the alongshore component of the wind stress and the temperature change $\left(\Gamma_{\partial_{t}(S T O)}^{F R F}\right)$ was computed for month-long time periods, and is shown plotted as a function of month for the years 1984-1995 (Figure 3.8A). The correlations for the monthly fits are shown in Figure 3.8B. The time series shows a clear seasonal signal, varying between small positive values from October through March, to large negative values from May through August.

It is desirable to check to see if the values of $\Gamma_{\partial_{t}(S T O)}^{F R F}$ shown in Figure $3.8 \mathrm{~A}$ are consistent, in order of magnitude, with the interpretations offered in the previous section. To do this, values of $\widehat{\Gamma}_{H F}$ are computed on a monthly basis using independent data. CTD measurements made as part of the Marine Resources Monitoring, Assessment, and Prediction (MARMAP) program include 25 surveys of a section extending offshore from Cape Henry, $80 \mathrm{~km}$ north of the CoOP Inner Shelf Study 

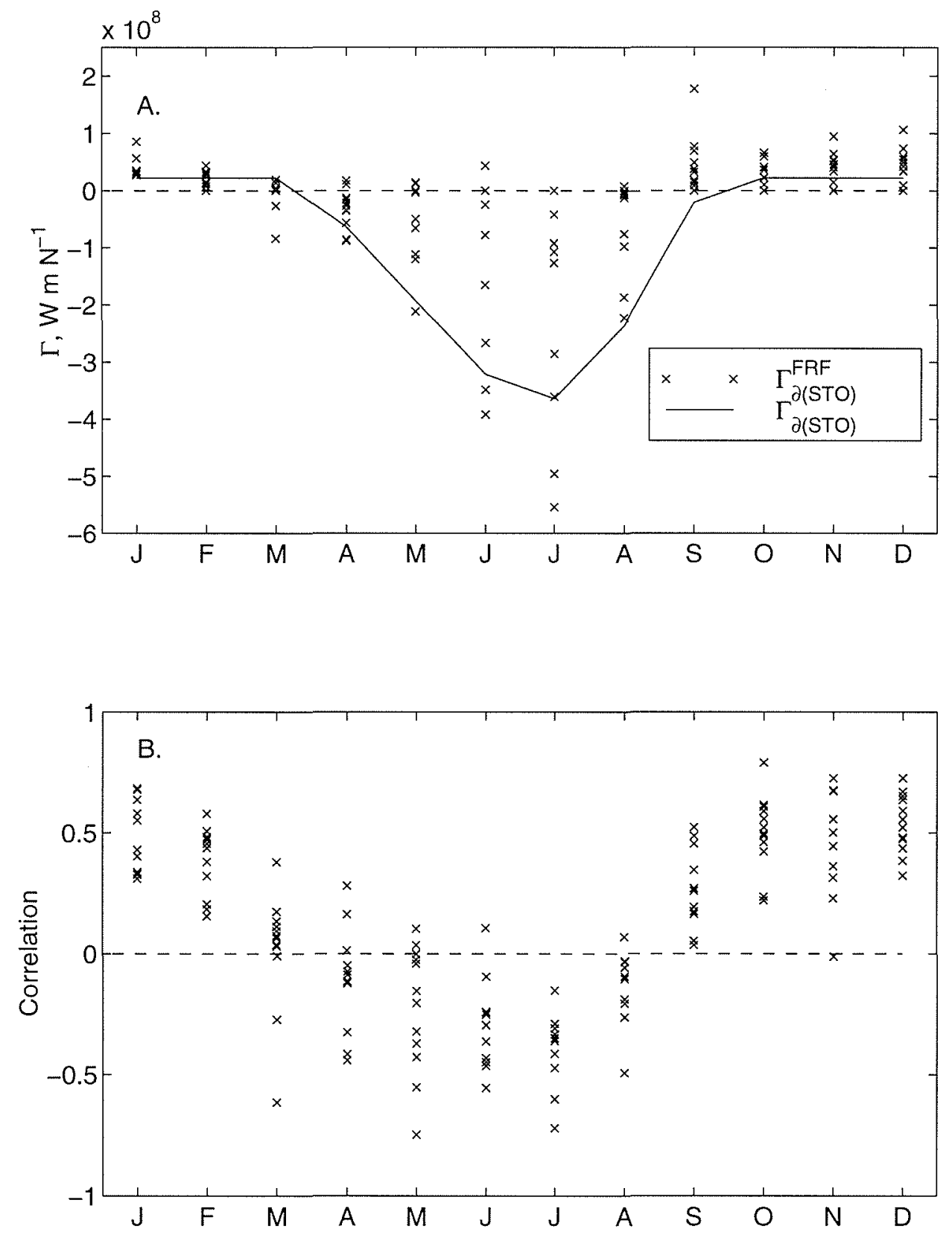

Figure 3.8: A. $\widehat{\Gamma}_{H F}$ as a function of month. X's are monthly values of $\Gamma_{\partial_{t}(S T O)}^{F R F}$, 19841995. Simple regression model $\widehat{\Gamma}_{H F}$ is indicated by solid line. B. Correlation of the alongshore wind component with the time-differenced temperature from the FRF, as a function of month. 
site, made between 1977 and 1985 [Manning and Holzwarth, 1990]. The surfacebottom temperature difference at station 13 (approximately $20 \mathrm{~km}$ offshore of the mouth of the Chesapeake Bay, in approximately $20 \mathrm{~m}$ of water) was used to determine a monthly mean $\Delta T$ (Figure $3.9 \mathrm{~A}$ ) to compute $\widehat{\Gamma}_{C H F}$. Climatic summaries of water temperature data from the NDBC CHLV2 buoy and from the FRF were differenced, and suggest that, for the purposes of this model, $\frac{d T}{d y}$ is approximately constant on seasonal scales, and a value of $-1.2 \times 10^{-5}{ }^{\circ} \mathrm{C} \mathrm{m}^{-1}$ (colder to the north) is used to compute $\widehat{\Gamma}_{A H F}$. This is consistent in both sign and magnitude with historical values of the alongshore temperature gradient [Walford and Wicklund, 1968]. Annual variation in $\kappa$, necessary for understanding the seasonal cycle of the surface heat flux contribution, cannot be estimated without more heat flux data, so it is assumed to be constant, with a value of $\kappa=2500 \frac{\mathrm{Wm}-2}{\mathrm{Nm}^{-2}}$, to estimate $\widehat{\Gamma}_{S H F}$. The conclusions of this section are not heavily dependent on seasonal variation in $\widehat{\Gamma}_{S H F}$, as this term is small compared to variations in the corresponding cross-shore heat flux values (Figure 3.9B).

The resulting monthly $\widehat{\Gamma}_{S H F}, \widehat{\Gamma}_{A H F}$, and $\widehat{\Gamma}_{C H F}$ (Figure $3.9 \mathrm{~B}$ ) can be summed to create $\widehat{\Gamma}_{H F}$ (Figure $3.8 \mathrm{~A}$, solid line), and compared to the data from the FRF. They are consistent in magnitude with the direct measurements made at the FRF, and suggest a strong seasonal cycle in the dominant term of the fluctuating heat budget. Between May and August, wind-driven cross-shore heat flux dominates the heat content variability in very shallow water. The budget in October through March is dominated by the surface heat flux and, to a lesser extent, the alongshore flux. In March, April and September, the coefficients and the model prediction are indistinguishable from zero, suggesting that neither process is dominant during these times, or that the timing of the seasonal cycle drifts to the extent that variation in 

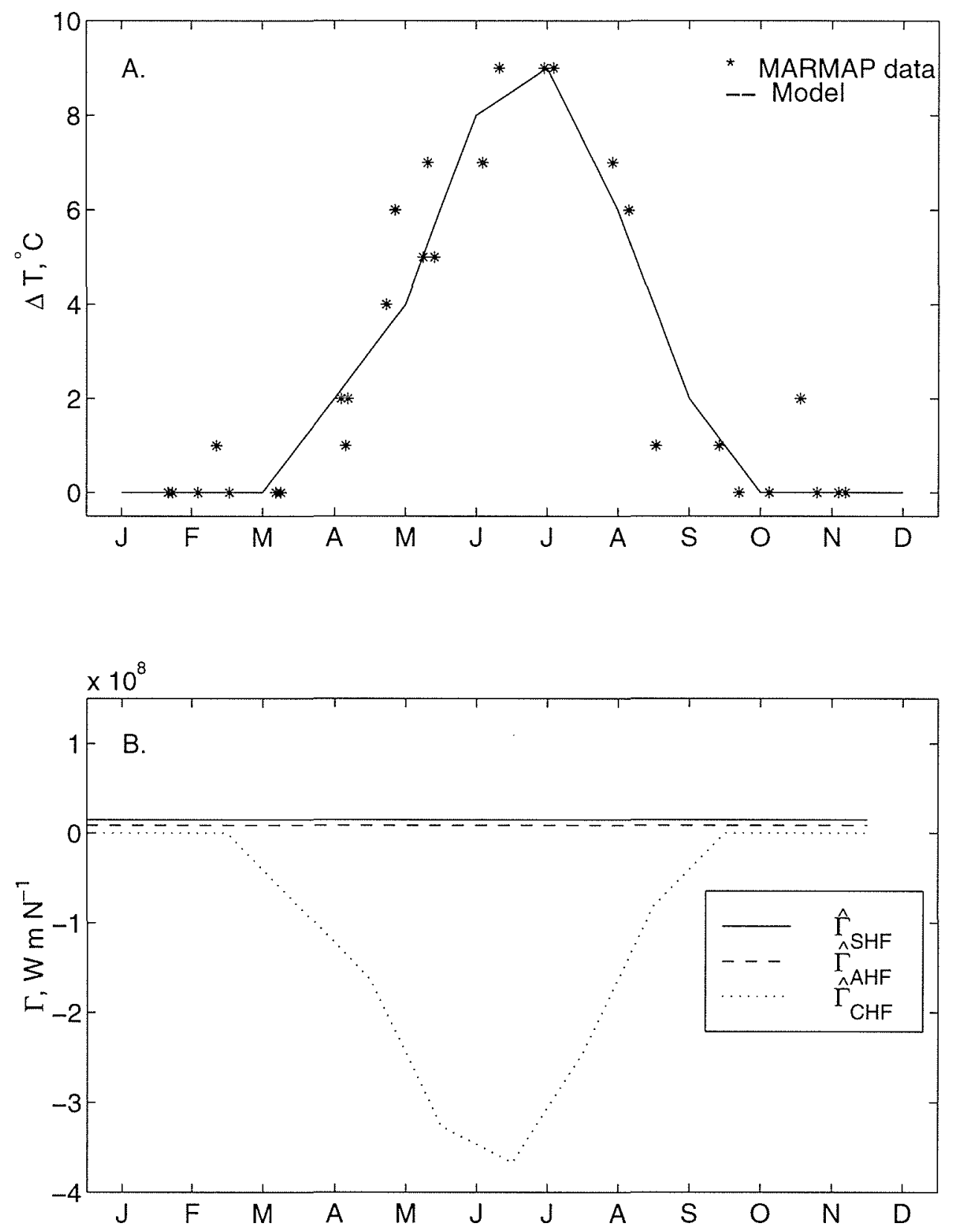

Figure 3.9: A. Surface-bottom temperature difference at station 13, as a function of month from the MARMAP data set (stars), and monthly temperature difference used in model (solid line). B. $\widehat{\Gamma}_{S H F}, \widehat{\Gamma}_{C H F}$, and $\widehat{\Gamma}_{A H F}$ as a function of month. 
any given March, April or September can be dominated by one or the other. This is due to the fact thermal stratification tends to be initially established in March or April, and destroyed in September, a trend consistent with the CTD sections presented in Manning and Holzwarth [1990].

The model prediction for the months May-August is notably larger than the measured values. This may be due to the discrete nature of the measurement of the heat content of the inner shelf. Instead of reflecting a continuous change of heat on the inner shelf, a time series of change of heat content estimated from the single FRF temperature measurement would have "spikes" as the thermocline passed through the measurement site, causing the correlations and regression parameters to be smaller than expected.

The strength and regularity of the seasonal cycle in the fit and correlation can be addressed by comparing the relative sizes of the modeled surface and alongshore heat flux and the cross-shore heat flux. Forming the ratio of surface and alongshore to cross-shore heat flux, from equations (3.4), (3.6), and (3.8):

$$
\frac{A H F+S H F}{C H F}=\frac{\widehat{\Gamma}_{A H F}+\widehat{\Gamma}_{S H F}}{\widehat{\Gamma}_{C H F}}=\frac{c_{p} \Delta A r^{-1} \frac{d T}{d y}-\kappa L}{c_{p} \Delta T f^{-1}}
$$

If the alongshore plus surface heat flux and the cross-shore heat flux were to be equally important to the heat budget, this ratio would be about 1 . This constraint requires the temperature difference across the thermocline to be on the order of $0.5^{\circ} \mathrm{C}$. This corresponds to a bulk richardson number on the order of 0.1 . If $\Delta T$ is small, it is more easily mixed away by a small amount of wind or surface cooling, causing the cross-shore heat flux to be negligible and making the ratio large. In summary, if this ratio is large, the alongshore and surface heat flux dominate the 
budget; if it is $O(1)$, it may rapidly become large due to the influence of mixing; if it is small, the cross shore flux dominates the budget. Essentially, the cross-shore heat flux either dominates the budget or is zero.

\subsection{Summary}

Variation in the heat content of the North Carolina Inner Shelf is dynamically linked to the alongshore wind stress. If there is vertical thermal stratification, the crossshore heat flux dominates through Ekman dynamics, and if there is no vertical thermal stratification, the surface heat flux and the alongshore heat flux dominate. The dominant source of variation in the heat content varies on an annual cycle, due to the seasonal nature of the vertical thermal stratification. This hypothesis is supported by the CoOP Inner Shelf Study data, in which variation during the August time period was dominated by the cross-shore flux, and variation in the October time period by the surface and alongshore heat fluxes. Analysis of wind and water temperature data from the FRF allowed a more basic test of this hypothesis over a 12-year time period. This analysis showed that between May and August, a time period characterized by strong thermal stratification, the cross-shore heat flux dominates variation in heat content, and between October and February the surface heat flux and alongshore flux dominate variation. These results differ from those of Dever and Lentz [1997], Lentz and Chapman [1989], and Lentz [1987] who all found variation in the heat balance off of the California coast to be dominated by cross-shore heat flux, independent of season. This difference is presumably due to the much weaker seasonal cycle of stratification on the west coast. 


\subsection{Acknowledgments}

The moored meteorological and oceanographic measurements used in this paper were funded by National Science Foundation grant OCE-92-21615, and were provided by S. Lentz. Other data was kindly provided by the Field Research Facility in Duck, NC. Support for the analysis of the data was provided by National Science Foundation grant OCE-96-33025. JAA was supported by an ONR AASERT grant, N00014-93-1-1154. Conversations held with S. Lentz helped tremendously in the production of this paper. This is WHOI contribution 9559 . 


\subsection{Appendix A: Derivation of the Heat Budget Equation}

The heat budget equation can be derived by combining equations for the conservation of heat and mass of a fixed control volume. If it is assumed that there is no heat flux through the bottom of the domain, the statement of heat conservation can be written:

$$
\frac{\partial}{\partial t} \iint T d A+\int_{-H(L)}^{0}(u T)_{x=L} d z+\frac{\partial}{\partial y} \int v T d A=\int_{0}^{L} \frac{Q}{\rho c_{p}} d x
$$

where $d A$ is the area bounded by the surface, bottom, and offshore extent, $L$, and $H(x)$ is the bottom depth. Decomposing $u$ and $T$ into their instantaneous vertical average and an anomaly $(u=\langle u>(x, t)+\widetilde{u}(x, z, t), T=<T>(x, t)+\widetilde{T}(x, z, t)$, where $\langle u\rangle=\frac{1}{H} \int_{-H}^{0} u d z$ and $\left.\langle T\rangle=\frac{1}{H} \int_{-H}^{0} T d z\right)$ yields, for the second term:

$$
\int_{-H}^{0} u T d z=<u><T>H+\int_{-H}^{0} \widetilde{u} \widetilde{T} d z
$$

The third term in (3.15) can also be expanded, this time by breaking $\mathrm{T}$ into its

area-average and anomaly $\left(T=\bar{T}+T^{\prime}\right.$, where $\left.\bar{T}=\frac{1}{A} \int T d A\right)$. The third term becomes:

$$
\iint \frac{\partial\left(v\left(\bar{T}+T^{\prime}\right)\right)}{\partial y} d A=\iint v \frac{\partial T}{\partial y} d A+\iint \bar{T} \frac{\partial v}{\partial y} d A+\iint T^{\prime} \frac{\partial v}{\partial y} d A
$$

The third term on the RHS of ( 3.17 cannot be evaluated with the data collected in this experiment and is disregarded; any real contribution from this term is reflected in the error. By mass conservation, the first term on the right-hand side of (3.16) and the second term on the right-hand side of (3.17) combine to form $<u>H(\bar{T}-<$ 
$T>$ ). This term represents heat deposited in the region due to transport divergence, and appears to be small for observed values of $\langle u\rangle$ in the CoOP ISS data set, as $\bar{T} \approx\langle T\rangle$. Therefore, the two divergence terms is dropped. The heat budget equation now becomes:

$$
\underbrace{\frac{\partial}{\partial t} \int_{0}^{L} \int_{-H(x)}^{0} T d z d x}_{\partial(S T O)}=\underbrace{-\int_{-H(L)}^{0} \tilde{u} \widetilde{T} d z}_{C H F} \underbrace{-\int_{0}^{L} v \frac{\partial T}{\partial y} d z d x}_{A H F} \underbrace{+\int_{0}^{L} \frac{Q}{\rho c_{p}} d x}_{S H F}
$$

\subsection{Appendix B: Discretization of the Heat Bud- get Terms}

\subsubsection{The Storage Term}

The storage term can be approximated as:

$$
\partial_{t}(S T O) \approx \Delta\left(\sum_{i=1}^{3} \sum_{j=1}^{n(i)} T_{i j} \alpha_{i j}\right) / \Delta t
$$

where $n$ is the number of instruments on the $i^{\text {th }}$ mooring, with $n(1)=7, n(2)=12$, and $n(3)=10 . \alpha_{i j}$ represents the weight given to each measurement, equal to the area of the region each instrument represents. The area of influence of each instrument extended to the horizontal and vertical midpoints of the distance to the next adjacent instrument. The top and bottom instruments were extrapolated to 
the surface and bottom, respectively. The sum of the weights is equal to the total cross-sectional area of the region inshore of $\mathrm{d} 3 . \Delta t$ is the time interval between measurements, in this case $3600 \mathrm{~s}$. In October, the mooring at the d1 site was not present for most of the time series, and the $\mathrm{d} 2$ data was accordingly weighted to compensate. As the near shore cross-shore temperature gradients during October were observed to be small from other data sources (such as the CTD surveys), this should make very little difference.

Error in the storage term is due primarily to low spatial resolution of the temperature measurements. This may be significant when there are strong horizontal density gradients, such as during upwelling and downwelling events.

\subsubsection{The Cross-Shore Heat Flux}

The cross-shore flux at $\mathrm{d} 3$ is approximated using:

$$
C H F \approx-\sum_{j=1}^{6}\left(\widetilde{u}_{3 j}\right)\left(\widetilde{T}_{3 j}\right) \beta_{j},
$$

where the $\beta_{j}$ represent vertical weightings. This term represents the exchange of heat across the offshore boundary at $x=L$, in this case $16.4 \mathrm{~km}$ offshore at the $\mathrm{d} 3$ site. For a given cross-shelf velocity profile, this term is smaller when the vertical

temperature gradient is weak, as $\widetilde{T}_{3 j} \approx 0$. Essentially, if there is no vertical temperature gradient, water moving onshore and water moving offshore have the same heat content and no net heat transport occurs.

Error in computing the cross-shore heat flux has two primary sources: not prop- 
erly choosing the cross-shore direction and the finite vertical resolution of the velocity and the temperature. The extrapolation of the top VMCM velocity to the surface is another potential source of error, but a comparison of the VMCM data with OSCR data [Shay et al., 1996] suggests that the surface shear is not large, and hence the extrapolation made here is not a large source of error. Temperature data taken closer to the surface suggested that the extrapolation of temperature data to the surface is a reasonable approximation.

\subsubsection{The Surface Heat Flux}

The surface heat flux was approximated using:

$$
S H F=Q \times L
$$

where $\mathrm{Q}$ is the estimated total surface heat flux measured at $\mathrm{d} 2$, and $\mathrm{L}$ is the width of the shelf. $\mathrm{d} 2$ is the only location where reliable surface heat flux measurements were made (see Chapter 2).

There are two sources of error in determining the surface heat input to the region. First, reliable meteorological measurements were made at only one site ( $\mathrm{d} 2$ ) and it is known that meteorological fields varied considerably across the shelf (as discussed in Chapter 2). However, d2 was in the center of the domain, and cross-shore variations in the estimated surface heat flux occurred only during upwelling favorable winds in August. In the absence of reliable measurement of the surface heat fiux at different cross-shelf locations, the other source of error is due to the fact that the estimates of surface heat flux at d2 contain error (see chapter 2 for a more thorough discussion of error associated with determining $Q$ ). 


\subsubsection{The Alongshore Heat Flux}

The alongshore heat flux was approximated using

$$
A H F=-\frac{1}{\Delta y} \sum_{i=1}^{m} \sum_{j=1}^{n(i)} \Delta T_{i j} v_{i j} \gamma_{i j} .
$$

The alongshore heat flux was the poorest resolved of the components of the heat flux, due to the poor alongshore resolution of temperature, which was measured only on the $6-\mathrm{m}$ and $20-\mathrm{m}$ isobath. The difference in temperature between $\mathrm{j} 3$ and $\mathrm{j} 1$ was used to estimate the temperature gradient at d1. The difference between the surface temperature at NSC and SSC was used for the top half of the water column at $\mathrm{d} 2$ and $\mathrm{d} 3$, and the difference between the bottom of NSC and SSC was used for the bottom half of the water column at d2 and $\mathrm{d} 3$. Along the 6 - $\mathrm{m}$ isobath, $\Delta y=34 \mathrm{~km}$, and along the $20-\mathrm{m}$ isobath, $\Delta y=58 \mathrm{~km}$. This term represents the advection of alongshore temperature gradients. The other component of the alongshore heat flux, the flux divergence term $\left(\int T \frac{\partial v}{\partial y} d A\right)$ is ignored in this formulation.

Inaccuracy in the alongshore heat flux is due primarily to poor resolution of the alongshore gradient. In addition to the fact that the differences were made over a long alongshore distance $(60 \mathrm{~km})$, there were only 3 alongshore temperature gradient measurements used. Finally, the term representing alongshore heat flux due to alongshore mass divergence could not be estimated, further degrading the measurement. 


\section{Chapter 4}

\section{The Dynamics of Upwelling on a Shallow, Stratified Shelf}

\subsection{Introduction}

Much of the emphasis on wind-driven upwelling circulation in the past has been on the circulation around and offshore of the upwelling front, where an upwelled pycnocline intersects the sea surface. However, a significant portion of the shelf may be onshore of this location, and it is in this region, the inner shelf, where the surface Ekman transport must adjust to the coastal boundary condition. This region is the location of the "closure" of the cross-shelf circulation, where the surface and bottom boundary layers interact directly through the stress field, and where water parcels leave the bottom boundary layer and feed the surface layer. To address this problem, a numerical model with a constant-sloped bottom and initial stratification characterized by a surface mixed layer and a pycnocline overlying a mixed lower layer is forced with constant alongshelf wind stress. 
Previous studies of upwelling circulation on the shelf have yielded insight into various aspects of the problem. Csanady [1971] explored the formation of upwelling fronts using a flat-bottomed, two-layered analytic model. He estimated displacement scales and showed that the front stays displaced offshore after a wind event, in geostrophic balance with an alongshelf jet. The model did not consider the role of mixing, which was shown to have a significant impact on the upwelling process by deSzoeke and Richman [1981], also using a two-layered model. They also explored what role surface buoyancy flux plays in determining the circulation, showing that it can establish different types of equilibria during upwelling that cannot be achieved without surface buoyancy fluxes. The circulation on an unstratified inner shelf was first considered by Ekman [1905] who appreciated the necessity for a region of transport divergence in the vicinity of a coastal boundary. Mitchum and Clarke [1986] explored the role of vertical stress divergence in determining horizontal transport divergence on the inner shelf, in a model with constant eddy viscosity. They concluded that the cross-shelf circulation in water of less than three Ekman depths was weak and did not significantly affect the circulation offshore. This is an important result for coastal trapped wave theory, as it provides a useful coastal boundary condition. Lentz [1995] considered the role of the vertical structure of the eddy viscosity profile on the cross-shelf transport divergence, and determined that it played a quantitative, but not a qualitative role in the transport divergence. With the addition of more advanced turbulence closure schemes, numerical models such as Hamilton and Rattray [1978], Foo [1981], and Kundu [1984] all considered upwelling circulation on stratified shelves, but mainly concentrated on flat-bottomed models, or models with sloped bottoms and deep coastal boundaries. The most recent process study of two-dimensional coastal upwelling is due to Allen et al. [1995]. They concentrated 
on the long-time (over 20 days) response to steady upwelling favorable winds in a two dimensional model (the Princeton Ocean Model, Blumberg and Mellor [1987]), using an advanced turbulence closure submodel (Mellor-Yamada level 2.5, Mellor and Yamada [1982]). The parameter space they chose to explore was centered on a case representative of the Oregon coast, which is characterized by steep bathymetry and continuous stratification. The qualitative response of the inner shelf generated by their model is different from that described in this chapter. This difference is due to the use of continuous stratification in their model, as opposed to the strong pycnocline considered here. The specific distinctions between the parameter regimes and the underlying dynamical differences are discussed in this chapter.

There are several primary results of potential importance in this chapter. First of all, the formation of the inner shelf region under conditions similar to those observed during CoOP ISS (gently sloping bottom, strong, two-layered stratification, moderate wind stresses) develops in a novel fashion relative to previous upwelling studies. The pycnocline initially shoals offshore, trapping a region of light water near the coast. The light water is held in place by an advective-diffusive density balance. The cross-shelf circulation is similar to that modeled in the neutral (unstratified) case, but stronger in magnitude due to the presence of density gradients. For a region of light water to be trapped near the shore, the coastal wall must be placed in sufficiently shallow water. Uniformly stratified water displays a qualitative difference in circulation from the strong pycnocline case. In this case, the continual introduction of denser water onto the lower half of the inner shelf keeps the inner shelf strongly vertically stratified, supporting cross-shelf circulation far in excess of what is modeled in the strong pycnocline case. In addition, the character of the inner-shelf response in the uniform stratification case depends on the value 
of the slope Burger number. This is a consequence of the formation of "slippery" Ekman layers, as discussed by Trowbridge and Lentz [1991] and MacCready and Rhines [1993]. The novel cross-shelf circulation may have potentially important implications for cross-shelf transport and exchange processes.

There are limitations to this simplified approach, as several potentially important forcing mechanisms have been ignored. First, the response may be sensitive to the mixing scheme used. The feedback between the dynamical fields and the mixing fields is of central importance, and without running the model with other mixing schemes, it is not clear what part of the response, especially that on the inner shelf, is dependent on the use of the particular mixing scheme. There are also many potential forcing mechanisms in the real world which are left out to make the model results simple enough to interpret. Tidal currents can significantly increase the effective bottom drag. Diabatic processes (surface heat fluxes), have been shown to be potentially important in maintaining upwelling circulation and allowing steady states of the system [deSzoeke and Richman 1984]. Only one dynamically significant tracer was used, ignoring the distinct effects of salinity and temperature (e.g. [Blanton, et al. 1989b]). Freshwater runoff is a potentially important source of forcing, especially in regions such as the North Carolina Inner Shelf, where plume water from the Chesapeake estuary was a large source of variation during the CoOP Inner Shelf Study [Rennie 1997]. Alongshelf pressure gradients (Zamudio and Lopez [1994], Lentz [1995], Lentz et al. [1998]) can significantly modify the crossshelf circulation. Finally, baroclinic instability cannot develop in a two-dimensional model, but could have a significant impact on the alongshelf mean response [Barth 1989, 1994]. Regardless of these limitations, it is important to develop a strong and dynamically-based "intuition" of the expected response due to the wind stress alone 
before moving on to more complex, realistic models of the inner shelf circulation.

The chapter proceeds as follows. Section 4.2 is a description of the model used and of the domain, initial stratification, and forcing. Section 4.3 consists of a description of the temporal development of the upwelling system and a discussion of some of the novel features of the circulation. This circulation divides the shelf into dynamically distinct regions, which are considered in turn. The criterion for the trapping of light water near the coast is also discussed. In section 4.4, the distinction between the strong pycnocline and uniformly stratified case is discussed, as well as the Burger number criterion which determines the character of the inner shelf in this case. In section 4.5 , observations of inner shelf regions are discussed, and the potential impact of upwelling circulation on passive tracers is considered.

\subsection{The Numerical Model}

The use of a numerical model allows the investigation of idealized two-dimensional stratified coastal circulation under a wide range of conditions. In this section, the model and the bathymetry, initial stratification, and forcing used in the model are discussed. As this is a process study, the goal of this work is not to simulate a particular region or event, but to understand the basic dynamics that control the upwelling response. By utilizing simple bathymetry, forcing, and stratification, insight gained can then be applied to more complex and realistic systems. The section proceeds as follows: first, a description of the numerical model, followed by a description of the physical parameters used in the model, and the numerical values of these parameters used in a "base case" run of the model, which is the focus of section 4.3 . 


\subsubsection{Description of the Model}

The Princeton Ocean Model (hereafter POM) [Blumberg and Mellor, 1987] is a hydrostatic, free-surface, numerical model written for the study of coastal circulation, and has been used by many investigators in the past. In this study, the model is run in a two-dimensional channel configuration eliminating alongshelf variability, leaving variation in only the vertical and cross-shelf directions. Mixing is provided by the Mellor-Yamada level 2.5 turbulence submodel [Mellor and Yamada 1982], with a modification concerning the limitation of the mixing length scale as described by Galperin et al. [1988]. In addition, there is a background vertical eddy viscosity and diffusivity of $\nu=2 \times 10^{-5} \mathrm{~m}^{2} \mathrm{~s}^{-1}$, and a constant horizontal kinematic viscosity and diffusivity of $A_{M}=A_{H}=2 \mathrm{~m}^{2} \mathrm{~s}^{-1}$.

\section{The field equations}

The cross-shelf and along-shelf momentum equations are:

$$
\frac{\partial u}{\partial t}+u \frac{\partial u}{\partial x}+w \frac{\partial u}{\partial z}-f v=-\frac{1}{\rho_{0}} \frac{\partial p}{\partial x}+\frac{\partial}{\partial z}\left(K_{M} \frac{\partial u}{\partial z}\right)+\frac{\partial}{\partial x}\left(A_{M} \frac{\partial u}{\partial x}\right)
$$

and

$$
\frac{\partial v}{\partial t}+u \frac{\partial v}{\partial x}+w \frac{\partial v}{\partial z}+f u=\frac{\partial}{\partial z}\left(K_{M} \frac{\partial v}{\partial z}\right)+\frac{\partial}{\partial x}\left(A_{M} \frac{\partial v}{\partial x}\right) .
$$

where $x, y$, and $z$ are coordinates in a right-handed coordinate system, with $x$ positive offshore, $y$ positive alongshelf, and $z$ positive upward. $K_{M}$ is the vertical eddy viscosity determined by the turbulence closure scheme. In all of the model runs, 
$f=10^{-4} \mathrm{~s}^{-1}, g=9.80 \mathrm{~ms}^{-2}$, and $\rho_{0}=1020 \mathrm{~kg} \mathrm{~m}^{-3}$.

The equation of conservation of density $\rho$ is

$$
\frac{\partial \rho}{\partial t}+u \frac{\partial \rho}{\partial x}+w \frac{\partial \rho}{\partial z}=\frac{\partial}{\partial z}\left(K_{H} \frac{\partial \rho}{\partial z}\right)+\frac{\partial}{\partial x}\left(A_{H} \frac{\partial \rho}{\partial x}\right)
$$

where $K_{H}$ is the vertical eddy diffusivity determined by the turbulence closure scheme. Although technically density is not a conserved quantity, a linear equation of state is used so that density is linearly proportional to salinity or temperature, which are conserved.

The water is assumed to be incompressible, so

$$
\frac{\partial u}{\partial x}+\frac{\partial w}{\partial z}=0
$$

\section{Boundary conditions}

The surface stress is set by

$$
\left.K_{M} \frac{\partial(u, v)}{\partial z}\right|_{z=0}=\left(\tau^{x}, \tau^{y}\right)^{S} / \rho_{0}
$$

where $\tau^{x}$ and $\tau^{y}$ are the surface cross-shelf and alongshelf wind stress components, respectively. There is no buoyancy flux through the surface.

The bottom boundary condition for momentum is a quadratic drag law: 


$$
\left.K_{M} \frac{\partial(u, v)}{\partial z}\right|_{z=-H}=\rho_{0} C_{D}\left(u_{b}^{2}+v_{b}^{2}\right)^{1 / 2}\left(u_{b}, v_{b}\right)
$$

where $\left(u_{b}, v_{b}\right)$ represents the velocity in the bottom grid cell. $C_{D}$ is a drag coefficient determined by:

$$
C_{D}=\kappa^{2}\left(\ln \frac{\Delta z_{b}}{z_{R}}\right)^{-2}
$$

where $\kappa=0.4$ is von Kármán's constant, $\Delta z_{b}$ is half the vertical grid spacing at the bottom, and $z_{R}=10^{-2} \mathrm{~m}$ is the bottom roughness scale. Due to variation in the

grid spacing as a function of depth, the numerical value of $C_{D}$ varies in the base case from approximately $4.8 \times 10^{-2}$ in $5 \mathrm{~m}$ of water to $6.9 \times 10^{-3}$ in $55 \mathrm{~m}$ of water. There is no buoyancy flux through the bottom.

At the coastal wall, the velocity boundary condition is free-slip, and there is no volume or buoyancy flux.

\section{Spatial and temporal grids}

POM is a sigma-level model, meaning the vertical grid resolution is proportional to the water depth. In the base-case, the depth varied from $5 \mathrm{~m}$ to $55 \mathrm{~m}$ (in a steep-slope run, the maximum depth was $155 \mathrm{~m}$ ). With 40 sigma levels, the vertical resolution varied from approximately $0.13 \mathrm{~m}$ in shallow water to $1.4 \mathrm{~m}$ in the deepest portion of the domain ( $4.1 \mathrm{~m}$ in the steep-slope case). The vertical spacing near the surface and bottom is slightly smaller to resolve the boundary layers, although this 
is not an issue in this particular study, due to the shallowness of the water.

The horizontal grid size was varied in proportion to the square root of the local depth, maintaining numerical stability while providing high resolution in shallower water. The horizontal resolution varied from approximately $150 \mathrm{~m}$ in the shallowest portion of the domain to approximately $450 \mathrm{~m}$ in the deepest part of the domain. The model utilizes a split time step, with an external time step $\left(\Delta t_{E}=10 \mathrm{~s}\right)$ to resolve the barotropic mode and an internal time step $\left(\Delta t_{I}=300 \mathrm{~s}\right)$ to resolve the baroclinic portion of the solution. Halving the time steps and halving both the time steps and the spatial grid made no qualitative or significant quantitative change in response.

\subsubsection{Configuration of the Base-Case Model}

There are three basic physical components which uniquely define the two dimensional model runs: the bathymetry, the initial stratification, and the wind forcing (the model runs are always started at rest so the initial velocity field is zero). Very simple forms of these three components are used so that they can be described with as few parameters as possible, thereby simplifying the analysis. Values of these parameters used in a "base case" are discussed in detail in the next section, motivated by the observations made during the CoOP Inner Shelf Study. The dependence of the qualitative and quantitative response of the model on the forcing, stratification, and bathymetry are considered using other model runs in which one or more of these parameters is varied. 


\section{Bathymetry}

The model domain is a symmetric channel with bathymetry $H(x)$ given by

$$
H(x)= \begin{cases}H_{0}+\alpha x & x<L \\ H_{0}+\alpha L & L<x<2 L \\ H_{0}+\alpha(3 L-x) & 2 L<x<3 L\end{cases}
$$

The variable parameters in this case are $H_{0}$, the depth of the coastal boundary; $\alpha$, the bottom slope; and $L$, the width of the sloped portion of the shelf. In all of the cases, $L=50 \mathrm{~km}$. Test runs were performed (not presented here) which showed that doubling $L$ did not qualitatively affect the response over the sloped shelf, suggesting that the domain was sufficiently large to avoid offshore boundary effects. In the base case, $H_{0}=5 \mathrm{~m}$ and $\alpha=10^{-3}$ (Figure 4.1). An advantage of the symmetric configuration is that the downwelling and upwelling cases are solved simultaneously. The slope is approximately consistent with the bathymetry observed off the North Carolina Inner Shelf (Chapter 3, Figure 3.6), where the cross-shelf bottom slope was on the order of $\left(\frac{1}{2}-1\right) \times 10^{-3}$ over most of the shelf, with significant variation on shorter spatial scales.

\section{Stratification}

The initial stratification consists of well mixed surface and bottom layers and a continuously stratified region in between. The initial density as a function of depth is: 


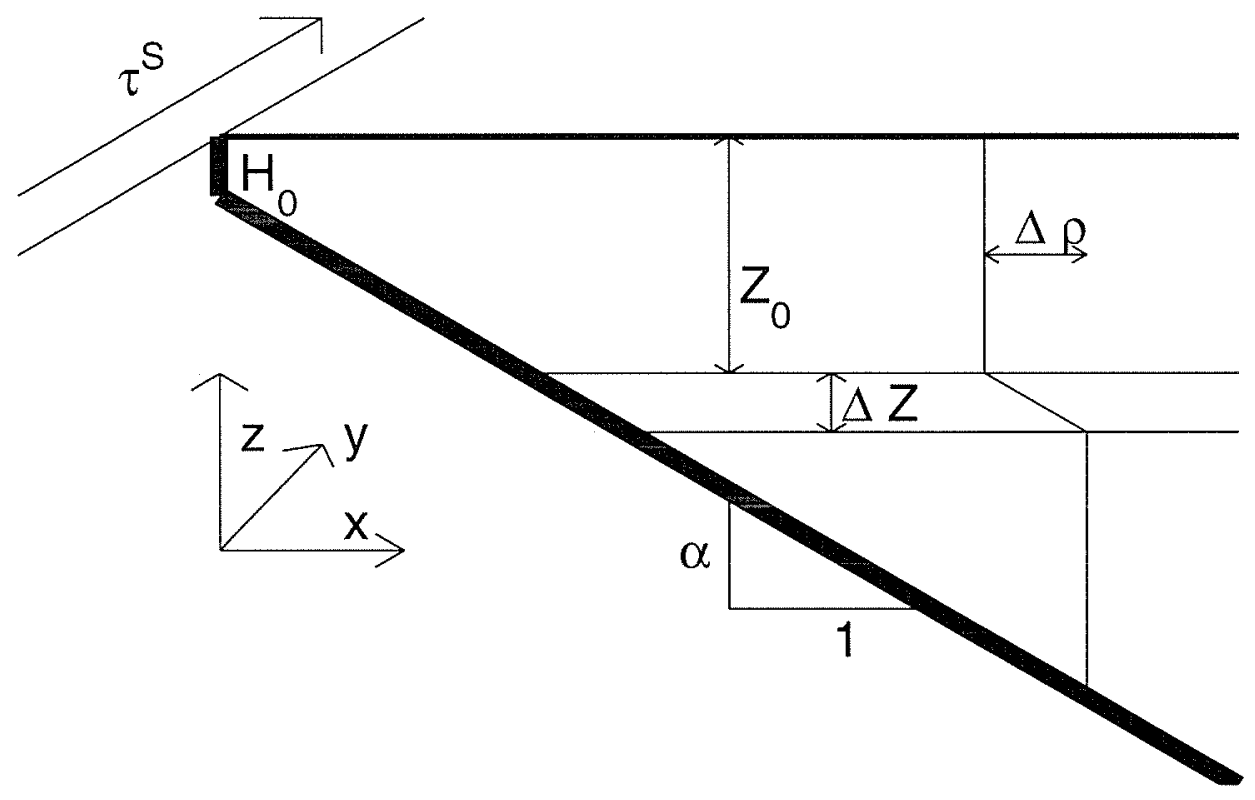

Figure 4.1: The idealized model geometry and initial stratification. The following parameters are defined: $H_{0}$, the coastal wall depth; $\alpha$, the bottom slope; $\Delta \rho$, the initial density difference across the pycnocline; $\Delta Z$, the initial pycnocline thickness; $Z_{0}$, the initial surface layer thickness; and $\tau^{S}$, the alongshelf wind stress magnitude.

$$
\rho(z)= \begin{cases}\rho_{0} & z>-Z_{0} \\ \rho_{0}+\Delta \rho \frac{\left(-Z_{0}-z\right)}{\Delta Z} & -Z_{0}<z<-Z_{0}-\Delta Z \\ \rho_{0}+\Delta \rho & -Z_{0}-\Delta Z>z .\end{cases}
$$

The variable parameters which determine the stratification are $Z_{0}$, the initial thickness of the surface mixed layer; $\Delta \rho$, the density change across the pycnocline; and $\Delta Z$, the thickness of the pycnocline. The stratification observed during the August period of the CoOP Inner Shelf Study was primarily characterized by a strong 


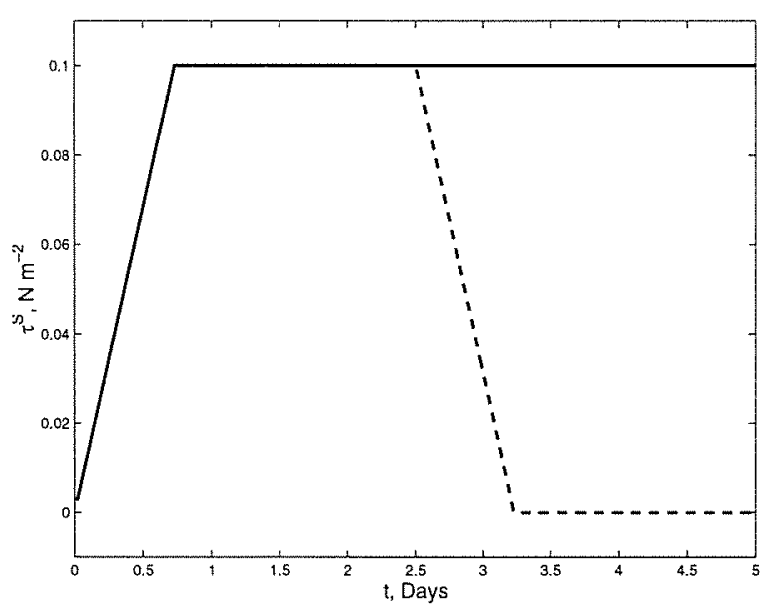

Figure 4.2: The time series of $\tau^{S F C}$ in the constant-stress case (solid line) and the episodic wind case (dashed line).

pycnocline centered at approximately $10 \mathrm{~m}$ depth (Chapter 3 , figure 3.6), so the parameters in the base case were: $Z_{0}=8 \mathrm{~m}, \Delta Z=4 \mathrm{~m}$, and $\Delta \rho=2 \mathrm{~kg} \mathrm{~m}^{-3}$ (Figure 4.1).

\section{Forcing}

Surface forcing consisted of alongshelf wind stress $\tau^{S F C}$, uniform in the cross-shelf direction, ramped up over an inertial period, and left on for the duration of the model run (Figure 4.2).

$$
\tau^{S F C}(t)= \begin{cases}\tau^{S} \frac{f t}{2 \pi} & t<\frac{2 \pi}{f} \\ \tau^{S} & t>\frac{2 \pi}{f}\end{cases}
$$

The ramp-up length was chosen to quell inertial energy. In the base case, $\tau^{S}=$ $0.1 \mathrm{Nm}^{-2}$, equivalent to a wind of about $8 \mathrm{~m} \mathrm{~s}^{-1}$ at $10 \mathrm{~m} \mathrm{[Fairall} \mathrm{et} \mathrm{al.} \mathrm{1996].} \mathrm{The}$ behavior of the circulation after the cessation of wind is an interesting topic as 
well, so the scenario in which the wind is turned off after 2.5 days is also discussed. The response of the model is observed for several days after the cessation of the wind in order to understand the relaxation response. This scenario, although more complicated, is interesting due to the similarity to the forcing observed during the CoOP Inner Shelf Study.

\section{Parameter space}

Several of the quantitative features of the upwelling response scale with the model parameters discussed here. In order to verify scalings, a large set of model runs have been performed in which one of the model parameters has been varied. These model runs also serve to determine the parameter range within which the shelf displays the same qualitative response. Table 4.1 lists the other runs, which are referred to in this and the next chapter. The description refers to the parameter that has been

changed; all others are kept the same. A neutral run is also included, in which there is no initial density difference, to use for comparison to the stratified case. 
Table 4.1: Description of parameter space model runs.

\begin{tabular}{ll}
\hline Abbreviation & Description \\
\hline \hline $\mathrm{BC}$ & Base Case \\
$\frac{1}{2} \tau^{S}$ & $\tau^{S}=0.05 \mathrm{~N} \mathrm{~m}^{-2}$ \\
$\frac{1}{4} \tau^{S}$ & $\tau^{S}=0.025 \mathrm{~N} \mathrm{~m}^{-2}$ \\
$2 \tau^{S}$ & $\tau^{S}=0.2 \mathrm{~N} \mathrm{~m}^{-2}$ \\
$4 \tau^{S}$ & $\tau^{S}=0.4 \mathrm{~N} \mathrm{~m}^{-2} \quad a$ \\
$\frac{1}{2} \alpha$ & $\alpha=0.0005$ \\
$2 \alpha$ & $\alpha=0.002$ \\
$3 \alpha$ & $\alpha=0.003$ \\
$\frac{1}{2} H_{0}$ & $H_{0}=2.5 \mathrm{~m}$ \\
$2 H_{0}$ & $H_{0}=10 \mathrm{~m}$ \\
$3 H_{0}$ & $H_{0}=15 \mathrm{~m}$ \\
$4 H_{0}$ & $H_{0}=20 \mathrm{~m}$ \\
$\frac{1}{2} Z_{0}$ & $Z_{0}=4 \mathrm{~m}$ \\
$2 Z_{0}$ & $Z_{0}=16 \mathrm{~m}$ \\
$\mathrm{NEUT}$ & $\Delta \rho=0$ \\
$\frac{1}{2} \Delta \rho$ & $\Delta \rho=2 \mathrm{~kg} \mathrm{~m}^{-3}$ \\
$2 \Delta \rho$ & $\Delta \rho=8 \mathrm{~kg} \mathrm{~m}{ }^{-3}$ \\
$\frac{1}{2} \Delta Z$ & $\Delta Z=2 \mathrm{~m}$ \\
$2 \Delta Z$ & $\Delta Z=8 \mathrm{~m}$ \\
$\frac{\mathrm{a}}{\mathrm{a}}=100 \mathrm{~km}$. &
\end{tabular}

\subsection{The Base Case}

This section consists of a non-dynamical description of the circulation and stratification modeled during the base case run, to familiarize the reader with the basic features of the flow, followed by a region-by-region dynamical interpretation, utilizing the terms of the momentum balance to better understand the overall response. 

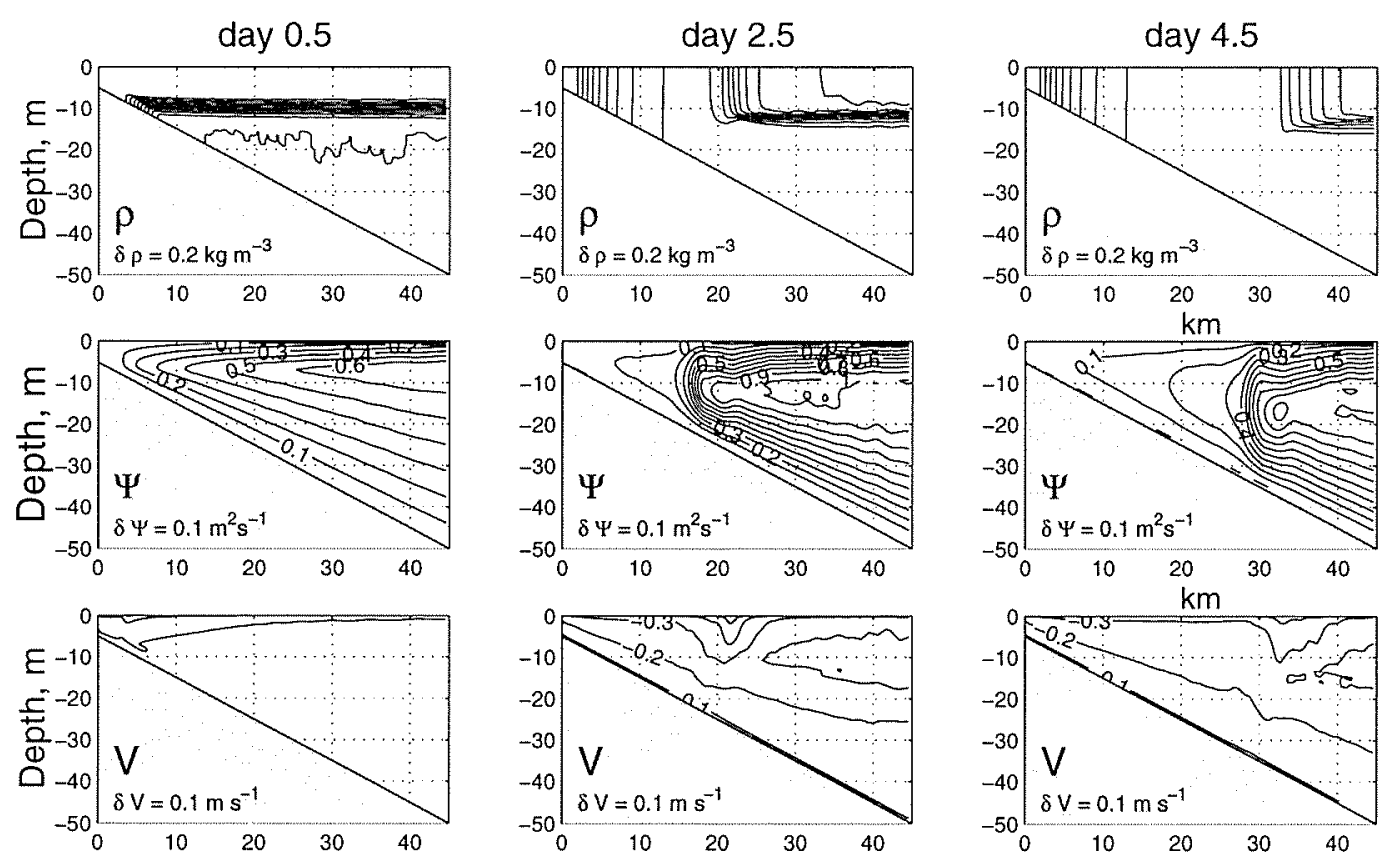

$\vec{\infty}$
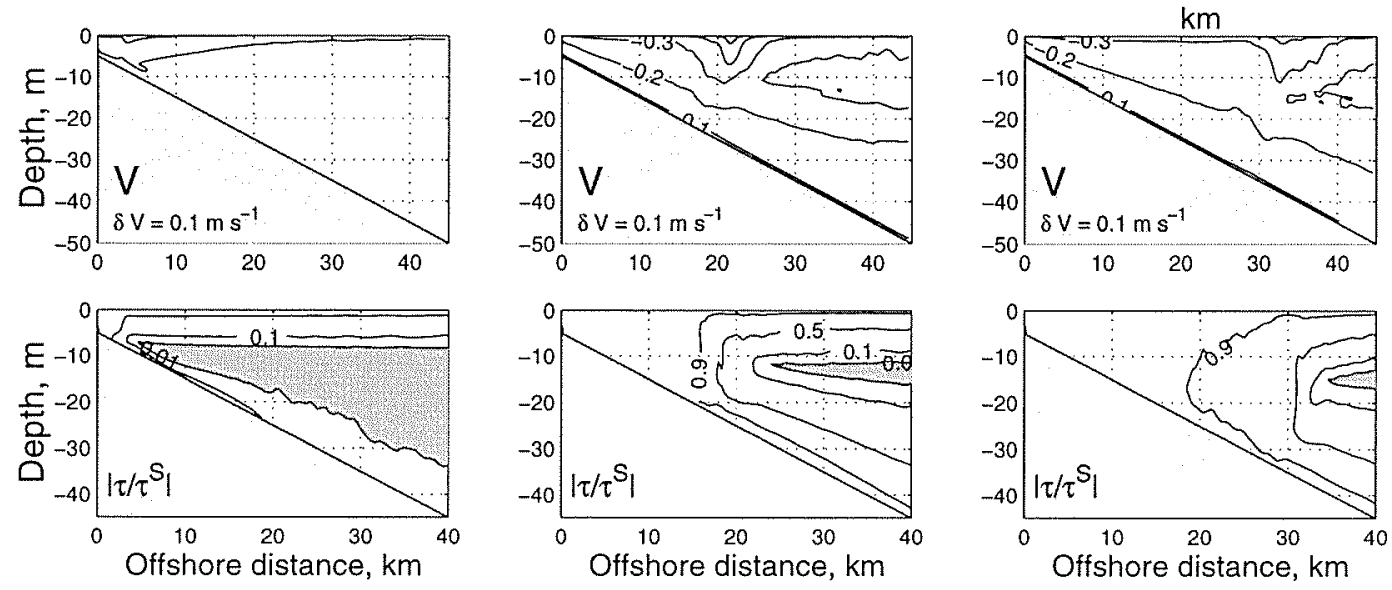

Figure 4.3: The density field, cross-shelf streamfunction, alongshelf velocities and stress magnitude at $0.5,2.5$ and 4.5 days. The stress contours represent $0.01,0.1,0.5$, and 0.9 of the surface stress. The region with stress magnitude less than $0.01\left|\tau^{S}\right|$ is shaded. 


\subsubsection{Basic Description}

The development of the circulation and density field in the base case (Figure 4.3) is to first order what is expected during an upwelling-favorable wind event: cross-shelf circulation upwells the pycnocline and moves it offshore, accompanied by alongshelf flow in the direction of the wind. However, there are some aspects of the upwelling circulation that are unfamiliar, and this section is intended to summarize the major features of the development and spatial distribution of the circulation.

After half a day there is strong cross-shelf circulation (represented with a crossshelf streamfunction $\Psi$, where $\Psi_{x}=w,-\Psi_{z}=u$ ) consisting of offshore flow in the upper $5 \mathrm{~m}$, with surface velocities approaching $0.2 \mathrm{~m} \mathrm{~s}^{-1}$, and a vertically uniform return flow throughout the rest of the water column, with typical velocities on the order of $0.01-0.02 \mathrm{~m} \mathrm{~s}^{-1}$. Over the next few days, the surface transport continues to develop and the return transport becomes concentrated near the bottom. The maximum value of the streamfunction as a function of cross-shelf position (Figure 4.4, similar to Allen et al [1995], Figure 9) demonstrates the temporal development of this circulation in a more compact fashion. (The maximum value of the crossshelf streamfunction at a given horizontal location, denoted $\|\Psi\|$, is equivalent to the maximum cross-shelf transport at that location.) At 0.5 days, more than half of the divergence in the cross-shelf transport occurs within the nearest $20 \mathrm{~km}$ to shore. The circulation is supported by strong vertical stratification which spans almost the entire shelf. The magnitude of the circulation has not yet reached $\frac{\tau^{s}}{\rho_{0} f}$ since the wind has just been turned on. As the front moves offshore, it leaves a weakly stratified region onshore. The cross-shelf circulation produces approximately uniform transport divergence in this region. Offshore of the upwelling front, the 


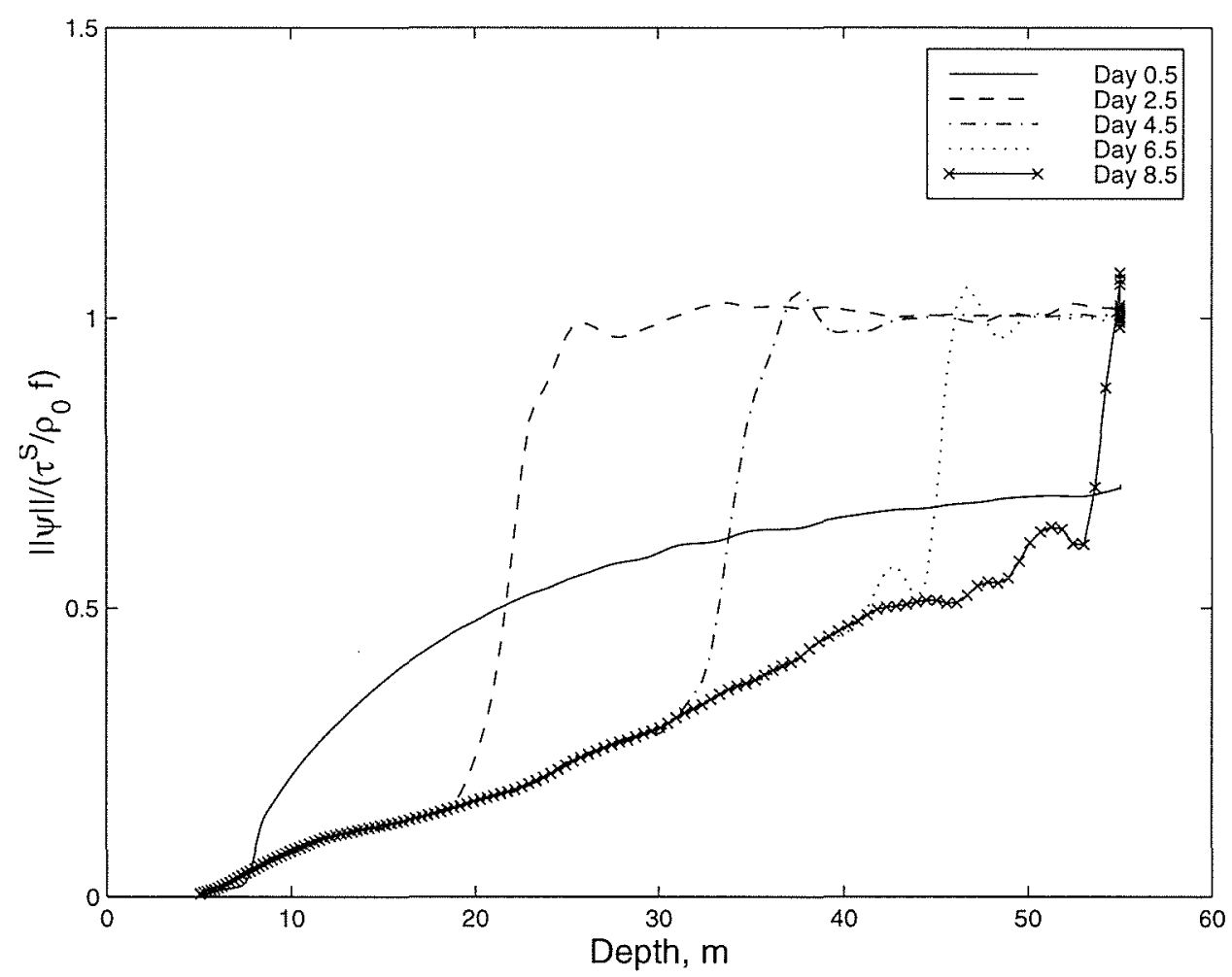

Figure 4.4: The maximum value of the streamfunction as a function of cross-shelf position, on days $0.5,2.5,4.5,6.5,8.5$.

transport is divergence free and with a value of approximately $\frac{\tau^{S}}{\rho_{0} f}$, and a region of strong transport divergence moves offshore with the front. The region of large transport divergence represents the transition from the region onshore of the front, which can support circulation slightly in excess of the neutral (unstratified) case (the reasons for this excess will be discussed) to offshore of the upwelling front, where the circulation is fully developed. As the front moves into deeper water, the circulation just onshore of the upwelling front is stronger and hence there is less divergence at the front.

The density field responds, to first order, as expected in the presence of upwelling 
favorable cross-shelf circulation; the pycnocline is brought to the surface and is advected offshore. By day 2.5 , it has been displaced approximately $20 \mathrm{~km}$ offshore (Figure 4.3). As the pycnocline shoals, some light water is pinched off next to the coast so that the maximum surface density is displaced offshore, and weak stratification persists inshore of the upwelling front. By day 4.5, this region has broadened as the upwelling front moves further offshore.

The development of the surface density as a function of time (Figure 4.5) gives a different perspective on the development of the density field. The pycnocline initially contacts the surface at some offshore position $X_{S}$ at some time $t_{S}$ (Figure 4.5), and the offshore movement of the cross-shelf surface density maximum is indicated with a heavy line, regarded as the location of the front. Inshore of this line, a crossshelf density gradient forms as isopycnals are initially advected towards shore. The isopycnals are pinched off, forming an inner shelf region with a horizontal density gradient. The front propagates offshore, and the isopycnals in the front slowly spread out. The front is initially approximately $5 \mathrm{~km}$ wide, but continues to widen, surpassing $10 \mathrm{~km}$ by day 4 . Offshore of the upwelling front, on the mid-shelf, the surface mixed layer entrains water from below the pycnocline, and slowly becomes denser.

The alongshelf velocity field, always in the direction of the wind, is initially uniform in the cross-shelf direction and concentrated in the upper $5 \mathrm{~m}$ (day 0.5 , Figure 4.3). As the upwelling front is advected offshore, expanding the inner shelf region, the alongshelf velocity is characterized by a strong jet in the vicinity of the upwelling front. Maximum velocities in this jet are approximately $0.5 \mathrm{~m} \mathrm{~s}^{-1}$. The shear associated with this jet is consistent in sign and magnitude with the horizontal density gradients associated with the upwelling front, through the thermal wind 


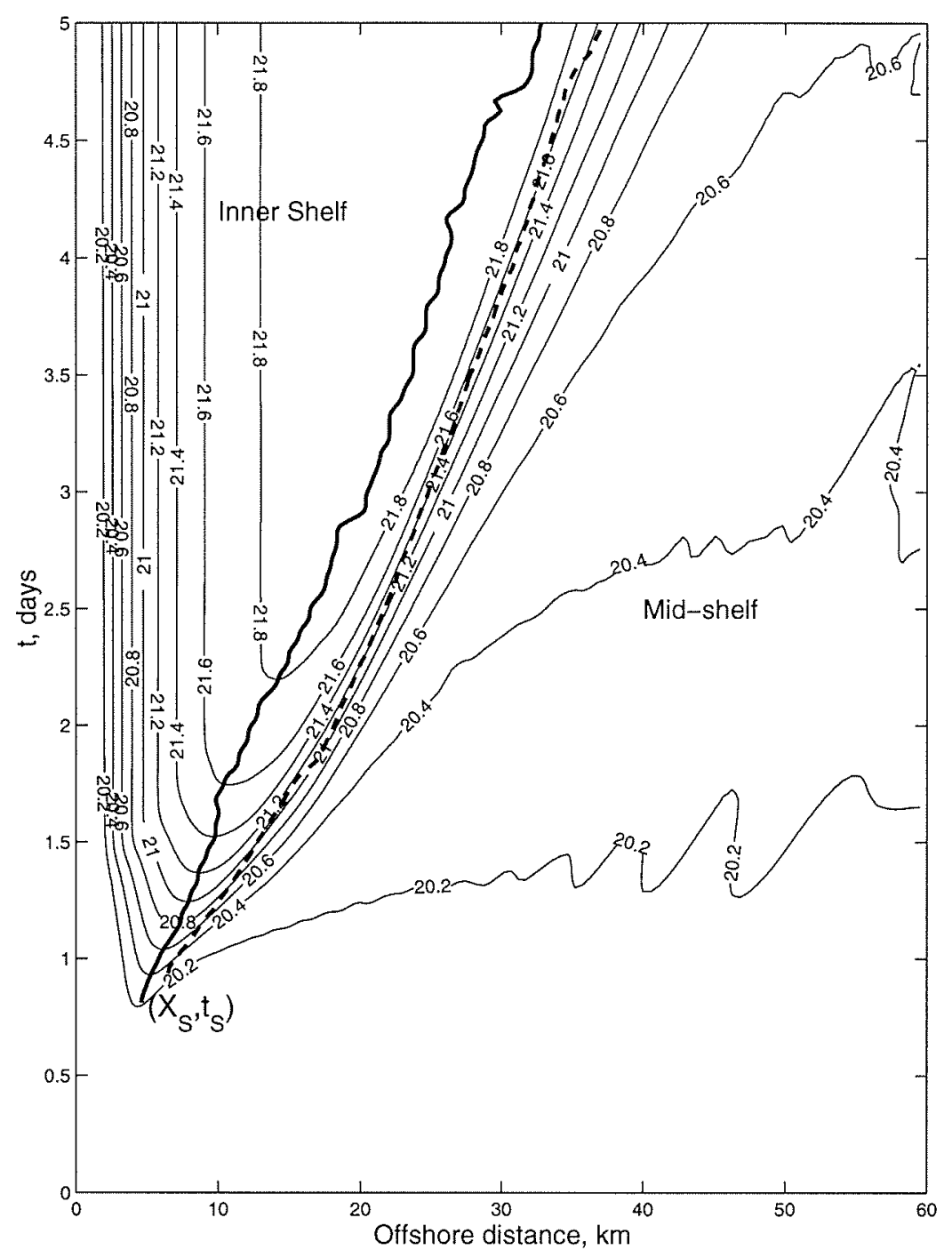

Figure 4.5: The surface density as a function of cross-shelf distance and time. $\left(X_{S}, t_{S}\right)$ is the location and time of the initial intersection of the pycnocline with the surface. The heavy line is the position of the surface density maximum. The dashed line is the location of the strongest surface density gradient. 
relationship. Away from the jet, much of the shear in the alongshelf velocity field is located near the surface and bottom of the water column.

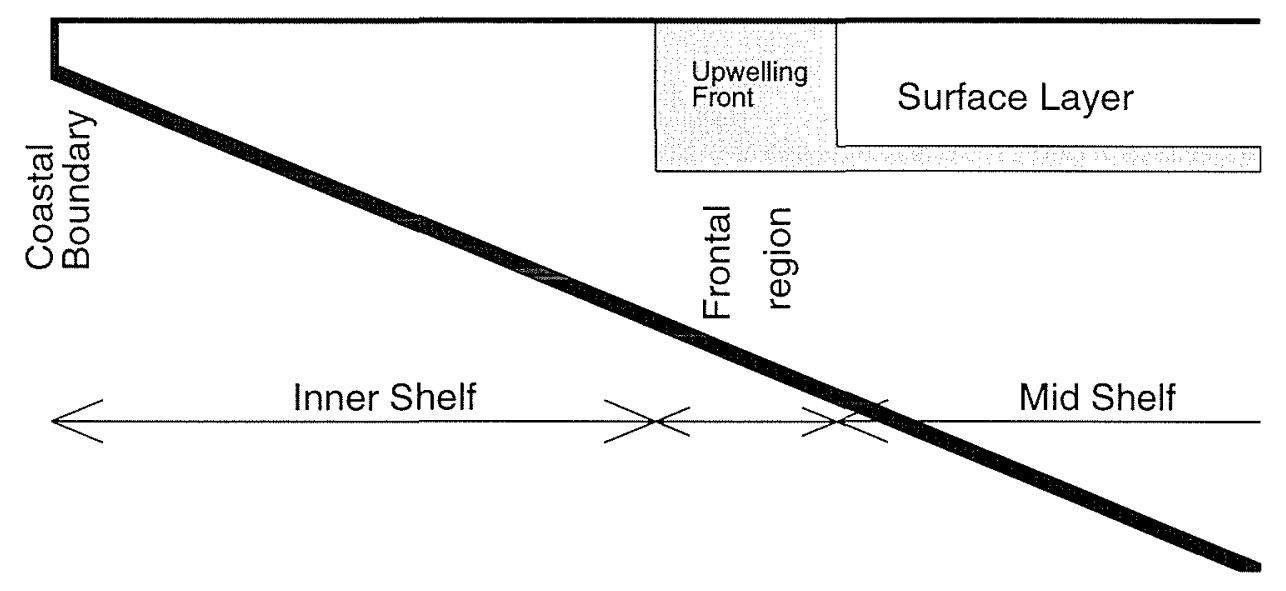

Figure 4.6: A schematic of the shelf during an upwelling event, defining some of the basic terms used. The shaded region represents the pycnocline and the upwelling front.

\subsubsection{Regional Dynamics}

The upwelling front divides the shelf into dynamically distinct regions (Figure 4.6), which provide a natural framework for approaching the dynamics of the shelf during upwelling. The main division is between the inner shelf and the mid-shelf, determined by the location of the upwelling front. The emphasis of this section is on the inner shelf, since its behavior during wind-forced events is poorly understood. The primary dynamical distinction between the inner and mid shelf is illustrated by the vertical distribution of stress magnitude, which is an indication of whether 
the surface and bottom Ekman layers are interacting through the stress field or not. The region of negligible stress magnitude (Figure 4.3, lower panels, shaded regions represent stress magnitude less than $1 \%$ of the applied surface stress) is clearly associated with the region of strong vertical stratification, suggesting that the strong vertical stratification acts to confine the stress, and hence the stress divergence, to the surface and bottom layers.

\subsubsection{The Inner Shelf}

The inner shelf is defined as the region inshore of the upwelling front. Unless the upwelling front is advected very far offshore (so that the front is in water so deep that the Ekman layers are separate even in the absence of strong vertical stratification), the region is characterized by the interaction of the surface and bottom boundary layers through the stress field (Figure 4.3). This interaction leads to cross-shelf

divergence in the Ekman transport, satisfying the Lentz [1995] definition of the inner shelf. To better understand the transport divergence and density structure of the inner shelf, a simple one-dimensional model is developed. This model and the assumptions made in its construction follow a short discussion of the spinup of this region.

The development of the inner shelf region takes place in several steps. First, a bottom boundary layer forms and dense water is advected onshore (Figure 4.7, 12-24 hours). As isopycnals approach the surface, mixing shoals the top isopycnal, pinching off light water near the shore. (Figure 4.7, 24 hours). This process continues, building up the horizontal density gradient inshore of the shoaling point (Figure 4.7, 24-36 hours). At this stage, even though there is significant cross-shelf circulation 

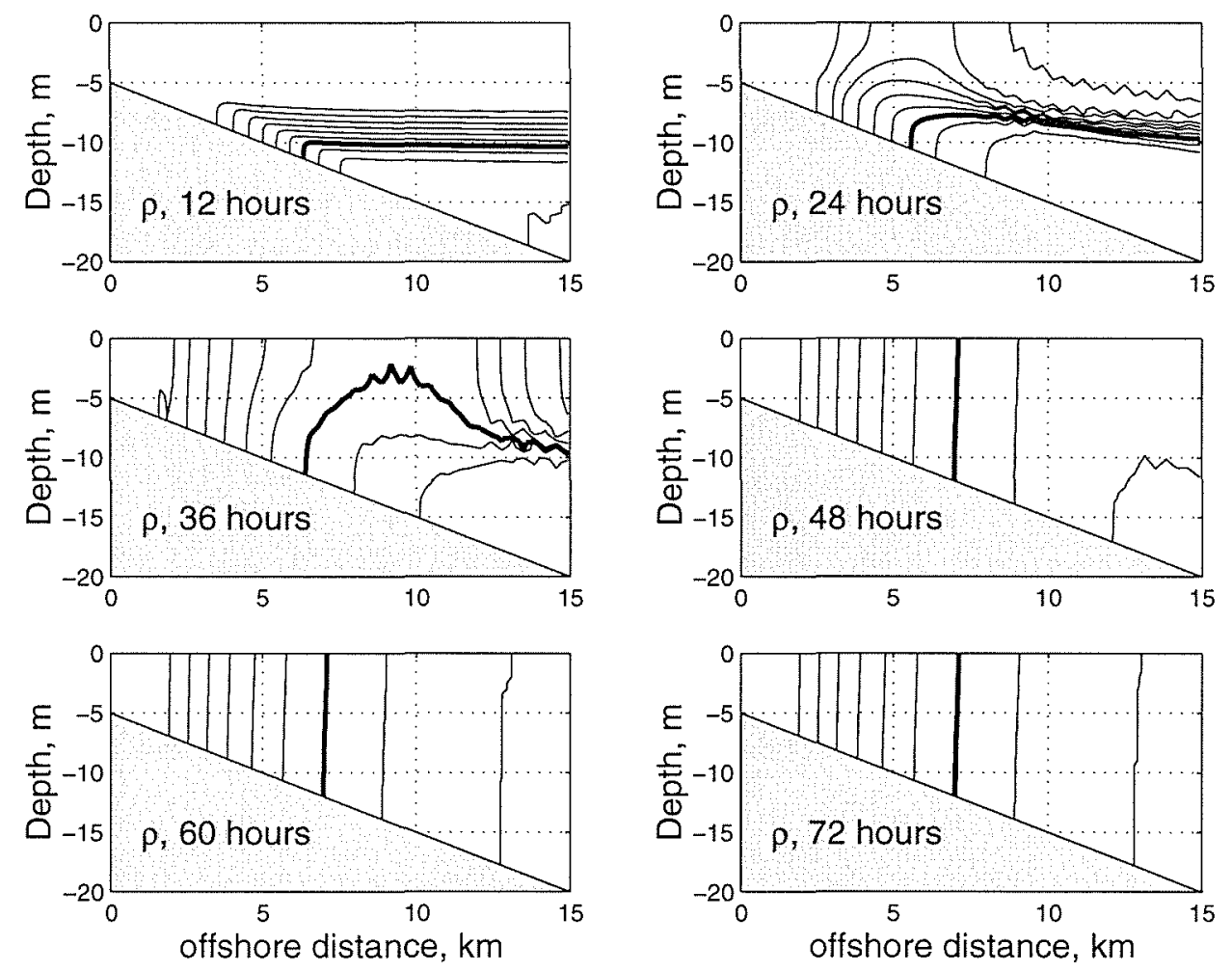

Figure 4.7: The density field at 12 hour intervals, showing the development of the inner shelf region. The heavy line is a fixed $\sigma_{\theta}$ contour, made distinct so that it can be followed. 
in this region, the isopycnals remain fixed in place, since the density balance at this stage is purely between the horizontal advection and vertical mixing (Figure 4.7, 48-72 hours). The isopycnals appear nearly vertical due to the aspect ratio of the plots. The isopycnals are actually sloped on the order of $10^{\circ}$ from the horizontal. Once they have reached this configuration, the isopycnals stay in place, since the time rate of change of density at a given location is small compared to the advective and diffusive terms.

The dominant terms of the momentum and density balances in this region (Figure 4.8) suggest relatively simple dynamics. The momentum balance is between the stress divergence term and the Coriolis term, plus a surface pressure gradient. The density balance is between horizontal advection and vertical diffusion. To a good approximation, the momentum and density balance equations on the inner shelf are:

$$
\begin{gathered}
-f v=-\rho^{-1} p_{x}+\left(K_{M} u_{z}\right)_{z} \\
f u=\left(K_{M} v_{z}\right)_{z} \\
u \rho_{x}=\left(K_{H} \rho_{z}\right)_{z},
\end{gathered}
$$

The alongshelf momentum balance represents the interaction of surface and bottom boundary Ekman layers, in which the stress magnitude never becomes small relative to the surface stress magnitude. The cross-shelf balance is the same except for the inclusion of a cross-shelf pressure gradient, mostly barotropic, which drives the 

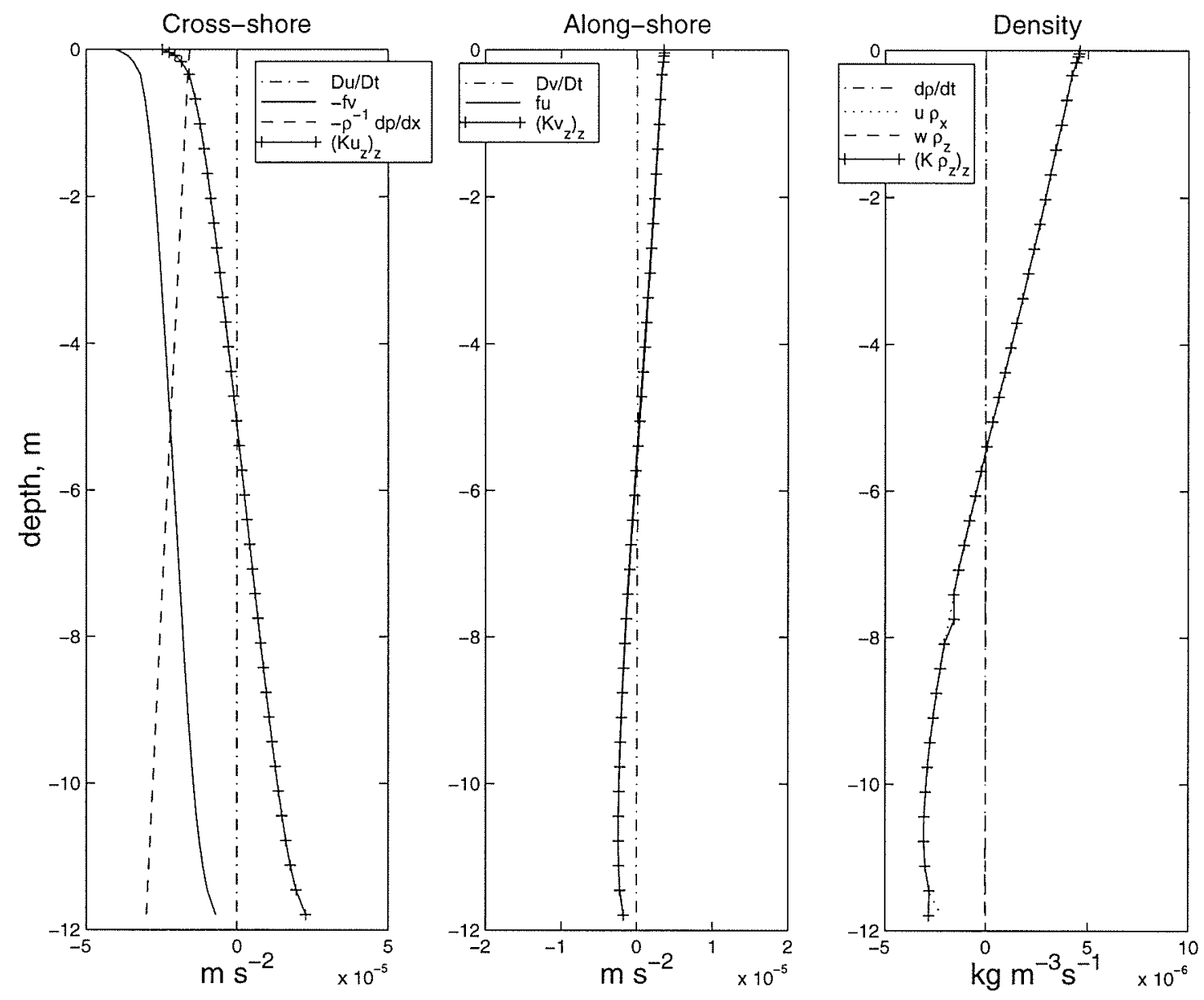

Figure 4.8: Momentum and density balances on the inner shelf ( $5 \mathrm{~km}$ offshore, 4.5 days). In these balances and the ones to follow, the horizontal diffusion term is not displayed as it is almost uniformly small. 
bottom Ekman layer. This system of equations, when combined with the boundary conditions $(4.5,4.6)$ implies that the cross-shelf circulation is a function of the local depth, surface stress, and $K_{M}$ alone. In the rest of this section, $K_{M}$ is shown to be a function of the surface forcing, so that the local cross-shelf circulation is a function of only the local water depth and the surface forcing.

A model eddy viscosity $K$ can be written as a function of local parameters, such as the surface forcing and water depth. (The Prandtl number in the model is between 0.75 and 1 , and for the sake of the simple models here will be assumed to be 1 , so that $K_{H}=K_{M}$.) The eddy viscosity profiles in this region are roughly parabolic (Figure 4.9A,B). The vertical gradient in eddy viscosity at the boundaries conforms to the logarithmic layer scaling for an unstratified fluid, i.e. $K \sim \kappa u_{\star} z^{\prime}$, where $z^{\prime}$ is the distance to the nearest boundary and $u_{\star}=\sqrt{\frac{\tau^{s}}{\rho_{0}}}$ (Figure 4.9C). The eddy viscosity goes to zero at the boundaries. Therefore, the model must conform to the following conditions:

$$
\begin{gathered}
K(0)=0 \\
K(-H)=0 \\
\frac{d K}{d z}(z=0)=-\kappa u_{\star} \\
\frac{d K}{d z}(z=-H)=\kappa u_{\star} .
\end{gathered}
$$

The simplest continuous function which satisfies these boundary conditions [Signell 

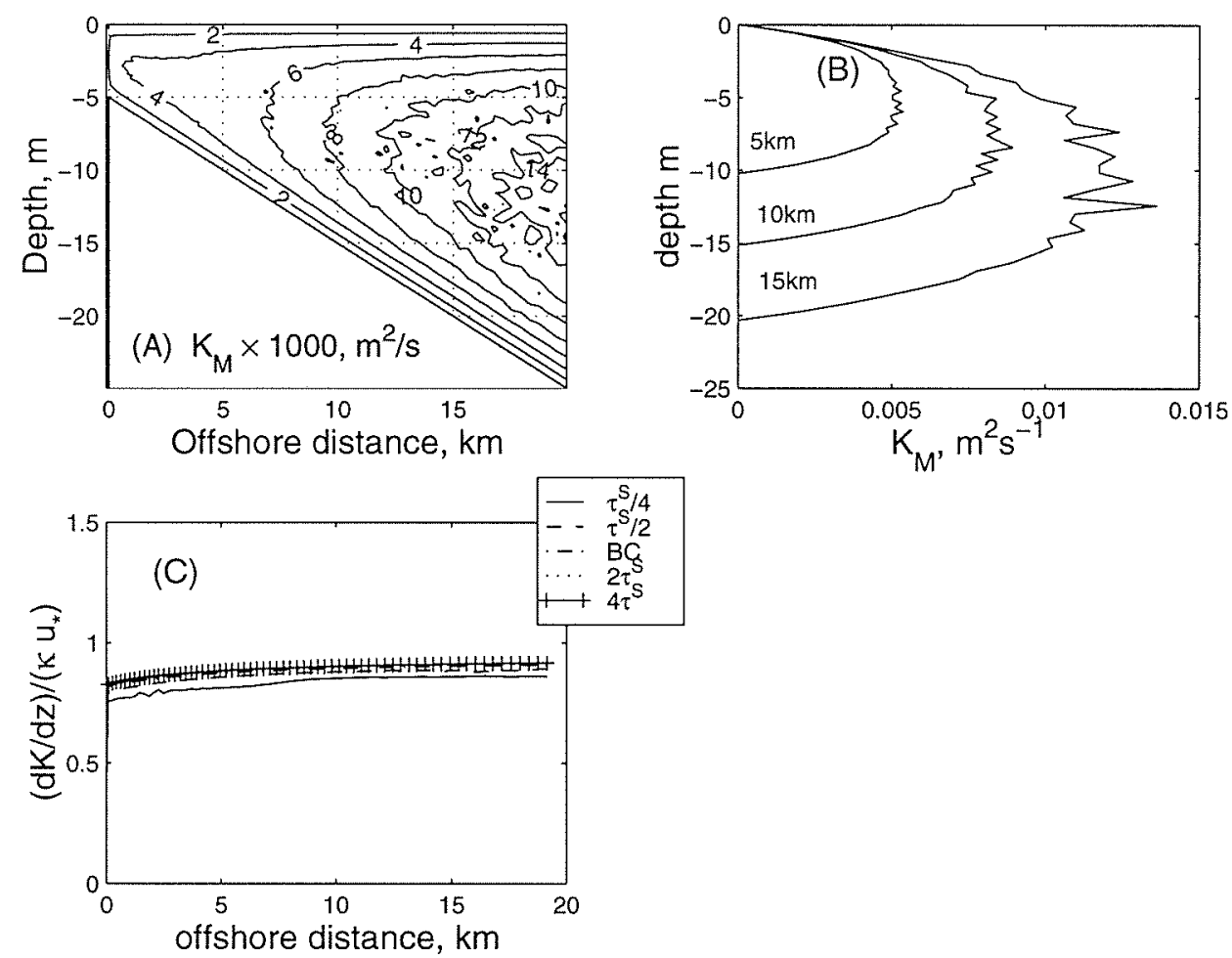

Figure 4.9: (A) Contours of eddy viscosity $K_{M}$ after 5 days of upwelling favorable alongshelf winds; (B) Profiles of $K_{M}$ at $5 \mathrm{~km}, 10 \mathrm{~km}$, and $15 \mathrm{~km}$ offshore after 5 days; (C) $\frac{d K}{d z}$ at $z=0$ as a function of cross-shelf distance, scaled by neutral value $\kappa u_{\star}$.

et al. 1990] is parabolic, i.e.:

$$
K(x, z)=\Gamma z\left(1+\frac{z}{H}\right)
$$

where

$$
\Gamma=\kappa u_{\star}
$$


$\Gamma$ can be interpreted as a turbulent vertical velocity scale associated with vertical mixing. $\Gamma$ becomes larger as the implied surface stress is increased. This profile is identical to the "cubic" profile of Lentz [1995], which shows that there should be approximately uniform transport divergence in water shallower than 3 Ekman depths, where the Ekman depth is $\delta=\frac{\kappa u_{\star}}{f}$. For the base case, $\delta \approx 40 \mathrm{~m}$, so the inner shelf should be characterized by uniform transport divergence as long as the upwelling front is in waters shallower than approximately $120 \mathrm{~m}$.

Knowledge of the mixing and the transport divergence on the inner shelf can be used to estimate scales for the density balance terms on the inner shelf, and ultimately lead to a better understanding of the orientation of isopycnals in this region. First of all, the circulation at a given location in this region is approximately steady once the front has move offshore of it, so time dependence will be disregarded. From Lentz [1995], Figure 4, the vertical profile of cross-shelf velocity is approximately linear in the cubic case, so it can be written as:

$$
u(x, z)=u_{0}\left(1+\frac{2 z}{H(x)}\right)
$$

The transport above the zero-crossing is $\frac{u_{0} H}{4}$. From Lentz [1995], Figure 3, the transport can be estimated as

$$
U_{T} \approx \frac{\tau^{S}}{\rho_{0} f} \frac{H}{3 \delta}
$$

so that

$$
u_{0}=\frac{4}{3 \delta} \frac{\tau^{S}}{\rho_{0} f}
$$


Substituting the expression for $u(4.20,4.22)$ and for $\Gamma(4.19)$ into the density balance (4.13) yields an estimate for the ratio of the vertical and horizontal density gradients on the inner shelf:

$$
\frac{\rho_{x}}{\rho_{z}}=\frac{\Gamma}{u_{0}},
$$

or

$$
\frac{\rho_{x}}{\rho_{z}}=\frac{3}{4} \kappa^{2} \approx 0.12
$$

This is equivalent to the tangent of the angle that isopycnals make with the horizontal:

$$
\theta \approx \arctan \frac{3}{4} \kappa^{2} \approx 0.12 \approx 6^{\circ}
$$

Model runs confirm this scaling, at least qualitatively. As vertical stratification increases, the eddy viscosity is reduced relative to that expected in the neutral case, reducing the effective value of $\Gamma$ and causing the isopycnal slope to be smaller.

Both vertical advection of density $\left(w \rho_{z}\right)$ and the time rate of densification $\left(\rho_{t}\right)$ have been ignored in the previous scaling. The prescription of the cross-shelf velocity provides enough information to estimate a posteriori scales for both of these terms. First, the vertical velocity can be estimated using the simple profile for $u$ (Equation $4.20)$ and the mass conservation equation (4.4):

$$
w=\frac{u_{0} \alpha z^{2}}{H^{2}}
$$

implying, as expected, that the vertical velocity is larger over steeper-sloped bot- 
toms. Then the vertical advection of density becomes:

$$
w=\frac{\rho_{z} u_{0} \alpha z^{2}}{H^{2}}
$$

The region must slowly get denser since the near-bottom water moving onshore is slightly denser than the near-surface water moving offshore. The rate of densification can be scaled in terms of the cross-shelf transport and the vertical density gradient. The two-dimensional heat balance in a region onshore of some cross-shelf position $L$ can be written:

$$
\int \rho_{t} d A=-\int_{-H(L)}^{0} \tilde{u} \tilde{\rho} d z
$$

where $\tilde{u}$ and $\tilde{\rho}$ are the variation from the vertical mean of the cross-shelf velocity and the density, respectively, as in chapter $3 . \tilde{u}$ is prescribed by (4.20). The simplest form of the vertically varying portion of the density field consistent with the model results is:

$$
\tilde{\rho}=\rho_{z}\left(z+\frac{1}{2} H\right)
$$

where $\rho_{z}$ is still unknown. Using the approximations for $\tilde{u}$ and $\tilde{\rho}$ yields the area integrated change in density:

$$
\int \rho_{t} d A=-\frac{1}{6} u_{0} H^{2} \rho_{z}
$$


which can be differentiated in $x$ and divided by the local depth to yield the local rate of densification:

$$
\rho_{t}=\frac{1}{3} u_{0} \alpha \rho_{z}
$$

This solution, like the vertical advection term, is a function of the bottom slope, as the rate of densification increases with increased bottom slope. This behavior is different from that expected if the process was purely advective, in which the time scale for homogenizing the region would be the flushing time of the region, proportional to the advective velocity scale, inversely proportional to the horizontal length scale of the region, and unrelated to the size of the gradient.

Now that scales for vertical advection and cooling have been estimated in terms of $\rho_{z}$, the assumption that they are not important to the heat balance can be checked by scaling all four terms. The magnitudes of the terms are as follows:

$$
\begin{array}{lcccc}
\text { Term: } & \rho_{t} & u \rho_{x} & w \rho_{z} & \left(K \rho_{z}\right)_{z} \\
\text { Scaling: } & \frac{1}{3} u_{0} \alpha \rho_{z} & u_{0} \theta \rho_{z} & u_{0} \alpha \rho_{z} & \Gamma \rho_{z} \\
\text { Base Case: } & 1 \times 10^{-5} \rho_{z} & 3.6 \times 10^{-3} \rho_{z} & 3 \times 10^{-5} \rho_{z} & 3.6 \times 10^{-3} \rho_{z}
\end{array}
$$

where $\theta=\frac{\Gamma}{u_{0}}$ is assumed. Since, for most shelves, $\alpha \ll \theta$, the vertical advection and rate of change terms should usually be small compared to the horizontal advection and vertical diffusion terms.

Comparing the profile observed in the model with the profile observed in the neutral case (Figure 4.10A) shows that the interior eddy viscosity is smaller than in the neutral case. This reduction is due to the presence of weak vertical stratification, which is created as the cross-shelf circulation in this region tilts over the nearly 
vertical isopycnals. The balance between vertical mixing and horizontal advection in the density equation keep the isopycnals essentially fixed in place. The gradients are strongest near the coast, and the greatest increase in transport over the neutral case is observed there (Figure 4.10B).
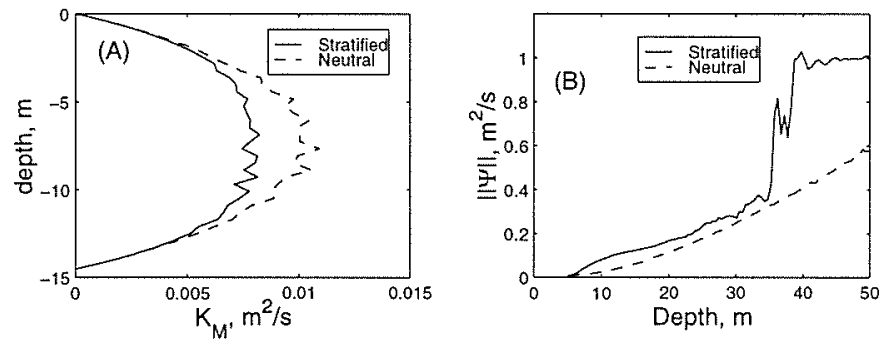

Figure 4.10: A comparison of the neutral (unstratified) upwelling case and the upwelling base case (strong pycnocline). (A) Profiles of eddy viscosity $10 \mathrm{~km}$ offshore; (B) the maximum streamfunction as a function of local water depth.

\section{The Density Gradient}

The quantitative scaling of the size of the horizontal density gradient on the inner shelf remains unresolved. However, the dependence of the size of the gradient on the model parameters can still be considered empirically. Since the isopycnals are nearly vertical, the surface density is assumed to be a reasonable proxy for the density structure, and is shown for a number of runs as a function of cross-shelf position at 4.5 days (Figure 4.11 ). The density has been scaled by the initial density difference so that 0 represents water with the same density as that initially at the surface and 1 represents the initial density below the pycnocline. More light water is trapped onshore when the initial density difference is small, when the coastal wall is shallow, the bottom slope small, or the surface forcing strong. All of these variations can 

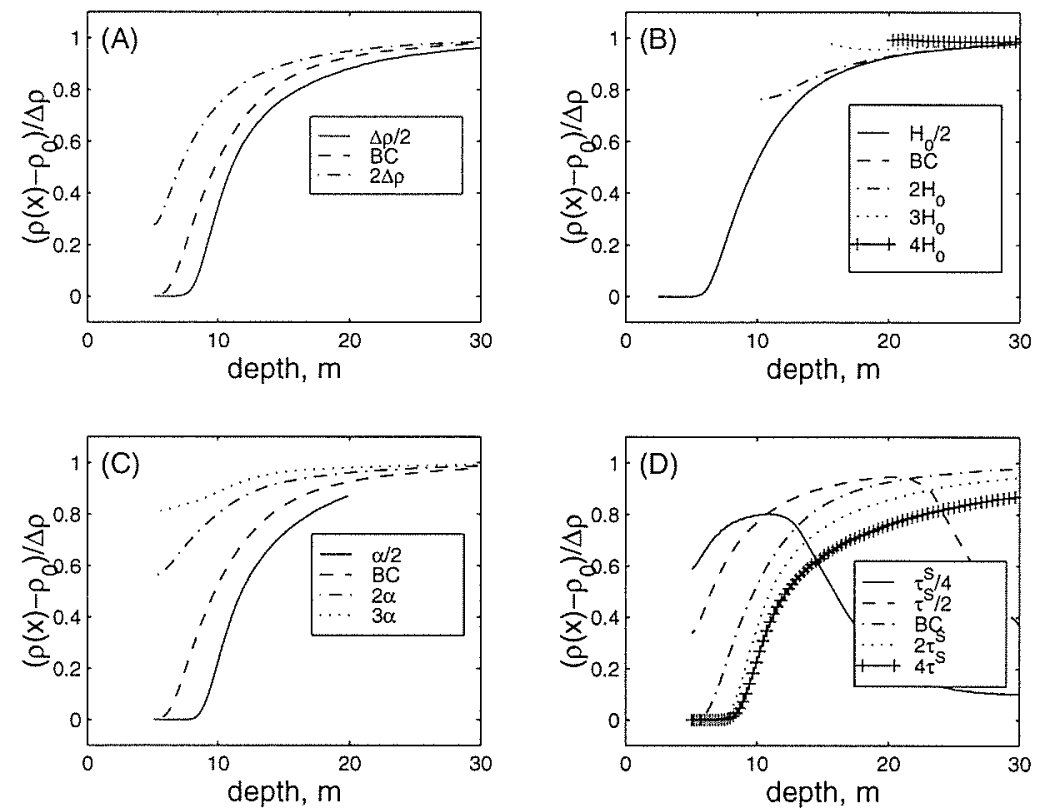

Figure 4.11: The cross-shelf distribution of surface density, scaled by the initial density difference $\Delta \rho$, at 4.5 days for varying parameters. (A) $\Delta \rho$; (B) $H_{0}$; (C) $\alpha$; (D) $\tau^{S}$. The negative gradient offshore of approximately $5 \mathrm{~km}$ in the $\tau^{S} / 4$ case and offshore of $15 \mathrm{~km}$ in the $\tau^{S} / 2$ case is the upwelling front, which has not moved very far offshore due to the weak forcing.

be understood in terms of a relatively simple relationship between the depth of the coastal wall and the thickness of the bottom boundary layer, discussed next.

\section{The Coastal Wall Criterion}

The choice of the location of a coastal wall is a "necessary evil" of coastal models, neglecting a potentially important region under the assumption that it has little effect on the response further offshore. (The problem considered here is a separate issue from that considered by Mitchum and Clarke [1986], who were concerned with picking a coastal wall depth that would preserve the properties of coastally- 

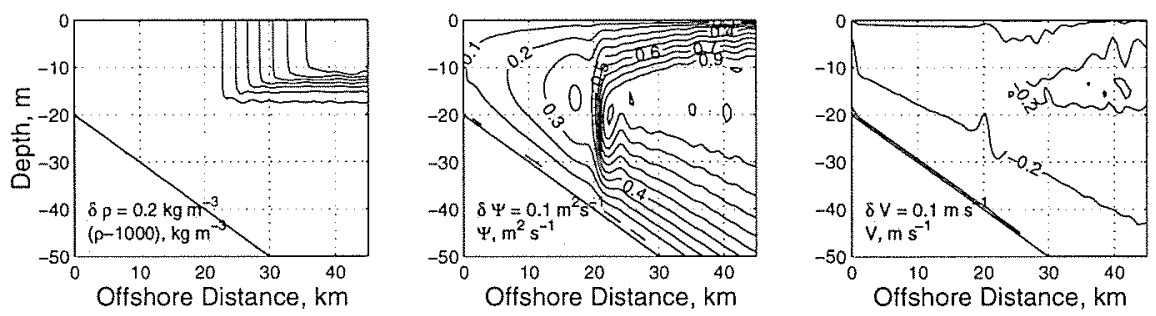

Figure 4.12: Density $\rho$, cross-shelf streamfunction $\Psi$, and alongshelf velocity $v$ in the $4 H_{0}$ case $\left(H_{0}=20 \mathrm{~m}\right)$, at 4.5 days. Same data as heavy line, figure $4.11 \mathrm{~B}$.

trapped waves further offshore.) If the coastal wall is placed in water deeper than the bottom boundary layer thickness, shoaling isopycnals reach the coastal boundary first, as opposed to intersecting the surface at some point offshore. In this case, light water is not trapped on the inner shelf (Figure 4.12; compare with Figure 4.3, 4.5 days). Instead, the inner shelf is filled with homogeneous water from below the pycnocline and all of the surface water is advected offshore. This criterion suggests that the amount of light water trapped near the coast is a function of the ratio of the bottom boundary layer thickness to the coastal wall depth (Figure 4.11B). Although scalings for the thickness of the bottom boundary layer have not been derived for strong pycnocline systems such as this one, this scaling has been considered for a continuously stratified fluid [Trowbridge and Lentz 1991, Middleton and Ramsden 1997]. These scalings suggest that the thickness increases for weaker stratification, weaker bottom slope, and stronger forcing. In the cases with strong stratification, steeper bottom slope, and weak forcing, the bottom boundary layer was less thick and therefore less light water is trapped near shore. 


\subsubsection{The Frontal Region}

The front separates the inner shelf from the mid-shelf, and is characterized by the strongest horizontal density gradients anywhere on the shelf during upwelling. Strong vertical stratification also present in this region leads to a region of small stress magnitudes, effectively separating the surface and bottom boundary layers (Figure 4.3). In addition, it is in this region that the most intriguing response to the cessation of wind is observed, so the behavior of the spin-down problem is considered briefly in this section. First, however, the dynamical balance in this region during the constant wind stress event is considered.

\section{The Balances}

Profiles of the momentum and density balance terms at 4.5 days, $38 \mathrm{~km}$ offshore (Figure 4.13), show that the cross-shelf momentum balance is primarily geostrophic above the bottom boundary layer. Above the pycnocline, the strong horizontal density gradient accounts for shear in the alongshelf velocity in agreement with thermal wind balance. The alongshelf shear at the bottom is associated with the bottom Ekman layer. The alongshelf momentum balance is primarily an Ekman balance throughout the water column, showing the strong capping effect of the pycnocline. The density balance above the pycnocline is between horizontal advection $\left(u \rho_{x}\right)$ and the local rate of change $\left(\rho_{t}\right)$, as expected in the vicinity of the front, which is moving offshore.

\section{The Spin-Down}

In a case where the surface stress is turned off (Figure 4.2, dotted line) just before 

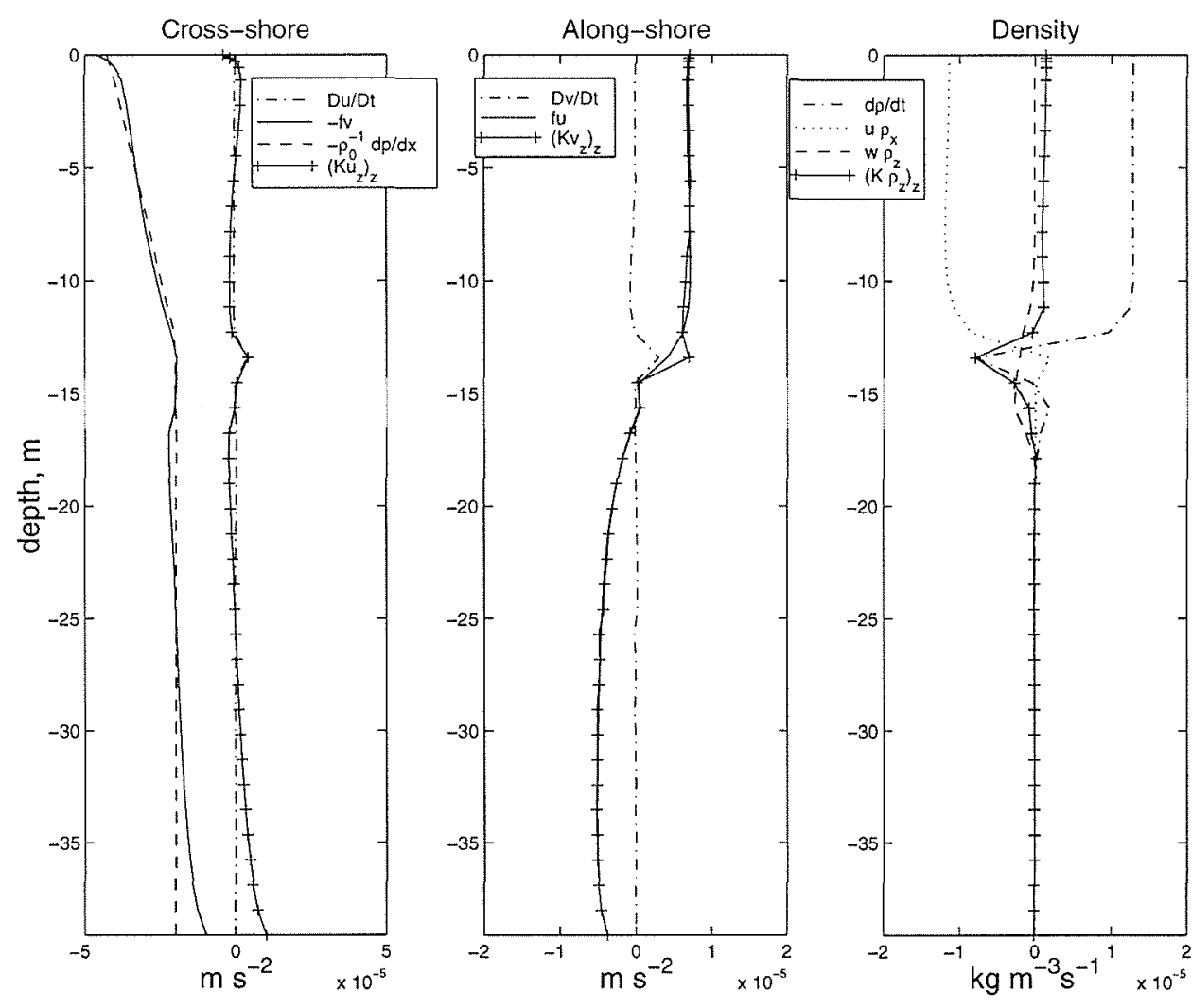

Figure 4.13: Cross-shelf, alongshelf, and density balances from the frontal region ( $38 \mathrm{~km}$ offshore, 4.5 days). The shaded region represents the depth range with strong vertical stratification $\left(\frac{d \rho}{d z}>0.05 \mathrm{~kg} \mathrm{~m}^{-3} \mathrm{~m}^{-1}\right)$.

the end of the third day, the shelf reaches geostrophic balance (Figure 4.14). On the inner and mid-shelf, the spun-down state is basically stagnant (Figures 4.14B,C), since the horizontal density gradients there are weak. In the frontal region, the horizontal pressure gradient is close to geostrophic balance with an alongshelf jet when the wind is turned off, and comes completely into balance soon thereafter (Figure 4.14D,E), essentially "trapping" alongshelf momentum in the surface layer in the vicinity of the upwelling front. The balance achieved is similar to that in Csanady's [1971] two-layered model. Since there are no significant cross-shelf or alongshelf 

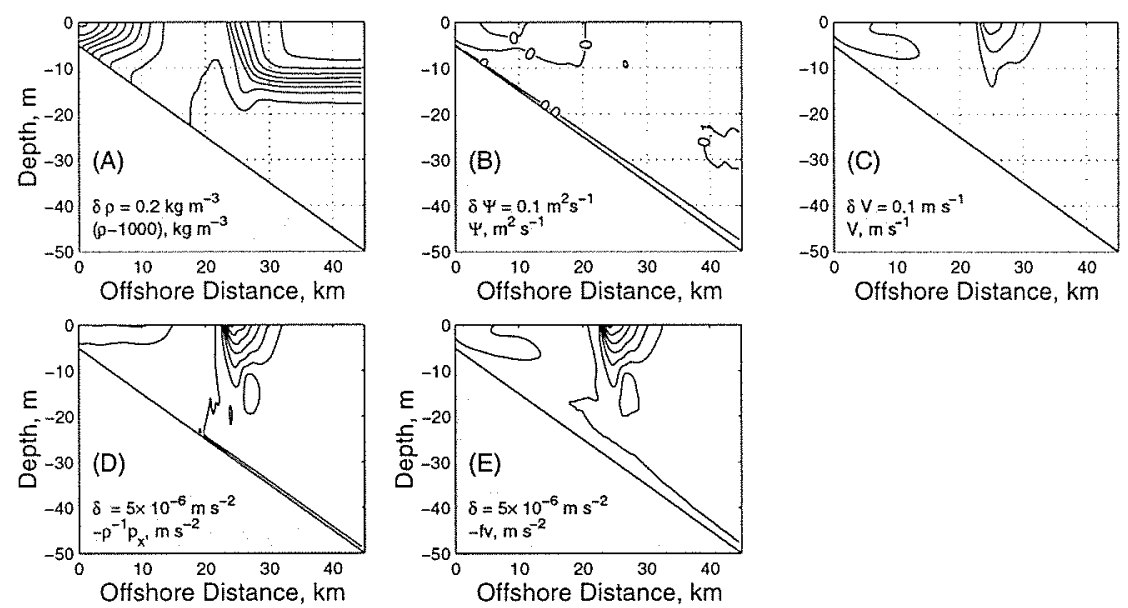

Figure 4.14: Model and balance fields of day 4.5 in the spindown case. (A) density; (B) streamfunction; (C) alongshelf velocity; (D) total cross-shelf pressure gradient; (E) Coriolis force.

velocities near the bottom, there is no significant dissipation in the system and the jet will maintain the displacement of the pycnocline until background diffusive processes transport the jet momentum into the bottom boundary layer. The decay time scale for this process should be approximately $\frac{\nu}{H^{2}}$, where $H$ is the local water depth, and $\nu=2 \times 10^{-5} \mathrm{~m}^{2} \mathrm{~s}^{-1}$ is the background viscosity. With $H=20 \mathrm{~m}$, the time scale is around 200 days. This has not been tested with the numerical model, and is not relevant to the real world since it would require a period of several months without significant alongshelf wind stress.

The alongshelf transport in the steady jet can be calculated by assuming that the system is in thermal wind balance:

$$
-f v_{z}=\frac{g}{\rho_{0}} \rho_{x},
$$




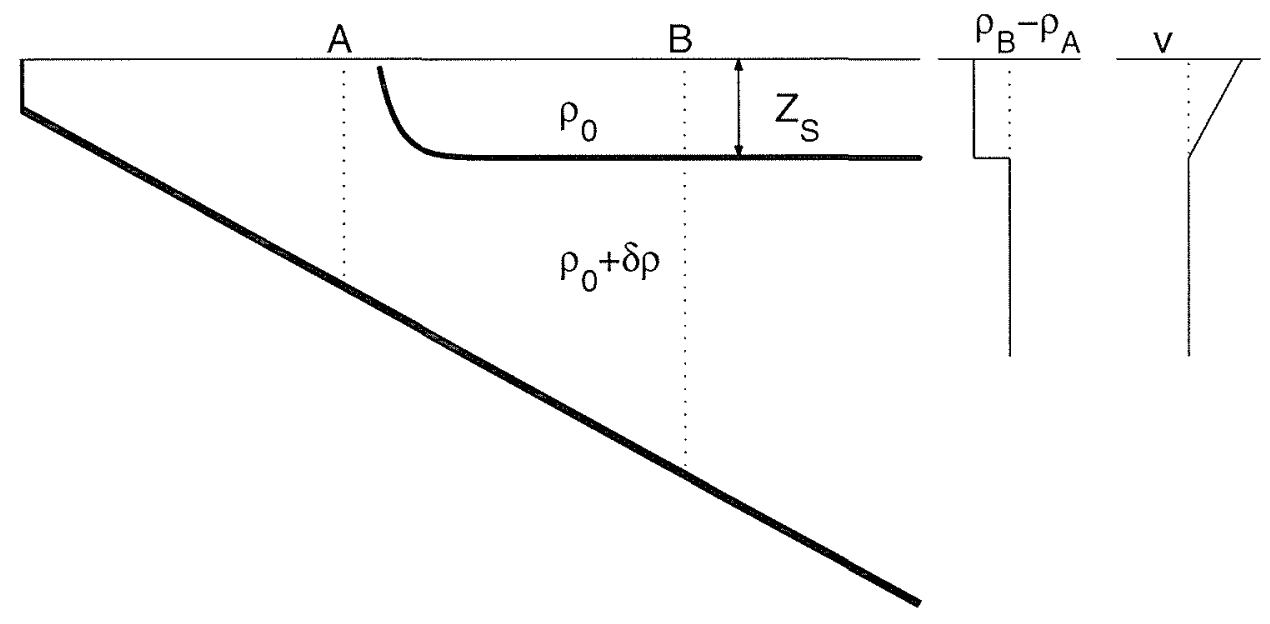

Figure 4.15: Schematic of the density field used to derive alongshelf jet transport scaling, and profiles of density difference and alongshelf velocity.

and that there is no motion in the lower layer (reasonable since any motion in the lower layer is dissipated by bottom friction). Just inshore of the front the water is assumed homogeneous and of the same density $\left(\rho_{0}+\delta \rho\right)$ as that in the lower layer offshore (Figure 4.15). If the upper layer has density $\rho_{0}$, and the pycnocline is horizontal and located at some depth $Z_{S}$ sufficiently far offshore, the alongshelf transport scales as:

$$
V=\frac{g \delta \rho_{0} Z_{S}^{2}}{2 \rho_{0} f}
$$

This estimate is independent of the structure of the relaxed upwelling front. To first order, assume that mixing does not appreciably deepen or densify the surface layer, 
so that $\delta \rho=\Delta \rho$ and $Z_{S}=Z_{0}+\Delta Z / 2$. The relationship becomes:

$$
V=\frac{g \Delta \rho\left(Z_{0}+\Delta Z / 2\right)^{2}}{2 \rho_{0} f}
$$

which is a function entirely of the initial model parameters. The result is interesting not only because of what it depends on but because of what it does not depend on. The only parameters that (4.34) depends on are the initial density difference across the pycnocline and the initial pycnocline depth. It is not dependent on the bottom topography, which does not affect the thermal wind balance. The solution also does not depend on the magnitude or duration of the surface forcing, which simply determine the final location of the pycnocline. Measuring the total transport in the model runs after the wind has been turned off is difficult because of the uncertainty in defining what portion of the alongshelf velocity is part of the jet and what is still decaying away. Integrating the weak residual alongshelf velocity over the entire model domain swamps the signal from the strong, but small in spatial extent, alongshelf jet. To avoid this problem, the bottom alongshelf velocity is subtracted from the entire water column, assuming that the shear is fairly small throughout the water column at this stage, and by integrating over grid cells with velocities greater than $0.05 \mathrm{~m} \mathrm{~s}^{-1}$ (Figure 4.16). The scaling appears to reflect the correct dependence on the pycnocline depth and the density difference. However, there appears to be a considerable dependence in POM on the magnitude of surface forcing. The surface forcing effects the actual transport by modifying the appropriate values for $\delta \rho$ and $Z_{S}$, through entrainment through the pycnocline.

In the case that the water is entrained into the surface layer from the lower layer, assume that buoyancy is conserved, so that $\delta \rho Z_{S} \approx \Delta \rho\left(Z_{0}+\Delta Z / 2\right)$ regardless of 

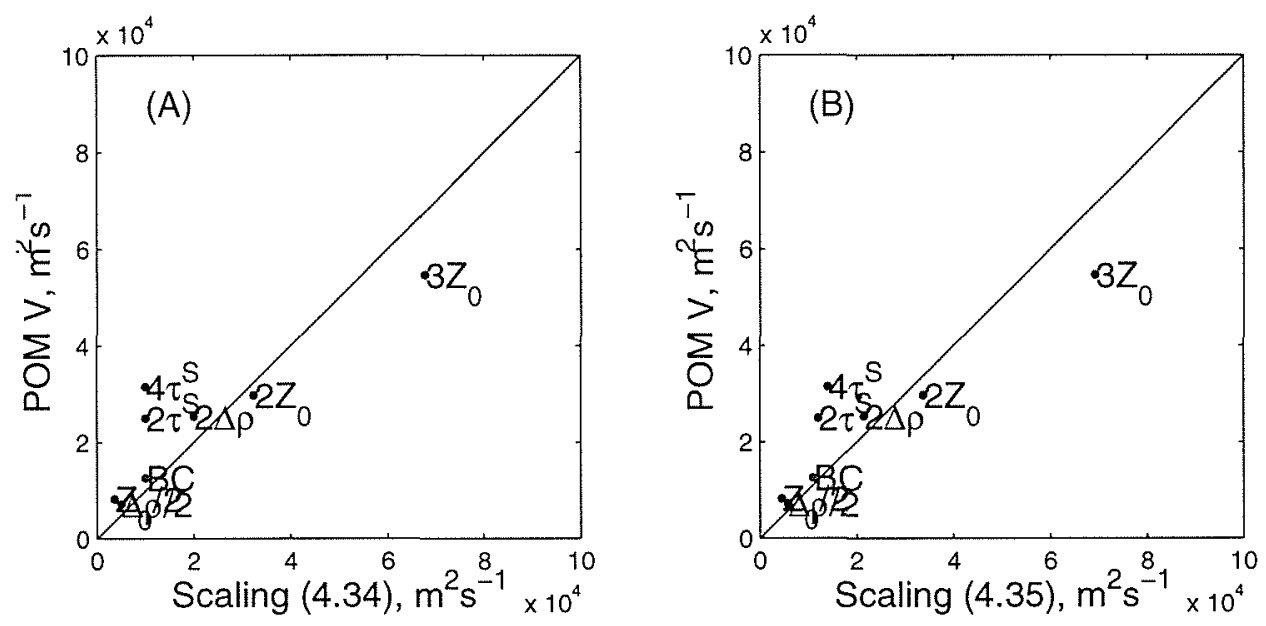

Figure 4.16: Estimated POM transport in the alongshelf jet at 4.5 days, compared to the scaling. (A) Without mixing (4.34); (B) with mixing (4.35).

the amount of mixing. The scaling in this case is

$$
V=\frac{g \Delta \rho\left(Z_{0}+\Delta Z / 2\right) Z_{S}}{2 \rho_{0} f}
$$

Since mixing always deepens the mixed layer, $Z_{S}>\left(Z_{0}+\Delta Z / 2\right)$, so (4.35) suggests that mixing should increase the jet transport. Using the scaling of Appendix A to estimate the pycnocline deepening and the change in density in the upper layer results in a small correction to the jet transport estimates (Figure 4.16B), but not enough to fully explain the discrepancy between the model and the scaling. This may be due to the fact that the scaling for the deepening of the mixed layer breaks down when the deepening is on the order of or larger than the initial depth, which 
is the case for the strong forcing events. The mixed layer actually deepens more than predicted by the scaling in these cases, resulting in underestimates of the jet transport.

The inner shelf relaxes as well. During the wind stress event, the shear in this region is in the opposite direction as the thermal wind shear, so during the wind event the inner shelf is not close to thermal wind balance, as it is in the frontal region (Figure 4.8). Therefore, the adjustment process consists initially of cross-shelf velocities which displace the isopycnals, eventually resulting in an alongshelf jet that balances the density gradients through the thermal wind relation. Jet velocities are small since the horizontal density gradient is relatively weak compared to that in the front and because they span a small depth range. This jet is in the opposite direction of the one associated with the upwelling front.

The most significant implication of the spin-down problem is that the final displacement of the pycnocline is a function of the integrated alongshelf wind stress, as Csanady [1971] indicates for an impulse-type wind event, even when the total impulse is distributed over finite time. Without downwelling favorable wind (or some other process), the pycnocline should remain displaced offshore unless acted upon by, for instance, downwelling winds or some other forcing mechanism. In the next chapter, this result (which is true for downwelling as well) is discussed in the context of some of the CoOP ISS observations.

\subsubsection{The Mid-Shelf}

The mid-shelf is probably the easiest understood of the regions because it represents the portion of the shelf where strong vertical stratification in the pycnocline isolates 
the surface and bottom Ekman layers (Figure 4.17). The bottom boundary layer is driven primarily by the surface pressure gradient set up by the surface Ekman layer, whereas inshore the Ekman layers "communicated" through the stress field as well. The surface Ekman layer is constrained to the surface layer by the strong stratification in the pycnocline. Figure 4.3 shows a tongue of low stress magnitude approximately coincident with the pycnocline, further demonstrating the "capping" effect of the pycnocline on the surface Ekman layer.

\subsubsection{Offshore Propagation}

The upwelling front moves offshore during upwelling, separating the mid-shelf from the inner shelf (Figure 4.5). Consequently, the inner shelf grows in extent with time. In order to estimate the width of the inner shelf region as a function of time, the propagation speed of the upwelling front $\left(U_{F}\right)$ and the initial location $\left(X_{S}\right)$ and time $\left(t_{S}\right)$ (Figure 4.5 ) of the pycnocline shoaling must all be determined in terms of the original parameters of the problem.

The location of the front can be written approximately as a function of time:

$$
X_{F}(t)=X_{S}+\left(t-t_{S}\right) U_{F}
$$

where $X_{S}$ is the initial position of the front, $t_{S}$ the time at which the pycnocline intersects the surface, $X_{F}$ the cross-shelf position of the front, and $U_{F}$ the average speed of the front. This assumes that the propagation speed is approximately constant, and is only valid for $t>t_{S}$. Ideally, scales for $U_{F}, t_{S}$, and $X_{S}$ will yield a scaling which reflects the dependence of the width of the inner shelf region on the 

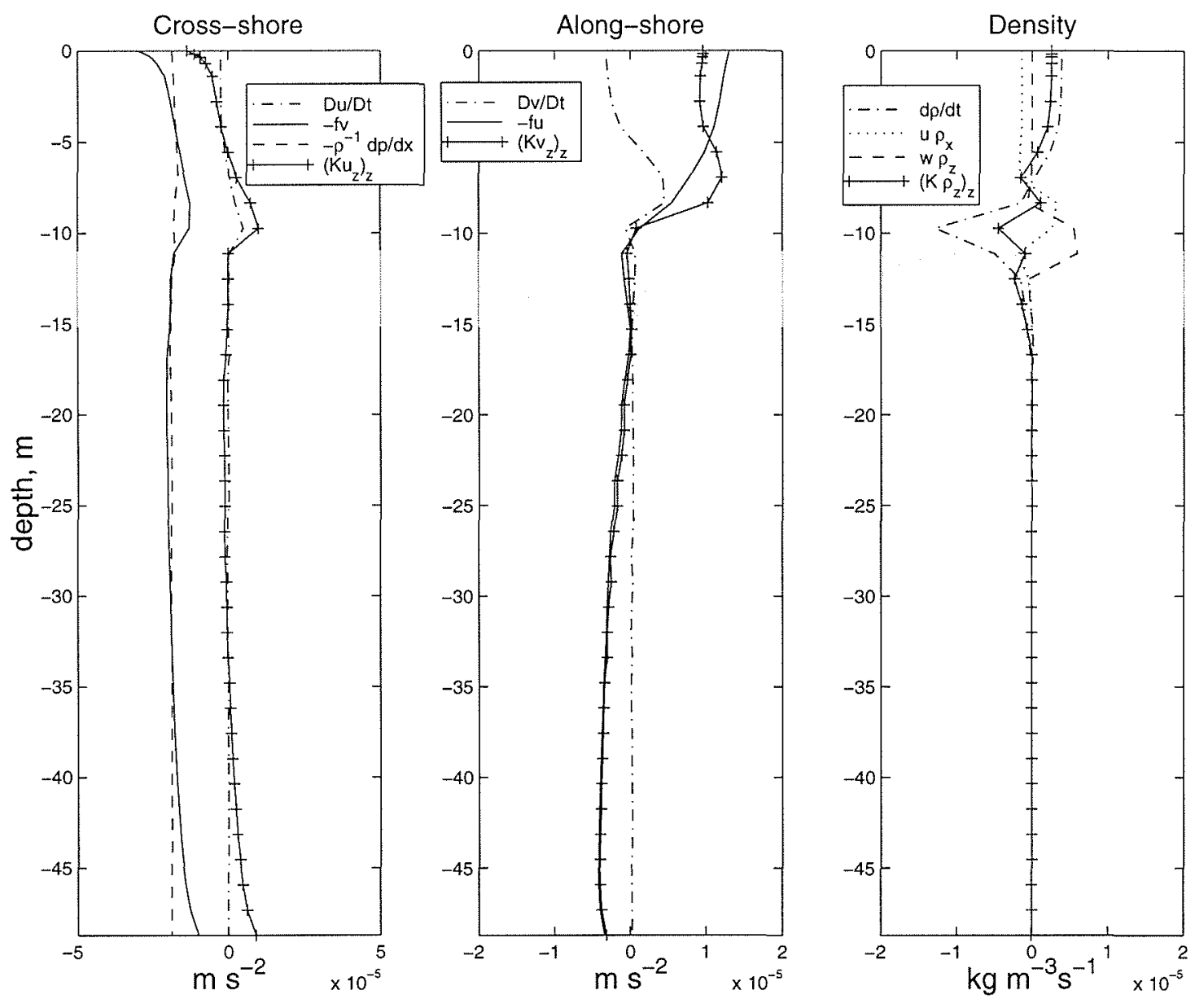

Figure 4.17: Cross-shelf, alongshelf, and density balances from the mid-shelf ( $45 \mathrm{~km}$ offshore, 2.5 days) in the base case. The shading represents the depth range of strong vertical stratification $\left(\frac{d \rho}{d z}>0.05 \mathrm{~kg} \mathrm{~m}^{-3}\right)$. 
model parameters.

\section{The Advective Speed}

The offshore propagation speed of the shoaled pycnocline can be modeled in terms of the surface stress and the thickness of the surface Ekman layer, $Z_{S F C}$ :

$$
U_{F}=\frac{\tau^{S}}{\rho_{0} f Z_{S F C}} .
$$

A simple hypothesis is that the speed of the inshore edge of the front is determined by the depth of the front at its inshore edge, so that $Z_{S F C}=Z_{0}+\Delta Z$ (Figure 4.18A). This simple scaling tends to overestimate the propagation speed in many cases, especially during strong forcing events. This suggests that the appropriate depth for the surface layer is greater than this estimate, possibly due to deepening of the pycnocline through entrainment.

Entrainment across the pycnocline can deepen the surface mixed layer significantly during the course of the upwelling event, and hence slow down the progress of the upwelling front. The rate of deepening is dependent on the model mixing scheme, as it is fundamentally a mixing process. The total amount of deepening can be compared to the initial mixed layer depth to determine if mixing is going to play a first-order role in determining the propagation speed of the front. The ratio of the change in mixed layer depth to the initial mixed layer depth is:

$$
\frac{h_{t} \Delta t}{Z_{0}}=\frac{3 \beta R i_{C}^{1 / 2} \tau^{S} \Delta t}{Z_{0}^{3 / 2}(2 g \rho \Delta \rho)^{1 / 2}}
$$



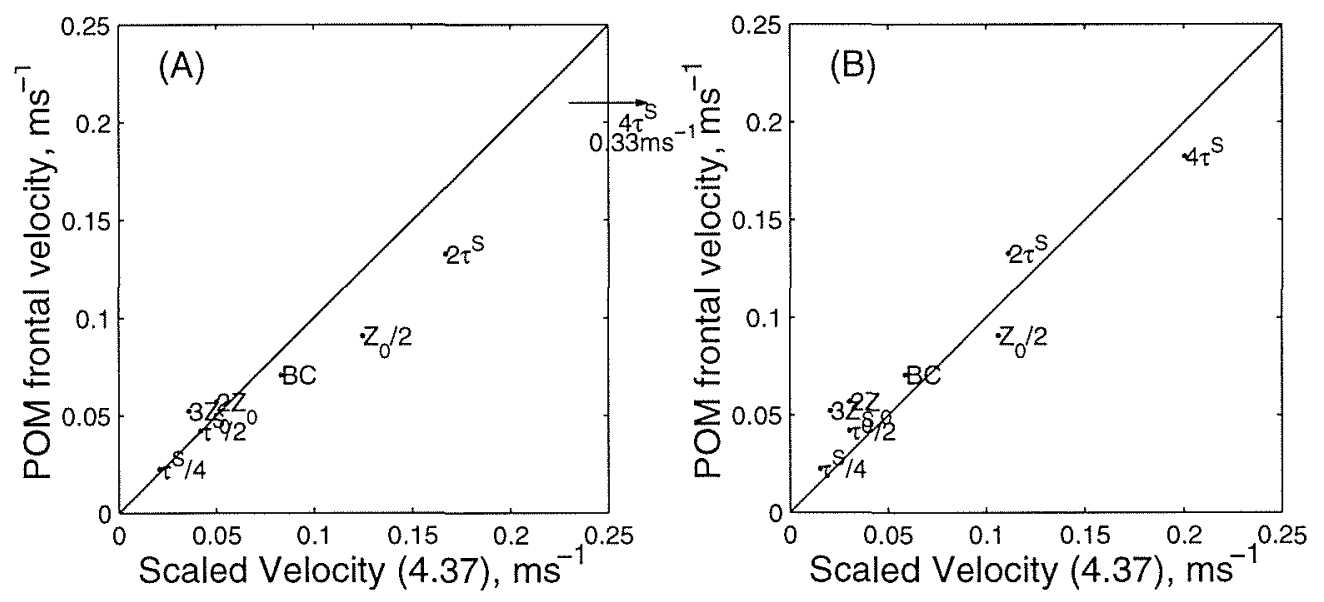

Figure 4.18: The scaled frontal propagation velocity versus the modeled frontal velocity. (A) Advective scaling: $Z_{S F C}=Z_{0}+\Delta Z$. The scaling for $4 \tau^{S}$ predicted $0.33 \mathrm{~ms}^{-1}$; (B) Scaling with mixing: $Z_{S F C}=Z_{0}+\Delta Z+\frac{1}{2} h_{t} \Delta t$. 
where $\beta \approx 0.025$ is a proportionality constant, $R i_{C}=0.25$, and $\Delta t$ is the duration of the forcing event, discussed along with a derivation of this scaling in Appendix A, and assuming, for simplicity, that $\frac{1}{2} \Delta Z \ll Z_{0}$. For the base case parameters and a 5 day wind event, this ratio is approximately 0.25 . This implies that the frontal speed will decrease by approximately $25 \%$ during the course of the forcing event, and that the estimate of the total offshore displacement of the upwelling front is over-estimated by approximately half of this, or about $12 \%$. For shorter forcing events (typical of the CoOP Inner Shelf Study) the error is correspondingly smaller. Applying this scaling to the determination of the propagation speed allows the scaling to be refined to $Z_{S F C}=\left(Z_{0}+\Delta Z\right)+\frac{1}{2} h_{t} \Delta t$, where $\Delta t$ is the duration of the forcing event. The $\frac{1}{2}$ appears in front of the mixing term because the average mixed-layer depth anomaly due to mixing processes is approximately half of the final anomaly. For mixing events in which the depth of the mixed layer changes considerable relative to the initial depth, the $\frac{1}{2}$ may not be satisfactory. For forcing events where $Z_{S F C}$ does not change very much relative to its original value, however, this is a reasonable approximation. This modified scaling is displayed in Figure $4.18 \mathrm{~B}$, and shows better agreement with the frontal velocity data from the numerical model than the purely advective model does.

\section{Initial Shoaling Point, $X_{S}$}

The pycnocline initially intersects the surface some distance $X_{S}$ offshore of the

coastal boundary some time $t_{S}$ after the forcing is turned on (Figure 4.5). The process through which the pycnocline initially intersects the surface is fundamentally a mixing process, having to do with the interaction between the surface and bottom boundary layers, and as such no simple scaling is forthcoming for either of these 
parameters. However, some basic ideas about the geometry of the upwelling process and the development of boundary layers can yield some insight into the parameter dependence of $X_{S}$ and $t_{S}$, and hence the width of the inner shelf.

In the model, the offshore distance of the initial shoaling $\left(X_{S}\right)$ appears to be related to the thickness of the bottom boundary layer, in that thicker boundary layers tend to shoal in deeper water. If the pycnocline shoals in water approximately as deep as the bottom boundary layer is thick, the offshore position can be written:

$$
X_{S}=\frac{\delta-H_{0}}{\alpha}
$$

where $\delta$ is the thickness of the bottom boundary layer when it intersects the surface. This scaling is only useful if $\delta$ is known. The only strong dependence in this case is on the initial depth of the pycnocline, $Z_{0}$. This dependence is due to the fact that the bottom boundary layer thickness grows with time. If the pycnocline is initially close to the surface, the bottom boundary layer has very little time to grow and is not very thick when it intersects the surface. When the pycnocline is started deeper, it has more time to develop and hence is thicker when it intersects the surface. The thickness of the bottom boundary layer may have an upper bound, established for uniformly stratified shelves (Trowbridge and Lentz [1991], Middleton and Ramsden [1997]), and this thickness may be a function of model parameters. However, it appears that the shoaling depth of the pycnocline does not depend on the maximum thickness, since it shoals while it is still developing. If all of the runs were redone with a much deeper pycnocline, these dependences might be apparent. There is no significant dependence on the coastal wall depth, as long as the bottom boundary layer thickness $\delta$ is greater than the coastal wall depth. If the coastal 

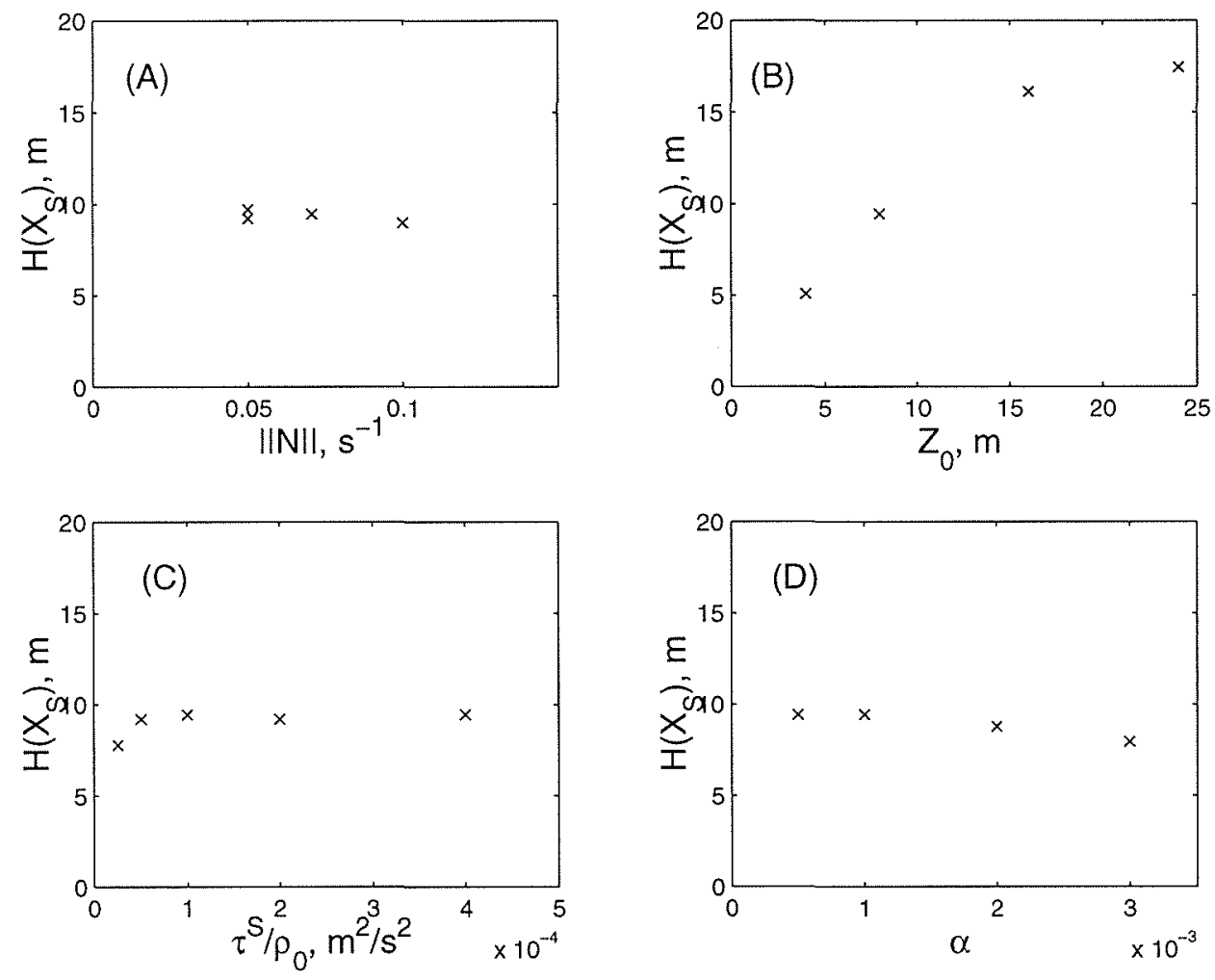

Figure 4.19: The depth at which the pycnocline shoals, as a function of different model parameters. (A) Maximum $N$ of the initial density profile $(\|N\|=$ $\left.\left(g \rho_{0}^{-1} \Delta \rho \Delta Z^{-1}\right)^{1 / 2}\right)$; (B) Initial mixed-layer depth; (C) Surface stress; (D) Bottom slope. 
wall is deeper than the bottom boundary layer is thick, the pycnocline shoals at the coastal boundary, resulting in significantly different inner shelf stratification. This problem is addressed in section 4.1 .

\section{Shoaling time, $t_{S}$}

The amount of time it takes for the pycnocline to reach the surface is empirically shown to be proportional to the initial depth of the surface layer $\left(Z_{0}\right)$ and inversely proportional to the intensity of the forcing $\left(\tau^{S}\right)$. This relationship suggests that the shoaling time is related to the rate of thickening of the bottom boundary layer. The time scale $t_{S}$ scales as:

$$
t_{S}=\frac{Z_{0} t^{\star}}{u_{\star}}
$$

where $t^{*}$ is a proportionality constant that takes into account the relationship between the forcing and the deepening rate. The numerical value for $t^{\star}$ that best fits the model results is $t^{\star} \approx 100$ (Figure 4.20). The shoaling time does not appear to depend strongly on any of the other parameters. The dynamics behind this scaling are not well understood.

\section{Frontal displacement}

The lack of a simple scaling for the bottom boundary layer thickness point makes a

generalized expression for the position of the upwelling front difficult. However, the 


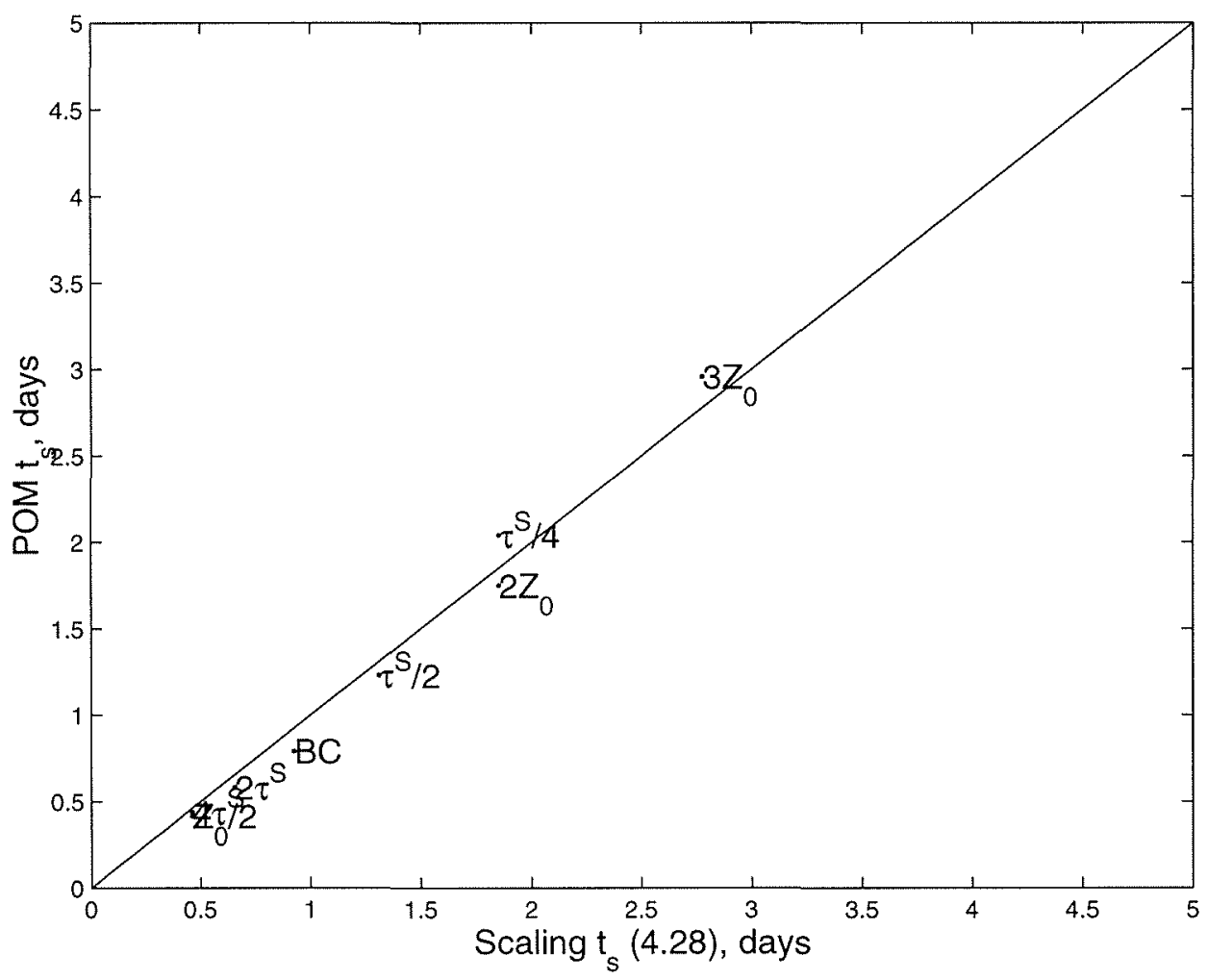

Figure 4.20: The time of initial shoaling $\left(t_{S}\right)$ as a function of the surface forcing and the initial pycnocline depth. The dependence on the other model parameters is weak. 
basic dependence can be written as:

$$
X_{F}(t)=\frac{\delta-H_{0}}{\alpha}+\left(t-\frac{t^{\star} Z_{0}}{u_{\star}}\right) \frac{\left(u_{\star}\right)^{2}}{f\left(Z_{0}+\Delta Z+\frac{1}{2} h_{t} \Delta t\right)}
$$

This is only valid for $\delta>H_{0}$, as the case where $\delta<H_{0}$ has been shown to result in a distinct upwelling scenario. In model runs where $\delta>H_{0}$, the first term of this equation is positive, becoming larger for smaller $\alpha$. In the absence of a scaling for $\delta$, the above scaling can be compared to the model results assuming a constant $\delta=10 \mathrm{~m}$ (Figure 4.19), acknowledging that this introduces error into the scaling. The $4 \tau^{S}$ run is not displayed but was displaced $78 \mathrm{~km}$ and the scaling predicted $90 \mathrm{~km}$. The scalings for $3 H_{0}$ and $4 H_{0}$ are not valid because in these cases $H_{0}>\delta$. The strongest dependences are the forcing, the pycnocline depth, and the bottom slope. The bottom slope is only a factor in determining the initial shoaling location.

\subsection{Uniform Stratification}

The behavior of the inner shelf is significantly different if the water column is uniformly stratified. The continuously stratified case differs from the sharp pycnocline case in that there is denser water continuously being fed onto the lower half of the inner shelf, which keeps the region vertically stratified. This section consists of a comparison of the strong pycnocline base case, previously discussed, and the continuously stratified case, in which a shelf with constant buoyancy frequency $N$ is considered. This is followed by a discussion of the Burger number criterion for stratified shelves. The response of a uniformly stratified shelf is only qualitatively explored in this section, and the problem warrants future research. 


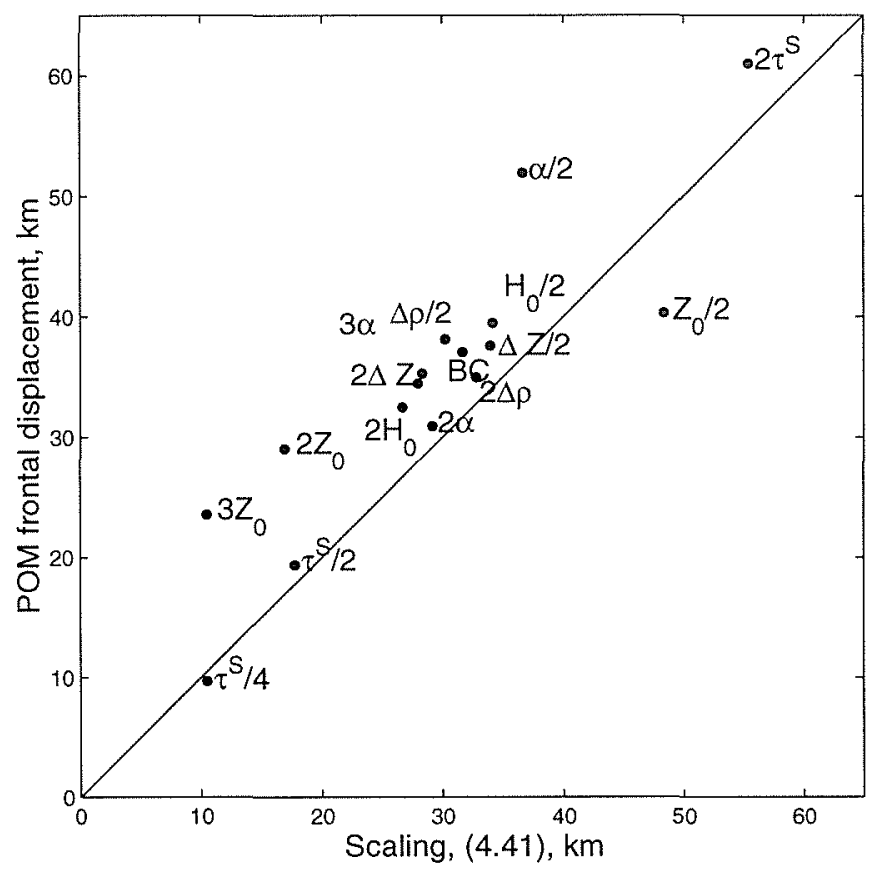

Figure 4.21: The offshore location of the upwelling front after 5 days as a function of the model parameters. The line represents the scaling (4.41).

The basic features of the circulation are considerably different between the strong pycnocline model (Figure 4.22, first column) and a continuously stratified model (Figure 4.22, second column). In the continuous-stratification case, the cross-shelf circulation is considerable in much shallower water, with almost fully developed Ekman transport $\left(\frac{\tau^{S}}{\rho_{0} f}\right)$ in water as shallow as $20 \mathrm{~m}$. At the same location in the base case, the circulation only reaches about $0.2 \frac{\tau^{S}}{\rho_{0} f}$. The stress distributions are different as well, with lower stresses observed over a much wider range of the shelf in the continuously stratified case. The lowered stress in the continuously stratified case is due to the continuous flux of denser water into the lower portion of the inner shelf, providing strong vertical stratification that more effectively isolates the surface and bottom Ekman layers from each other than in the base case. The location of the 

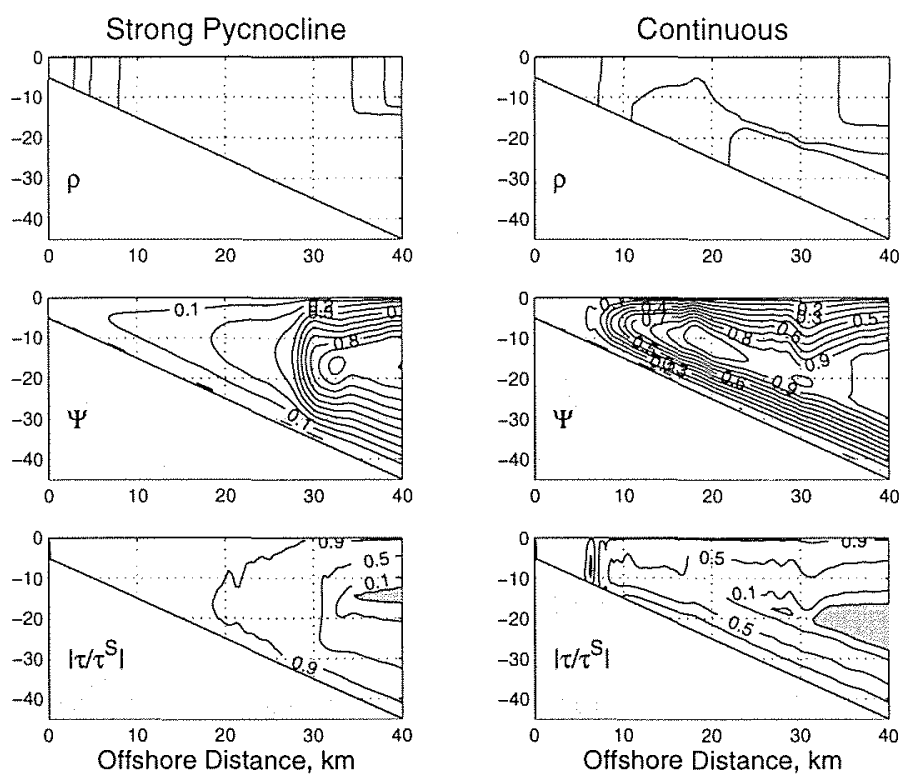

Figure 4.22: A comparison of the density field, cross-shelf streamfunction, and stress distribution at 4.5 days in the base case (column 1) and a uniformly stratified case (column 2).

strong transport divergence in the uniformly stratified case is steady in time once the inner shelf has developed. The portion of the shelf spanned by circulation in excess of the neutral case is a function of the bottom slope and the stratification (Figure 4.23). With increased bottom slope (Figure 4.23A), equivalent horizontal displacement along the bottom results in proportionally larger vertical displacements, resulting in larger buoyancy flux. Similarly, increased vertical stratification (Figure 4.23B) results in a larger effective buoyancy flux onto the inner shelf. In both cases, this results in enhanced circulation into shallower water. In the continuously stratified case, a region of light water can still be pinched off near the shore. This behavior is dependent on the model parameters. In continuously stratified water, the formation of the pinched-off region is contingent on the slope Burger number, discussed next. 

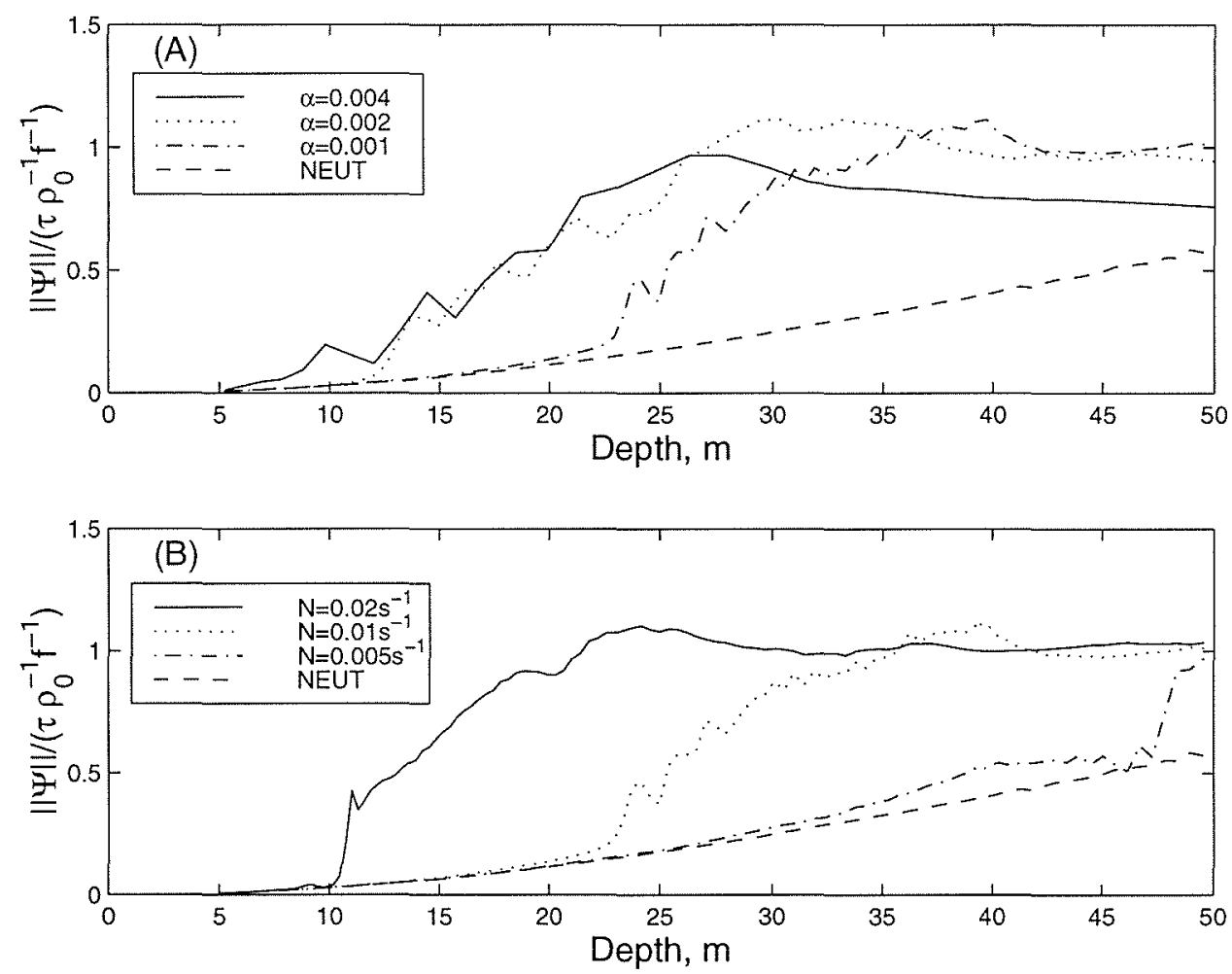

Figure 4.23: The maximum streamfunction, scaled by $\frac{\tau^{s}}{\rho_{0} f}$, as a function of local water depth in a neutral run and several continuously stratified runs, all at 4.5 days. (A) Variations in $\alpha, N=0.01 \mathrm{~s}^{-1}$ fixed; (B) variations in $N, \alpha=0.001$ fixed.

\subsubsection{The Burger Number Criterion}

The qualitative response of the inner shelf to upwelling on a continuously stratified shelf depends on the size of the slope Burger number. This is a consequence of the formation of "slippery" Ekman layers, as discussed by trowbridge and Lentz [1991] and MacCready and Rhines [1993]. They propose a time scale over which the transport in the bottom Ekman layer decays, as buoyancy counters the Coriolis force and shuts down the stress divergence. If this time scale is shorter than an inertial period, a bottom Ekman layer does not form. Without the development of a 
(A)

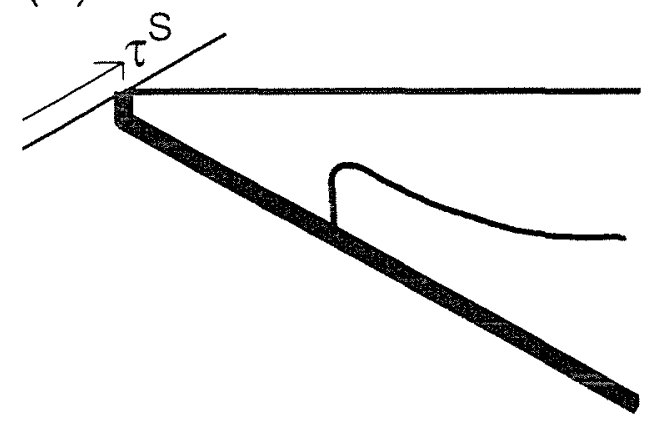

(B)

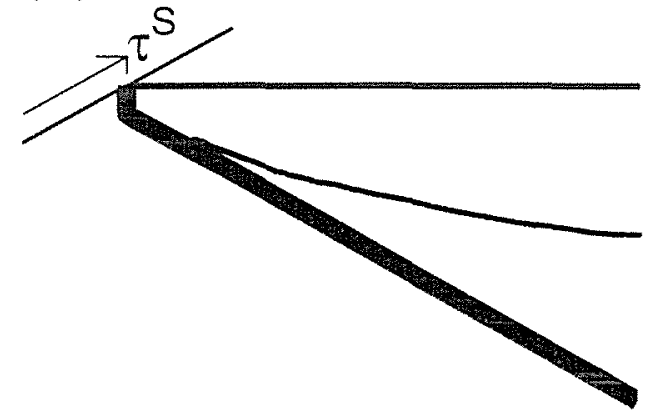

Figure 4.24: Schematic of isopycnal displacement in two different cases: (A) onshore flow due to bottom Ekman layer; (B) onshore flow due to interior flow.

bottom Ekman layer, the onshore transport is always due to the uniform "interior" return flow (illustrated by the cross-shelf streamfunction at 0.5 days in figure 4.3 ). The advection of the pycnocline takes place in a different manner if the cross-shelf advection is due to this interior flow instead of a bottom Ekman layer (Figure 4.24). In the case where a bottom boundary layer forms (Figure 4.24A), the isopycnals "dome" resulting in shoaling taking place offshore of the coastal boundary (contingent on the coastal wall criterion $H_{0}<\delta$, which applies in the uniform stratification case as well). In the case where the return flow is due to the interior flow (Figure $4.24 \mathrm{~B}$ ), the isopycnals are brought smoothly to the surface, and the surface density maximum is always at the coastal boundary. In this case, the inner shelf is stratified and circulation is maintained, but the character of the stratification is very different. in that isopycnals are not pinched off near the coast, and the densest water at the surface is found at the coastal boundary. 
MacCready and Rhines [1993] state that the bottom boundary layer will decay over a continuously stratified sloping shelf over a time scale $t_{B}=\frac{f}{(N \alpha)^{2}}$. If this occurs in less than an inertial period, about the time it takes for the bottom boundary layer to spin up, then $f^{-1}>\frac{f}{(N \alpha)^{2}}$, which is equivalent to the criterion that the slope Burger number, $S \equiv\left(\frac{\alpha N}{f}\right)^{2}>1$. So, for strongly sloped or strongly stratified scenarios (both of which should exhibit strong horizontal buoyancy fluxes along the bottom) the bottom boundary layer will not have a chance to form. If no bottom boundary layer forms, then the isopycnals, instead of doming and intersecting the surface some distance offshore, will rise to the surface at the coastal boundary. Density cross sections from two runs with different stratifications, and hence different Burger numbers, are shown in Figure 4.25. In the small Burger number run $(S=$ 0.0225), light water has clearly been pinched off near the coast, although it is not very wide due to the steep slope. The streamfunction clearly shows a bottom Ekman layer forming. In the higher stratification run $(S=2.25)$, the inner shelf has a very different character, as isopycnals are drawn smoothly into the coastal boundary before moving offshore at the surface, resulting in the densest water at the surface always located at the coast. In the example plotted it does appear that a very weak bottom boundary layer is forming in the nearest $5 \mathrm{~km}$ to shore. The streamfunction indicates that there is very little flow in the bottom Ekman layer, and that most of the onshore flow is relatively evenly distributed throughout the water column. The distribution of stress magnitude throughout the water column shows a well-formed bottom Ekman layer in the $S=0.0225$ case, but low stress very near the bottom in the $S=2.25$ case. The alongshelf bottom stress in these two runs (Figure 4.26) illustrates the shutdown of the bottom Ekman layer (i.e. no bottom stress) in the strongly stratified case, except in the nearest $7 \mathrm{~km}$ to shore. The behavior of the 
strongly stratified case in very shallow water is not currently understood, but may be due to the relatively weak vertical stratification in this region due to the proximity of the surface mixed layer. The behavior in this region merits further research. Regardless of the differences in the transport mechanisms and stratification, in both cases the circulation is strong across the entire shelf compared to the neutral case.
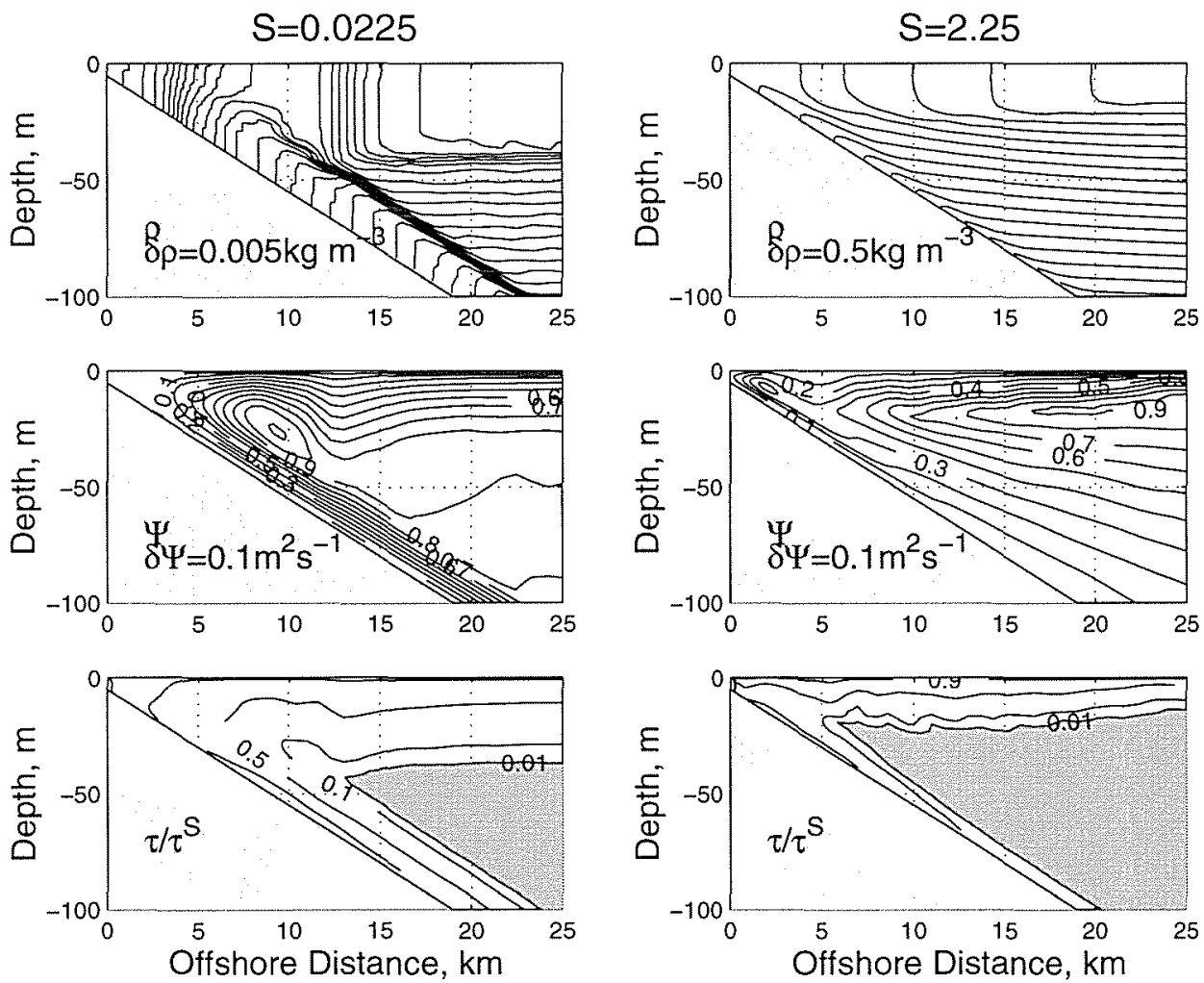

Figure 4.25: Density and cross-shelf streamfunction, at 4.5 days for two continuously stratified runs with different $N$. The bottom slope is $\alpha=0.005$. Column 1: $N=$ $0.003 \mathrm{~s}^{-1}, S=0.0225$. Column $2: N=0.03 \mathrm{~s}^{-1}, S=2.25$.

The extension of this criterion to non-uniform stratification, such as the strongpycnocline case, is not yet clear. An interesting example of non-constant stratification appears in the upwelling study of Allen et al. [1995] who used "realistic" stratification from the Oregon coast, in which a strong pycnocline overlies weaker 


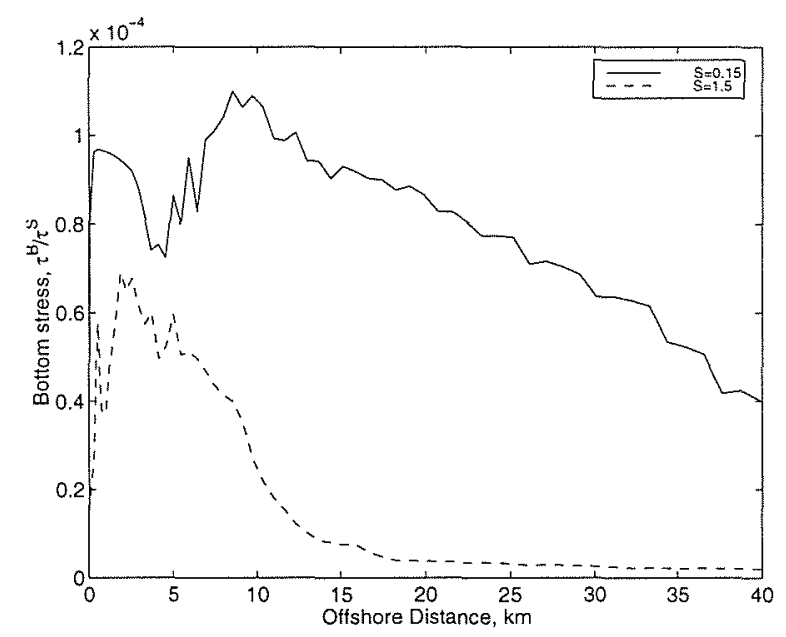

Figure 4.26: Bottom stress as a function of offshore distance at 4.5 days, in the two runs from Figure 4.25.

stratification below the pycnocline. In their base case the strongest stratification in the water column is such that $\|S\|>1$ (where $\|S\|=\frac{\alpha\|N(z)\|}{f}$ ), but most of the water column has $S(z)<1$. In this case (Figure 4.27A), the isopycnals shoal at the coastal boundary. However, in the very weak stratification case (Figure 4.27B, C) and in the wide-shelf ( small $\alpha$ ) case (Figure 4.27D), it appears that the maximum surface density may be displaced offshore. In both these cases, $S<1$ for the entire water column. In addition, the cross-shelf distribution of bottom stress in three runs with different bottom slopes (Figure 4.27F) shows the shutdown of the bottom stress in the strong-sloped and base case, but not in the gently sloped case, further suggesting the shutdown of the bottom Ekman layer for large Burger number flows. This result suggests that the Burger number may be a useful parameter for determining the fate of the inner shelf, but the extension of the criterion to the non-constant stratified case is not clear. 
(A)
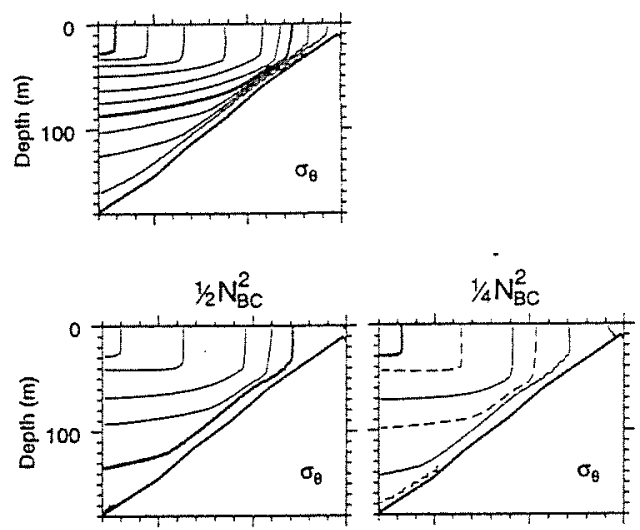

(C)

(D)

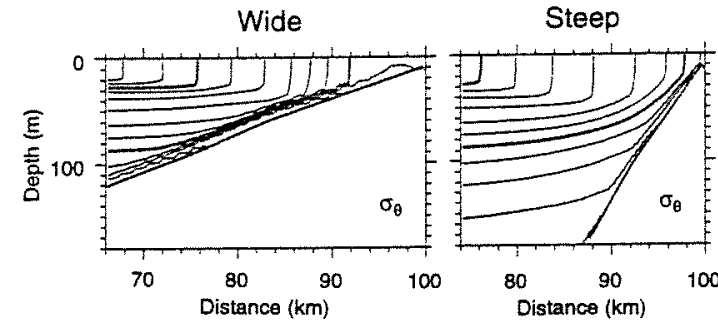

$(E)$

(F)

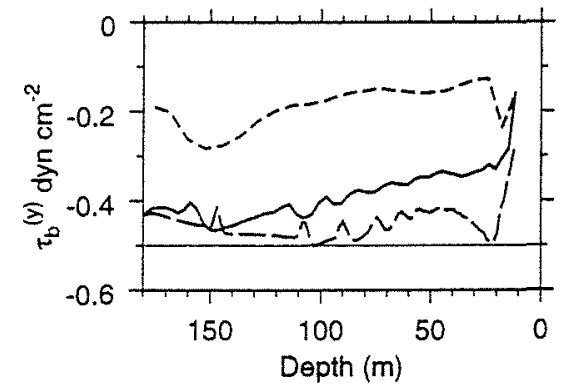

---- Steep, - BC, - Wide

Figure 4.27: Model fields from Allen et al. [1996], all taken after 16 days of $\tau^{S}=0.05 \mathrm{~N} \mathrm{~m}^{-2}$. $\|S\|$ refers to the maximum Burger number throughout the water column. A. The density field in the base case, $\|S\|=1.8$. B. Density in a weakly stratified case, $\|S\|=0.9$. C. Density in an even more weakly stratified case, $\|S\|=0.45$. D. Density at in a wide-shelf case, $\|S\|=0.45$. E. Density in a steep-shelf case, $\|S\|=7$. F. Bottom stress in the Steep, Base-case, and wide shelf cases. 


\subsection{Discussion}

\subsubsection{Observations}

Many observations have been made of upwelling circulation. Certain conditions must be met in order for a stratified inner shelf to form, and few observations have been made of stratified inner shelves (much of the upwelling literature concentrates on fairly steep shelves, and may not satisfy the small Burger number criterion for the formation of the light water wedge). However, a few observations are suggestive of the sorts of hydrographic scenarios posed in this chapter. The two most thorough sets of observations that display this behavior were made in Lake Ontario [Csanady 1977] and off the coast of Northwest Africa [Barton et al. 1977].

Observations of Lake Ontario taken during the International Field Year for the Great Lakes (IFYGL, 1972) included CTD sections and surface temperature radiometry imagery during upwelling events. Great Lakes are ideal testbeds for inner shelf studies because of the many features they have in common with the inner shelf, as well as the considerably simpler equation of state (as there is no significant impact of density from salinity). (The similarities are nicely laid out in Pettigrew [1981].) As an example of the inner shelf response during upwelling, data taken during an event in which the wind blew to the east from October 14-17, 1972 (Figure 4.28) shows a region of lighter (warmer) water near the coast, both from airborne radiometry (Figure 4.28A) and from a CTD survey (Figure 4.28B). Several other CTD sections from the same region show the "doming" of isotherms which leads to the formation of the inner shelf region. The fact that the coldest water at the surface is $4^{\circ} \mathrm{C}$ may be tied to the density maximum at that temperature in fresh water. It 

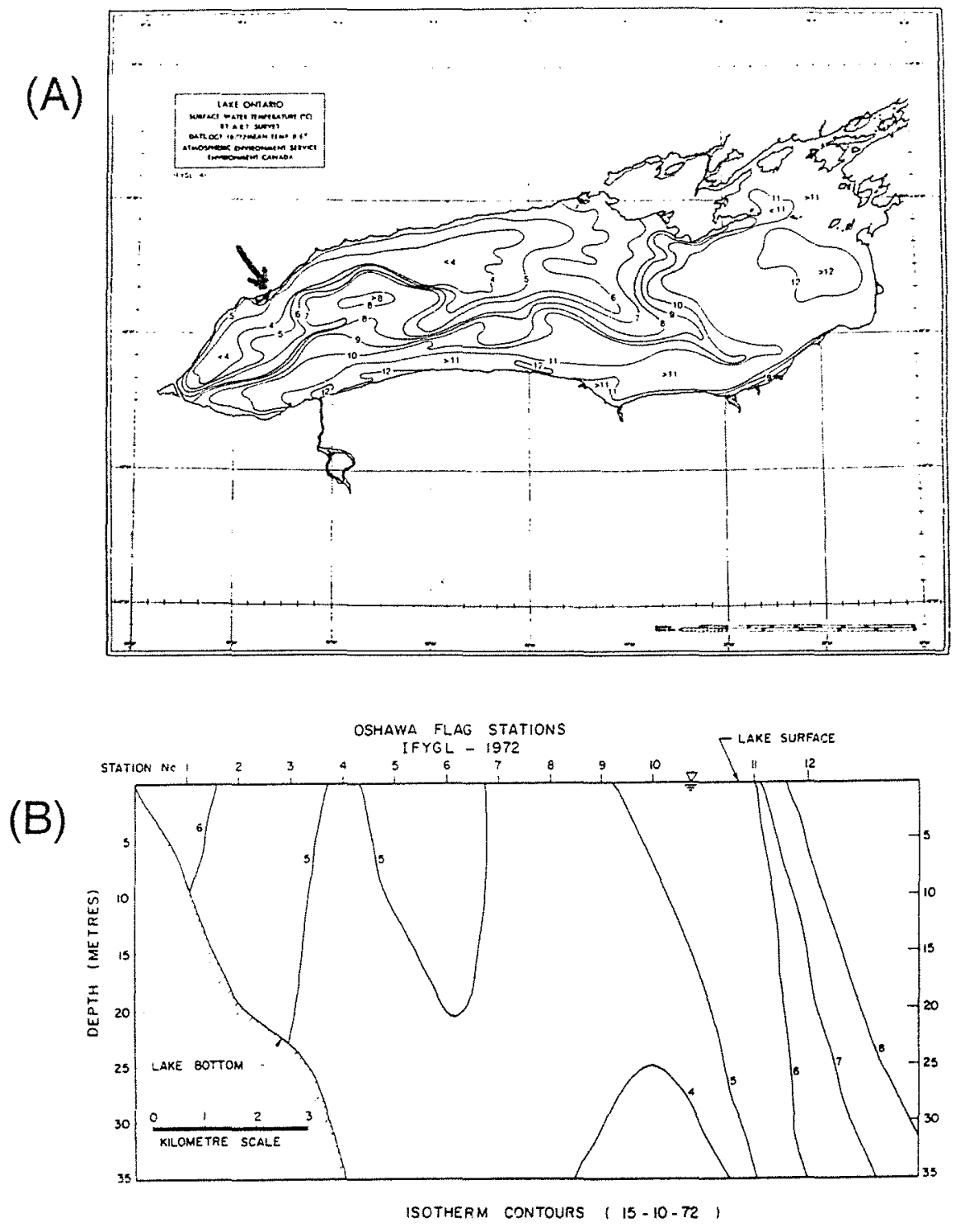

Figure 4.28: Taken from Csanady [1977]. A. Satellite image of Lake Ontario on October 18, 1972. B. CTD section taken three days earlier. Approximate location of section, on the northwest shore of the lake, indicated by arrow on $\mathrm{A}$. 
is not clear what role the nonlinearity in the equation of state at this temperature may be playing in the dynamics.

JOINT-1 was a coastal observation program conducted off the coast of Northwest Africa in 1974 [Barton et al. 1977]. The shelf is relatively gently sloped $(\alpha=0.002)$ and stratification was continuous and weak, with no distinct pycnocline. the maximum Burger number was on the order of 0.02. During February-April 1974, there
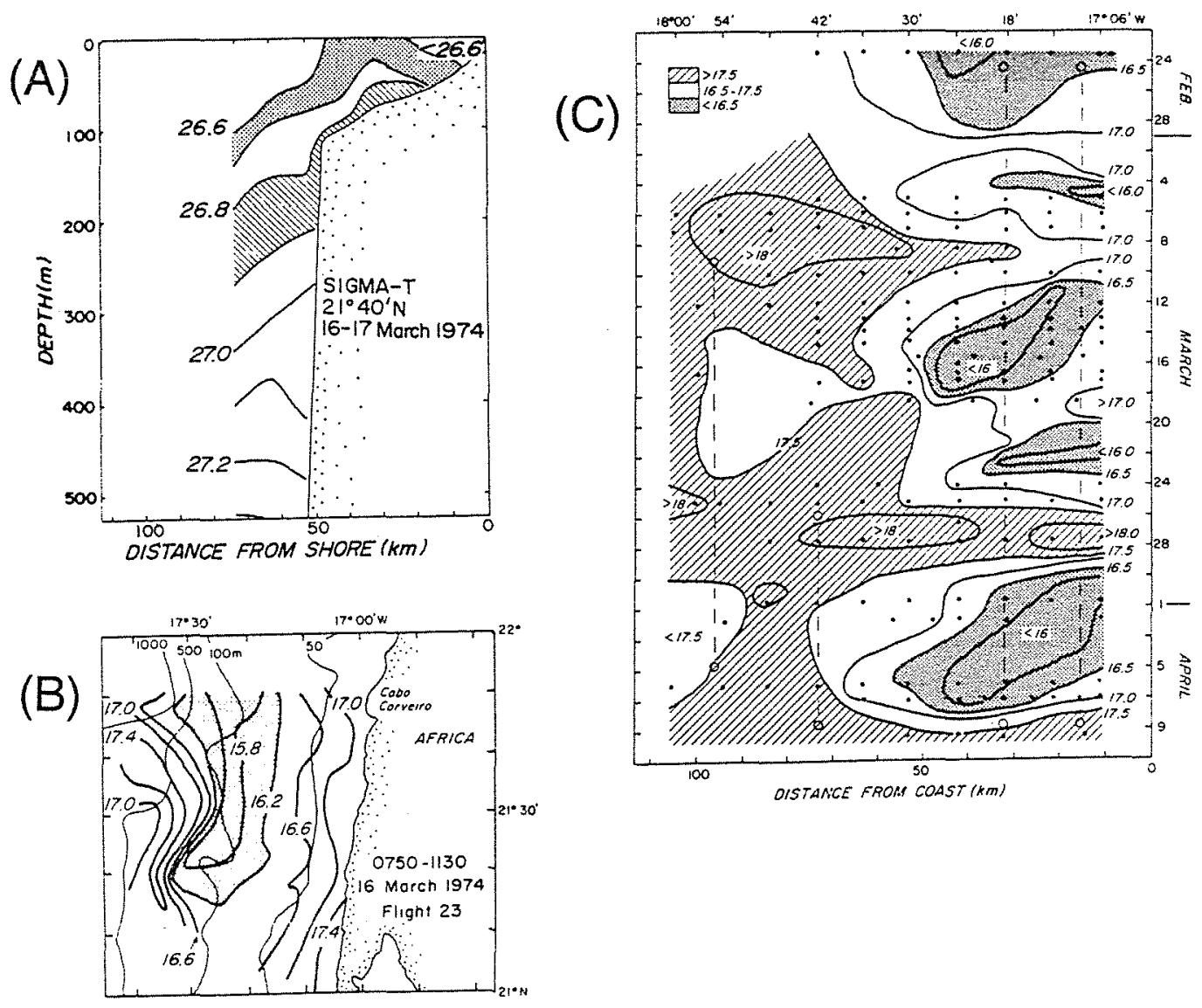

Figure 4.29: Taken from Barton et al. [1977]. Data from the JOINT-1 experiment. A. Density section from 16 March. B. Surface temperature from 16 March. C. Surface temperature as a function of time at $21^{\circ} 40^{\prime} \mathrm{N}$.

were two major upwelling events (March 10-20 and March 30-April 9) and two smaller events (March 4 and March 20-24). The surface temperature as a function 
of these events (Figure 4.29C) shows the surface temperature minimum forming near the coast and moving offshore with time, at approximately $0.05 \mathrm{~m} \mathrm{~s}^{-1}$, with a wedge of warmer water trapped closer to shore. Surface temperature measurements made from an airplane (Figure 4.29B) show that there was little variation in the alongshelf direction, and CTD surveys made during an event (Figure 4.29A) confirm the existence of doming isotherms (salinity coverage was poor during the experiment but the authors point out that salinity and temperature were well correlated, suggesting that temperature is a reasonable proxy for density). All of this hydrographic data is consistent with the stratified inner shelf scenario developed in this chapter. The velocity data (not presented here) suggest a region of slightly stronger alongshelf flow approximately coincident with the region of lowest surface temperature, also approximately consistent with the stratified inner shelf scenario.

\subsubsection{Passive Tracer Experiments}

One of the stated goals of the CoOP ISS was to collect data and develop conceptual models that would lead towards a greater understanding of the influence of circulation on the cross-shelf transport of larval species [Butman, 1994]. The potential influence of the inner shelf circulation on passive larvae was studied by introducing a passive tracer into the model. Two experiments were performed; one with the tracer starting out at the coastal boundary, and one with the tracer starting out in a uniform blob below the pycnocline, $20 \mathrm{~km}$ offshore (Figure 4.30 ). 

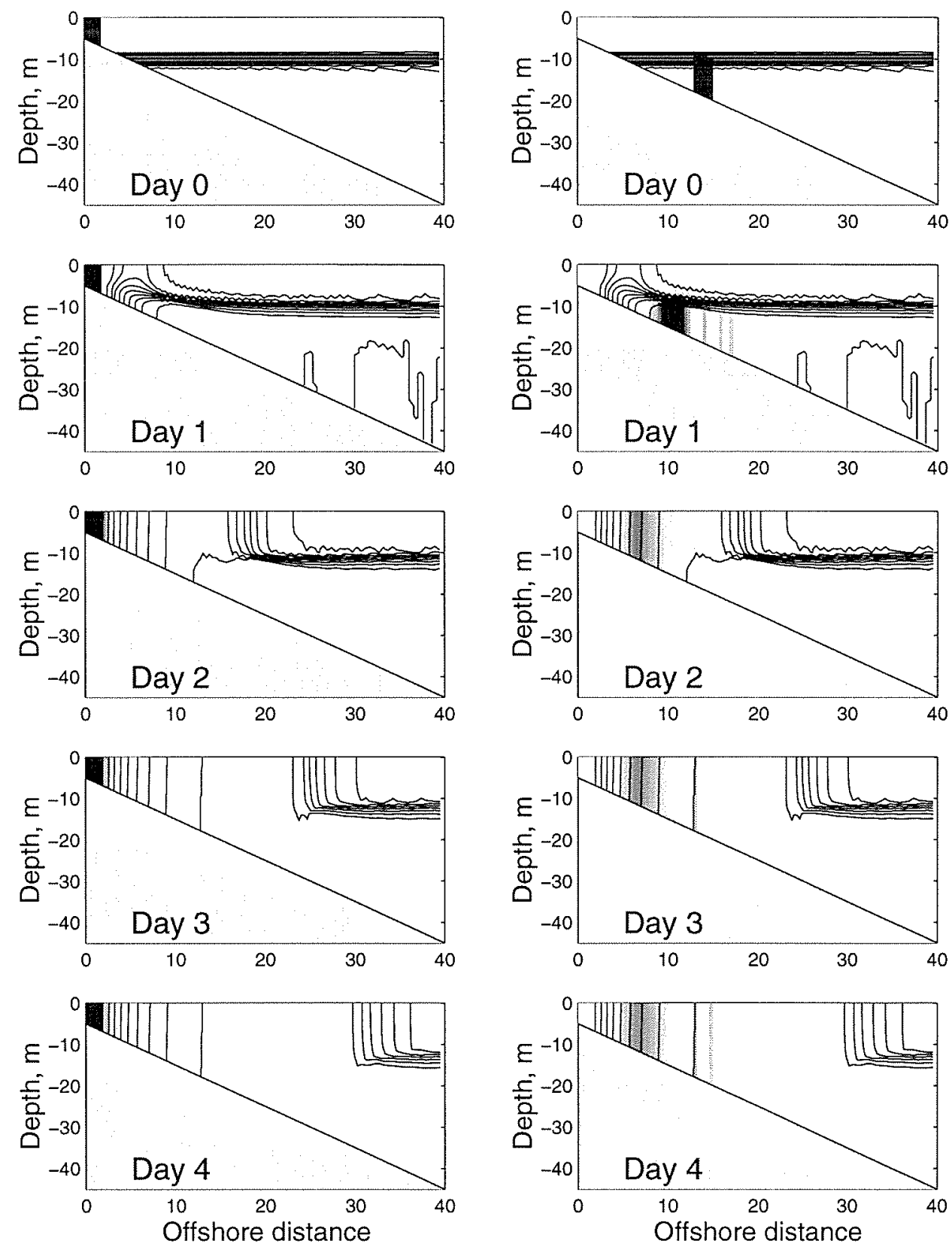

Figure 4.30: The advection of a passive tracer during upwelling in two scenarios. Shading represents tracer concentration, contours are isopycnals. Column 1: Tracer starts in a uniform patch offshore, below the pycnocline. Column 2: Tracer starts in a uniform patch at the coastline. 
In the first experiment, the tracer is started in a uniform patch at the coastal boundary. The pycnocline shoals offshore of the location of the patch and the cross-shelf velocities in the region of the patch are never great enough to advect it appreciably away from the boundary. The patch remains essentially fixed for the duration of the forcing event, even though it began in the upper layer. In the experiment in which the tracer is begun offshore, the patch moves onshore until the upwelling front passes above it. A portion of the tracer patch becomes trapped in the upwelling front and is advected offshore at the surface. Most of the tracer, however, enters the inner shelf, where not only are the cross-shelf velocities weak, but the vertical mixing is vigorous enough that the tracer patch ceases to make progress onshore.

Zooplankton are known to exhibit vertical migration behavior [Longhurst 1976], either through variations in buoyancy or by motility. Vertical migration has been postulated to be a behavior that zooplankton could use to enhance their horizontal migration by taking advantage of vertically varying horizontal currents [Hill 1991]. In both of the scenarios presented in this section, it is reasonable to expect that vertical migration behaviors could have an effect on the efficiency of the cross-shelf transport. By showing a preference for being near the surface or bottom, an organism spends more time in water moving predominantly offshore or onshore. In the case where the tracer starts offshore, it is reasonable to expect that downward migration behavior will increase the likelihood of reaching the shore, once the creature is on the inner shelf. Likewise, in the case where the tracer starts at the coast, upward migration behavior will increase the likelihood that a particle gets advected offshore. Although it is unlikely that zooplankton are capable of detecting, and hence taking advantage of, upwelling circulation per se, they are known to 
cue behavior to external stimuli such as light or temperature. This sort of behavior coupled with the upwelling circulation discussed in this chapter may make the timing of some upwelling events more likely to produce efficient cross-shelf transport than others. More needs to be known about vertical migration behavior before this line of reasoning can be advanced.

\subsubsection{Summary}

Upwelling circulation on the inner shelf differs from circulation offshore of the upwelling front, due to the differing character of the stratification. Inshore of the front, the momentum balance is primarily Ekman and the density balance is advectivediffusive, keeping isopycnals fixed in place. The presence of stratification on the inner shelf enhances the cross-shelf circulation over that expected in the neutral case. Variation of model parameters can alter not only the quantitative response but the qualitative response as well. An example of this is the coastal wall criterion, which states that the coastal wall must be placed in shallower water than the bottom boundary layer thickness in order that light water be pinched off on the inner shelf.

Uniformly stratified shelves can display qualitatively different behavior from the strong pycnocline case. By continuous advection of denser water onto the inner shelf, the shelf remains sufficiently vertically stratified to support cross-shelf transport far in excess of that in the neutral case. In addition, there is a further parameter criterion in the continuously stratified case. The value of the slope Burger number determines the structure of the onshore transport below the mixed layer. If the Burger number is small, the onshore transport occurs in to the bottom Ekman 
layer. If it is larger, the bottom Ekman layer shuts down and the onshore transport is in the interior. This impacts how isopycnals are advected onshore and the eventual density structure of the inner shelf. There is tentative but encouraging observational evidence for the inner shelf circulation similar to that discussed in this chapter. The inner shelf circulation discussed in this chapter may also have significant implications for cross-shelf transport processes, due to the role of vertical mixing in determining the fate of a passive tracer. 


\subsection{Appendix A: Surface Mixed-Layer deepening}

The densification in the surface layer due to entrainment of heavy water across the pycnocline is a complex process and it is difficult to come up with an analytical scaling for it. Simple scalings for the deepening rate (and, by extension, the rate of densification) have been derived by several investigators under varied conditions (Kato and Phillips [1969], Kantha et al. [1977], Trowbridge [1992], etc.). The simplest fundamental functional dependence for the mixing rate, and probably the most appropriate to the strong-pycnocline case considered in this chapter and the next, is given by Kantha et al.,[1977]. It assumes that there is a surface mixed layer, a sharp pycnocline of depth $h$, and a bottom mixed layer, with density difference $\delta \rho$ across the interface. The rate of deepening depends on the parameters as:

$$
h_{t}=\frac{3 R i_{C}^{1 / 2}}{2} \frac{u_{\star}^{2}}{B^{1 / 2}},
$$

where $R i_{C}=0.25$ is a critical Richardson number and $B=\frac{g}{\rho} \int \delta \rho d z$, the buoyancy anomaly of the surface layer. For the model configuration in this paper (figure 4.1), let $B=\frac{g}{\rho} \Delta \rho Z_{0}$, the initial buoyancy anomaly at the surface, which makes the assumption that $Z_{0}>>\frac{1}{2} \Delta Z$. This implies that the mixing rate is greater for stronger forcing and for weaker stratification (smaller $B$ ), as expected from basic Richardson number criteria. One attractive feature of this simple scaling is that the deepening rate is constant with time, since the buoyancy anomaly remains constant. Using data from the model runs the parameter dependence, but not the magnitude, appears to be valid, as (4.42) predicts much faster deepening than observed in the 
model. Rewriting the deepening rate with a coefficient:

$$
h_{t}=\beta \frac{3 R i_{C}^{1 / 2}}{2} \frac{u_{\star}^{2}}{B^{1 / 2}}
$$

where $\beta \approx 0.025$, is quantitatively consistent with the deepening rate in the POM model runs. This difference may be due to the stabilizing effect of rotation.

This scaling can be used to estimate the rate of densification in the surface layer. By assuming that the buoyancy anomaly at the surface is constant, that is,

$$
h(t) \delta \rho(t)=h(0) \delta \rho(0)
$$

which implies:

$$
\delta \rho_{t}=-\frac{h(0) \delta \rho(0)}{h^{2}} h_{t} .
$$

If it is assumed that the total change in $h$ is small relative to the initial mixed layer depth, then $Z_{0}=h(0) \approx h(t)$, and, using 4.43 ,

$$
\delta \rho_{t}=\left(\tau \frac{\Delta \rho^{1 / 2}}{Z_{0}^{3 / 2}}\right)\left(\frac{3 \beta R i_{C}^{1 / 2}}{2 g^{1 / 2} \rho_{0}^{1 / 2}}\right) .
$$

Assuming that the rate of change is approximately constant, the density in the surface layer can be written as a function of time as:

$$
\left.\rho_{S F C}(t)=\rho_{S F C}(0)+t\left(\frac{\tau \Delta \rho^{1 / 2}}{Z_{0}^{3 / 2}}\right)\left(\frac{3 \beta R i_{C}^{1 / 2}}{2 g^{1 / 2} \rho_{0}^{1 / 2}}\right)\right) .
$$




\section{Chapter 5}

\section{The Dynamics of Downwelling on a Stratified Shelf}

\subsection{Introduction}

The modeled inner shelf response to two-dimensional, wind-driven downwelling is considerably different than the upwelling response. The interaction of the surface and bottom boundary layers is a characteristic of both, but the resulting circulation is different, due to the feedback between the stratification and the eddy viscosity. What little is known about downwelling has often been based on the assumption that a certain amount of symmetry exists between it and upwelling, a more heavily studied phenomenon. In the absence of stratification, there is little difference between upwelling and downwelling circulation (except for the direction of the flow). This chapter focuses on the response of a two-dimensional, stratified shelf to downwelling-favorable wind forcing. The main result of this study is that, during two-dimensional wind-driven downwelling, the density field on the inner shelf 
acts to reduce the magnitude of the cross-shelf circulation below that expected in the absence of stratification. This behavior is consistent for a wide range of model parameters, and in fact does not change with the introduction of continuous stratification, unlike the upwelling case. The goal of this chapter is to develop a framework for the understanding of wind-driven downwelling circulation on stratified shelves. The approach to the problem is identical to that of the previous chapter. The model configuration used is the same as that used in the upwelling study, as are the parameters except for the wind stress, which is of the opposite sign.

\subsubsection{Previous work}

One of the few modeling studies to concentrate on the idealized coastal downwelling response is Allen and Newberger [1996], a process-oriented study of the downwelling response off of the Oregon coast. They acknowledge the importance of considering the upwelling and downwelling responses individually, as several of the results of the paper differ considerably from an earlier upwelling study [Allen et al. 1995]. This work was oriented towards a shelf-wide understanding of downwelling circulation, and on symmetric instability which occurs in the bottom boundary layer during downwelling on a continuously stratified shelf. Their model also displays the shutdown of cross-shelf circulation on the inner shelf (Figure 5.1), similar to that discussed and explained in this chapter. They found this behavior over a wide range of model parameters, such as varied bathymetry (Figure 5.1A,B) and stratification (Figure 5.1C,D). 


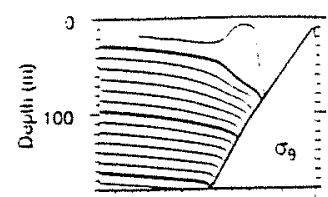

(A)
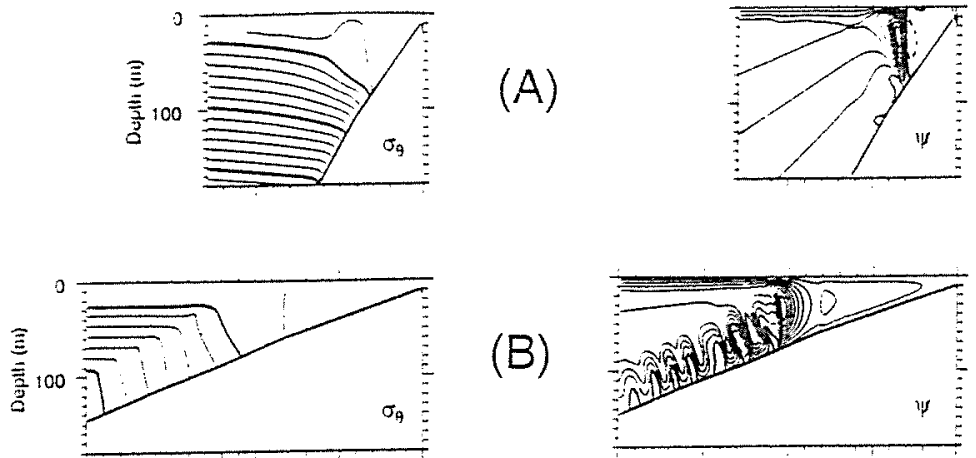

(B)
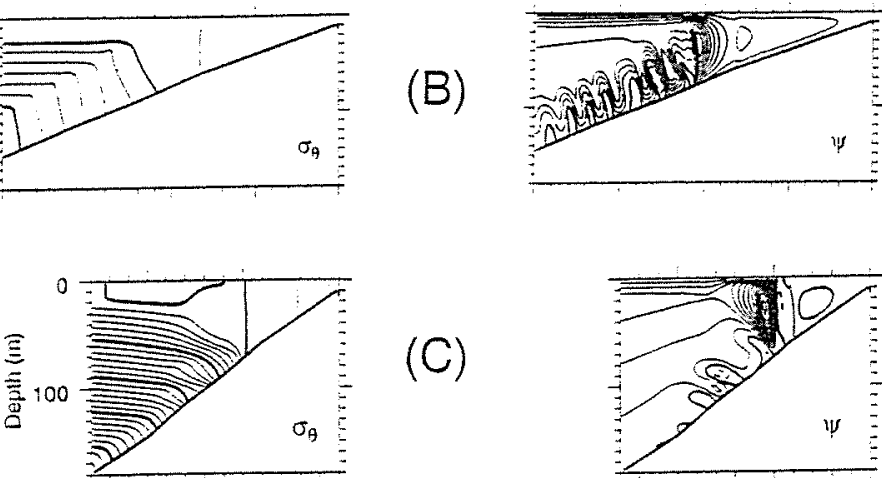

(C)
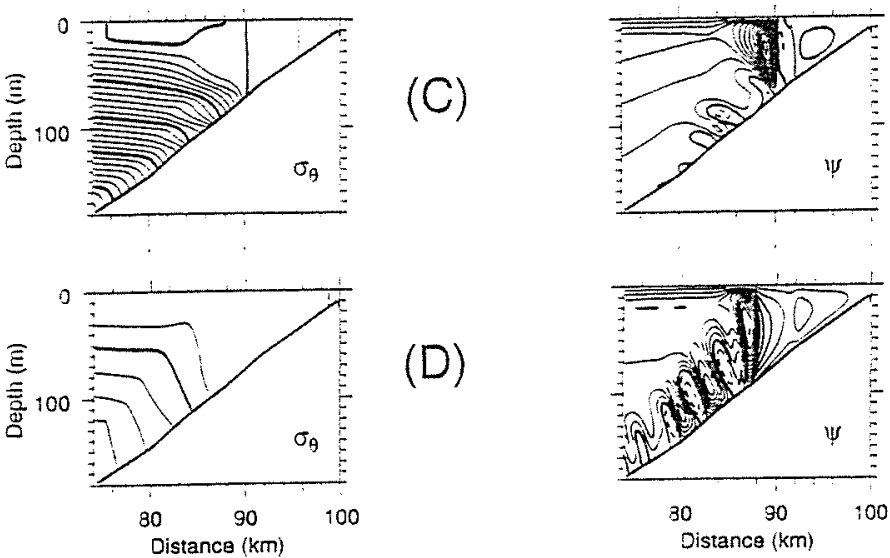

(D)

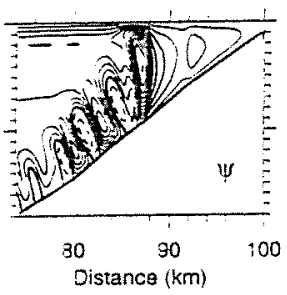

Figure 5.1: The density field and streamfunction in the model of Allen and Newberger [1996]. A. Steep slope case. B. Shallow slope case. C. Strong stratification. D. Weak stratification.

\subsubsection{Outline}

This chapter is organized as follows. Section 5.2 is a description of the downwelling response and a region-by-region discussion of the dynamics. The emphasis is on the inner shelf region. Section 5.3 is a discussion of a model run with continuous stratification, some downwelling observations, and the potential significance of the downwelling circulation for passive tracers. 


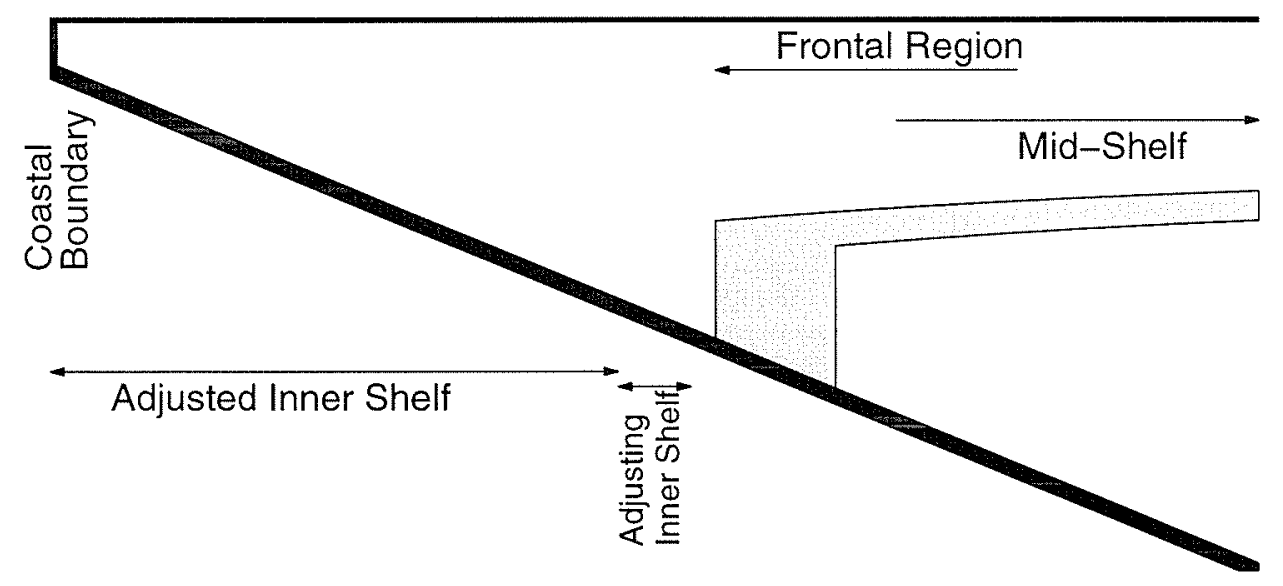

Figure 5.2: Definition of terms referred to in the regional analysis.

\subsection{The Downwelling Response}

The response of a shallow pycnocline to alongshelf surface forcing develops temporally and partitions the shelf into dynamically distinct spatial regions. This provides an ideal framework for the discussion of the dynamics. This section addresses the shelf response and the regional dynamics, from both descriptive and dynamical standpoints. First, the basic response of the system to the alongshelf wind is described. The dynamics of the inner shelf, the frontal region, and the mid-shelf (Figure 5.2), are then discussed individually. 

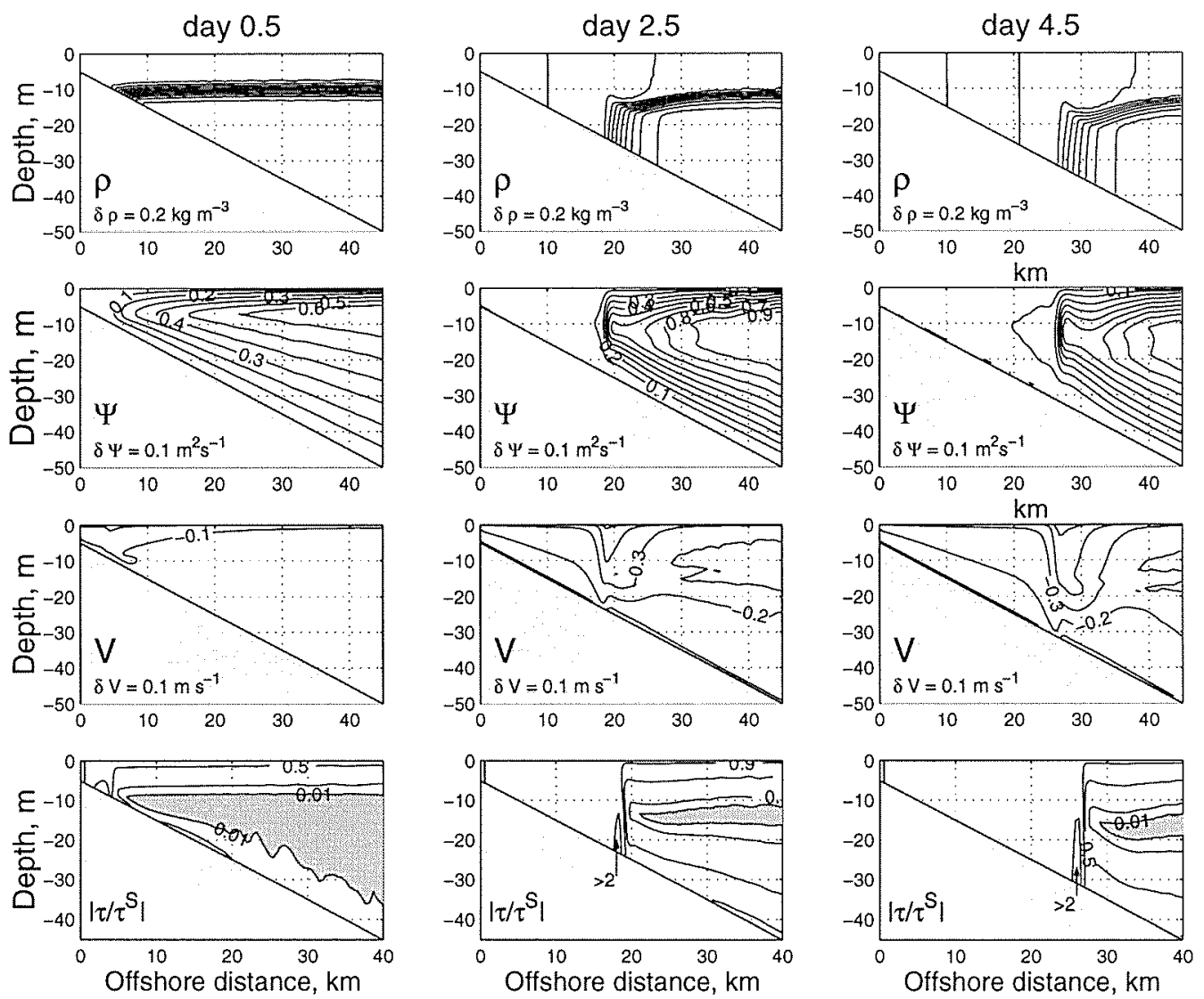

Figure 5.3: The base-case response to downwelling favorable alongshelf wind stress. The instantaneous fields of density, alongshelf velocity, cross-shelf stream function and the stress magnitude are shown for $0.5,2.5$ and 4.5 days. The contour intervals for $\rho, \Psi$, and $V$ are specified on the plots. The stress magnitude is plotted for $0.01,0.1,0.5,0.9$ and 2 times the surface stress. The region with $\left|\tau / \tau^{\mathcal{S}}\right|<0.01$ is shaded. The stream function $\Psi$ is defined as $\Psi_{x}=w, \Psi_{z}=-u$. 


\subsubsection{Description of the Base-Case Response}

The initial response of the model to the alongshelf wind is the acceleration of surfaceintensified alongshelf flow, which in turn accelerates the surface layer onshore due to the Coriolis force, resulting in the formation of a surface Ekman layer (Figure 5.3 , day 0.5$)$. The wind-forced onshore volume transport in the surface layer is initially balanced by a vertically uniform offshore flow. The offshore flow displaces the pycnocline by deepening it across the shelf, with greater deepening closer to shore (Figure $5.3, \rho$, day 2.5). By day 2.5 , the offshore flow has become concentrated near the bottom, suggesting the formation of a bottom boundary layer. The bottom boundary layer transport deflects and steepens the downwelling front, producing a region of strong horizontal density gradient. Just onshore of the downwelling front is a region of strong transport divergence, leaving the shelf inshore of this point essentially stagnant with respect to cross-shelf velocities. There is little development in the cross-shelf transport between days 2.5 and 4.5 except for the location of the region of strong divergence, which moves offshore as the downwelling front is advected offshore.

The alongshelf velocity field also changes character in the vicinity of the down-

welling front. It is initially surface intensified and varies very little across the shelf (at day 0.5 ). By day 2.5 , a strong surface-intensified jet has formed in the vicinity of the downwelling front. Velocities in the jet near the surface approach $0.5 \mathrm{~m} \mathrm{~s}^{-1}$, and increase in time as the depth of the downwelling front increases. Inshore of the jet the alongshelf velocities are much weaker, and the flow is less sheared, with velocities throughout the region on the order of $0.2 \mathrm{~m} \mathrm{~s}^{-1}$.

The basic qualitative response described here is similar for all of the model runs 
listed in table 4.1. Some quantitative aspects of the response are dependent on the model parameters. These relationships will be considered in subsequent sections of the chapter.

\subsubsection{Regional Analysis}

The vertical integral of the alongshelf momentum balance terms at two days (Figure 5.4A) suggests that there are at least four dynamically distinct regions spanning the shelf. The characteristics of the density and velocity fields (Figure 5.4B-D) are significantly different in the different regions. The inner shelf, the portion of the shelf inshore of the downwelling front, consists of two regions: an adjusted region, in which the velocity field has reached a steady state and the surface and bottom stresses balance, and an adjusting region, a narrow region just inshore of the downwelling front, in which the water column is decelerating as water previously over the downwelling front is moved onto the inner shelf. The frontal region is characterized by weakened bottom friction due to acceleration of the surface layer as the downwelling front is advected offshore, under the surface layer. Finally, the midshelf is the offshore region in which there are no significant cross-shelf density gradients, and the surface and bottom stress balance. As the dynamics here are essentially the same as for the mid-shelf in the upwelling case, it will not be discussed. The boundaries of these regions are tied to the downwelling front and hence change in time as the downwelling front is advected offshore. A discussion of the parameter dependence of the advection speed of the front will be presented first, since aspects of the regional analysis depend on it. 

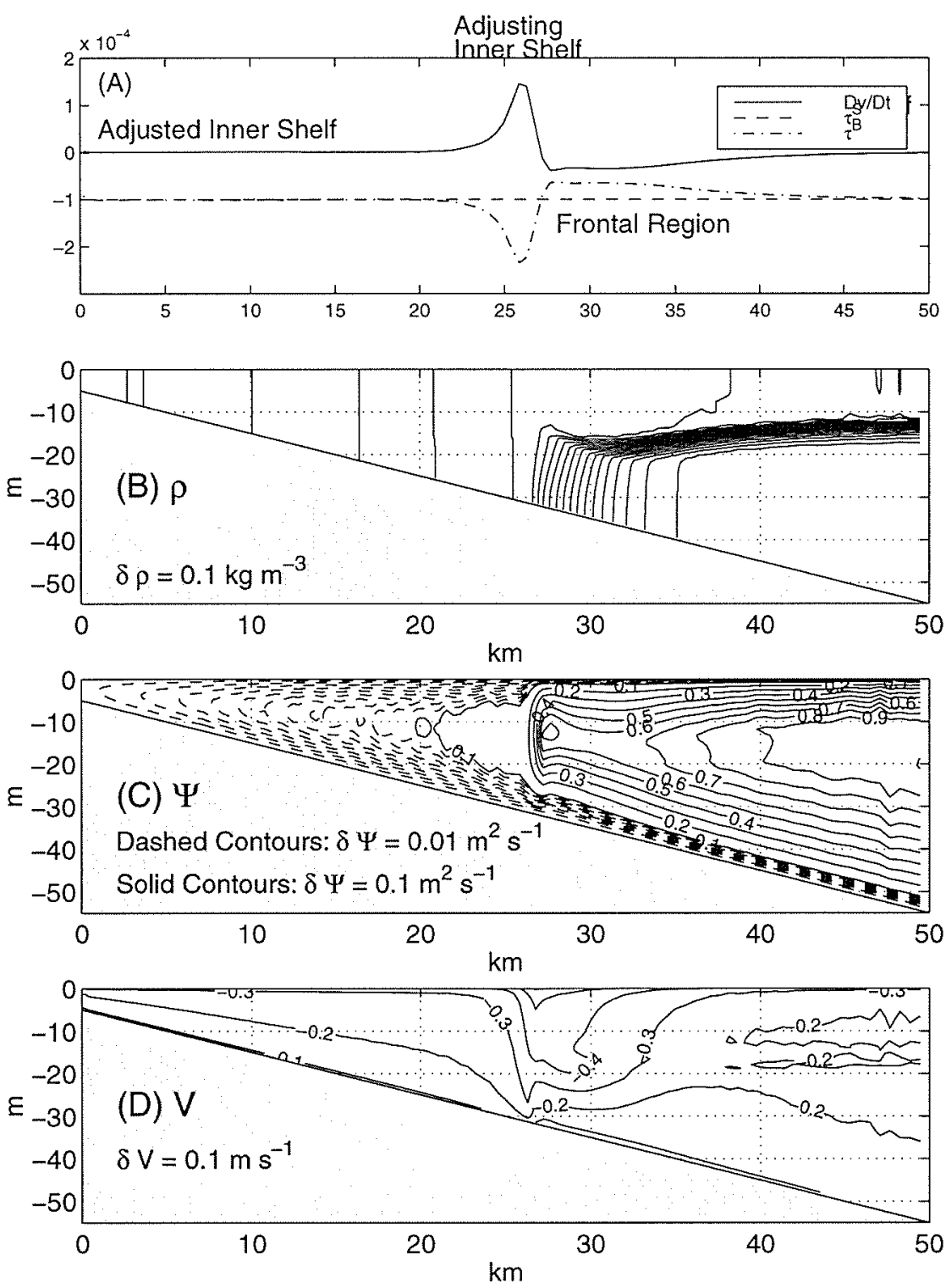

Figure 5.4: (A) The vertically integrated alongshelf momentum balance at day 2.5; (B) The density field; as in Figure 5.3; (C) The cross-shelf streamfunction; (D) The alongshelf velocity. The momentum terms shown here and in subsequent displays of the momentum and heat balances represent a two hour average centered on the stated time. 


\section{Frontal Advection}

The offshore advection of the downwelling front is due to two separate mechanisms: first, the deepening of the pycnocline due to an initial cross-shelf barotropic transport response, followed by steepening and offshore advection due to the bottom Ekman layer, which develops over approximately the first day. Although these two processes act on the pycnocline through different mechanisms, the scaling of the offshore displacement is similar. This section outlines the relative importance of these two mechanisms and their potential impact on the pycnocline.

The time evolution of the "interior" (or barotropic) transport and the bottom Ekman layer is a basic problem in coastal physical oceanography [Csanady 1982, Dever 1995]. This consists of modeling cross-shelf transport in terms of a surface Ekman layer where the surface stress and the Coriolis force are balanced, a bottom Ekman layer in which bottom stress and the Coriolis force are balanced, and an interior layer in which the Coriolis force and the surface pressure gradient are balanced. The cross-shelf transport in the three layers must sum to zero. The interior layer also plays the role of allowing the surface and bottom Ekman layers to communicate, as it is assumed that they do not communicate through the stress field. Because it is assumed that the surface and bottom boundary layers do not communicate through the stress field, it is clear that this model does not apply inshore of the downwelling front, where the stress is approximately constant through the water column. However, it does apply in the vicinity of and offshore of the front, where the stress becomes small in the vicinity of the pycnocline (Figure 5.3). To determine whether the POM model response can be understood in terms of a simple model, the POM layer transports are estimated and compared to an analytic formulation 
of the layer transport model.

The transport equations can be written, following Dever [1995], in terms of the balance in the surface layer:

$$
\begin{gathered}
U_{t}^{S}-f V^{S}=0 \\
V_{t}^{S}+f U^{S}=\frac{\tau^{s}}{\rho_{0}},
\end{gathered}
$$

the interior, or barotropic response:

$$
\begin{gathered}
U_{t}^{I}-f V^{I}=-g H \eta_{x} \\
V_{t}^{I}+f U^{I}=0
\end{gathered}
$$

and the bottom layer:

$$
\begin{aligned}
& U_{t}^{B}-f V^{B}=-r\left(\frac{U^{I}}{H}+\frac{U^{B}}{h_{B}}\right) \\
& V_{t}^{B}+f U^{B}=-r\left(\frac{V^{I}}{H}+\frac{V^{B}}{h_{B}}\right),
\end{aligned}
$$

where $U$ and $V$ represent layer transports in the cross- and alongshelf directions, respectively, and the superscripts $S, I$, and $B$ refer to "Surface", "Interior", and "Bottom", respectively, and $h_{B}$ is the estimated thickness of the bottom boundary 
layer. In addition, the absence of alongshelf variation requires, from continuity,

$$
U^{S}+U^{I}+U^{B}=0 .
$$

The bottom friction coefficient $r=5 \times 10^{-4} \mathrm{~ms}^{-1}$. Integrating the equations with quadratic bottom drag does not result in a qualitatively distinct solution. Numerically integrating these equations with $H=40 \mathrm{~m}$ and $h_{B}=20 \mathrm{~m}$ (Figure 5.3, $\Psi, 2.5$ 4.5 days) results in time series of the $U^{S}, U^{I}$, and $U^{B}$ (Figure 5.5).

This suggests that the initial barotropic response is the dominant mode of offshore transport for approximately the first day of the wind stress event, after which most of the onshore surface transport is balanced by the bottom Ekman layer. The spinup process can be thought of dynamically as follows. Initially, surface Ekman transport moves water onshore, resulting in a surface pressure gradient. A barotropic offshore transport develops to balance this transport, which accelerates an alongshelf barotropic flow. This alongshelf barotropic flow creates bottom stress which results in the spinup of the bottom Ekman layer. As the system develops, the bottom boundary layer is eventually responsible for balancing the transport and the interior alongshelf flow balances the surface pressure gradient. When the wind is shut off, a similar process occurs in which the transient barotropic response which in turns shuts down the bottom Ekman layer. However, this shutdown does not result in any onshore transport of the pycnocline, leaving the downwelling front displaced offshore after a wind event.

The equivalent transports can be estimated in the POM by assuming the surface stress and measured bottom stress are proportional to the transport in the surface 

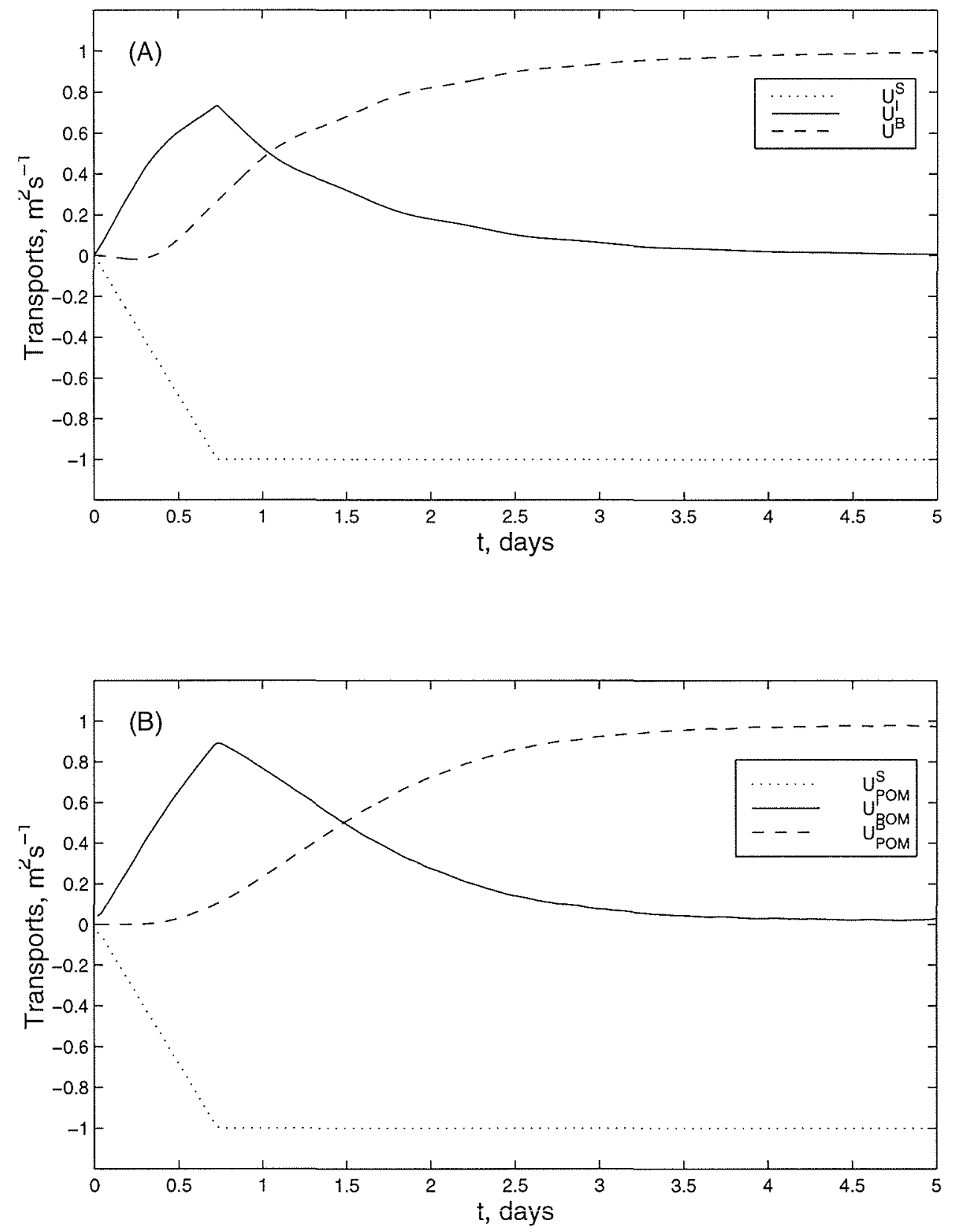

Figure 5.5: Surface, interior and bottom transports from (A) the simple layered model and (B) estimated from POM at $x=40 \mathrm{~km}$. 
and bottom layer:

$$
\begin{aligned}
& U_{P O M}^{S}=\frac{\tau^{S}}{\rho_{0} f}, \\
& U_{P O M}^{B}=\frac{\tau^{B}}{\rho_{0} f},
\end{aligned}
$$

where $\tau^{B}$ is the alongshelf component of the bottom stress at a given location. The interior transport in POM is assumed to close the transport balance, so that

$$
U_{P O M}^{I}=-U_{P O M}^{S}-U_{P O M}^{B}
$$

There is only one truly independent time series here, since $U_{P O M}^{S}$ is imposed on the system and $U_{P O M}^{I}$ is estimated using the assumption that the total cross-shelf transport is zero. Comparing these time series (Figure 5.5B) to the analytic model (Figure 5.5A), using the bottom stress measured $40 \mathrm{~km}$ offshore in POM, suggest that the simple transport model provides a reasonable framework for discussing the offshore transport of the pycnocline. The simple transport modeled here does not take stratification into account. The fact that POM at least qualitatively agrees with the simple transport model suggests that the stratification in POM has little effect on the transport structure offshore of the downwelling front.

The initial response of the pycnocline is to the barotropic transport response, which is assumed to be depth independent (Figure 5.3, $\Psi, 0.5$ days). Uniform offshore flow over a sloped bottom results in vertical velocities, which is zero at the surface and largest at the bottom. These vertical velocities displace the pycnocline downwards, most strongly where the pycnocline is close to the bottom (close to 
shore) and less strongly where the pycnocline is relatively high in the water column (further offshore). This results in the pycnocline sloping downwards towards the shore and being displaced offshore, which is observed at 2.5 days in the density contours (Figure 5.3). If it is assumed that the initial transport response can be approximated by $U^{I} \approx-U^{S}$, then the approximate deflection of the pycnocline due to the barotropic response can be estimated.

If the horizontal velocity field is

$$
u_{B A R O}(x)=-\frac{U^{S}}{H(x)},
$$

(4.4) can be used to estimate the vertical velocity field $w$ :

$$
w_{B A R O}(x, z)=\frac{\alpha U^{S} z}{H(x)}
$$

It can also be used to estimate the displacement of isopycnals. Define a coordinate system $x^{\prime}=H_{0} \alpha^{-1}+x$ so that $H=\alpha x^{\prime}$. Then, writing (5.11) as a differential equation

$$
\frac{d x^{\prime}}{d t}=-\frac{U^{S}}{\alpha x^{\prime}}
$$

yields

$$
\left(x^{\prime 2}-x_{0}^{2}\right)=2 \alpha^{-1} \int_{0}^{t} U^{S} d t
$$

Since particles in this field will move along $\sigma$ surfaces,

$$
\frac{x^{\prime}(t)}{z(t)}=\frac{x_{i}}{z_{i}},
$$




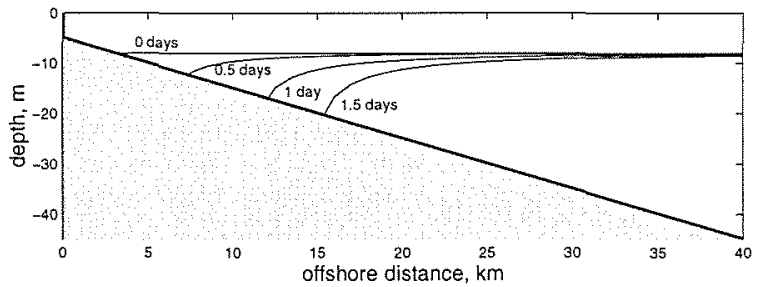

Figure 5.6: The displacement of an isopycnal initially at $8 \mathrm{~m}$ depth, due to a purely barotropic transport response (5.16).

where $\left(x^{\prime}(t), z(t)\right)$ is the path of a particle initially at $\left(x_{i}, z_{i}\right)$. These can be combined to yield an expression for the depth of an isopycnal initially at depth $z_{i}$ :

$$
z(t)=\frac{z_{i}}{\sqrt{1-\frac{2 \int_{0}^{t} U^{S} d t}{\alpha x^{2}}}} .
$$

This solution is shown for the first 1.5 days at half-day intervals (Figure 5.6), showing vertical displacements on the order of $10 \mathrm{~m}$ at the onshore extent of the pycnocline. The location of the intersection of the pycnocline with the bottom has also clearly moved offshore. This displacement of the location of the intersection of the pycnocline with the bottom can be written as a function of time:

$$
x_{B A R O}(t)=\sqrt{\int_{0}^{t} \frac{2 U^{S}}{\alpha} d t+X_{0}^{2}}
$$

where $X_{0}$ is the initial position of the front.

The Ekman response results in slightly lighter water from just onshore of the downwelling front being pushed under the front, resulting in steepening (Figure 5.3, $\rho$, day $2.5,4.5)$. The steepening behavior is similar to that observed in upwelling fronts in other modeling studies [Hamilton and Rattray, 1978, Chen et al., 1990]. In 


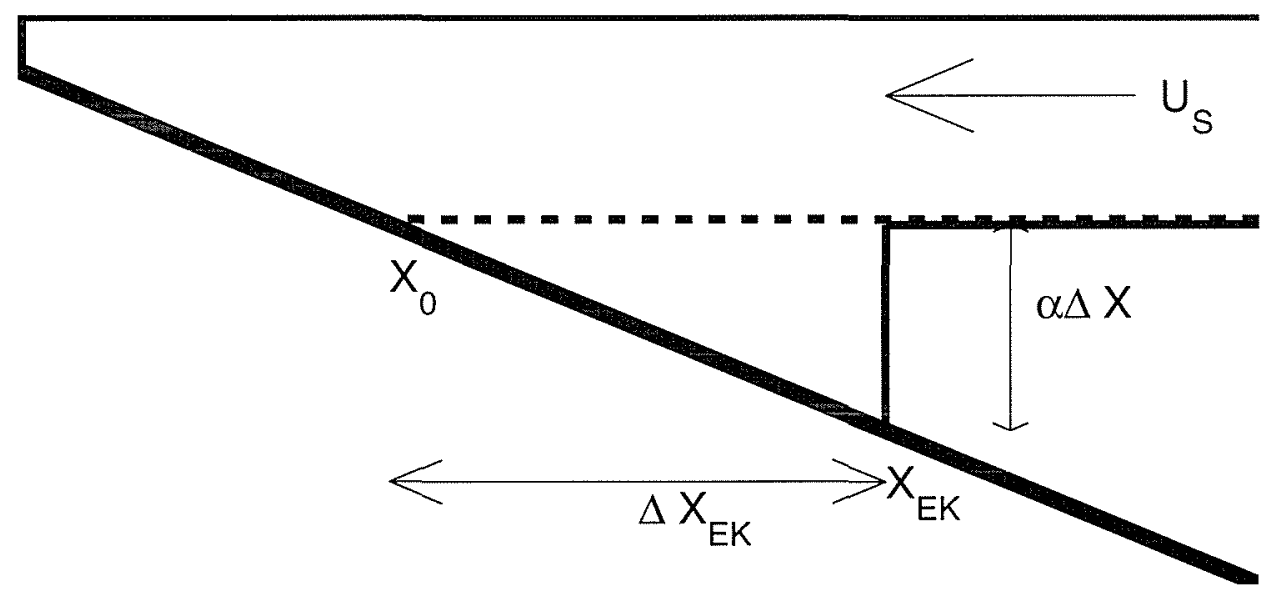

Figure 5.7: Schematic of the derivation for the Ekman advection model. The dashed line is the location of the pycnocline at time 0 ; the solid line is the location at time $t$, assuming all displacement is due to the Ekman deepening mechanism.

the upwelling case, denser water from onshore is advected over the slightly lighter water offshore of the front, resulting in convective adjustment. If the barotropic transport is ignored, so that $U^{B} \approx-U^{S}$, and the effect of the Ekman response is to simply deepen the front, a simple geometrical argument (Figure 5.7) can be used to estimate a displacement scale:

$$
\frac{1}{2}\left(\Delta x_{E K}\right)\left(\alpha \Delta x_{E K}\right)=\int_{0}^{t} U^{S} d t
$$

or

$$
x_{E K}(t)=X_{0}+\sqrt{\int_{0}^{t} \frac{2 U^{S}}{\alpha} d t} .
$$


After one day, $U_{B}>U_{I}$ (Figure 4.16), and this is the predominant deepening mechanism. The actual deepening process is a combination of these two processes, initially the shelf-wide deepening of the pycnocline by the barotropic response, and then the steepening of the front by the bottom Ekman layer. These two processes combine to create the actual displacement, which cannot be modeled analytically. However, the displacement scales in both mechanisms as approximately:

$$
\Delta X \approx \sqrt{\frac{2 \tau^{S} \Delta t}{\rho_{0} f \alpha}}
$$

where $\Delta t$ is the duration of a steady wind event. The success of this scaling suggests that the initial density structure plays little role in determining the offshore propagation of the pycnocline, and in fact model runs where stratification parameters are varied show little variation in pycnocline displacement. The displacement of the downwelling front in the base case is shown in Figure 5.8 (heavy lines) along with the barotropic displacement scale (5.17) and the Ekman displacement scale (5.19). These two estimates differ by approximately $2 \mathrm{~km}$, and predict the development of

the frontal position reasonably well. Variations in the frontal displacement due to changes in $\tau^{S}$ and $\alpha$ are in good agreement with this scaling (Figure 5.9).

\section{Inner shelf, adjusted region}

The adjusted inner shelf is the region closest to shore, and grows in extent as the downwelling front is advected offshore. It is characterized by a weak cross-shelf density gradient (Figure 5.4B) with the lightest water onshore, weak cross-shelf circulation and alongshelf flow with little stress divergence.

The momentum balance in this region is simple (Figure 5.10). In the alongshelf 


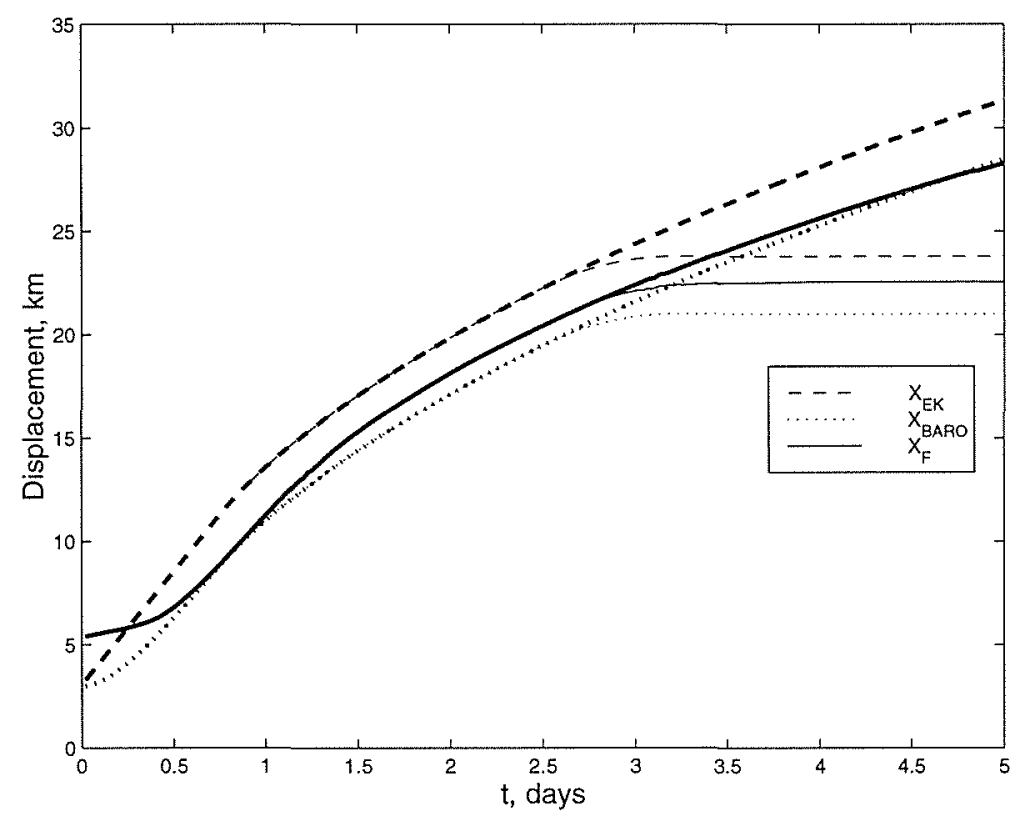

Figure 5.8: The displacement of the downwelling front in the POM base case as a function time and the barotropic (5.17) and Ekman (5.19) displacement scales. Heavy lines: constant forcing. Light lines: relaxation case (dashed line, Figure 4.2). 


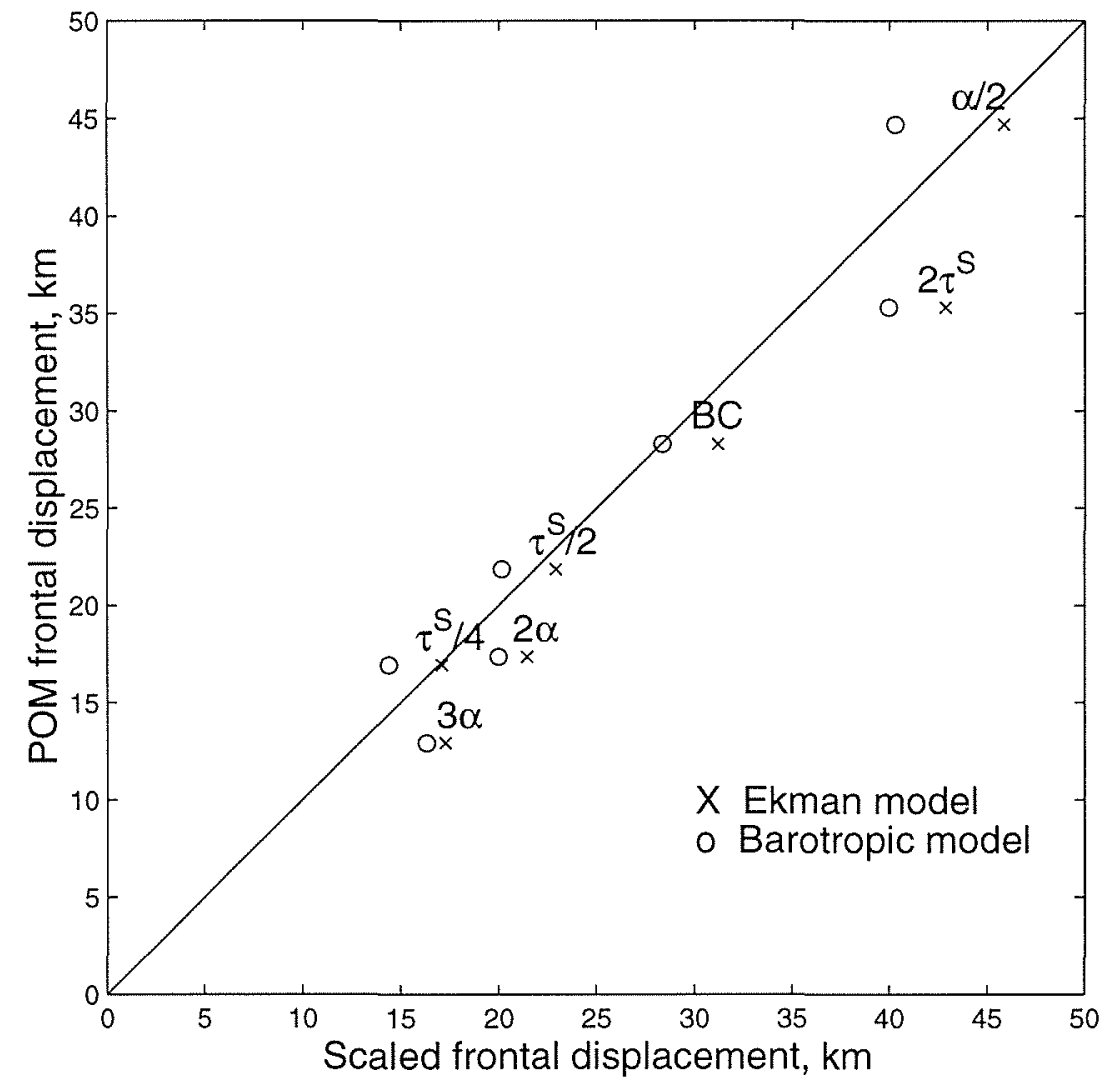

Figure 5.9: The displacement of the downwelling front at 5 days, versus the barotropic and Ekman displacement scales. x: Ekman scale vs. POM. o: Barotropic scale vs. POM. 

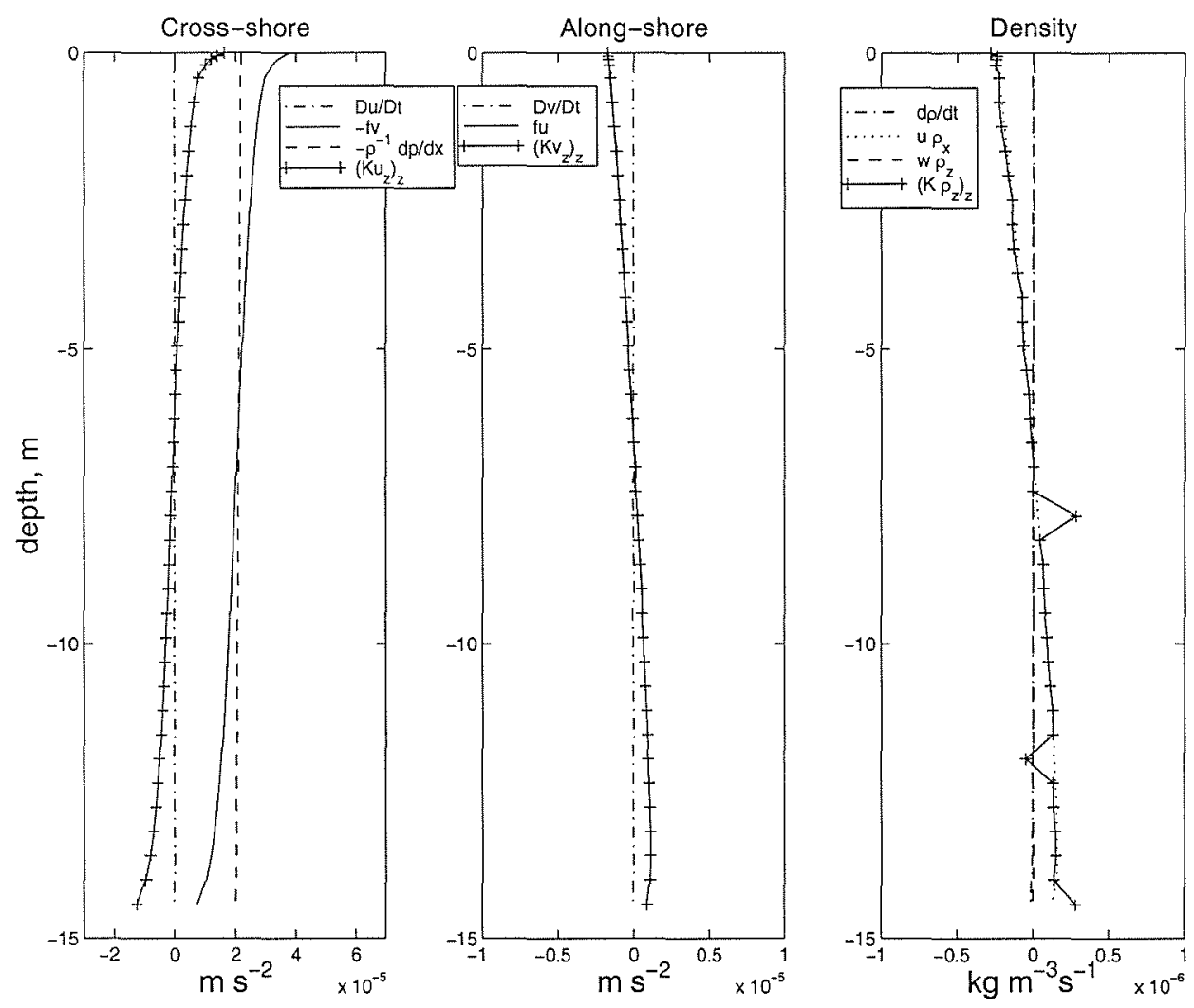

Figure 5.10: Terms of the cross-shelf momentum balance, alongshelf momentum balance, and density balance on the inner shelf, at $10 \mathrm{~km}$ offshore at 4.5 days. The "spikes" in the density mixing profile at $8 \mathrm{~m}$ and $12 \mathrm{~m}$ are balanced by the horizontal diffusivity (not shown).

momentum equation, the terms are all sufficiently small that the stress throughout the water column is approximately constant (for any value of $z, \int_{z}^{0}\left(K_{M} v_{z}\right)_{z} d z<<$ $\left.\tau^{S} \rho^{-1}\right)$, so that:

$$
\underline{K}_{M} v_{z} \approx \frac{\tau^{S}}{\rho}
$$

In the cross-shelf direction, there is a balance between the pressure gradient, which is due mainly to the barotropic (surface) contribution $g \eta_{x}$, the stress divergence, 
and the Coriolis term:

$$
-f v=-g \eta_{x}+\left(K_{M} u_{z}\right)_{z}
$$

Since the alongshelf stress divergence is weak, the cross-shelf velocities are weak in this region. The stress divergence is weak because the eddy viscosities are enhanced by persistent, but weak, convective overturning on the inner shelf. The source of the convective overturning will be discussed next.

The density field is vertically homogeneous and has a very weak cross-shelf density gradient with the lightest water near the coast. The cross-shore gradient is the result of a combination of two processes: the offshore movement of the downwelling front and the slow entrainment of heavier water across the pycnocline into the surface layer. Since the cross-shelf circulation on the inner shelf is stagnant, isopycnals are fixed into place once on the inner shelf. Therefore, the density at a given cross-shelf location is determined by the density in the upper layer at the time the downwelling front passes that location. If the cross-shelf position of the downwelling front is $x_{F}(t)$ and the density in the surface layer offshore of the downwelling front is $\rho_{S}(t)$, then the expected density field over the adjusted inner shelf $\rho_{I S}(x)$ can be written as:

$$
\rho_{I S}(x)=\rho_{S}\left(x_{F}^{-1}(x)\right)
$$

where $x_{F}^{-1}$ is the inverse function of $x_{F}$ (which is monotonic and hence easily inverted). Comparing the actual adjusted inner shelf horizontal density profile, $\rho_{I S}$ to the estimate given above using the mean offshore density at the surface for $\rho_{S}$ (Fig- 


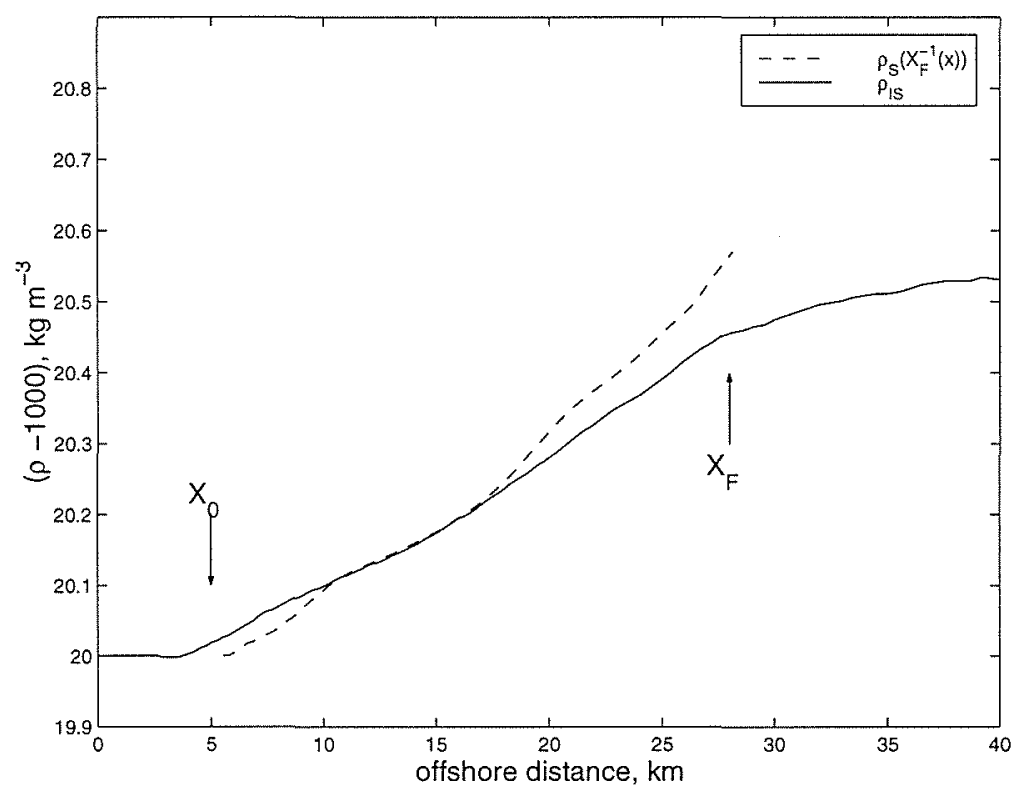

Figure 5.11: Cross-shelf density structure in the POM and from scaling (5.23) on the inner shelf at 5 days. The water on the inner shelf (onshore of the front, in this case approximately $18 \mathrm{~km}$ offshore ) is vertically homogeneous.

ure 5.11), suggests that this is indeed the process responsible for the weak density gradient on the inner shelf. Equation (5.23) only applies to the range $X_{0}<x<X_{F}$, i.e. the range through which the downwelling front has passed; therefore it is invalid inshore of the initial position of the front and offshore of the current position of the front. The pycnocline initially intersects the bottom approximately $5 \mathrm{~km}$ offshore, and the density in this region is approximately constant and equal to the initial density of the surface layer. Offshore of the downwelling front, the surface density is approximately constant. 


\section{The inner shelf density gradient}

Combining the cooling rate of the surface layer (Chapter 4, Appendix A), with the pycnocline displacement scale (5.20), (5.23) allows the estimation of the dependence of the size of the cross-shelf density gradient on the inner shelf on the model parameters. If the offshore position of the front is approximated using:

$$
X_{F}(t) \approx X_{0}+\sqrt{\frac{2 \tau^{S t}}{\rho_{0} f \alpha}},
$$

(this assumes that most of the deepening is due to the Ekman deepening mechanism), and the density of the upper layer is, as a function of time:

$$
\rho_{S F C}(t)=\rho_{0}(0)+t\left(\frac{\Delta \rho^{1 / 2} \tau^{S}}{Z_{0}^{3 / 2}}\right) \frac{3 \beta R i_{C}^{1 / 2}}{2 g^{1 / 2} \rho_{0}^{1 / 2}}
$$

(Chapter 4, Appendix A) then, inverting the displacement scaling (5.24), solving for $t$ as a function of $X_{F}$, and substituting into (5.25) yields an estimate for the horizontal density profile of the inner shelf:

$$
\rho_{I S}(x)=\rho_{0}+\frac{\Delta \rho^{1 / 2} \alpha}{\left(Z_{0}\right)^{3 / 2}}\left(\frac{3 \beta f \rho_{0}^{1 / 2} R i_{C}^{1 / 2}}{4 g^{1 / 2}}\right)\left(x-X_{0}\right)^{2},
$$

which is valid for $X_{0}<x<X_{F}(t)$. Intriguingly, the gradient does not depend on the forcing intensity; as the forcing gets stronger, the front moves offshore faster, but the surface densifies faster as well, the effects canceling out. It also predicts stronger gradients for shallower mixed layers, for steeper shelves, and for larger initial density differences. Fitting a profile of form $\rho_{0}+\gamma\left(x-x_{0}\right)^{2}$ to the model density profiles for $X_{0}<x<X_{F}$ allows comparison of this scaling to the model results. The predicted variations are reflected in the model runs (Figure 5.12). The estimate for $Z_{0} / 2$ is 


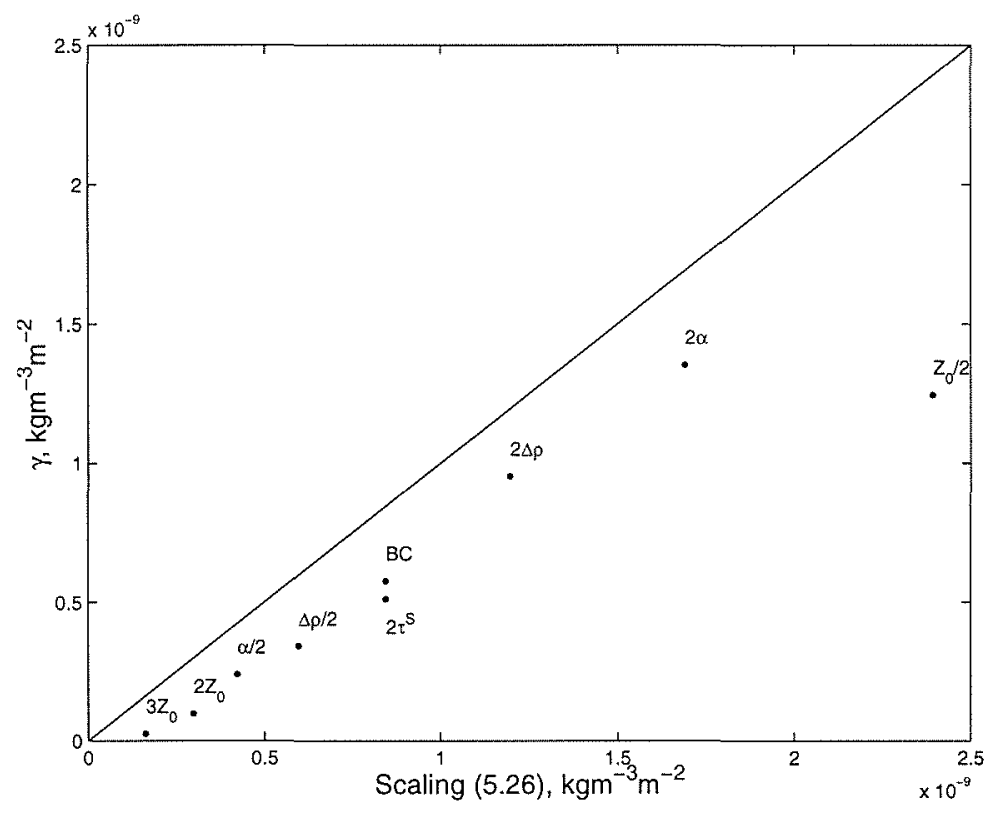

Figure 5.12: The quadratic coefficient of (5.26) versus the best quadratic fit of the inner shelf density gradient in POM.

too large because the change in the depth of the mixed layer is small compared to its original depth, whereas the scaling for the rate of change of density assumes that the change in mixed layer depth is small compared to the initial depth. The scaling overpredicts the rate at which the upper layer becomes denser, and hence overpredicts the size of the inner shelf gradient. Regardless of the parameters chosen, the density gradients produced by this process are weak, and therefore processes not considered here (such as surface heating or cooling, or the influx of freshwater) may act to modify this gradient. The most important aspect of this process, however, is that the density gradient will always be of the same sign- the lightest water will always be found closest to the shore. In the limit of strong forcing, when local mixing may be more important than advection for determining the eventual crossshelf density profile (Figure 5.13), the lightest water is still found near the coast. As 

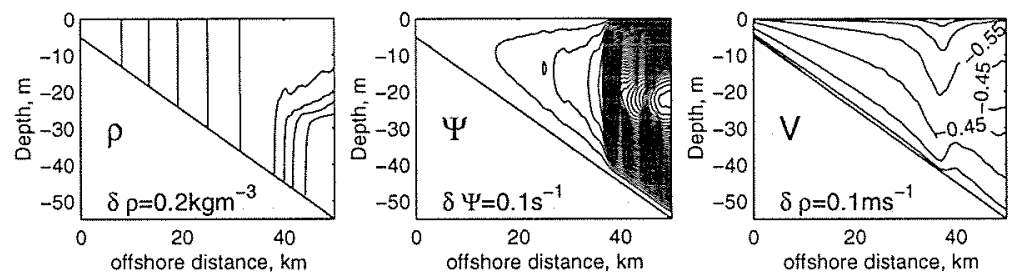

Figure 5.13: The density field, streamfunction, and alongshelf velocity at 2 days in the $4 \tau^{S}$ case, demonstrating the formation of the inner shelf density gradient in the presence of strong vertical mixing.

the actual shelf response is going to be some combination of advection and mixing, this suggests that the orientation of this gradient is not sensitive to the strength of the mixing event, and the lightest water is always found onshore.

The weak density gradient is kept in place by the weak downwelling-favorable circulation. As water moves onshore at the surface, slightly lighter water is displaced offshore at the bottom, resulting in convective adjustment. The observed circulation is weaker than expected from the neutral case (Figure 5.14B). The convective adjustment increases the eddy viscosity above what would be expected in the absence of stratification (Figure 5.14A). This increases the Ekman depth and decreases the strength of the circulation (Figure 5.14B). The upwelling and downwelling crossshelf transport in the neutral case were found to be nearly identical, as is expected for unstratified water. As the upwelling circulation was considerably stronger than that in the neutral case, the upwelling circulation in the base case is more than twice as strong as that modeled in the downwelling case. This asymmetry increases as the initial density difference in the system is increased. 

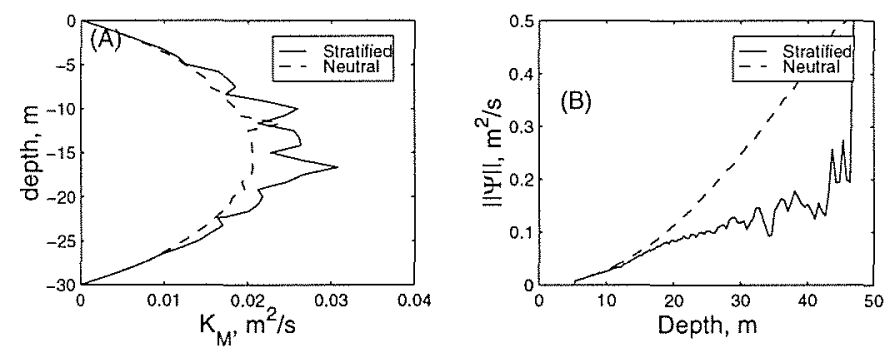

Figure 5.14: A comparison of the neutral (unstratified) downwelling case and the downwelling base case, at 9 days. (A) Profiles of eddy viscosity $25 \mathrm{~km}$ offshore; (B) the maximum streamfunction as a function of local water depth.

\section{Inner shelf, adjusting region}

The adjustment region of the inner shelf is a transitional region from the frontal region, in the vicinity of the pycnocline, to the adjusted portion of the inner shelf, inshore of the pycnocline. As the front moves offshore, it exposes water previously above the pycnocline to the bottom. The water directly above the downwelling front has large alongshelf velocities, due to thermal wind shear below it. As the pycnocline moves offshore of a given location, the momentum of the jet at that location is immediately mixed downwards and dissipated by bottom friction. The adjustment region is the region in which this deceleration occurs. The regions of large stress magnitude at days 2.5 and $4.5,18$ and $26 \mathrm{~km}$ offshore, respectively (Figure 5.3) are indicative of this region, as well as the region of large bottom stress (Figure 5.4A). This region is evident in cross-shelf profiles of bottom stress generated in the results of Alleñ and Newberger [1996] (their Figure 13).

The momentum balances in this region (Figure 5.15) are similar to those on the adjusted inner shelf, except for the presence of a time-dependent (deceleration) term 


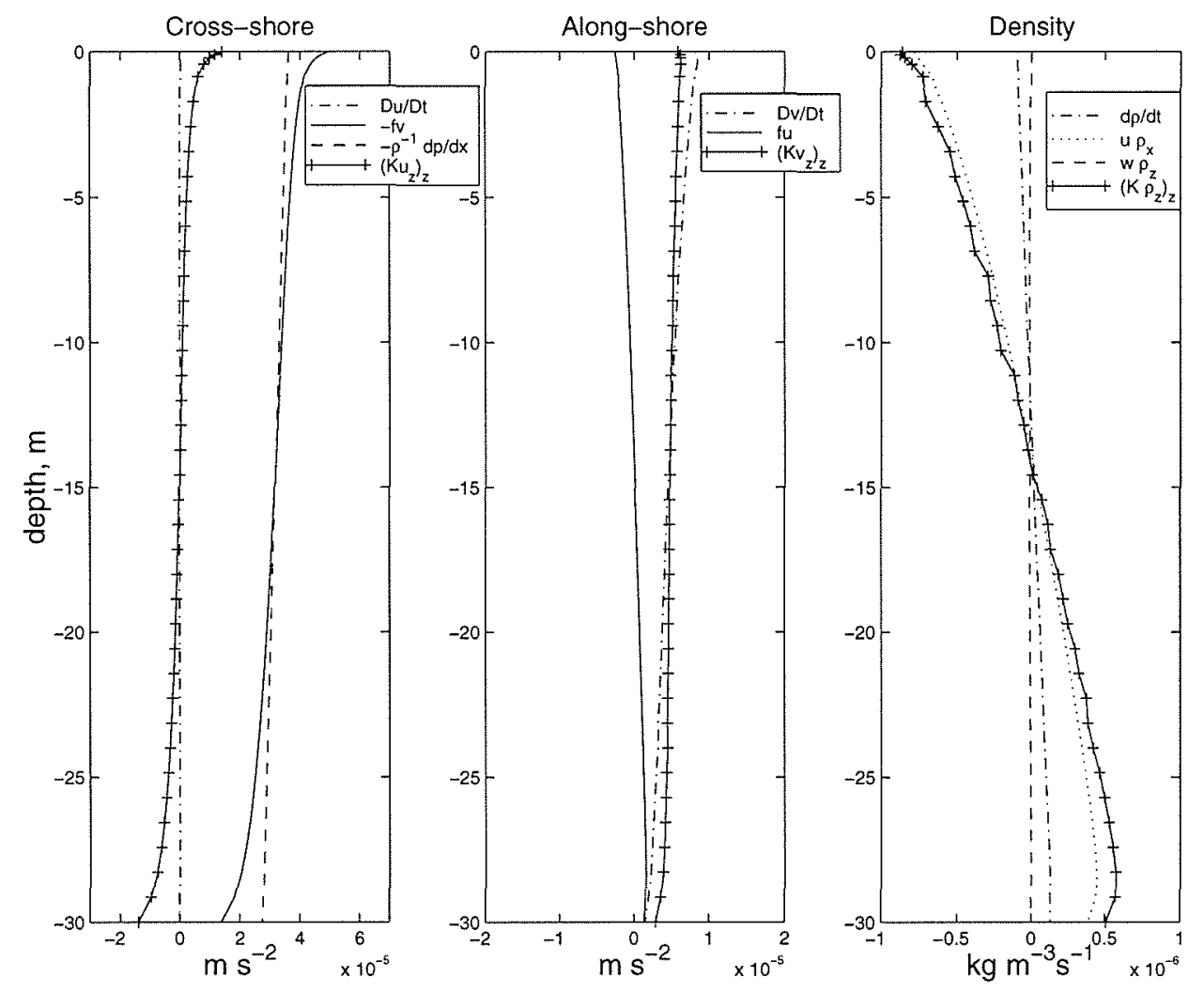

Figure 5.15: Terms of the cross-shelf balance, alongshelf balance, and density balance on the adjusting inner shelf, at $24 \mathrm{~km}$ offshore at 4.5 days. 
in the alongshelf equation. The alongshelf balance is approximately:

$$
v_{t}=\left(K_{M} v_{z}\right)_{z} .
$$

The cross-shelf momentum balance and the density balance are both essentially the same as on the adjusted inner shelf. In this sense, the adjustment region is simply an extension of the adjusted inner shelf, with the added dynamic element of strong alongshelf deceleration. These two regions combine to form the inner shelf.

The width of the adjustment region can be scaled using (5.27) the frontal speed. Since the region represents water adjusting to unstratified condition after the front has passed by, the width of the region should be the product of the adjustment time and the frontal velocity. The adjustment time can be estimated from (5.27), which is similar in form to the heat equation, using

$$
T_{A D J}=\frac{H^{2}}{\|K\|},
$$

where $\|K\|$ is an eddy diffusion scale and $H$ the local water depth. With $\|K\| \approx$ $2 \times 10^{-2} \mathrm{~m}^{2} \mathrm{~s}^{-1}$ and $H \approx 30 \mathrm{~m}$ (Figure 5.4 ), and a frontal velocity of approximately

$0.06 \mathrm{~m} \mathrm{~s}^{-1}$, this estimate yields a time scale of approximately $\frac{1}{2}$ day, and a regional width of approximately $2.5 \mathrm{~km}$, in reasonable agreement with figure 5.4 .

\section{The Frontal Region}

The frontal region is characterized by both strong horizontal and vertical density gradients and strong alongshelf flows. Like the inner shelf regions, the frontal region does not occupy a fixed location on the shelf, but moves offshore as the pycnocline is advected further offshore during the wind event. The frontal region is considered 

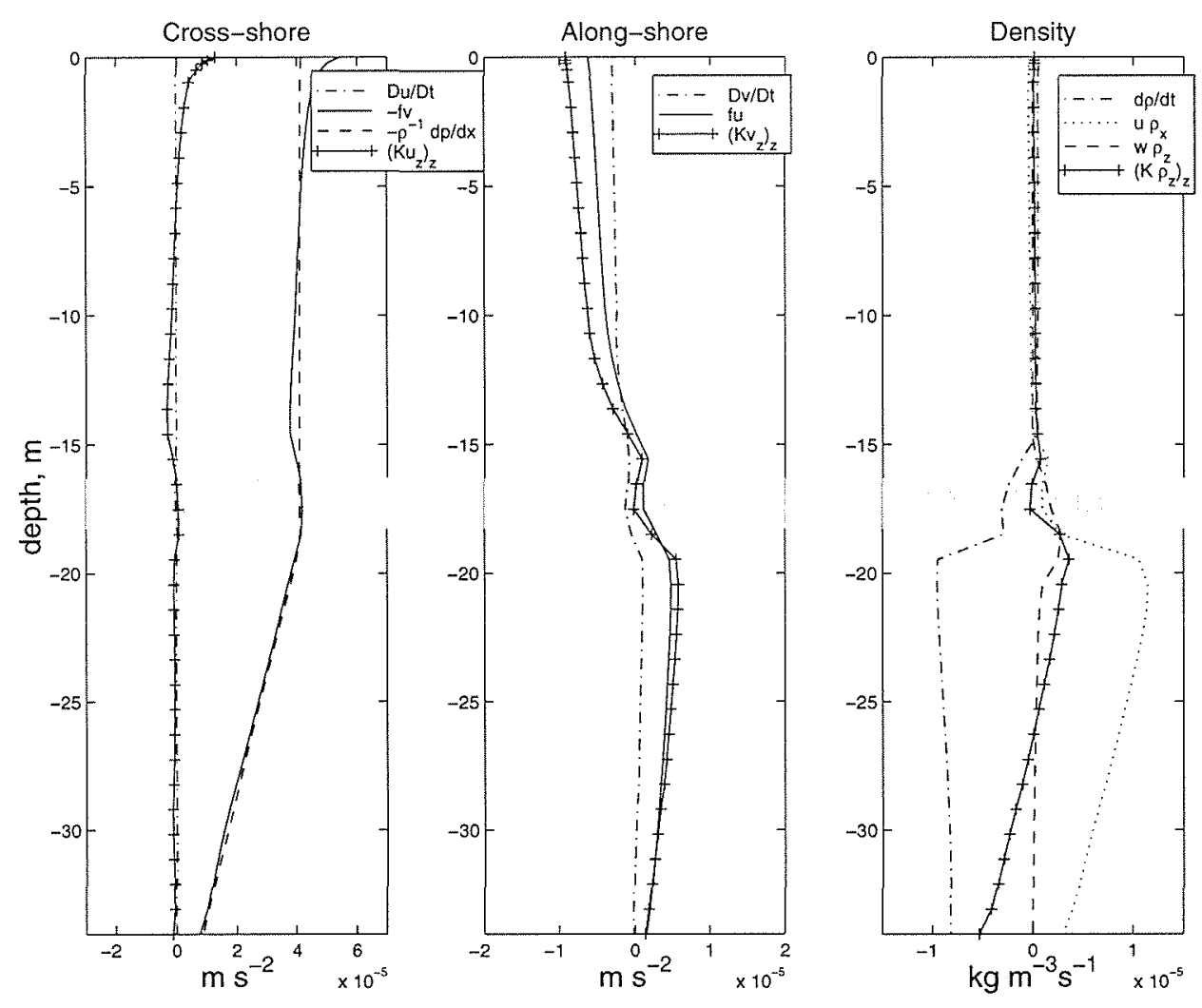

Figure 5.16: Terms of the cross-shelf momentum balance, alongshelf balance, and density balance in the frontal region, at $30 \mathrm{~km}$ offshore at 4.5 days. The shaded region represents the vertical range of strong vertical stratification $\left(\frac{d \rho}{d z}>0.05 \mathrm{~kg} \mathrm{~m}^{-3}\right)$.

to span not only the region of large horizontal gradient where the downwelling front intersects the bottom, but the portion of the shelf where horizontal density gradients are produced by the sloped pycnocline. In addition to strong horizontal density gradients, there are strong vertical density gradients, which inhibit vertical mixing, decoupling the surface and bottom boundary layers (Figure 5.3, last row).

The strong alongshelf flow and the horizontal pressure gradient provided by the strong horizontal density gradients are the dominant terms of the cross-shelf balance, as most of the alongshelf flow is in geostrophic balance with the density gra- 
dient. The strongest alongshelf flows, therefore, are located over the region of steep isopycnals where the pycnocline intersects the bottom. As the downwelling front is advected past a given location on the shelf, the amount of alongshelf shear which can be supported by the horizontal density gradient suddenly increases, resulting in alongshelf acceleration above the front. This acceleration reduces the bottom stress, since the local balance of vertically averaged alongshelf momentum is between the surface stress, bottom stress, and the alongshelf acceleration.

The density balance in the depth range of the downwelling front (Figure 5.16, below $17 \mathrm{~m}$ ) is mostly advective. As the pycnocline moves past a fixed point in this region, the water becomes less dense as the pycnocline is advected (primarily horizontally) offshore. The significant contribution from the mixing term represents overturning which acts to steepen the downwelling front.

\section{The Relaxation Response}

The relaxation response in the downwelling case is similar to that in the upwelling case. The density gradient associated with the front is already balanced to a large extent by vertical shear in the alongshelf jet, so that when the wind is shut off after 2.5 days, the bottom stress relaxes to zero, leaving momentum "trapped" in the upper water column (Figure 5.17A-C. This balance allows the front to stay displaced offshore (Figure 5.8, light lines). However, due to the location of the downwelling front compared to the upwelling front, the thermal wind shear is located near the bottom of the water column instead of the surface (Figure 5.17D-E). Because of this, the transport in the jet is greater than in the upwelling case, and the scaled jet transport after relaxation increases with greater downwelling front depth. As in the upwelling case, the alongshelf jet transport after relaxation can be scaled in terms 

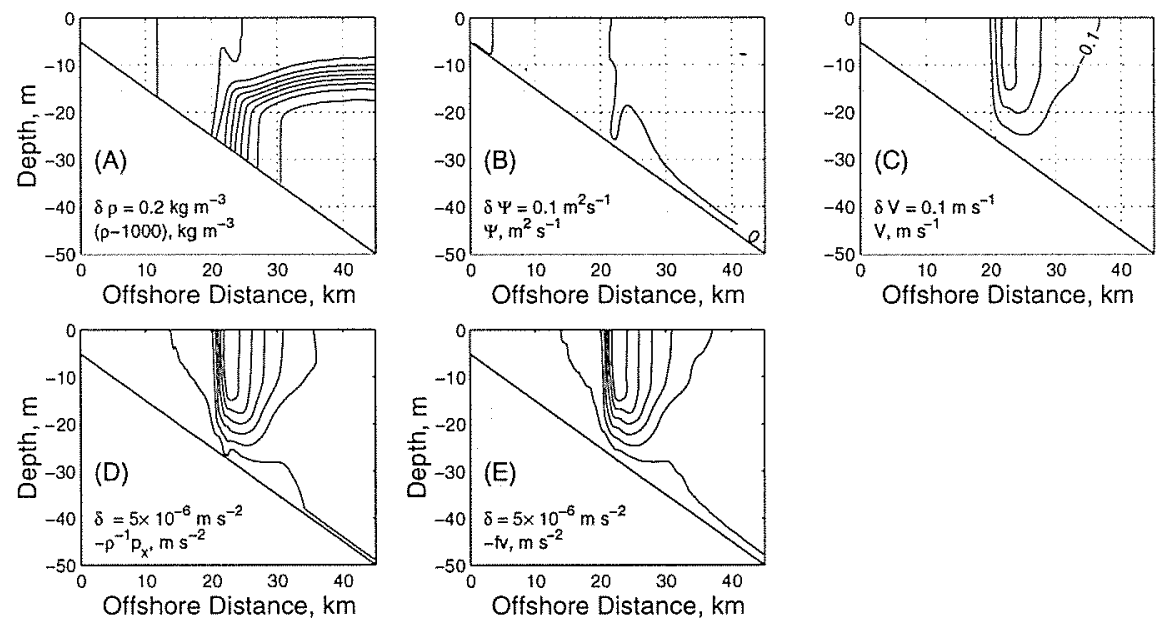

Figure 5.17: Contours of model and balance fields in the spindown base case at 4.5 days. (A) density; (B) cross-shelf streamfunction; (C) Alongshelf velocity; (D) total pressure gradient; (E) Coriolis force.

of the model parameters. Assume that sufficiently far offshore the pycnocline is flat with depth $Z_{S}$ and density difference $\delta \rho$ between the layers (Figure 5.18). Also assume that the downwelling front is located at $X_{F}$, so that the downwelling front intersects the bottom in water of depth $H\left(X_{F}\right)$. The density difference between two vertical sections, one just onshore of the front and one far offshore, distance $D$ apart, can be written:

$$
\partial \rho= \begin{cases}0 & z>-Z_{S} \\ \delta \rho & -H\left(X_{F}\right)<z<z_{S}\end{cases}
$$




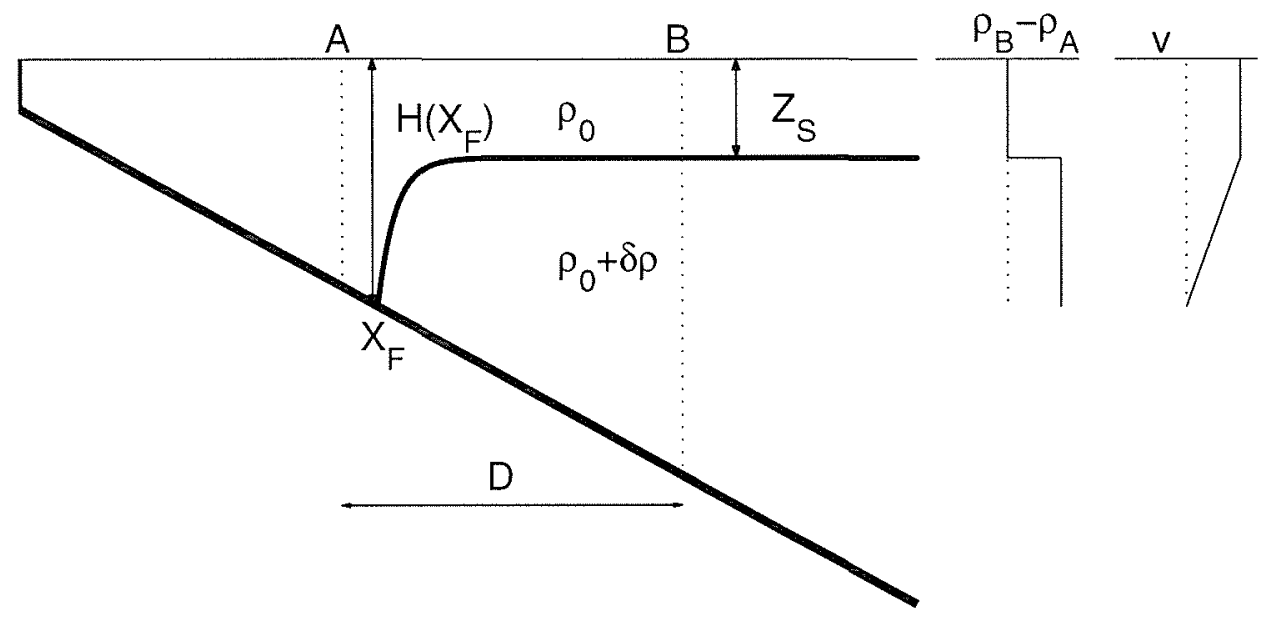

Figure 5.18: Schematic of the density structure used to determine the jet transport in the downwelling case.

Assuming the jet is in thermal wind balance with the density field, the average alongshelf velocity at a given depth can be written:

$$
v_{j e t}= \begin{cases}\frac{g}{\rho_{0} f} \frac{\partial \rho}{D}\left(H\left(X_{F}\right)-Z_{S}\right) & z>-Z_{S} \\ \frac{g}{\rho_{0} f} \frac{\partial \rho}{D}\left(z+H\left(X_{F}\right)\right) & -H\left(X_{F}\right)<z<z_{S}\end{cases}
$$

Integrating $v_{j e t}$ vertically and multiplying by the width $D$ results in a total jet transport:

$$
V=\frac{g \delta \rho}{2 \rho_{0} f}\left(H\left(X_{F}\right)^{2}-Z_{S}^{2}\right) .
$$

The frontal depth $H\left(x_{F}\right)$ can be estimated using the displacement scaling (5.24). The density difference and mixed layer depth can be approximated, to first order, as $\delta \rho=\Delta \rho$ and $Z_{S}=Z_{0}$. The scaling underestimates the jet transport by nearly a factor of two, but the parameter dependence is good (Figure 5.19A). The difference is presumably due to inappropriate choices of $\delta \rho$ and $Z_{S}$ due to the effects of 
entrainment. In the upwelling case, the deepening of the pycnocline and the reduction of the density difference partially canceled out, making the dependence of the transport estimate on mixing less sensitive to mixing than this estimate. During downwelling, reducing the density difference and deepening the mixed layer both reduce the total transport, causing the simple scaling to overestimate the transport. In addition, the magnitude of the jet in the downwelling case is much larger than in the upwelling case. For instance, the measured (POM) transport in the base case in the upwelling case is approximately $2 \times 10^{4} \mathrm{~m}^{3} \mathrm{~s}^{-1}$, whereas in the downwelling case it is nearly $6 \times 10^{4} \mathrm{~m}^{3} \mathrm{~s}^{-1}$. Another interesting difference between the two cases is the role mixing could play. In upwelling, it was shown that deepening they pycnocline increased the transport in the jet. In downwelling, mixing should play the opposite role. By reducing the density difference $\delta \rho$ and increasing the mixed layer depth, the transport is decreased. Applying the mixing scales of Appendix A results is improved jet transport estimates (Figure 5.19B). The CoOP ISS data did not exhibit the behavior discussed here; instead, the pycnocline was observed to move onshore, in some cases even before the downwelling favorable winds ceased. One such case is discussed in section 5.3.

\subsection{Discussion}

The analysis of the downwelling case has exposed several interesting similarities, and just as many distinctions, between the upwelling and downwelling case. This section will pursue a few interesting implications of the downwelling circulation. In the upwelling case, the inner shelf response differed between continuous and layered stratification. This is not the case for downwelling, where the response of a contin- 

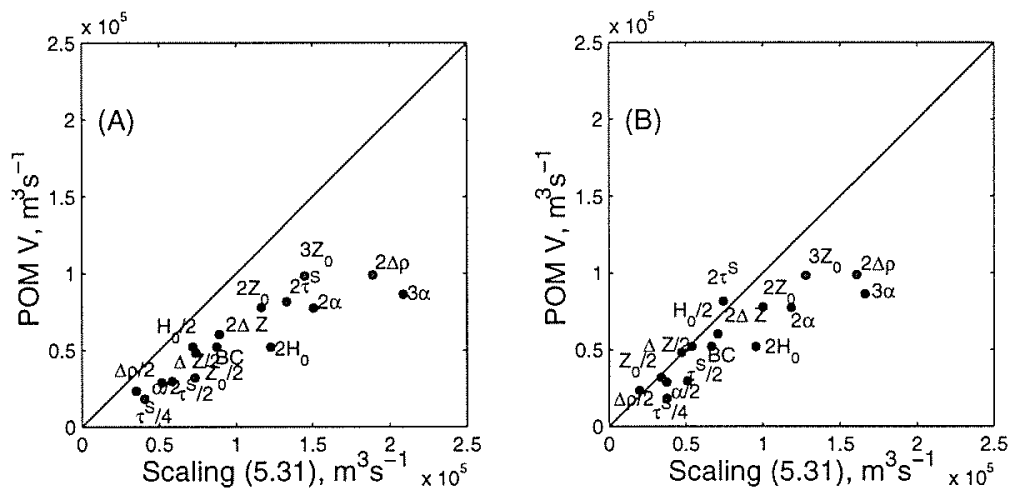

Figure 5.19: Transport in the alongshelf jet (5.31) after wind relaxation during downwelling. Transport measured in POM at 4.5 days. (A) Advective scaling; (B) Scaling with mixing.

uously stratified shelf is remarkably similar to that of the strong pycnocline case. Observations of coastal downwelling systems will be considered in the context of the circulation model proposed in this chapter. Finally, the behavior of a passive tracer on the inner shelf will be considered, with a discussion of the potential implications for shelf biology.

\subsubsection{Continuous Stratification}

The continuously stratified case (Figure 5.20), where $N=2 \times 10^{-2} \mathrm{~s}^{-1}$, is similar to the two-layered case discussed in the rest of this chapter. This is in marked contrast to the upwelling case, where the buoyancy flux along the bottom supported strong stratification and hence strong cross-shelf circulation across the entire inner shelf. One difference between the two-layered and continuously stratified case is the initial 

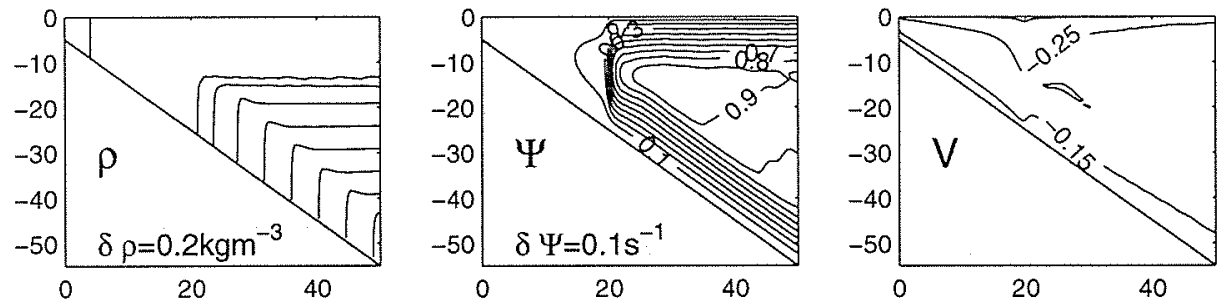

Figure 5.20: The density, cross-shelf streamfunction, and alongshelf velocity at 4.5 days in a run with continuous stratification.

formation of a surface boundary layer and the continuous thickening of the bottom boundary layer. The growth of the bottom boundary layer in a continuously stratified fluid over a sloped bottom is due to the offshore transport of lighter water, as discussed by Trowbridge and Lentz [1991]. The formation mechanism of the inner shelf region is identical to that modeled in the two-layered case, and the character of the inner shelf is the same: a weak cross-shelf gradient with lightest water near the coast, and weak cross-shelf circulation leading to convective instability and suppressing cross-shelf circulation. There is also a strong horizontal density gradient in the alongshelf velocity at the front. There is an alongshelf jet in the frontal region. The similarity between the inner shelves formed during the continuously stratified case and the two-layered case stems from the fact that the source water for the inner shelf (the surface boundary layer) are essentially the same. The absence of symmetric instabilities in this model run, a phenomenon associated with downwelling over a continuously stratified, sloping shelf by Allen and Newberger [1996], is due to the relatively short duration of the present model run. 


\subsubsection{Observational Evidence}

The circulation predicted for the inner shelf during downwelling favorable winds has not yet been directly observed in nature. This section is a short discussion of a possible indirect observation of a consequence of the inner shelf downwelling circulation and of the CoOP ISS observations in light of the displacement predictions.

In 1994 and 1995, surface drifters were deployed off of the coast of Oregon as part of an investigation of the circulation near Cape Blanco, Oregon [Barth and Smith, 1998]. The Oregon coast is an ideal regime for studying wind-driven circulation, as there are few strong sources of buoyant water, and the relatively straight coast simplifies the analysis of the dynamics. The drifters moved poleward and onshore during a downwelling event, but their onshore progress halted at approximately $20 \mathrm{~km}$ offshore (Figure 5.21). This may be due to the formation of an inner shelf region, where cross-shelf transport is suppressed. However, without more observational evidence it is impossible to confidently attribute the drifter behavior to this phenomenon.

On the other hand, the CoOP ISS data directly contradicts the relaxation response discussed in this chapter, which suggests that the pycnocline should stay displaced offshore in the absence of upwelling-favorable winds. The pycnocline clearly relaxes back onshore in the observations, even before the downwelling wind has fully ceased (Figure 5.22). The onset of strong alongshelf winds is followed by a sudden warming of the lower water column first at $\mathrm{d} 1$, then at $\mathrm{d} 2$, as the pycnocline is advected offshore. The forcing impulse is not large enough to advect the pycnocline past $\mathrm{d} 3$, but the deepening of the pycnocline at $\mathrm{d} 3$ is suggested by the warming of two thermistors in the center of the water column (the "pulsed" nature of this 


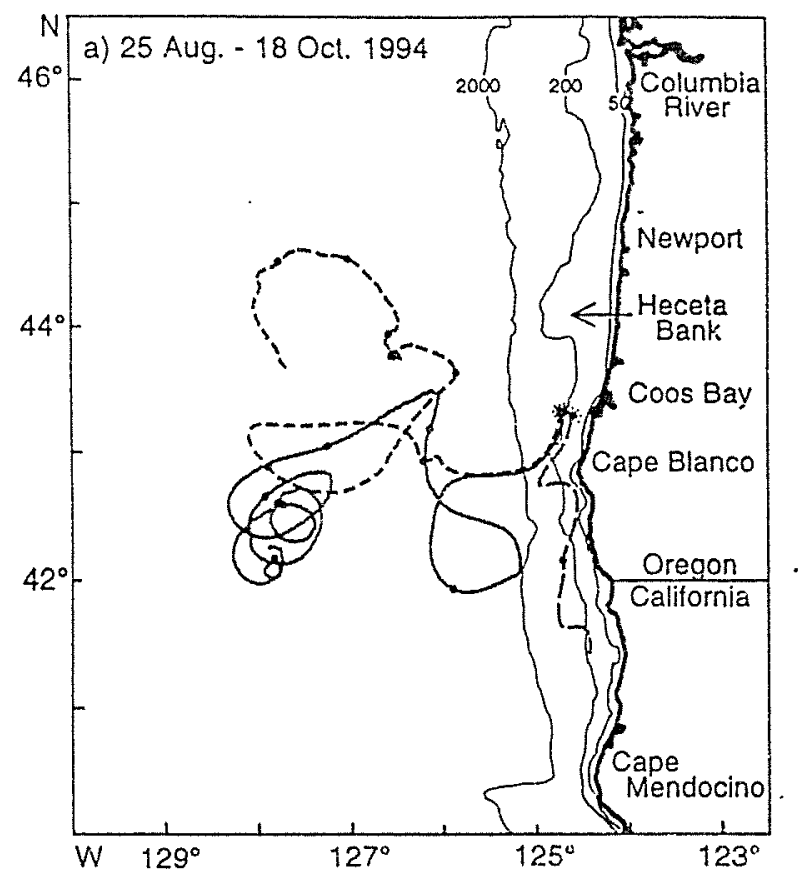

Figure 5.21: Trajectories of three satellite-tracked drifters released 25 August 1994, taken from Barth and Smith [1998].

signal is most likely due to an internal semi-diurnal tide). The deepening at $\mathrm{d} 3$ is consistent with the barotropic deepening mechanism. Late on August 25, the pycnocline passes $\mathrm{d} 2$ again, relaxing towards the shore, but it is nearly August 26 until the wind ceases to be downwelling favorable, and late on August 26 until it becomes substantially upwelling-favorable. This suggests that another forcing mechanism is at work. One such possibility is the alongshelf pressure gradient [Lentz et al., 1998], which was oriented in this case such that it opposed the downwelling cross-shelf circulation. Temperature records from the NSC and SSC mooring locations, $30 \mathrm{~km}$ to the north and south of the central line, respectively, suggest that the "relaxation" 

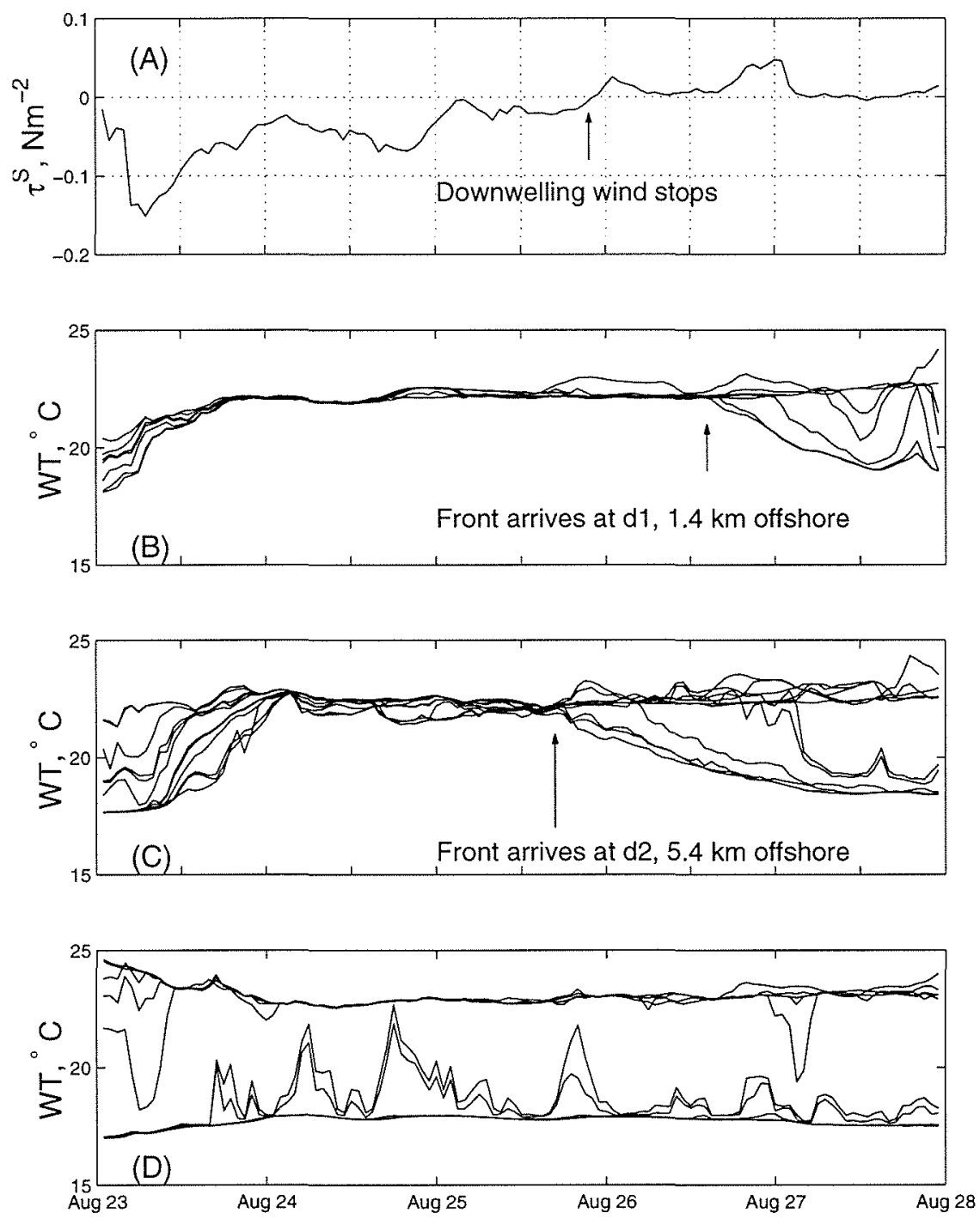

Figure 5.22: Detail of Figure 3.3, during the downwelling event of August 23-27, 1994. A. Alongshelf component of wind stress. B. 6 Temperature records from d1. C. 12 temperature records from d2. D. 10 Temperature records from d3. 

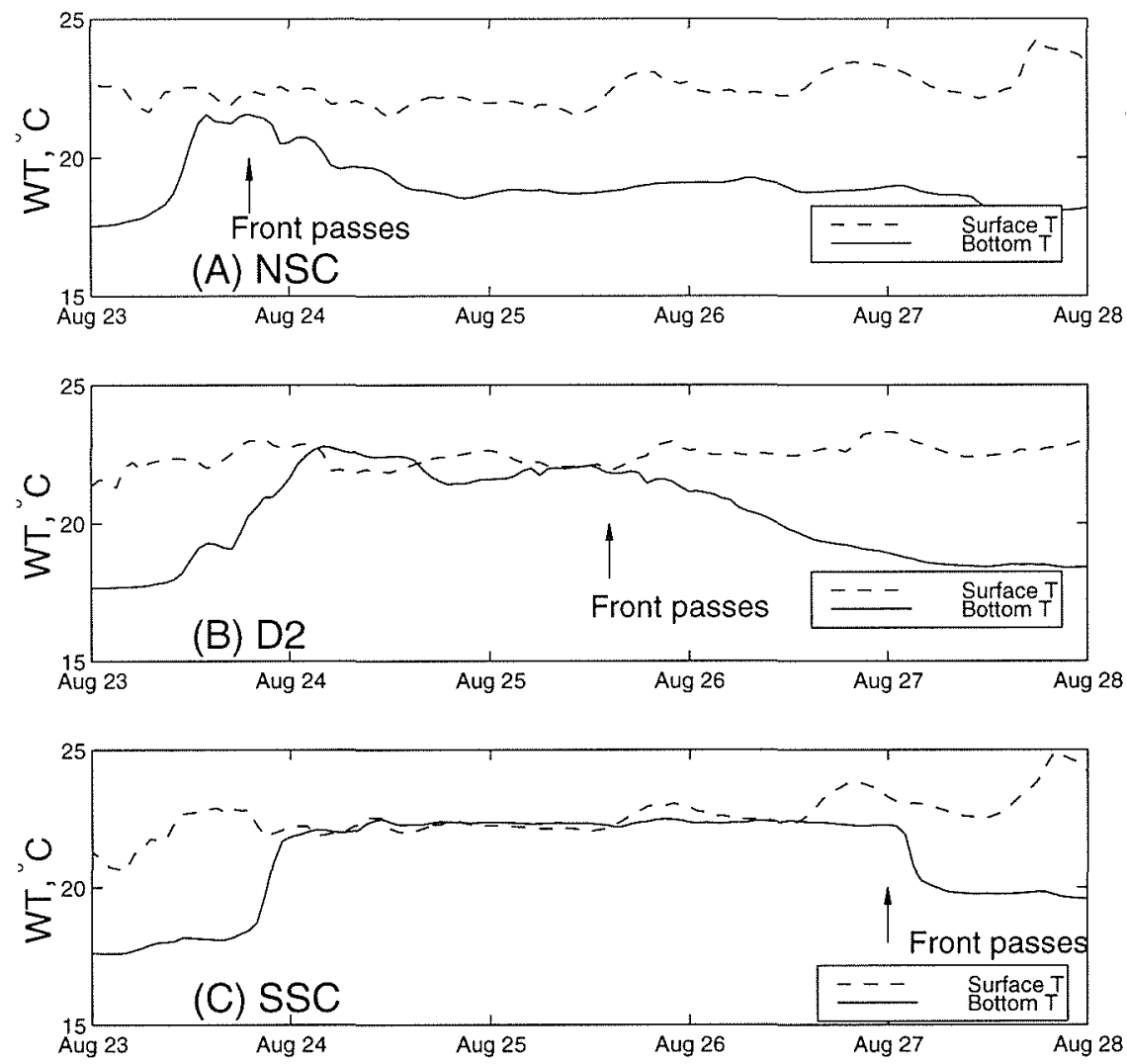

Figure 5.23: Near-surface and near-bottom temperature records from the $20 \mathrm{~m}$ isobath alongshelf array. (A) Near-surface and near-bottom temperature at NSC; (B) At d2; (C) at SSC. See Chapter 3, Figure 3.1 for locations.

propagates down the coast (Figure 5.23).

The possible role and sources of alongshelf variability will be discussed briefly in chapter 6.

\subsubsection{Passive Tracers}

As in the upwelling case, the fate of passive tracers on the inner shelf is of interest, especially the ability for wind-driven circulation to transport tracers to and from the 
coastal boundary. Two experiments are performed to address this problem. First, a uniform patch of tracer is placed in the surface layer, above the pycnocline, $20 \mathrm{~km}$ offshore before a downwelling favorable wind event (Figure 5.24, column 1). Next, a uniform patch of tracer is placed at the coastal boundary (Figure 5.24, column 2). The case in which the tracer is initially below the pycnocline is uninteresting in the context of the inner shelf since it simply gets advected offshore. The following discussion describes the evolution of these two experiments, and some of the potential biological implications.

In the case where the tracer is initially in a uniform patch above the pycnocline (Figure 5.24, column 1), the tracer becomes "trapped" at a certain distance from shore. The patch initially moves onshore under the influence of the surface Ekman layer, but after the downwelling front passes underneath the patch and the patch enters the inner shelf region, the cross-shelf velocities become weak and the patch stops its onshore progress. A small amount of the tracer becomes trapped in the downwelling front and is advected offshore. This implies that downwelling-favorable wind stress, by itself is not effective at moving a passive tracer field all the way onshore to the coastal boundary.

In the case where the tracer starts out at the coastal boundary (a passive tracer of uniform concentration was distributed in the water onshore of $2 \mathrm{~km}$ ), the tracer is not advected at all. The tracer patch is entirely contained in the inner shelf and the tracer field remains intact for the duration of the wind event. This suggests that downwelling is not an effective mechanism for transport away from the coast either. In both downwelling tracer experiments, the invocation of vertical migration behavior in the case of zooplankton is less effective at improving the efficiency of cross-inner-shelf transport than in upwelling, due to the weakened shears on the 

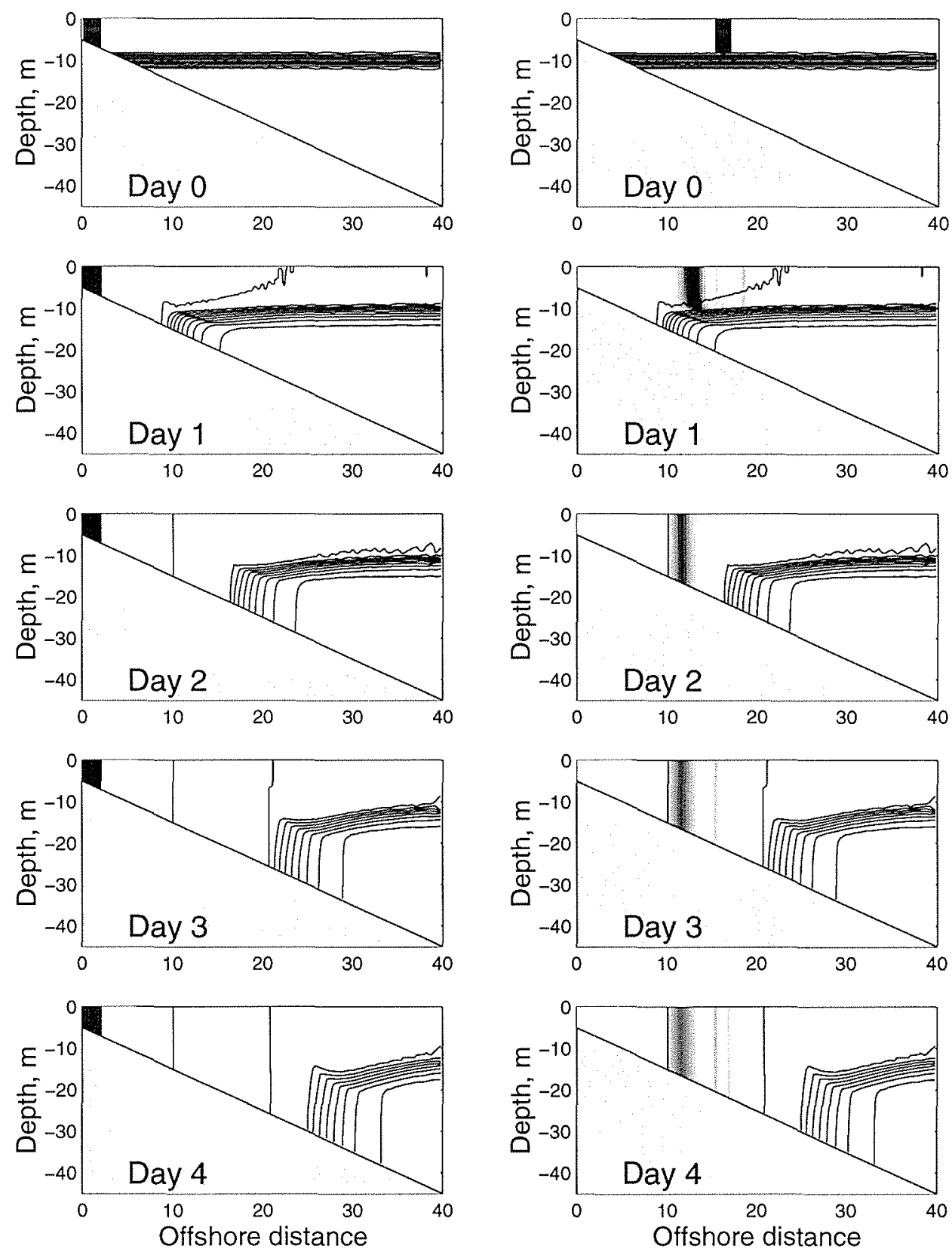

Figure 5.24: Distribution of a passive tracer patch at 0,1,2,3, and 4 days. Shading represents tracer concentration, contours are isopycnals. Column 1: Tracer patch initially above pycnocline and offshore of downwelling front. Column 2: Tracer patch initially uniform over nearest $2 \mathrm{~km}$ to shore. 
inner shelf during downwelling. In both downwelling experiments, once the tracer is on the inner shelf, there is little vertical shear to take advantage of to improve the chances of cross-shelf transport.

There are many conceivable mechanisms that could override the two-dimensional, purely wind-forced behavior described here, such as alongshelf variation, tides, and surface waves. These simple experiments simply suggest that two-dimensional downwelling, by itself, cannot be used to explain transport of tracer fields to or from the

coastal boundary. For a dynamically consistent model of cross-shelf migration, it must be combined with other processes which generate significant cross-shelf velocities on the inner shelf, and preferably processes that do not generate strong vertical mixing throughout the water column, as does Ekman transport on the inner shelf.

\subsubsection{Summary}

The modeling study of two-dimensional wind-driven downwelling covered in this chapter indicates that the presence of stratification on the shelf reduces circulation on the inner shelf. This response is independent of the model parameters. The shutdown is due to the tilting over of isopycnals on the inner shelf by weak cross-shelf circulation. This drives convective adjustment, enhancing eddy viscosities, which weaken the cross-shelf circulation. The displacement of the downwelling front, which determines the extent of the inner shelf, can be estimated in terms of the forcing and bathymetry. When the wind is turned off, the pycnocline remains displaced offshore, in geostrophic balance with an alongshelf jet, and presumably remains like this until background dissipation decays the jet. There is little observational evidence for these sorts of processes, but this may be due to the scarcity of downwelling observations. 
In fact, some observations contradict the simple wind-driven relaxation theory, suggesting the importance of other forcing mechanisms. As in upwelling, wind-driven circulation is not an effective mechanism for transporting passive tracers to or from the coastal boundary, suggesting that other processes must be considered in models of inner shelf transport processes. 


\section{Chapter 6}

\section{Discussion and Summary}

\subsection{Introduction}

The research presented in this thesis, particularly chapters 4 and 5 , represent progress towards a better understanding of the influence of stratification on the two dimensional wind-driven circulation on the inner shelf. In addition, the relaxation behavior of the pycnocline during both upwelling and downwelling in the model differs considerably from the CoOP observations, suggesting that mechanisms besides wind play a primary role in determining local shelf circulation. Additionally, in both upwelling and downwelling, strong vertical mixing on the inner shelf prevents significant cross-shelf transport of tracers. In this chapter, we summarize some of the differences between upwelling and downwelling and discuss potential directions that this research may lead. 


\subsection{Upwelling vs. Downwelling}

The prime difference between upwelling and downwelling on the inner shelf is due to the influence of the inner shelf stratification on the eddy viscosity. During both upwelling and downwelling, a density gradient is set up on the inner shelf, with the lightest water onshore. The circulation is similar to that expected in the neutral case, but the impact of the circulation on the stratification leads to reduced eddy viscosity during upwelling, and enhanced eddy viscosity during downwelling (Figure $6.1 \mathrm{~A})$.
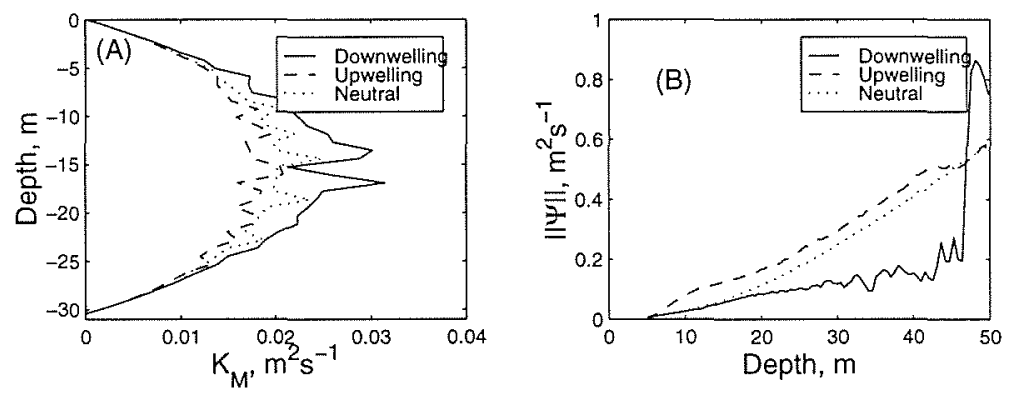

Figure 6.1: Comparison of inner shelf circulation development during upwelling and downwelling. (A) Profiles of vertical eddy viscosity on the $30 \mathrm{~m}$ isobath, on the inner shelf, for the base case. Neutral case is identical for upwelling and downwelling; (B) Maximum cross-shelf streamfunction as a function of local water depth during upwelling, downwelling, and in the neutral case. The circulation is identical in upwelling and downwelling in the neutral case. The strong divergence in the downwelling case at $45 \mathrm{~m}$ represents the location of the downwelling front. 
This results in enhanced circulation during upwelling and reduced circulation during downwelling (Figure 6.1B). Circulation on a continuously stratified shelf differs considerably between upwelling and downwelling, a result previously made clear in the work of Allen and Newberger [1996] and Allen et al. [1995]. Furthermore, the circulation during upwelling is a strong function of the bathymetry and stratification. Downwelling circulation on the inner shelf does not change appreciably between the strong pycnocline case and the continuously stratified case, although the character is different in the bottom boundary layer, offshore of the downwelling front, where symmetric instabilities develop in the stratified case [Allen and Newberger, 1995]. The change in character during upwelling is due to the reservoir of denser water continually being fed onto the inner shelf. The cross-shelf position of the location of strong transport divergence is a function of the bottom slope and the strength of stratification. Further, the character of the stratification on the inner shelf during upwelling depends on the size of the slope Burger number.

The offshore displacement of the upwelling front scales approximately linearly with the integrated wind stress and inversely with the surface layer thickness:

$$
\Delta X \sim \frac{\tau^{S}}{\rho_{0} f Z_{S}} .
$$

there are added complications in the upwelling case associated with the initial location and time of the front appearing at the surface, but the above equation reflects the main dependence in the displacement. During downwelling, the frontal displacement depends on the square root of the integrated wind stress, and is also a function 

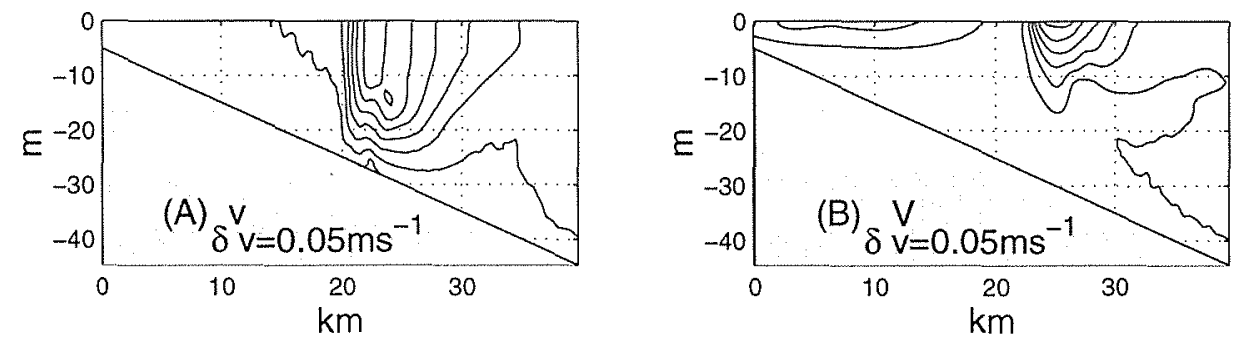

Figure 6.2: Alongshore velocity distribution in the jet, after relaxation.

of bathymetry:

$$
\Delta X \sim \sqrt{\frac{2 \tau^{S} \Delta t}{\rho_{0} f \alpha}} .
$$

In the case where the wind is shut off, the pycnocline front quickly comes into geostrophic balance with an alongshore jet. This jet is insulated from the bottom and hence does not dissipate, resulting in the pycnocline being held offshore essentially indefinitely. The transport in the jet can be scaled in terms of the initial model parameters. The transport in the jet associated with downwelling:

$$
V_{D W}=\frac{g \delta \rho}{2 \rho_{0} f}\left(H\left(X_{F}\right)^{2}-Z_{S}^{2}\right)
$$

tends to be larger than that during upwelling:

$$
V_{U W}=\frac{g \delta \rho\left(Z_{0}+\Delta Z / 2\right) Z_{S}}{2 \rho_{0} f}
$$

due to the vertical position of the thermal wind shear. In addition, the transport 
in the upwelling case is not a function of the intensity or duration of the wind stress event, but is in the downwelling case. The transport in the downwelling case is a function of the bathymetry, which it is not in the upwelling. Both transport estimates can be influenced by mixing through the deepening of the pycnocline and the reduction of the density difference across the pycnocline.

One of the most interesting implications of the inner shelf circulation scenarios proposed in this thesis is their potential effect on passive tracers. In both the upwelling case and the downwelling case, Ekman transport is not as effective at transporting a passive tracer across the inner shelf as it would in the absence of tracer mixing. In both cases, cross-shelf transport to or from the coastal boundary cannot be explained at all in terms of Ekman transport. In order for Ekman transport to be taken into cross-shelf transport and exchange hypotheses, it must be combined with other processes which produce significant cross-shelf velocities and do not result in strong vertical mixing.

\subsection{Other forcing Mechanisms; Future directions.}

This thesis concentrated on the response to alongshore winds alone, which are clearly only one of many conceivable influences on the near-shore circulation. Alongshore winds were chosen as they are often regarded as a dominant influence in the coastal environment, However, there are many other processes that are certainly as important to circulation on the shelf as the alongshore wind stress. Two possible paths that future research may take concern the effects of alongshore variation and surface buoyancy flux. 


\subsubsection{Alongshore Variation}

Alongshore variation is left out entirely in the models presented in this thesis. However, processes such as freshwater plumes and non-homogeneous alongshore reaction to wind driven processes will certainly be important to the near-shore response. In Figure 6.3, a satellite image of the North Carolina coast taken during the CoOP ISS shows evidence of an upwelling event. There is strong upwelling in the region just offshore of Duck, but south of Oregon Inlet there is almost no cold water at the surface. In addition, outside and to the south of the mouth of Chesapeake Bay, there is a region of weak upwelling, and north of Cape May strong upwelling again (in fact, north of Cape May, it appears that the upwelling is stronger, which may be due to the change in orientation of the coast). Other satellite images (not shown) and Figure 5.19 both suggest that the lack of an upwelling response at the mouth of the Chesapeake bay may propagate to the south, in the same sense as a coastally trapped wave. The same may be true for downwelling but this cannot be surmised from satellite images. Measurements of the alongshore pressure gradient along the $20 \mathrm{~m}$ isobath, when scaled to estimate cross-shelf geostrophic transport yield transport estimates on the same order as the scaled Ekman response to the wind field. The real difficulty in extending the model to incorporate alongshore setup is understanding the casual relationship between the wind and the pressure gradient. It may be that a more regional approach to inner shelf circulation is needed to accurately capture local variation, as opposed to the "local" approach taken in this thesis. 


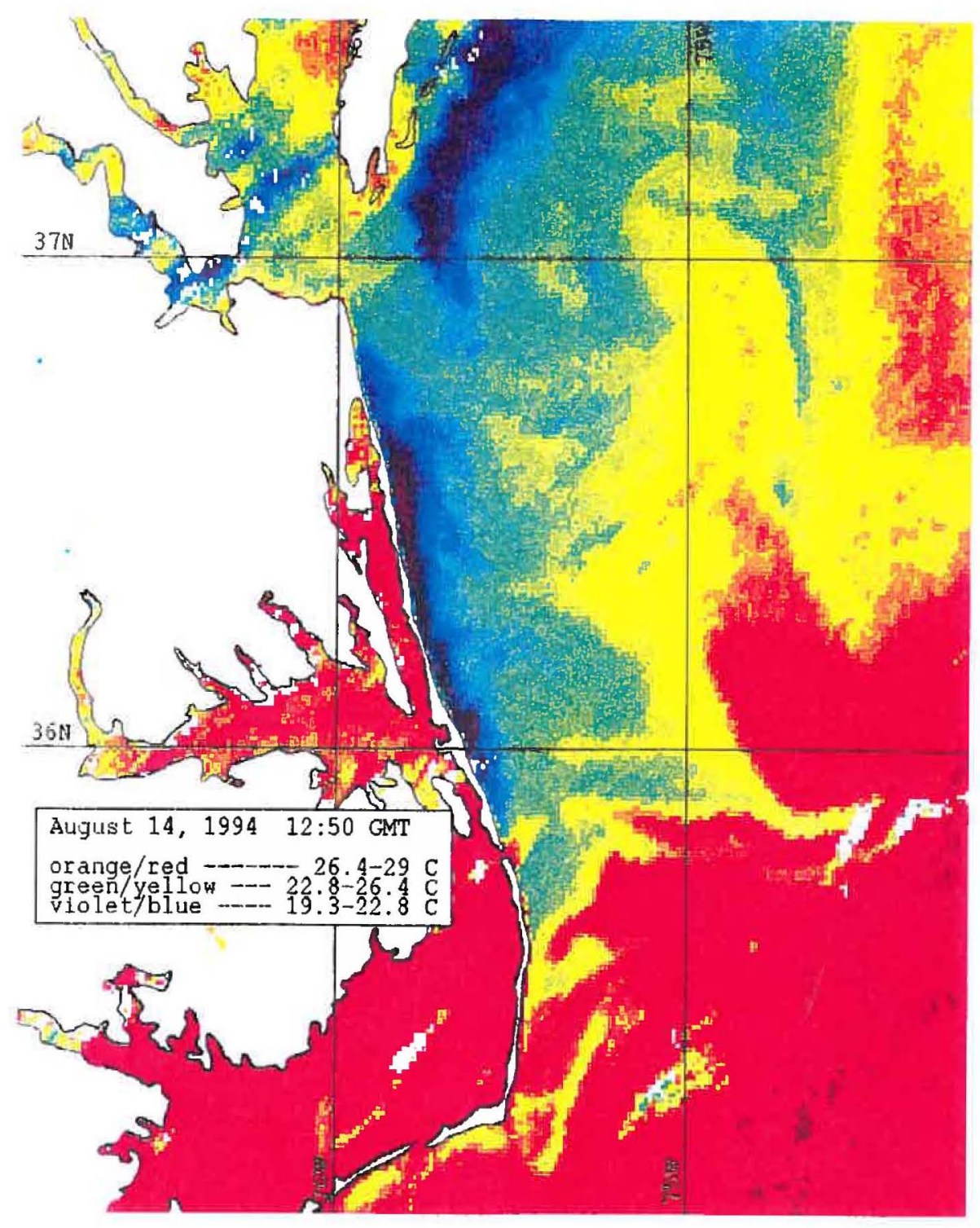

Figure 6.3: AVHRR image of sea surface temperature, taken of the North Carolina/Virginia coasts, 12:50GMT, 8/14/1994. Courtesy of Mathias Knecht and Scott Glenn, IMCS, Rutgers University. 


\subsubsection{Surface Heat Flux}

The surface heat flux during August, when the shelf was stratified, was positive (into the ocean), and had a mean value of approximately $150 \mathrm{~W} \mathrm{~m}^{-2}$, and large diurnal variability as well as subinertial variability. Its influence on the circulation of the inner shelf is not yet understood. It is entirely possible that the application of even small amounts of surface heat flux will disturb the delicate balance which creates and maintains the cross-shelf density gradient in the downwelling case. These sorts of effects will be speculated on here, but a careful analysis of their influence would take another large series of model runs and is outside of the scope of this thesis.

\section{Downwelling}

During downwelling, the strong Ekman divergence at the downwelling front is dependent on a cross-shelf gradient being formed over the inner shelf, with the lightest water onshore. The formation of that gradient, in turn, depends on the steady densification of the surface layer further offshore due to entrainment across the pycnocline. In the presence of heating, as the inner shelf is staying well-mixed due to convective adjustment, surface heating would only intensify the gradient (since uniform cooling would produce greater changes in temperature in shallower water) and further reduce the cross-shelf circulation. However, if the heating lightens the surface layer offshore of the downwelling front faster than entrainment makes it more dense, then the inner shelf density gradient would not be created in the first place. In the case of cooling, the same problem arises; the cooling would act to erase the gradient on the inner shelf but would also provide a greater gradient in the first place, since it would act in tandem with the entrainment mechanism to produce the 
initial gradient. The influence of the complex interplay of entrainment, cooling, and inner shelf bathymetry on the circulation is difficult to predict without considerably more analysis.

\section{Upwelling}

Upwelling circulation may also be affected by surface heating. An input of heat could increase the thermal stratification across the water column, reducing eddy viscosities and enhancing cross-shelf circulation. If the surface heat flux is positive,

the inner shelf is being made more dense by the influx of water from below the pycnocline, but lighter from surface heating, similar to the models of deZoeke and Richman [1984]. The surface heating will presumably enhance the stratifying effect of the advective flux in the lower layer, maintaining strong circulation across the inner shelf. Due both the surface heat flux and the advective density flux act to make the water on the shelf denser. In this case, the response may be dependent on the relative values of these two fluxes.

\subsection{Conclusion}

The inner shelf is a region where we are just beginning to collect large, coordinated data sets, and where our theoretical understanding is also at a fairly rudimentary stage. The role of stratification in this region, even under the influence of forcing as "simple" as alongshore winds, is more complex than previously anticipated. Understanding the circulation due to the many forcing mechanisms present in the coastal ocean, first on an individual basis, then in concert, in necessary for a fuller understanding of the inner shelf. Determining the physical oceanography of this region is 
an important step in the eventual interdisciplinary understanding of the inner shelf. 


\section{References}

Alados-Arboledas, L., J. Vida, and J.I. Jimenez, Effects of Solar Radiation on the Performance of Pyrgeometers with Silicon Domes. Journal of Atmospheric and Oceanic Technology, 5, 666-670, 1988.

Alessi, C.A, S.J. Lentz, J.A. Austin, Coastal Ocean Processes Inner-shelf Study: Coastal and Moored Physical Oceanographic Measurements. Technical Report WHOI 96-06, Woods Hole Oceanographic Institution, Woods Hole, MA, 1996.

Allen, J.S., Upwelling and Coastal Jets in a Continuously Stratified Ocean. Journal of Physical Oceanography, 3, 1973.

Allen, J.S., P.A. Newberger, and J. Federiuk, Upwelling Circulation on the Oregon Continental Shelf: Part 1: Response to Idealized Forcing. Journal of Physical Oceanography, 25, 1843-1866, 1995.

Allen, J.S. and P.A. Newberger, Downwelling Circulation on the Oregon Continental Shelf: Part 1, Response to Idealized Forcing. Journal of Physical Oceanography 26, 2011-2035, 1996.

Atkinson, L.P., O. Eiichi, S.Y. Wu, T.J. Berger, J.O. Blanton, and T.N. Lee. Hydrographic Variability of Southeastern United States Shelf and Slope Waters during the Genesis of Atlantic Lows Experiment: Winter 1986. Journal of Geophysical Research, 94, 10699-10713, 1989.

Barth, J.A., Stability of a Coastal Upwelling Front 1: Model Development and a Stability Theorem. Journal of Geophysical Research, 94, 10844-10856, 1989.

Barth, J. A., Short Wavelength Instabilities on Coastal Jets and Fronts. Journal of Geophysical Research, 99, 16095-16115, 1994. 
Barth, J.A., and R.L. Smith, Separation of a Coastal Upwelling Jet at Cape Blanco, Oregon, USA. S. Afr. J. Mar. Sci., in press.

Barton, E.D., A. Huyer, and R. Smith, Temporal Variation Observed in the Hydrographic Regime near Cabo Corveiro in the Northwest African Upwelling Region, February to April 1974. Deep Sea Research, 24, 7-23, 1977.

Beardsley, R.C., R. Limeburner, and L.K. Rosenfeld, Introduction to the CODE2 Moored Array and Large Scale Data Report, in CODE-2: Moored Array and Large Scale Data Report. CODE Technical Report No. 38, WHOI Technical Report 85-35, Woods Hole Oceanographic Institution, Woods Hole, MA, 1985.

Beardsley, R.C., E. Dever, S.J. Lentz, and J. Dean, Surface Heat Flux Variability Over the Northern California Shelf. In press, J. Geophys. Res.

Birkemeier, W. A., H. C. Miller, S. D. Wilhelm, A. E. DeWall, and C. S. Gorbics, A User's Guide to the Coastal Engineering Research Center's (CERC's) Field Research Facility. Department of the Army, CERC-85-1, 1985.

Blanton, J.O., J.A. Amft, D.K. Lee, and A. Riordan, Wind Stress and Heat Fluxes Observed During Winter and Spring 1986. J. Geophys. Res. 94, 1068610698, 1989a.

Blanton, J.O., L.-Y. Oey, J. Amft, and T.N. Lee, Advection of Momentum and Buoyancy in a Coastal Frontal Zone. Journal of Physical Oceanography, 19, 98-115, 1989b.

Blumberg, A.F., and G.L. Mellor, A Description of a Three-Dimensional Coastal Ocean Circulation Model. Three Dimensional Coastal Ocean Models. Coastal and Estuarine Science Series, Vol. 4, N. Heaps, Ed., Amer. Geophys. Union, 1-16, 1987.

Bunker, A., Computations of Surface Energy Flux and Annual Air-Sea Interaction Cycles of the North Atlantic Ocean. Monthly Weather Review, 104, 1122-1140, 
1976.

Butman, C.A., CoOP: Coastal Ocean Processes Study, Interdisciplinary Approach, New Technology to Determine Coupled Biological, Physical, Geological Processes Affecting Larval Transport on Inner Shelf. Sea Technology, 35, 44-49, 1994.

Chen, D. and D.-P. Wang, Simulating the Time-Variable Coastal Upwelling during CODE-2. Journal of Marine Research, 48, 335-358, 1990.

Churchill, J.H., and P.C. Cornillon, Gulf Stream Water on the Shelf and Upper Slope North of Cape Hatteras. Continental Shelf Research, 11, 409-431, 1991.

Csanady, G.T., On the Equilibrium Shape of the Thermocline in a Shore Zone. Journal of Physical Oceanography, 1, 263-270, 1971.

Csanady, G.T., Intermittent 'Full' Upwelling in Lake Ontario. Journal of Geophysical Research 82, 397-419, 1977.

Csanady, G. T., Circulation in the Coastal Ocean, 279 pp., D. Reidel Publishing Company, Dordecht, 1982.

Davidson, K.L., P.J. Boyle, C. Gautier, H.P. Hanson, and S.J.S. Khalsa, Mediumto Large-Scale Atmospheric Variability During the Frontal Air-Sea Interaction Experiment. J. Geophys. Res. 96, 8531-8551, 1991.

de Szoeke, R.A. and J.G. Richman, On Wind-Driven Mixed Layers with Strong Horizontal Gradients- A Theory with Application to Coastal Upwelling. it Journal of Physical Oceanography, 14, 364-377, 1984.

Dever E., and S.J. Lentz, Heat and Salt Balances over the Northern California Shelf in Winter and Spring. J. Geophys. Res. 99, 16001-16017, 1995.

Dever, E.P., Subtidal Cross-shelf Circulation on the Northern California Shelf. PhD thesis, MIT/WHOI Joint program, MIT/WHOI 95-16, 1995. 
Dickey, T.D., D. V. Manov, R. A. Weller, and D.A. Siegel, Determination of Longwave Heat Flux at the Air-Sea Interface Using Measurements from Buoy Platforms. Journal of Atmospheric and Oceanic Technology, 11, 1057-1078, 1994.

Ekman, V.W., On the Influence of the Earth's Rotation on Ocean-Currents. Arkiv för Mathematik, Astronomi och Fysik, Band 2, No. 11, 1905.

Enriquez, A.G. and C.A. Friehe, Bulk Parameterization of Momentum, Heat, and Moisture Fluxes over a Coastal Upwelling Area. J. Geophys. Res. 102, 5781-5798, 1997.

Fairall, C.W., E.F. Bradley, D.P. Rogers, J.B. Edson, and G.S. Young, Bulk Parameterization of Air-Sea Fluxes for Tropical Ocean-Global Atmospheric CoupledOcean Atmospheric Response Experiment. J. Geophys. Res. 101, 3747-3764, 1996.

Fairall, C.W., P.O.G. Persson, E.F. Bradley, R.E. Payne, and S.P. Anderson, A New Look at Calibration and Use of Eppley Precision Infrared Radiometers Part I: Theory and Application. In press, Journal of Atmospheric and Oceanic Technology.

Foo, E-C., A Two-Dimensional Diabatic Isopycnal Model- Simulating the Coastal Upwelling Front, J. Phys. Oc., 11, 604-626, 1981.

Friehe, C.A., W.J. Shaw, D. P. Rogers, K.L. Davidson, W.G. Large, S.A. Stage, G.H. Crescenti, S.J.S. Khalsa, G.K. Greenhut, and F. Li, Air-Sea Fluxes and Surface Layer Turbulence Around a Sea Surface Temperature Front. J. Geophys. Res. 96, 8593-8609, 1991.

Fung, I.Y., D.E. Harrison, and A.A. Lacis, On the Variability of the Net Longwave Radiation at the Ocean Surface. Reviews of Geophysics and Space Physics, 22, 177$193,1984$.

Galperin, B., L. H. Kantha, S. Hassid, and A. Rosati, A Quasi-equilibrium Turbulent Energy Model for Geophysical Flows, J. Atmos. Sci., 45, 55-62, 1988. 
Gawarkewicz, G., T.M. Church, G.W. Luther III, T.G. Ferdelman, and M. Caruso, Large Scale Penetration of Gulf Stream Water onto the Continental Shelf North of Cape Hatteras. Geophysical Research Letters, 19, 373-376, 1992.

Geernaert, G.L., K.A. Katsaros, and K. Richter, Variation of the Drag Coefficient and its Dependence on Sea State. J. Geophys. Res. 91, 7667-7679, 1986.

Gill, A.E., Atmosphere-Ocean Dynamics. Academic Press, 1982.

Hamilton, P. and M. Rattray, Jr., A Numerical Model of the Depth-Dependent, Wind-Driven Upwelling Circulation on a Continental Shelf. Journal of Physical Oceanography, 8, 437-457, 1978.

Hill, A.E., Vertical Migration in Tidal Currents, Marine Ecology Progress Series, 75, 39-54, 1991.

Kantha, L.H., O.M. Phillips, and R.S. Axad, On Turbulent Entrainment at a Stable Density Interface, J. Fluid. Mech. 79, 753-768, 1977.

Kato, H. and O.M. Phillips, On the Penetration of a Turbulent Layer into Stratified Fluid. Journal of Fluid Mechanics, 37, 643-655, 1969.

Knecht, M. and S. Glenn, Analysis of Satellite Images on Coastal Upwelling Events in North Carolina, unpublished report, Rutgers University, 1997.

Kundu, P.K., Numerical Calculations of Coastal Flow with Turbulent Dynamics, Deep Sea Res., 31, 39-60, 1984.

Large, W.G., J. Morzel, and G.B. Crawford, Accounting for Surface Wave Distortion of the Marine Wind Profile in Low-Level Ocean Storms Wind Measurements. Journal of Physical Oceanography, 25, 2959-2971, 1995.

Large, W.G. and S. Pond, Open Ocean Momentum Flux Measurements in Moderate to Strong Winds. Journal of Physical Oceanography, 11, 324-336, 1981. 
Large, W.G. and S. Pond, Sensible and Latent Heat Fluxes over the open ocean. Journal of Physical Oceanography, 12, 464-482, 1982.

Lee, T.N., E. Williams, J. Wang, R. Evans, Response of South Carolina Continental Shelf Waters to Wind and Gulf Stream Forcing During Winter of 1986. J. Geophys. Res. 94, 10715-10754, 1989.

Lentz, S.J., A Heat Budget for the Northern California Shelf during CODE 2, J. Geophys. Res. 92, 14491-14509, 1987.

Lentz, S.J., and D.C. Chapman, Seasonal Difference in the Current and Temperature Variability Over the Northern California Shelf During the Coastal Ocean Dynamics Experiment. J. Geophys. Res. 94, 12571-12592, 1989.

Lentz, S.J. Sensitivity of the Inner-Shelf Circulation to the form of the EddyViscosity Profile. Journal of Physical Oceanography, 25, 19-28, 1995.

Lentz, S.J., Herbers, T., Guza, R., Feddersen, F., and Elgar, S. Momentum balances on the North Carolina Shelf. Submitted to J. Geophys. Res.

Lewis, J.M., The Story behind the Bowen Ratio. Bulletin of the American Meteorological Society, 76, 2433-2443, 1995.

Longhurst, A.R., Vertical Migration, in: Cushing, A.R. and Walsh, J. (eds.) Ecology of the Seas, Blackwell Scientific, Oxford. p116-137, 1976.

MacCready, P., and P.B. Rhines, Slippery Bottom Boundary Layers on a Slope, J. Phys. Oc., 23, 5-22, 1993.

Manning, J., and T. Holzwarth, Description of Oceanographic Conditions on the Northeast Continental Shelf: 1977-1985. Northeast Fisheries Center Reference Document 90-04, 1990.

Mellor, G.L., and T. Yamada, Development of a Turbulence Closure Model for Geophysical Fluid Problems. Reviews of Geophysics and Space Physics, 20, 851-875, 
1982.

Middleton, J.F., and D. Ramsden, The Evolution of the Bottom Boundary Layer on the Sloping Continental Shelf: A Numerical Study. Jour. Geophys. Res. 101, 18061-18077, 1996.

Mitchum, G.T. and A.J. Clarke, The Frictional Nearshore Response to Forcing by Synoptic Scale Winds. Journal of Physical Oceanography, 16, 934-946, 1986.

Mooers, C.L., J. Fernandez-Partagas, and J. Price, Meteorological Forcing Fields of the New York Bight (First Year). Technical Report TR76-8, Rosenstiel School of Marine and Atmospheric Science, University of Miami, 1976.

Mountain, D.G., G.A. Strout, and R.C. Beardsley, Surface Heat Flux in the Gulf of Maine. Deep Sea Research, 43, 1533-1546, 1996.

National Oceanic and Atmospheric Administration, Daily Weather Maps, weekly series, 1994.

Payne, R. E., Albedo of the Sea Surface. Journal of Atmospheric Sciences, 29, 959-970, 1972.

Perry, A.H., and J.M. Walker, The Ocean-Atmosphere System, Longman Publishing Co., 1977.

Pettigrew, N.R., The Dynamics and Kinematics of the Coastal Boundary Layer off Long Island. PhD. Thesis, Woods Hole Oceanographic Institution, Massachusetts Institute of Technology, $262 \mathrm{pp}, 1981$.

Rennie, S., Wind Interaction with Buoyant Plumes on the Inner Shelf, PhD Thesis, Virginia Institute of Marine Sciences, 1997.

Roelofs, E.W. and D.F. Bumpus, The Hydrography of Pamlico Sound. Bulletin of Marine Science of the Gulf and Caribbean, 3, 181-205, 1953. 
Shay, L.K., S.J. Lentz, H.C. Graber, and B.K. Haus, Current Structure Variations Detected by High Frequency Radar and Vector Measuring Current Meters. Submitted to the Journal of Atmospheric and Oceanic Technology.

Signell, R.P., R.C. Beardsley, H.C. Graber, and A. Capotondi, Effect of WaveCurrent Interaction on Wind-Driven Circulation in Narrow, Shallow Embayments. J. Geophys. Res., 95, 9671-9678, 1990.

Trowbridge, J.H. and S.J. Lentz, Asymmetric Behavior of an Oceanic Boundary Layer above a Sloping Bottom. Journal of Physical Oceanography, 21, 1171-1185, 1991.

Trowbridge, J.H., A Simple Description of the Deepening and Structure of a Stably Stratified Flow Driven by a Surface Stress. Journal of Geophysical Research, 97, 15529-15543, 1992.

United States Naval Observatory, Almanac for Computers. Nautical Almanac Office, 1978.

Waldorf, B.W., J.L. Largier, S. Rennie, J. Austin, and C. Greengrove, Coastal Ocean Processes (CoOP) Pilot Project data Report: R/V Cape Hatteras Shipboard Measurements; Underway, CTD and ADCP data, August 1994. SIO Reference Series No. 95-29, Scripps Institution of Oceanography, 1995.

Waldorf, B.W., J.L. Largier, S. Rennie, and J. Austin, Coastal Ocean Processes (CoOP) Pilot Project data Report: R/V Cape Hatteras Shipboard Measurements; Underway, CTD and ADCP data, October 1994. SIO Reference Series No. 96-9, Scripps Institution of Oceanography, 1996.

Walford, L.A., and R.I. Wicklund, Monthly Sea Temperature Structure from the Florida Keys to Cape Cod. Serial Atlas of the Marine Environment, Folio 15, American Geographical Society, 1968. 
Weller, R.A., D.L. Rudnick, R.E. Payne, J.P. Dean, N.J. Pennington, and R.P. Trask, Measuring Near-Surface Meteorology over the Ocean from an Array of Surface Moorings in the Subtropical Convergence Zone. Journal of Atmospheric and Oceanic Technology, 7, 85-103, 1990.

Weller, R.A., D.L. Rudnick, C.C. Eriksen, K.L. Polzin, N.S. Oakey, J.W. Toole, R.W. Schmitt, and R.T. Pollard, Forced Ocean Response During the Frontal Air-Sea Interaction Experiment. J. Geophys. Res. 96, 8611-8638, 1991.

Willett, H.C., and F. Sanders, Descriptive Meteorology, Second edition. Academic Press, 355 pp, 1959.

Winant, C.D., and R.C. Beardsley, A Comparison of Some Shallow Wind-Driven Currents. Journal of Physical Oceanography, 9, 218-220, 1979.

Zamudio, L. and M. López. On the Effect of the Alongshore Pressure Gradient on Numerical Simulations over the Northern California Shelf, Journal of Geophysical Research, 99, 16117-16129, 1994. 